\title{
Applications of Surface and Subsurface Subsidence Theories to Solve Ground Control Problems
}

\author{
Biao Qiu \\ West Virginia University
}

Follow this and additional works at: https://researchrepository.wvu.edu/etd

\section{Recommended Citation}

Qiu, Biao, "Applications of Surface and Subsurface Subsidence Theories to Solve Ground Control Problems" (2013). Graduate Theses, Dissertations, and Problem Reports. 178.

https://researchrepository.wvu.edu/etd/178

This Dissertation is protected by copyright and/or related rights. It has been brought to you by the The Research Repository @ WVU with permission from the rights-holder(s). You are free to use this Dissertation in any way that is permitted by the copyright and related rights legislation that applies to your use. For other uses you must obtain permission from the rights-holder(s) directly, unless additional rights are indicated by a Creative Commons license in the record and/ or on the work itself. This Dissertation has been accepted for inclusion in WVU Graduate Theses, Dissertations, and Problem Reports collection by an authorized administrator of The Research Repository @ WVU.

For more information, please contact researchrepository@mail.wvu.edu. 


\title{
Applications of Surface and Subsurface Subsidence Theories to Solve Ground Control Problems
}

\author{
Biao Qiu
}

\author{
Dissertation submitted to the \\ Benjamin M. Statler College of Engineering and Mineral Resources \\ at West Virginia University \\ in partial fulfillment of the requirements \\ for the degree of \\ Doctor of Philosophy \\ in \\ Mining Engineering \\ Yi Luo, Ph.D., Chair \\ Keith A. Heasley, Ph.D. \\ Bruce Kang, Ph.D. \\ Brijes Mishra, Ph.D. \\ Peter Zhang, Ph.D.
}

Department of Mining Engineering

Morgantown, West Virginia

2013

Keywords: subsurface subsidence, pre-driven longwall recovery room, multiseam mining, hydrological system, improvements

Copyright 2013 Biao Qiu 


\section{ABSTRACT \\ Applications of Surface and Subsurface Subsidence Theories to Solve Ground Control Problems}

\section{Biao Qiu}

The stability of the underground mine openings largely depends on the surrounding ground conditions, such as stress concentrations, geological conditions and support intensities etc. In particular, the ground control stability associated with large movements and deformations of the strata is much more complicated and could induce much more severe safety problems. A ground control failure could endanger the coal miner's safety not only directly by roof, pillar, floor and/or rib failure, but also by ground cracks induced methane and water inundations indirectly. This study is aimed to develop comprehensive models to simulate the ground response to mining and solve the ground control problems associated with it.

During the last four decades, many research works have been conducted on the ground control study, and numerous models, including analytical, empirical, numerical and hybrid models, were developed to facilitate ground control and support design. If a model is to be used as a common mine design tool, the simplicity of the model itself and the consistency between actual in-mine and modeled ground response to mining are essential. For the study of the ground control stability associated with large movements and deformations, the key is to know the movements and deformations of the subsurface strata. The subsidence prediction models can determine the movements and deformations very accurately as proven by plenty of surface subsidence survey data. In this study, the subsidence prediction models are employed to analyze the stability of some subsidence related ground control problems based on the subsurface strata movements and deformations.

In this dissertation, an innovative approach, employing the influence function method while considering the hard rock layers, is applied in the development of an enhanced subsurface subsidence prediction model. This improved model is then applied in analyzing three specific subsidence related ground control problems. An analytical model, employing dynamic 
subsurface subsidence theory and considering the roof support interaction, is developed to analyze the stability of pre-driven longwall recovery room. The mechanism of the ground control stability problems as well as the potential safety problems associated with multi-seam mining interactions is discussed. Multi-seam mining subsidence prediction methods are re-examined based on the multi-seam mining interaction analysis. The redistribution of the stresses and strains in overburden is also able to affect the surface and subsurface water bodies in various degrees. Mathematical models are developed to link longwall induced overburden strata permeability change and subsurface deformations. A ground water flow model is used to assess the longwall mining impacts on surface and subsurface hydrological systems.

This study provides a greater understanding of the mechanism of the subsidence-related ground control problems. Innovative methods are developed to derive stress, strain and permeability change, and quantify the subsidence effects on mine structure stability and the hydrological system sustainability. The developed models are coded and incorporated into a software suite to provide an easy-to-use tool for the mine planning and designing of all subsidence related issues. 


\section{ACKNOWLEDGEMENT}

I would like to express my deepest appreciation to my committee chair, Dr. Yi Luo for his invaluable instructions, encouragement, and support during this research and throughout my graduate study. Without his guidance and persistent help this dissertation would not have been possible.

Special thanks are given to the committee members, Dr. Keith A. Heasley, Dr. Bruce Kang, Dr. Brijes Mishra and Dr. Peter Zhang for the time and the expertise contributed to the enhancement of this research.

Special thanks are also given to Kris Lilly from Red Bone Mining Company and Kevin Hatfield from MEPCO LLC. for their great assistances during this research, and mining engineering graduate students Xinyang Wang, Mingming Li, Peng Zhang, Yu Xiong, Dachao $\mathrm{Nie}$, Simon Prassetyo and Kaifang Li for their help in field observation and monitoring works and laboratory tests. The author also expresses sincere appreciation to staffs of the Mining Engineering Department for their selfless help.

I would also like to thank my former advisor Dr. Jing Chai and his wife Ms. Jinxuan Liu in Xi'an University of Science and Technology, who lead me to this interesting research field by providing me with many field study opportunities in coal mines, and continuously support and show loving care for my study abroad in US.

Finally, sincere gratitude goes to my family members, my father, Zeyan Qiu, and mother, Zhenzhi Zhou, my elder brother, Jiangbo Qiu. Special thanks are given to my beloved wife, Ping Yang, my son Perry and my daughter Kadee. Without their endless love, constant support, patience and understanding, I would never have reached this point. 


\section{TABLE OF CONTENTS}

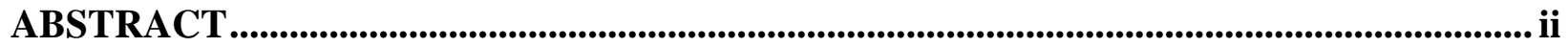

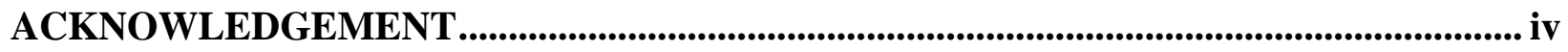

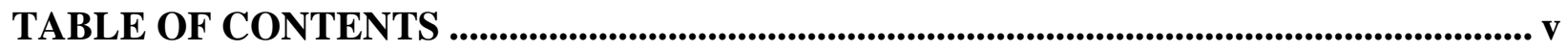

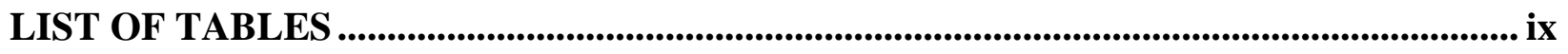

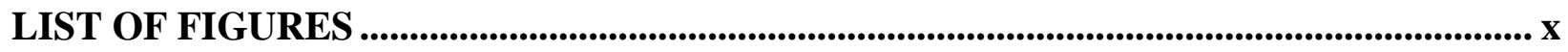

LIST OF ABBREVIATIONS AND SYMBOLS .................................................................. xiv

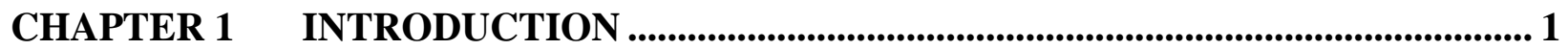

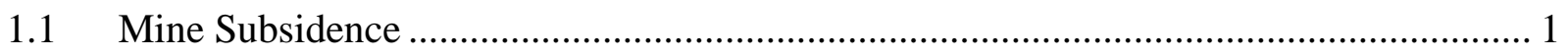

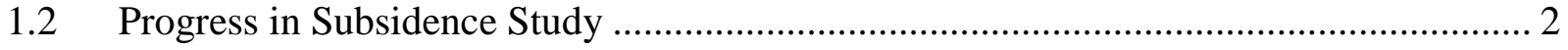

1.3 Problem Statement ......................................................................................... 3

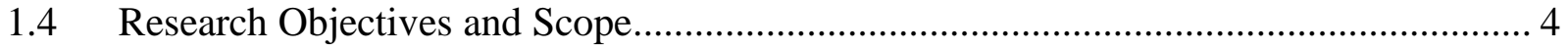

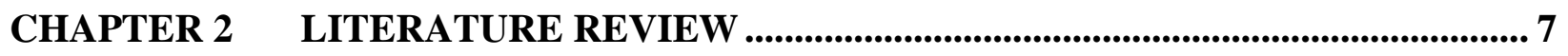

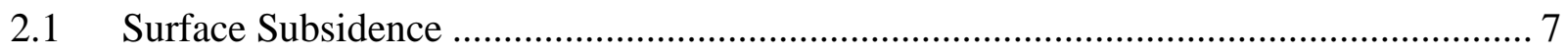

2.1.1 Overburden Movements .............................................................................................. 7

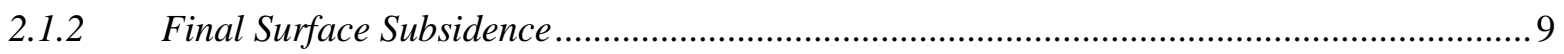

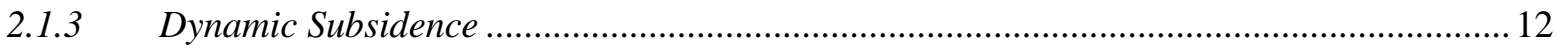

2.2 Subsurface Subsidence ..................................................................................... 15

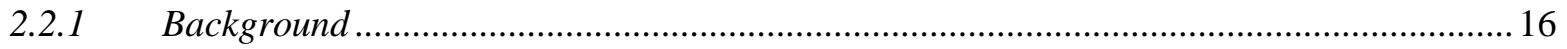

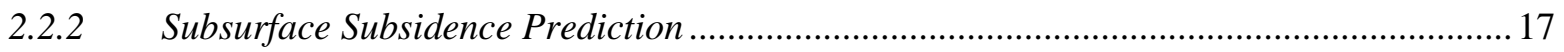

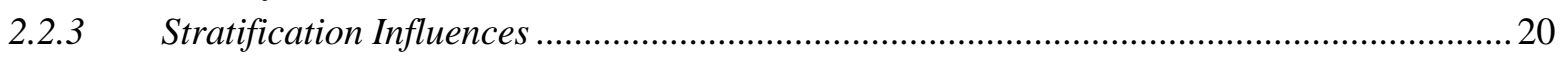

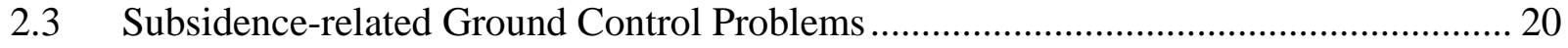

2.3.1 Pre-driven Longwall Recovery Room ............................................................................. 21

2.3.2 Multi-seam Mining Interaction and Subsidence ..........................................................28

2.3.3 Longwall Mining Impacts on Hydrological System ....................................................... 37

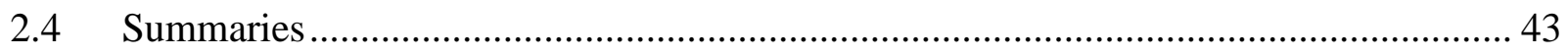

CHAPTER $3 \quad$ SUBSURFACE SUBSIDENCE PREDICTION ...................................... 46 


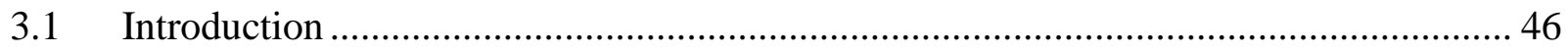

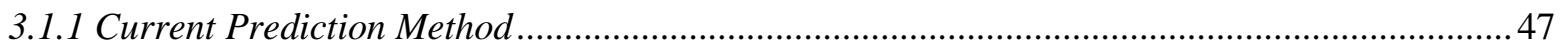

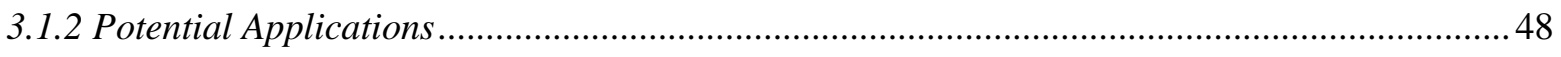

3.2 Enhanced Subsurface Subsidence Prediction Model ...................................................... 51

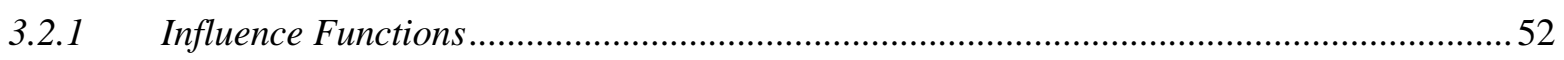

3.2.2 Final Subsurface Strata Movements ………………....................................................

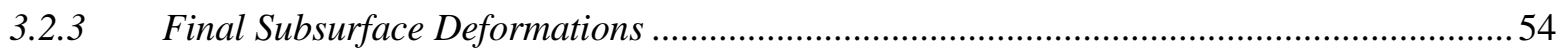

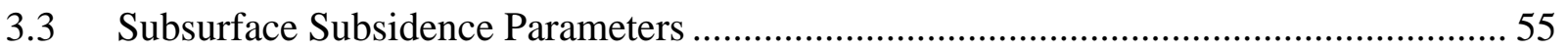

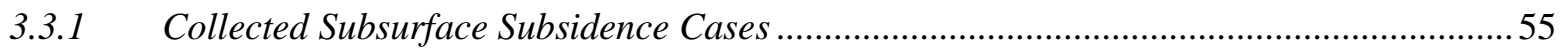

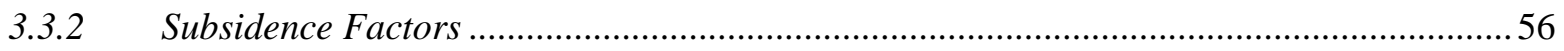

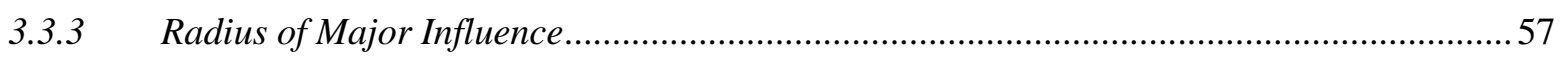

3.3.4 Offset of Inflection Point ........................................................................................

3.4 Dynamic Subsurface Subsidence …………………................................................ 59

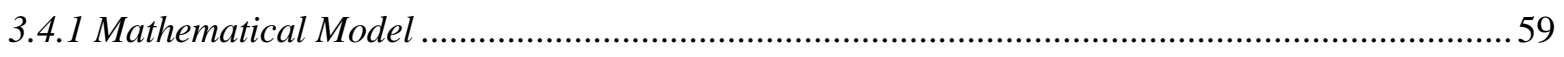

3.4.2 Dynamic Subsurface Subsidence Parameters ………………………………………........... 60

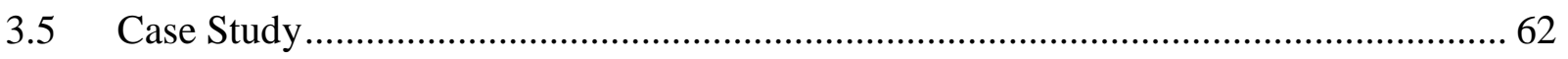

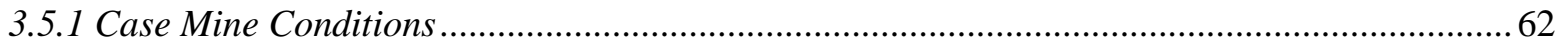

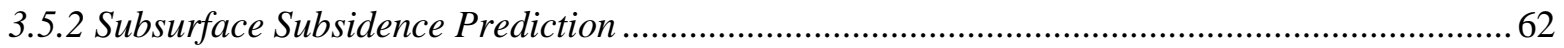

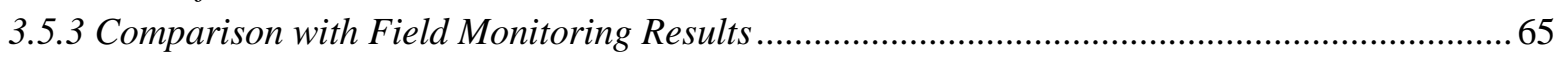

3.5.4 Sensitivity Analysis of Layer Thickness ...............................................................................6

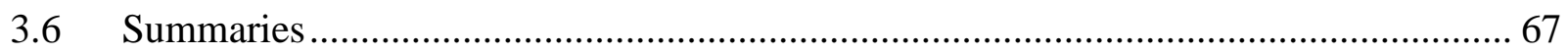

\section{CHAPTER 4 PRE-DRIVEN LONGWALL RECOVERY ROOM ................................. 69}

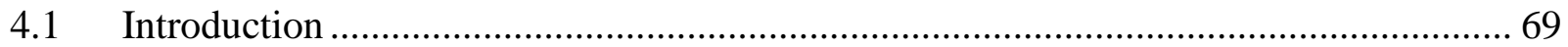

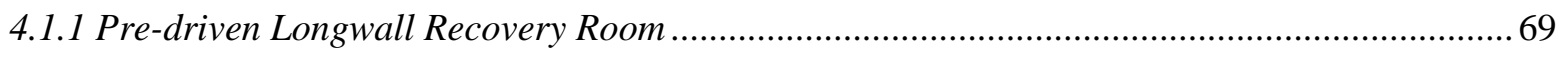

4.1.2 Support Design ……………………………………………………………………....

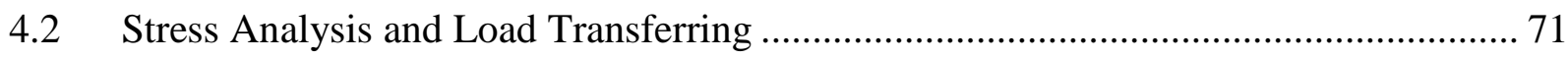

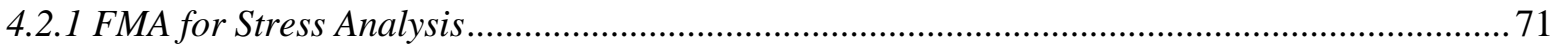

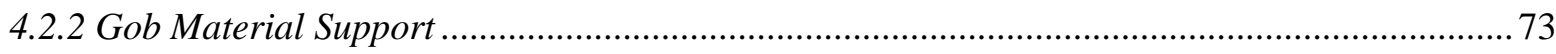

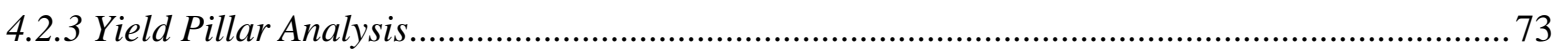

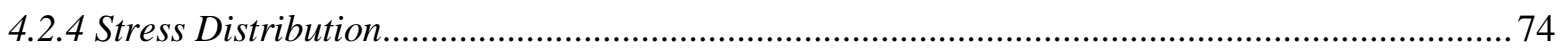

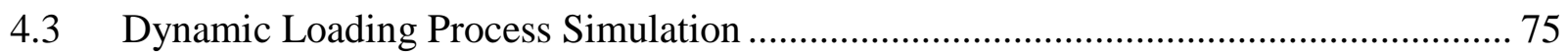

4.3.1 Roof Deflection Simulation ………………………………………………………..........

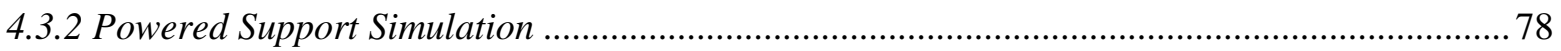

4.4 Stability Analysis and Evaluation ……………........................................................ 79

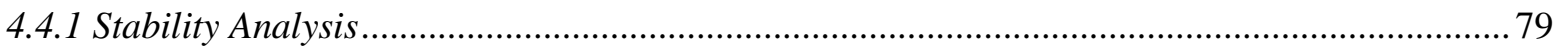

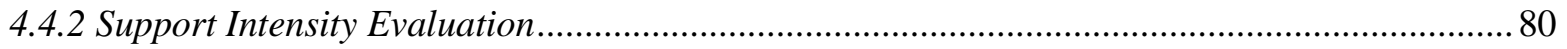

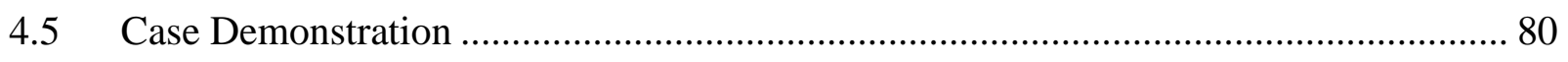

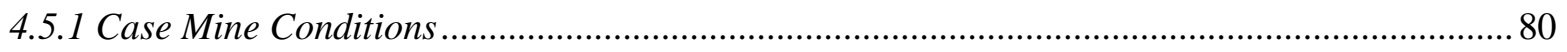




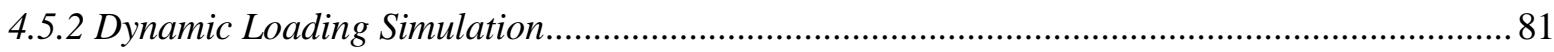

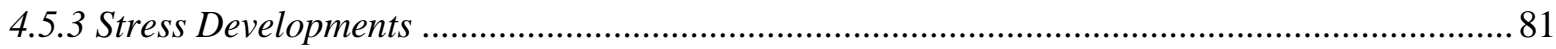

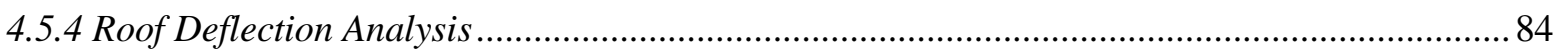

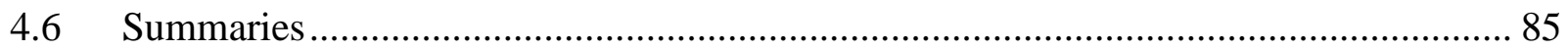

CHAPTER 5 MULTI-SEAM MINING INTERACTION AND SUBSIDENCE ........... 86

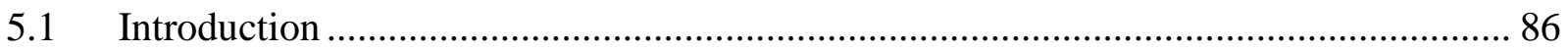

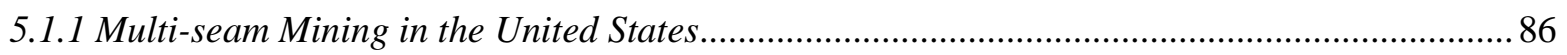

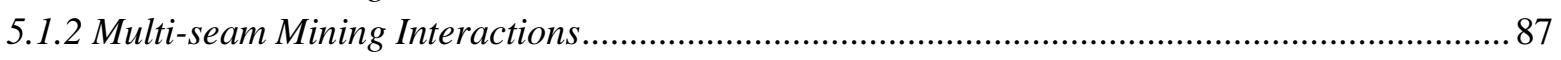

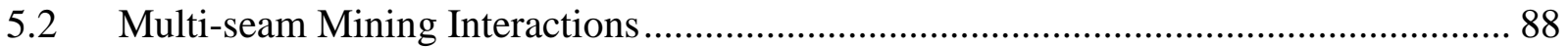

5.2.1 Characterization of Multi-seam Mining Interactions ...................................................... 89

5.2.2 Multi-seam Mining Pillar Stability .......................................................................... 92

5.2.3 Multiple-seam Mining Roof Stability ............................................................................ 98

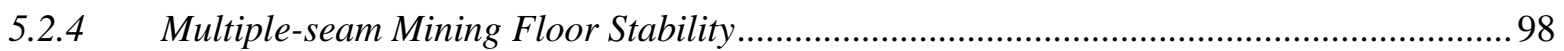

5.2.5 Multiple-seam Mining Interburden Stability ............................................................. 100

5.3 Multi-seam Mining Subsidence ......................................................................... 101

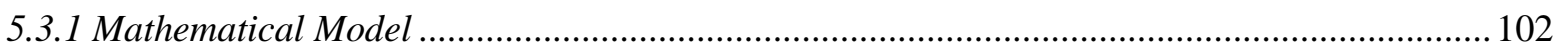

5.3.2 Multi-seam Mining Subsidence Cases ................................................................................. 103

5.4 Case Study of Remnant Structure .......................................................................... 104

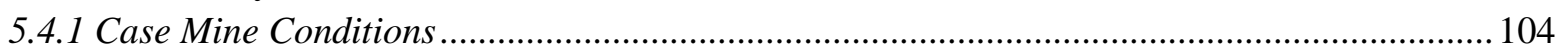

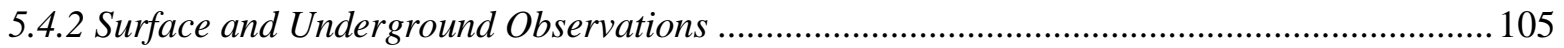

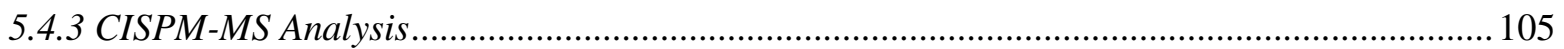

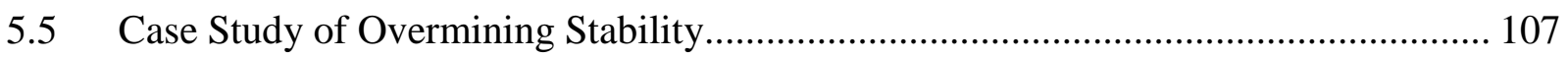

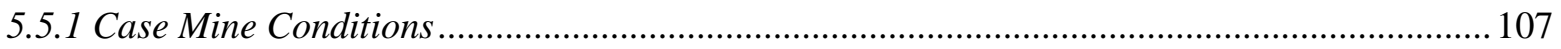

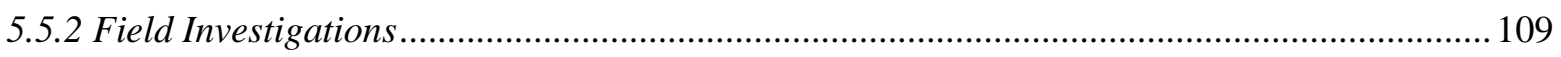

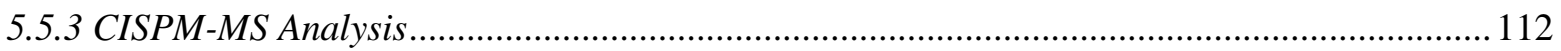

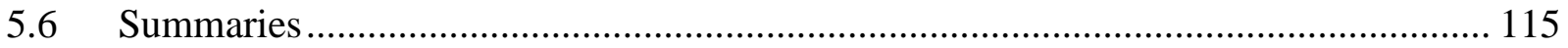

\section{CHAPTER 6 LONGWALL MINING IMPACTS ON HYDROLOGICAL SYSTEM 116}

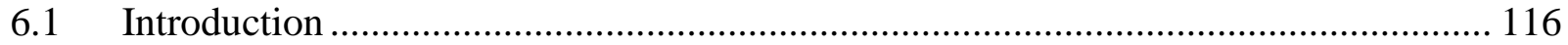

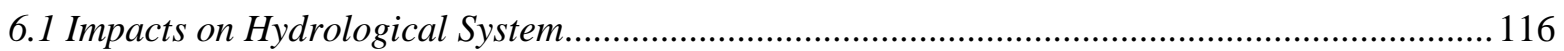

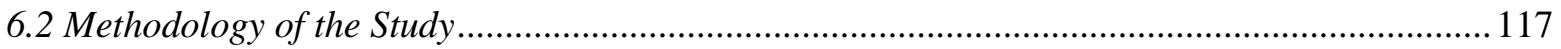

6.2 Temporary Redistribution of Hydrological Systems ............................................ 117

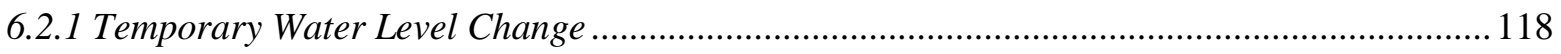

6.2.2 Subsided Area over Longwall Panels .............................................................................. 118

6.3 Mining Induced Subsurface Permeability Change .................................................... 119

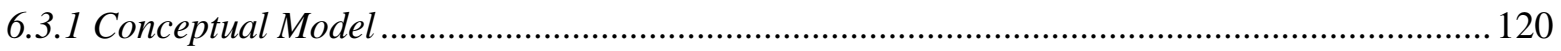

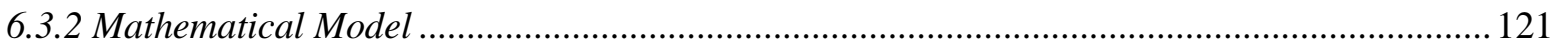

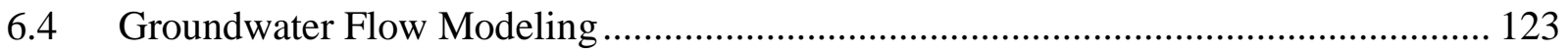


6.4.1 Darcy's Law

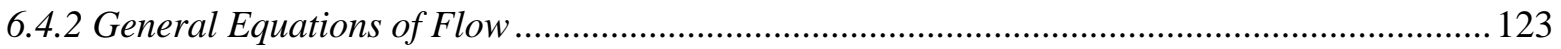

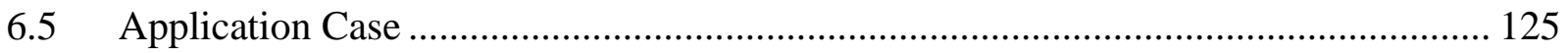

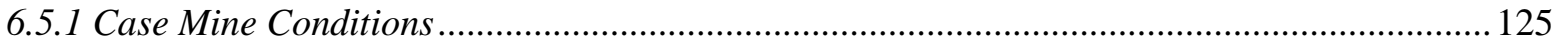

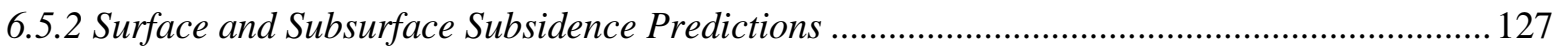

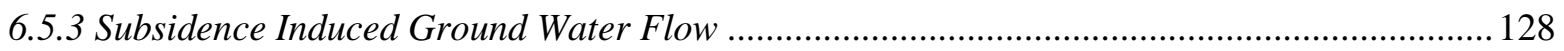

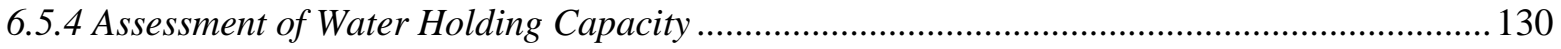

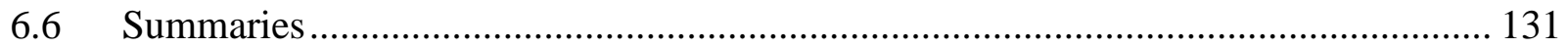

CHAPTER 7 PROGRAMMING AND SOFTWARE DEVELOPMENT .................... 133

7.1 Subsurface Subsidence Prediction ......................................................................... 133

7.2 Pre-driven Longwall Recovery Room Support Design........................................... 134

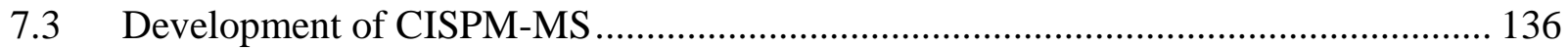

7.4 Longwall Mining Impacts on Hydrological System ............................................. 138

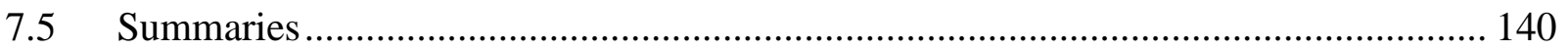

CHAPTER 8 SUMMARIES AND CONCLUSIONS ................................................. 141

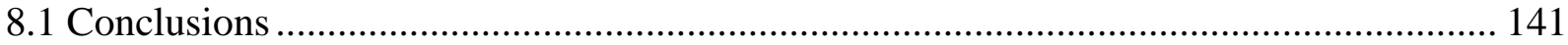

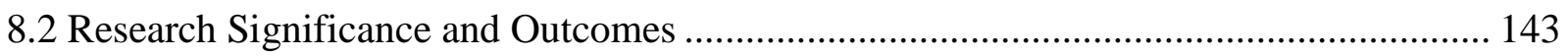

8.3 Recommendations for the Future Research .............................................................. 143

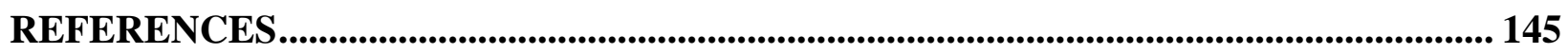

APPENDIX 


\section{LIST OF TABLES}

Table 2.1 Upper seam damage rating system for overmining operations (Zhou, 1988) ............. 36

Table 3.1 Subsurface subsidence monitoring sites ............................................................ 56

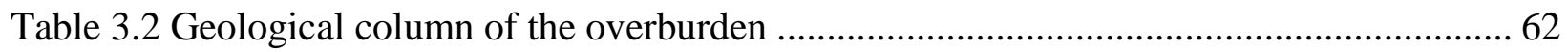

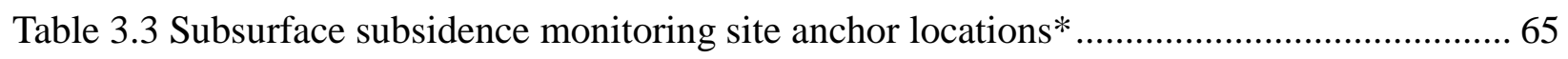

Table 3.4 Comparison of subsurface subsidence prediction and field monitoring results........... 66

Table 5.1 Cases of multi-seam mining subsidence (Li et al., 2011; Dyni, 1991; Kook et al., 2008)

Table 5.2 Stability factors calculations of the pillars at the upper seam mains ....................... 114

Table 6.1 Initial hydraulic property of coal measure rocks ............................................... 129 


\section{LIST OF FIGURES}

Figure 2.1 Overburden movements resulting from longwall mining (Peng, 1992) .................... 8

Figure 2.2 Final subsidence parameters (after Luo, 1989) ............................................... 9

Figure 2.3 Final subsidence prediction along a major cross-section (after Luo, 1989).............. 11

Figure 2.4 Coordinate Systems for Dynamic Subsidence Prediction (after Luo, 1989).............. 14

Figure 2.5 Components of surface and subsurface subsidence (after Shu and Bhattacharyya, 1990)

Figure 2.6 Schematic for influence function method (Luo and Peng, 2000)........................... 20

Figure 2.7 Weighting failure of the pre-driven room with a fracture observed at the front edge of the abutment pillar (Pulse, 1990) .......................................................................................... 23

Figure 2.8 Full face recovery room showing instrumentation locations (Oyler et al., 2001)...... 25

Figure 2.9 The changes of panel stress, abutment pillar stress and the convergences at the instrumentation site as fender pillar width decreasing (Oyler et al., 2001) ............................... 26

Figure 2.10 Undermining and overmining (Mark et al., 2007b) ............................................. 28

Figure 2.11 Disturbance in a superjacent seam (Stemple, 1956) ........................................... 30

Figure 2.12 Formation of subsidence trough above mined-out panel (Haycocks et al., 1982) .... 31

Figure 2.13 Interseam shearing (after Holland, 1951) ....................................................... 32

Figure 2.14 Change of subsidence parameters (subsidence factor, angle of major influence and time coefficient) due to multi-seam mining (Preusse et al., 2012) ............................................. 34

Figure 2.15 Hydrological changes in the overburden induced by longwall subsidence (modified

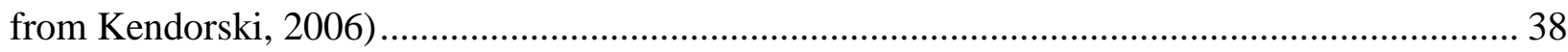

Figure 2.16 Conceptualized representation of overburden response (after Forster et al., 1995; Li,

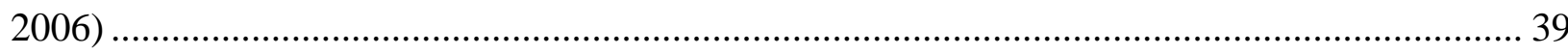

Figure 3.1 Void intensity distribution in overburden predicted by current subsurface subsidence

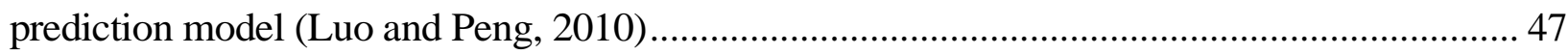

Figure 3.2 Subsidence effects on surface and subsurface hydrologic systems (after Luo and Peng,

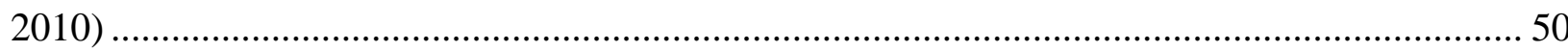

Figure 3.3 Subsurface subsidence prediction model........................................................ 52

Figure 3.4 Schematic for influence function method.................................................... 53 
Figure 3.5 Surface and subsurface subsidence factors (after Luo and Peng, 2000) .................. 56

Figure 3.6 Determination of the radius of major influence …............................................. 58

Figure 3.7 Schematic for dynamic subsurface subsidence associated with longwall mining ...... 59

Figure 3.8 Offset of subsidence velocity peak vs. distance above the seam (Luo and Peng, 2000)

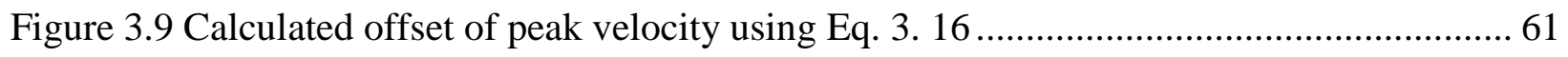

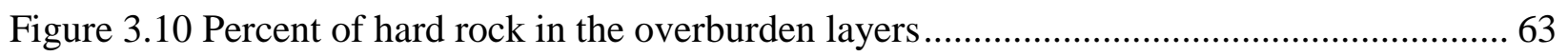

Figure 3.11 Final subsurface subsidence profiles formed at different levels above the longwall

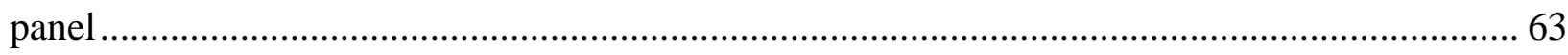

Figure 3.12 Contour plot of final subsurface vertical strain above the longwall panel .............. 64

Figure 3.13 Contour plot of final subsurface void intensity above the longwall panel .............. 64

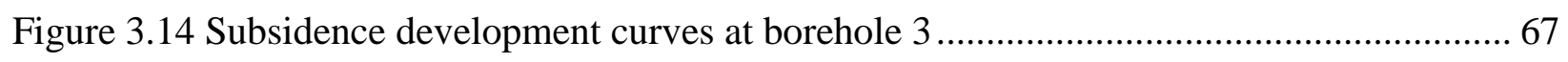

Figure 4.1 Schematic of Pre-driven Recovery Room for Longwall Mining Operation............. 70

Figure 4.2 Stress distributions adjacent to a crack of width of $2 \mathrm{a} 0$ within a uniform in-situ stress

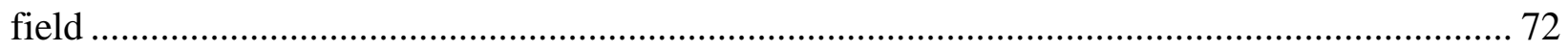

Figure 4.3 Crack with wedge force $\mathrm{P}$ located at $\mathrm{x}$ from its center ....................................... 72

Figure 4.4 Mechanics of roof behavior and manifestation of shield and fender pillar loading .... 75

Figure 4.5 Measured roof-to-floor convergence on pre-driven recovery room in a US mine...... 76

Figure 4.6 Global and dynamic coordinate system for roof floor convergence prediction .......... 77

Figure 4.7 NIOSH Safety structures testing laboratory fosroc tekpak support, units in this figure

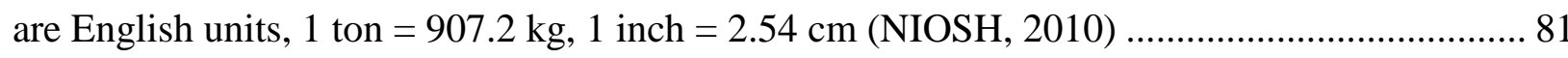

Figure 4.8 Vertical stress profiles for the pre-driven longwall recovery room system for various

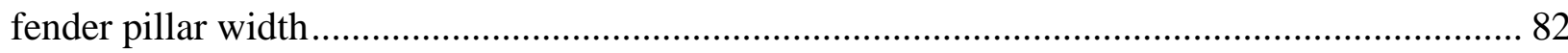

Figure 4.9 Vertical stress variations of the points at different depths in the barrier pillar as

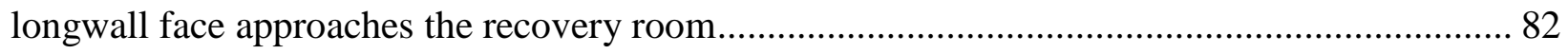

Figure 4.10 Crib load variations as longwall face approaches to recovery room (Crib diameter 76

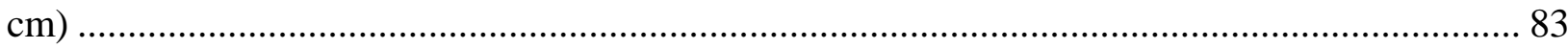

Figure 4.11 Crib load variations as longwall face approaches to recovery room (Crib diameter 61

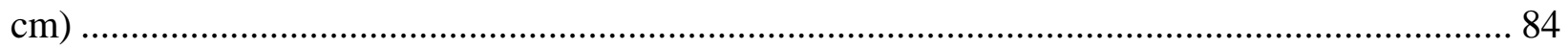

Figure 4.12 Cumulative Roof-to-floor Convergence .......................................................... 85

Figure 5.1 Intensive multi-seam mining conditions of Upper Big Branch Mine ..................... 87

Figure 5.2 Subsurface Subsidence Profile and Multi-seam Mining Interactions ...................... 88 
Figure 5.3 Typical pillar load transfer of multi-seam mining (after Peng and Chandra, 1980) .. 89 Figure 5.4 Subsidence type of multi-seam mining interaction and subsurface abutment load distribution. 91

Figure 5.5 The three-dimensional discretized view of quarter pillars $(\mathrm{w} / \mathrm{h}=5)$...................... 95

Figure 5.6 Stress strain curves under different W/H ratios................................................. 96

Figure 5.7 Comparison between proposed pillar strength formula and FLAC modeling results 97

Figure 5.8 Two types of floor heaves (after Peng, 2008). 99

Figure 5.9 Spatial relationships among surface structures and mains in the mines in the Sewickley and Pittsburgh Seams 104

Figure 5.10 Predicted subsurface subsidence in the Sewickley seam in rectangular area BCDE 106

Figure 5.11 Predicted subsurface void intensity in the Sewickley seam in rectangular area BCDE 106

Figure 5.12 Predicted Subsurface subsidence and horizontal strain along A-A' cross-section in the Sewickley seam above the Pittsburgh seam.... 107

Figure 5.13 Mine layout and topographic map at study site ............................................... 108

Figure 5.14 Geological column at study site ................................................................ 109

Figure 5.15 Subsidence downhill from right to left .......................................................... 110

Figure 5.16 Cracks caused by subsidence induced tension ............................................. 110

Figure 5.17 Subsidence up dip in the belt entry........................................................... 111

Figure 5.18 Field investigation results at study site ....................................................... 112

Figure 5.19 Subsurface vertical strain distribution along the cross-section A-A' .................. 113

Figure 5.20 Subsurface void intensity distribution along the cross-section A-A' ................... 113

Figure 5.21 Stability factors of the pillars at the upper seam mains with and without multi-seam

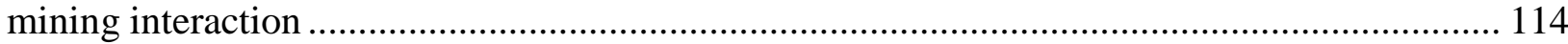

Figure 6.1Predicted final subsided area for four panel widths .......................................... 119

Figure 6.2 Overburden deformation zones caused by longwall subsidence ........................... 120

Figure 6.3 Relationship of total strain and permeability............................................... 122

Figure 6.4 Net flow of the representative elementary volume.......................................... 124

Figure 6.5 The reservoir and the longwall panels under it ........................................... 126

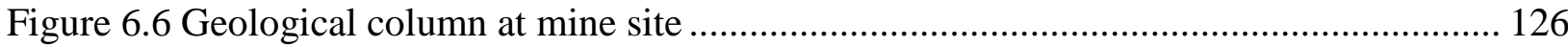


Figure 6.7 Permeability change $\left(k / k_{0}\right)$ caused by the mining of the longwall panel.

Figure 6.8 Post-mining vertical hydraulic permeability distribution over the longwall panel ... 129

Figure 6.9 Post-mining ground water pressure head and flow velocity distribution over the

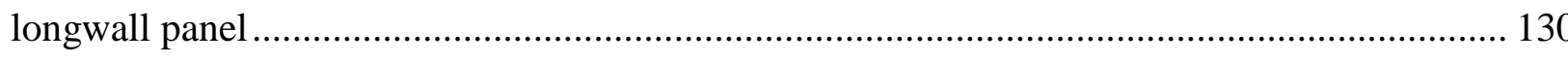

Figure 6.10 Surface elevation contours before (light blue) and after (black) mine subsidence . 131

Figure 7.1 Interface of the subsurface subsidence prediction program ................................ 134

Figure 7.2 Development of pre-driven longwall recovery room support design model............ 135

Figure 7.3 Interface of the pre-driven longwall recovery room support design program.......... 136

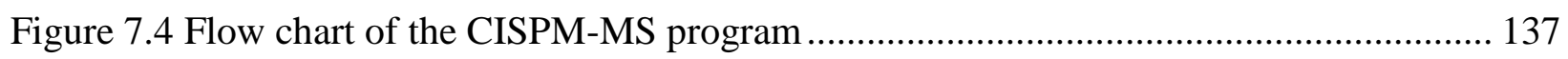

Figure 7.5 Interface of the CISPM-MS program ....................................................... 138

Figure 7.6 Interface of the computer program for evaluating longwall mining impacts on

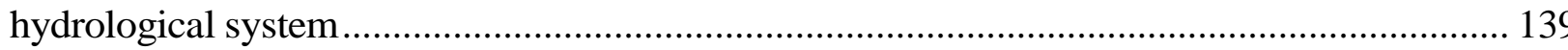




\section{LIST OF ABBREVIATIONS AND SYMBOLS}

\section{List of Symbols}

$$
\begin{array}{ll}
a & =\text { subsidence factor. } \\
a_{0} & =\text { half width of the crack. } \\
a_{i} & =\text { subsidence factor of the } i \text { th layer. } \\
A_{p} & =\text { area of cross-section of the leg piston. } \\
A & =\text { subsurface subsided area. } \\
C_{b} & =\text { the ultimate tensile strength of roof-bolts. } \\
C_{t} & =\text { the ultimate tensile strength of cables. } \\
c^{\prime} & =\text { the cohesion. } \\
d_{1} & =\text { offset of inflection point on the left panel edge. } \\
d_{2} & =\text { offset of inflection point on the right panel edge. } \\
d_{i} & =\text { offset of inflection point of the } i \text { th layer. } \\
d_{y} & =\text { depth of the yield zone. } \\
e & =\text { extraction ratio. } \\
e_{0} & =\text { surface strain. } \\
e_{s} & =\text { subsurface strain at depth } H_{s} . \\
E_{c} & =\text { the Young's modulus of the coal pillar. } \\
f_{s} & =\text { influence function for subsidence. } \\
f_{u} & =\text { influence function for horizontal displacement. } \\
H_{0} & =\text { surface tilt. } \\
g_{s} & =\text { subsurface tilt at depth } H_{s} . \\
H_{p} H & =\text { interburden thickness. } \\
h_{f} & =\text { fluid column height in the hydraulic leg. } \\
H_{p} & =\text { height of the pillar. } \\
& =\text { depth for subsurface subsidence prediction. } \\
& =
\end{array}
$$


$i \quad=$ final surface slope.

$i_{d} \quad=$ dynamic surface slope.

$K \quad=$ the hydraulic conductivity of the porous medium.

$K_{A} \quad=$ stress intensity factor at point $\mathrm{A}$.

$K_{B} \quad=$ stress intensity factor at point $\mathrm{B}$.

$k_{0} \quad=$ surface curvature.

$k_{s} \quad=$ subsurface curvature at depth $H_{s}$.

$k_{P} \quad=$ powered support stiffness.

$K_{d} \quad=$ dynamic surface curvature.

$K_{E} \quad=$ rock strata factor related to the Young's modulus.

$k_{w} \quad=$ bulk modulus of the water-oil mixture.

$K_{x} \quad=$ post-mining conductivity in the x-direction.

$K_{y} \quad=$ post-mining conductivity in the y-direction.

$K_{x 0}=$ pre-mining conductivity in the $\mathrm{x}$-direction .

$K_{y 0} \quad=$ pre-mining conductivity in the $\mathrm{y}$ - direction.

$l=$ offset of velocity peak or offset of dynamic inflection point.

$l_{1} \quad=$ offset of subsidence initiation point.

$L_{b} \quad=$ the thickness of the bolted horizon defined by roof bolts.

$L_{p} \quad=$ the pillar length.

$m \quad=$ mining height.

$n \quad=$ number of layers of overburden strata.

$n_{s} \quad=$ number of legs working in parallel in between canopy and base of the support.

$N_{b} \quad=$ the average number of roof-bolts in each bolt row.

$N_{t} \quad=$ the average number of cables in each cable row.

$N_{c}{ }^{\prime} \quad=$ the bearing capacity factor for the weak layer.

$P \quad=$ point force per unit plate thickness.

$Q \quad=$ rock factor.

$R \quad=$ radius of major influence.

$R_{i} \quad=$ radius of major influence of the $i$ th layer.

$S \quad=$ final surface subsidence.

$S_{b} \quad=$ the spacing between roof-bolt rows. 


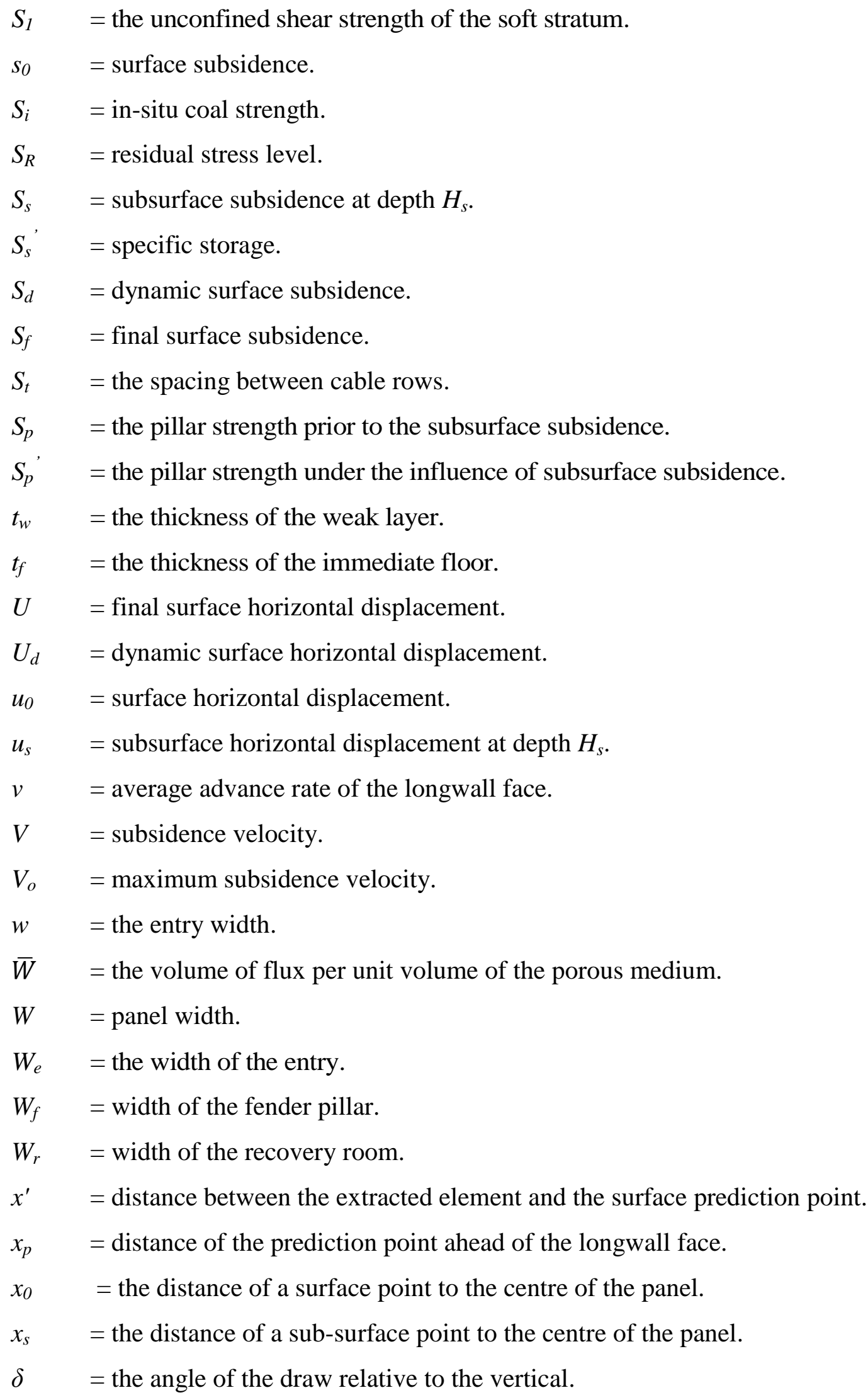


$\gamma \quad=$ average unit weight of the overburden strata.

$\lambda=$ the pillar strength reduction factor.

$\phi^{\prime} \quad=$ angle of internal friction.

$\phi_{0} \quad=$ the initial porosity.

$\Delta \varepsilon_{x} \quad=$ induced strain in the $\mathrm{x}$ direction.

$\Delta \varepsilon_{y} \quad=$ induced strain in the $\mathrm{y}$ direction.

$\Delta s \quad=$ maximum convergence of the immediate roof.

$\varepsilon \quad=$ final surface strain.

$\varepsilon_{d} \quad=$ dynamic surface strain.

$\varepsilon_{x} \quad=$ horizontal strain.

$\varepsilon_{z} \quad=$ vertical strain.

$\varepsilon_{t} \quad=$ total strain or void intensity.

$\eta \quad=$ percent of hard rock.

$\sigma_{\mathrm{i}} \quad=$ in-situ vertical stress.

$\sigma_{x x} \quad=$ the horizontal stress.

$\sigma_{y y} \quad=$ the vertical stress.

$\sigma_{x x 0}=$ the initial horizontal stress.

$\sigma_{y y 0}=$ the initial vertical stress.

$\sigma_{m} \quad=$ mean stress.

$\sigma_{p} \quad=$ the pillar load prior to the subsurface subsidence.

$\sigma_{p}{ }^{\prime} \quad=$ pillar load under the influence of subsurface subsidence.

$\omega \quad=$ the ratio of unconfined shear strength of the lower hard layer to the upper weak layer.

\section{List of Abbreviations}

DR $\quad=$ Damage Rating

HR $\quad=$ Hard Rock Percentage

SF $\quad=$ Stability Factor

CISPM = Comprehensive \& Integrated Subsidence Prediction Model

MSM = Multiple Seam Mining

SMCRA $=$ Surface Mining Control and Reclamation Act

GRSUP = Ground Support Rating 
GSI = Geological Strength Index

FMA $=$ Fracture Mechanics Approach

IB = Inter-Burden

$\mathrm{NCB}=$ National Coal Board

TMR = Telescopic Mesh Refinement 


\section{CHAPTER 1 INTRODUCTION}

\subsection{Mine Subsidence}

Mine subsidence, as a mining induced phenomenon, has a history nearly as long as underground coal mining itself. The study of mining subsidence is one of the most important branches in the field of mine ground control. However, mine subsidence due to underground mining was not paid sufficient attention in the US until after the middle 1960s (Peng, 1992). The increasing use of longwall mining and further housing development into abandoned mined lands in suburban areas further accelerated the public concerns about subsidence (Barkley, 2007). In 1977, the US Congress established the Surface Mining Control and Reclamation Act (SMCRA) in which it requires all coal operators to have approved surface subsidence plans. In response to this requirement, many research programs were initiated.

Caving methods, such as longwall mining and room and pillar mining with pillar extractions employed in US underground coal mines, normally cause immediate surface subsidence. Room and pillar mining without pillar extraction, though is generally designed for not causing subsidence, could still induce unexpected subsidence under certain conditions. The ground movements and deformations associated with the mine subsidence develop upwards from the excavation level, through the overburden strata, to the surface. Mine subsidence can cause disturbances not only to surface structures and the environment but also to subsurface strata and underground mine structures. Mine subsidence can significantly affect mining costs where major surface facilities and natural environments need to be protected. Severe subsidence disturbances could even endanger, directly or indirectly, the public safety on the surface and miner's safety underground.

Experience shows that accurate prediction of the mine subsidence process and its effects are the key to design and implement effective control measures in the efforts to reduce the severity of the subsidence disturbances and the subsequent consequences. The accuracy of the subsidence prediction method depends on the employed mathematical models and empirical formulae for subsidence parameters deduced from field works. 


\subsection{Progress in Subsidence Study}

Major surface subsidence research in the U.S. began in the late 1970s, and during the initial period, all subsidence theories were borrowed from those developed in Europe, especially the U.K. National Coal Board. As subsidence data accumulated, it was found that subsidence parameters for U.S. coalfields differed from those in Europe. Subsequently, subsidence prediction models specifically pertaining to U.S. coalfields and structural damage mitigation techniques were developed in the late 1980s and early 1990s (Peng, 2006).

In the last two decades, extensive subsidence research was conducted by government agencies, academic institutions, coal companies, and consulting companies in the United Sates. These research efforts include: (1) development of the final and dynamic surface subsidence prediction methods, (2) surface subsidence prediction software development, (3) assessment and mitigation of the subsidence effect on the surface structures and water resources, (4) surface subsidence measurement and monitoring, and (5) investigation of subsidence events above abandoned coal mines (Karmis et al., 2008; Preusse et al., 2012; Luo, 2013). As a result, the science of subsidence, or the prediction and control of surface subsidence in general, has approached significant maturity, as demonstrated in numerous case studies published in the relevant literature. In particular, the development, use and application of subsidence prediction methodologies can provide a powerful tool for subsidence engineering, mine planning and damage mitigation.

A strong subsidence research program has been gradually developed in the Department of Mining Engineering at West Virginia University (WVU). In building this program, a considerable amount of time and efforts have been made in (1) monitoring and collecting data of surface and subsurface subsidence, and the structural responses to subsidence process, (2) developing and refining mathematical models and computer programs for surface and subsurface subsidence predictions, (3) developing and field-testing criteria and techniques for assessing subsidence influences on various structures, (4) developing and field-testing mitigation measures to reduce the severity of anticipated subsidence disturbances. In particular, the subsidence prediction program package CISPM has been well received and proven to be accurate through numerous applications in the US coal mining industry and in a number of major coal producing countries (Luo, 1989; Luo et al., 2008; Luo and Qiu, 2012a). 


\subsection{Problem Statement}

However, as the good and easy-to-mine coal reserves are gradually depleted, coal mining operations will be conducted under more populated areas, in deeper and more difficult coal seams, and in multi-seam mining settings. These changes in mining practices will present more challenging subsidence problems to the coal mining industry in the future (Gale, 2011). This situation will be further compounded by the tightening of federal and state environmental and safety regulations imposed on the coal industry.

The study of the overburden movement and deformation over coal mining panels is essential for the safety and efficiency of coal mine operations. Observation boreholes, as a direct method, are drilled from the surface to a certain depth to study the movement and deformation of the overburden strata. However, it is too expensive to drill these boreholes at every coal mine. An alternative is to predict the movement and deformation of the overburden strata by a subsurface subsidence prediction model. A subsurface subsidence theory was proposed and developed in the 1990s and it was applied in many case studies (Shu and Bhattacharyya, 1990). However, this subsurface subsidence prediction model offers no means to consider the overburden stratifications which can affect the overburden movement and deformation significantly.

In the last three decades, the surface subsidence prediction models were well accepted and used in the mining industry. Numerous field monitoring subsidence data sets over longwall and room-and-pillar mine panels were collected to calibrate the models. The three decades' experience has proven that the surface subsidence prediction model can produce accurate surface movements and deformations that are essential for assessing and mitigating mine subsidence influences. It is believed that the application of subsidence theories can be expanded to solving many complex ground control problems related to the mining-induced movements and deformations of overburden strata.

In coal mine ground control, challenges still remain and warrant additional research work. Some of these challenges include the stability of pre-driven longwall recovery room, multi-seam mining interaction, and longwall mining effects on surface and subsurface hydrological systems. These mentioned ground control issues are all related to the subsidence of the overburden strata. Numerical simulation techniques, such as finite element method and boundary element method for continuous media, have been applied in the past to solve such ground control problems. 
These numerical techniques allow a detailed analysis to be performed on the ground control problems associated with mining, including essential material and geometric nonlinearities. Admitting notable progress in the area of numerical techniques application to ground control problems, we still have to mention that newly developed numerical techniques have not entered yet into the ground control analysis practice as a common tool. Obstacles still exist when

applying numerical continuous simulation techniques in solving ground control problems that involve large deformations and extensive discontinuities. Also, the application of a specific numerical simulation program code requires careful preliminary testing from the user. On the other hand, simplified analytical models can be more easily incorporated into the design guidelines and also provide a basis for verification of more complicated numerical models.

The subsurface subsidence prediction model, developed based on stochastic theory, is specifically suitable to deal with large strata movements and deformations associated with mine, especially longwall mine, subsidence process. However, in order to make the applications accurate and reliable, research efforts should be made to refine the subsurface subsidence prediction model and to develop the methods to apply subsidence theories in solving these targeted ground control problems.

\subsection{Research Objectives and Scope}

Based on the above needs assessment, continued efforts should be made to enhance the existing subsidence research capacity in the research toward the proposed dissertation. The proposed research works are listed as in the following sections.

- Development of the enhanced subsurface subsidence prediction model. The previous subsurface subsidence prediction models are unable to consider the overburden stratification, particularly the massive hard rock (i.e., limestone and sandstone) layers. The presence of massive hard rock layers in the overburden strata can greatly affect the magnitude and distribution of subsurface strata movements and deformations. An innovative approach to employ the influence function method while considering the hard rock layers will be applied in the development of a new subsurface subsidence prediction model.

- Pre-driven longwall recovery room support design. The pre-driven longwall recovery room is a relatively new technique to shorten the time required for a safe longwall face move. The 
design of the support system for a pre-driven recovery room is a complicated process because the stress distribution in the barrier pillar, standing supports, fender pillar and the immediate roof changes as the longwall face approaches the pre-driven recovery room. The movements of the immediate roof above the pre-driven recovery room system are important for the stability analysis of the recovery room. An analytical model is proposed to determine the dynamic load distribution in the barrier pillars, fender pillars, and standing supports. The dynamic subsidence development theory is also applied for roof deflection calculations and roof-support interaction analysis.

- Multi-seam mining interactions and multi-seam mining subsidence prediction. In areas with mining operations in multiple coal seams, the mining activities conducted in underlying seam(s) could affect the stability of mine structures, (i.e., coal pillars, entry floor, and roof) in the seams above. Unstable pillars, roofs and floors can not only cause significant problems to mining operations but also present hazardous conditions to mine workers. The subsurface subsidence prediction model can be used to assess the stability of these mine structures. Pillar failure in a sufficient and contiguous area could cause additional subsurface and surface subsidence. Such additional subsurface strata deformations could further affect the stability of the mine structures in the coal seams. In predicting multi-seam mining surface subsidence, the surface movements and deformations caused by the individual mining operations as well as the interactive effects are all considered.

- Longwall subsidence influences on overburden hydrological system. Voids and fractures created by the ground subsidence process associated with longwall mining operations can affect surface water bodies and subsurface aquifers. The voids created by differential subsurface subsidence in the upper aquifer strata can serve as additional storage for water from surface water streams and subsurface aquifers. The differential subsurface vertical and horizontal movements can create contiguous zones with high void intensity in the overburden strata near the edges of the longwall panel as well as a short distance behind the moving longwall face. The subsidence-induced total strain would change the hydrological conductivity in the overburden strata.

- Programming and software development for the subsurface subsidence prediction model and its applications. A computer software suite is developed to predict the subsurface movements and deformations over longwall mining panels. The applications 
of the subsurface subsidence prediction on, pre-driven longwall recovery room support design, multi-seam mining interactions and subsidence prediction and longwall mining impacts on overburden hydrological systems, are also incorporated in this software. This software suite provides a tool for analyzing most subsidence related problems of coal mining operations. 


\section{CHAPTER 2 LITERATURE REVIEW}

\subsection{Surface Subsidence}

The surface subsidence study begins with the overburden movement in response to the total extraction of coal. The overburden movement is the direct source of the surface subsidence, which will create two types of surface subsidence basins: the final subsidence basins are those that occur long after mining, and the dynamic subsidence basins which refers to the temporary basin when underground mining is in progress (Peng, 1992). Impacts from underground coal mining include impacts to buildings and structures, surface lands, water bodies, utilities (gas and water pipelines, power lines, etc.), and public infrastructures (Conte and Moses, 2005; Zimmermann and Fritschen, 2007; Gutierrez et al., 2010; Witkowski, 2011; Iannacchione et al., 2011; Hanna and Heasley, 2011).

\subsubsection{Overburden Movements}

When total extraction is used, it produces a large void in the coal seam and disturbs the equilibrium conditions of the surrounding rock strata. The roof strata bend downward. When the excavated area (or gob) expands to a sufficient size, the roof strata will cave. As a result, the overlying strata continue to bend and break until the piles of the fallen rock fragments are sufficiently high to support the overhanging strata. At this time, the overhanging strata no longer cave, but bend and rest on the underlying strata or gob piles. Bending of these strata develop upward until reaching the surface and form a subsidence basin. The overburden strata and the surface subsidence basin will further go through a period of compaction and gradually become stabilized.

Figure 2.1 shows the four zones of disturbance in the overburden strata in response to the longwall mining (Peng, 2006). The caved zone, which is the immediate roof before it caves, ranges in thickness from two to ten times of the mining height. In this zone, the strata fall on the mine floor and, in the process, are broken into irregular but platy shapes of various sizes. They are crowded in a random manner. Thus, the rock volume in its broken state is considerably larger 
than that of the original intact strata. The volume ratio of broken strata to its original intact strata is called the expansion ratio or bulking factor. Expansion ratio is a very important factor because it determines the height of the caved zone. There are various estimates of expansion ratios for various rock types.

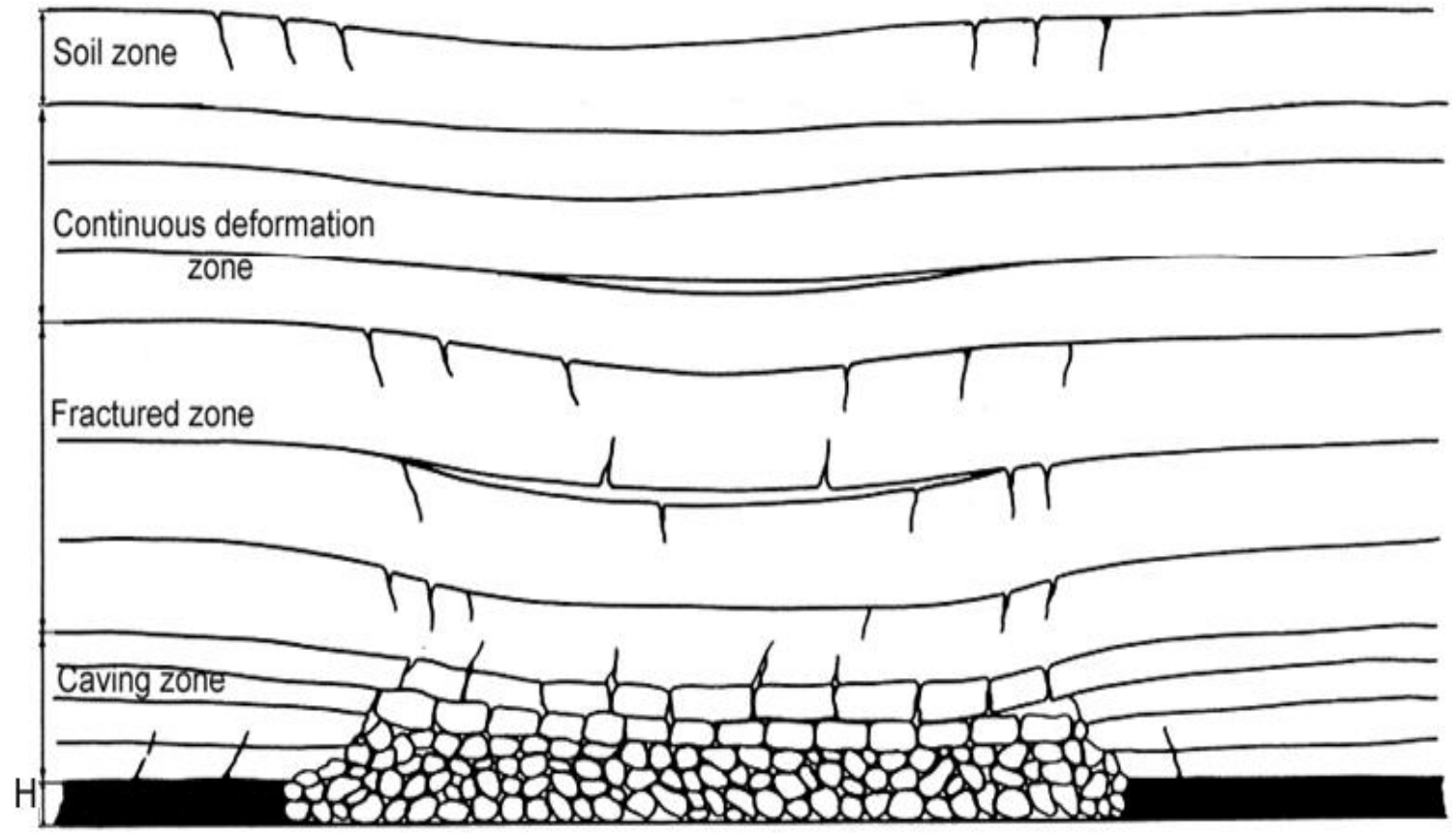

Figure 2.1 Overburden movements resulting from longwall mining (Peng, 1992)

Above the caved zone is the fractured zone. In this zone, the strata are broken into blocks by vertical and/or sub-vertical fractures and horizontal cracks due to bed separation. The adjacent blocks in each broken stratum still maintain contact either fully or partially across the vertical or sub-vertical fractures. Thus, there is a horizontal force that is transmitted through and remains in these strata. With this horizontal force, the individual blocks in these broken strata cannot move freely without affecting the movements of the adjacent blocks. These broken strata are called the force-transmitting beams. The thickness of the fractured zone ranges from 28 to 52 times the mining height. The combined thickness of the caved and fractured zones ranges from 30 to 60 times the mining height (Peng, 1992; Luo, 2013).

Between the fractured zone and the ground surface is the continuous deformation zone. Unlike the fractured zone, the strata in this zone deform gently without causing any major cracks that extend long enough to cut through the thickness of the strata. Therefore, the strata behave essentially like a continuous or intact medium. 
On the surface, there is a soil zone of varying depth depending on the location. In general, cracks on and near the panel edges tend to remain open permanently, whereas those in and around the center of the panel will close back up when the longwall face has passed by a sufficient distance. Depending on the mining depth and other factors, the cracks vary from barely visible to $3-4 \mathrm{ft}(0.91-1.22 \mathrm{~m})$ wide and from less than $1 \mathrm{ft}(0.3 \mathrm{~m})$ deep to as deep as the soil zone.

\subsubsection{Final Surface Subsidence}

Figure 2.2 is a schematic of the subsidence profile that shows the descriptive or numerical terms to define the depth, extent, relative location and shape of a subsidence basin (Peng, 1992; Peng et al., 1995; Luo, 2013).

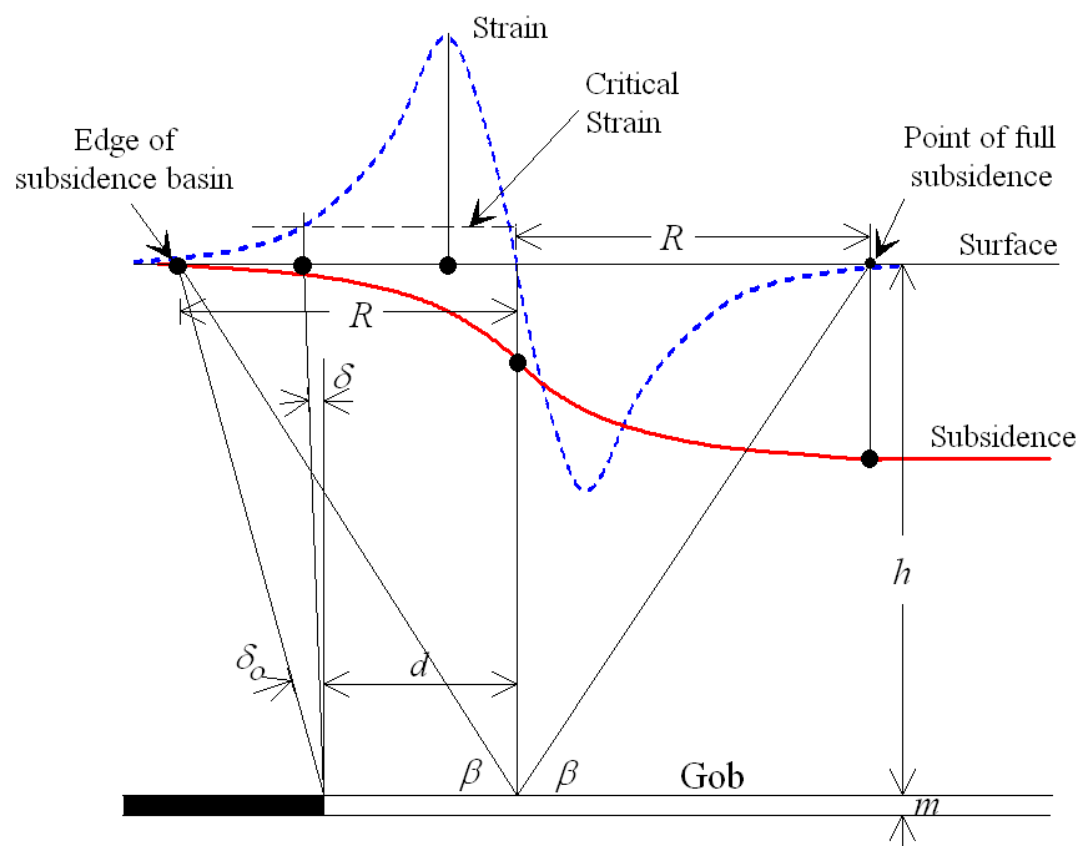

Figure 2.2 Final subsidence parameters (after Luo, 1989)

Accurate subsidence prediction is essential for assessing and mitigating subsidence influences to surface and subsurface structures and environment. The subsidence prediction methods are classified into the empirical methods, the influence function methods, physical modeling and numerical modeling (Karmis et al., 1990; Karmis et al., 1992; Peng, 1992; Luo, 2013).

The NCB method (NCB, 1975), as an empirical method, is the most comprehensive and popular graphical method in the field of mining subsidence. It was developed from subsidence 
observations at around 200 sites in several UK coal fields during the 1950s and early 1960s. In another kind of empirical method, the profile function methods, the measured final subsidence profiles (full or half) are fitted into a selected mathematical function. The derived profile functions will then be used in subsidence predictions.

In the physical modeling, small scale models built with various real rocks or artificial materials are used to simulate the ground subsidence process. Various mixtures of readily available construction materials were used to simulate the floor, coal and overburden strata. A miniature longwall shield was placed in the coal seam. The longwall mining operation was simulated by removing the coal seam block by block with a predetermined rate. The movements of the overburden strata were monitored using total survey stations and strain measured with imbedded strain gauges. Most recently, Trckova (2009) conducted a 3-D physical modeling of surface subsidence affected by underground mining activities.

Numerical modeling methods, the fastest developing methods, apply numerical modeling tools to simulate the movement and deformation in the overburden strata. Various numerical simulation software, employing finite element method (ANSYS and ABAQUS), finite difference method (FLAC), discrete element method (UDEC), and boundary element method (LaModel), are applied to study the mining induced overburden movements and deformations. However, these numerical methods have limitations in dealing with large deformation and discontinuity commonly encountered with coal mine ground control problems.

The influence function method is one of the most popular and accurate subsidence prediction methods (Karmis et al., 1990; Karmis et al., 1992; Peng, 1992; Luo, 2013). The influence function is the mathematical function chosen to represent the distribution of the subsidence influence caused by the extraction of an element in the coal seam. The final subsidence at a surface point is expressed as the integral of the influence function throughout the "mined area".

The most popular influence function method is developed based on the Knothe's theory (Knothe, 1953 and 1957). In this method, the influence functions for subsidence and horizontal displacement can be derived as following equations. In order to match the mathematical model with the field data, it is found that a constant of $2 \pi$ should be multiplied to the right side of the expression as shown in Eq. 2.2 (Peng, 1992; Luo, 1989). 


$$
\begin{aligned}
& f_{s}\left(x^{\prime}\right)=\frac{S_{\max }}{R} e^{-\pi\left(\frac{x^{\prime}}{R}\right)^{2}} \\
& f_{u}\left(x^{\prime}\right)=-\frac{2 \pi S_{\max }}{R h} x^{\prime} e^{-\pi\left(\frac{x^{\prime}}{R}\right)^{2}}
\end{aligned}
$$

where:

$$
\begin{aligned}
S_{\text {max }} & =\text { maximum possible subsidence, } S_{\text {max }}=m a \\
R & =\text { radius of major influence. } \\
h \quad & =\text { overburden depth. } \\
x^{\prime} & =\text { distance between the extracted element and the surface point where final subsid- }
\end{aligned}
$$
ence to be calculated.

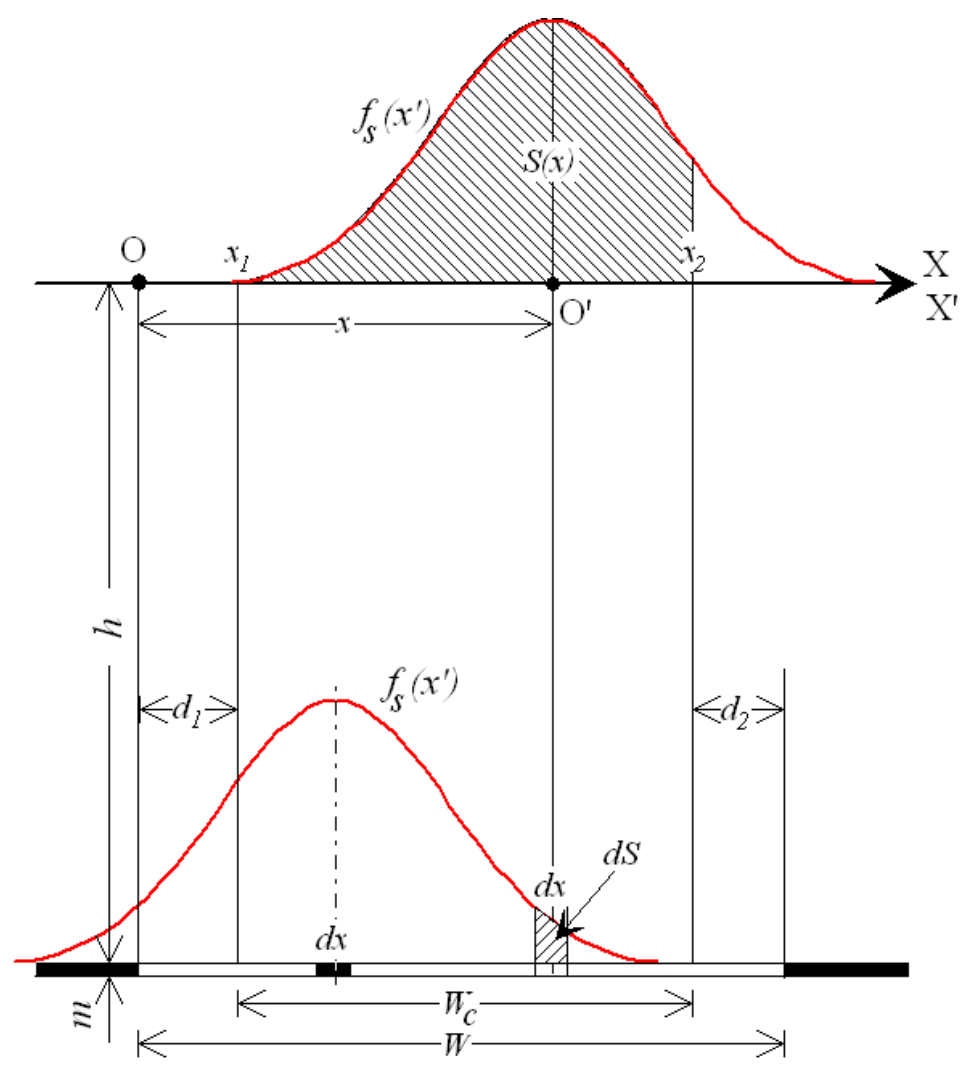

Figure 2.3 Final subsidence prediction along a major cross-section (after Luo, 1989)

The final subsidence and horizontal displacement are determined by integrating the influence functions for subsidence and horizontal displacement over the computing area as shown in Fig. 2.3. The final surface subsidence along a major cross-section is, 


$$
S(x)=\frac{S_{\max }}{R} \int_{d_{1}-x}^{W-d_{2}-x} e^{-\pi\left(\frac{x^{\prime}}{R}\right)^{2}} d x^{\prime}
$$

where:

$d_{1}, d_{2}=$ offsets of inflection points on the left and right panel edge, respectively.

$W \quad=$ panel width.

The final surface horizontal displacement along a major cross-section is,

$$
U(x)=\frac{R S_{\max }}{h}\left[e^{-\pi\left(\frac{d_{1}-x}{R}\right)^{2}}-e^{-\pi\left(\frac{W-d_{21}-x}{R}\right)^{2}}\right]
$$

The final slope is,

$$
i(x)=\frac{S_{\max }}{h}\left[e^{-\pi\left(\frac{d_{1}-x}{R}\right)^{2}}-e^{-\pi\left(\frac{W-d_{21}-x}{R}\right)^{2}}\right]
$$

The final strain is,

$$
\varepsilon(x)=\frac{2 \pi S_{\max }}{h}\left[\frac{d_{1}-x}{R} e^{-\pi\left(\frac{d_{1}-x}{R}\right)^{2}}-\frac{W-d_{2}-x}{R} e^{-\pi\left(\frac{W-d_{21}-x}{R}\right)^{2}}\right]
$$

The final curvature is,

$$
K(x)=\frac{2 \pi S_{\max }}{R^{2}}\left[\frac{d_{1}-x}{R} e^{-\pi\left(\frac{d_{1}-x}{R}\right)^{2}}-\frac{W-d_{2}-x}{R} e^{-\pi\left(\frac{W-d_{21}-x}{R}\right)^{2}}\right]
$$

Recently, some of the mine subsidence researchers are conducting studies for improving the subsidence prediction accuracy for special mining conditions, such as subsidence caused by top-coal caving and subsidence caused by steeply dipping coal seam mining in China (Cui et al., 2000; Luo and Cheng, 2009).

\subsubsection{Dynamic Subsidence}

In the dynamic subsidence process, surface movements and deformations are functions of time and the relative face location to the surface point. The dynamic subsidence process associated with a longwall mining operation still can be divided into four basic phases, i.e. 
subsidence initiation and development phase, normal subsidence phase, residual (creep) subsidence phase and long-term subsidence phase (Luo and Peng, 1991; Peng, 1992).

In predicting dynamic subsidence, the development pattern of subsidence velocity is the most important piece of information (Peng and Luo, 1988). The subsidence velocity is the incremental subsidence at a surface point over a unit time, $\mathrm{ft} / \mathrm{day}$ or $\mathrm{mm} / \mathrm{day}$, which can be expressed by the following equation,

$$
V\left(x^{\prime}, y\right)=V_{o}(x, y) e^{-2\left(\frac{x^{\prime}+l}{l+l_{1}}\right)^{2}}
$$

where:

$l \quad=$ offset of velocity peak or offset of dynamic inflection point.

$l_{1} \quad=$ offset of subsidence initiation point where about $2 \%$ of the final subsidence has accumulated.

$V_{o}(x, y)=$ maximum subsidence velocity at the prediction point.

The dynamic subsidence parameters, $l$ and $l_{l}$, are derived based on the regression study of many dynamic subsidence cases (Luo, 2013).

$$
\begin{aligned}
l & =h \times 0.382075 \times 0.999253^{h} \cdot\left(1+1.5731 \times 10^{-4} \times v^{1.967}\right) \\
l_{1} & =\frac{0.113 h}{1+0.1825 \sqrt{v}}
\end{aligned}
$$

where:

$v \quad=$ average advance rate of the longwall face, $\mathrm{ft} /$ day.

The subsidence at the prediction point is the accumulation of the incremental subsidence received as shown in Fig. 2.4, which can be expressed by the following equation (Luo, 1989).

$$
S_{d}\left(x^{\prime}, y\right)=\frac{1}{2} S_{f}(x, y)+\sqrt{\frac{2}{\pi}} \frac{S_{f}(x, y)}{l+l_{1}} \int_{x_{p}}^{-l} e^{-2\left(\frac{x^{\prime}+l}{l+l_{1}}\right)^{2}} d x^{\prime}
$$

where:

$x_{p} \quad=$ distance of the prediction point ahead of the longwall face.

$S_{f}(x, y)=$ final surface subsidence at the prediction point. 


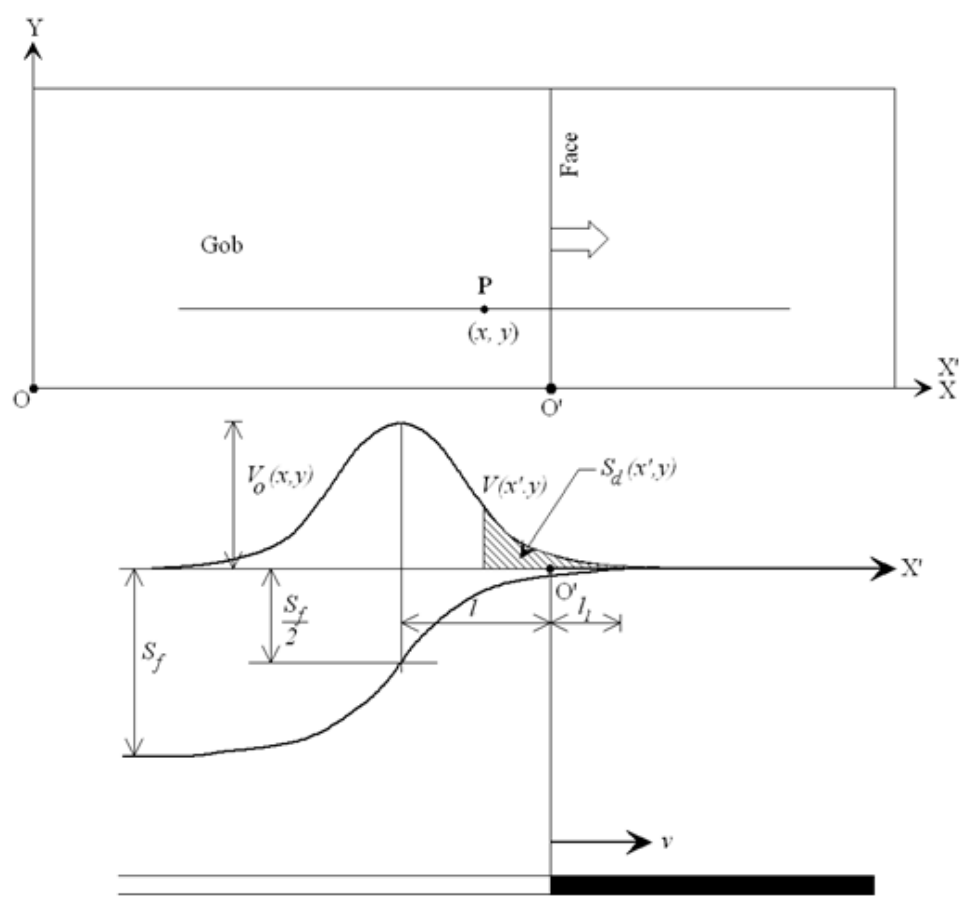

Figure 2.4 Coordinate Systems for Dynamic Subsidence Prediction (after Luo, 1989)

The normal dynamic slope is,

$$
i_{d}\left(x^{\prime}, y\right)=\frac{d S_{d}}{d x^{\prime}}=-\sqrt{\frac{2}{\pi}} \frac{S_{f}(x, y)}{l+l_{1}} e^{-2\left(\frac{x^{\prime}+l}{l+l_{1}}\right)^{2}}
$$

Maximum Dynamic Slope

$$
i_{d \max }(x, y)=\sqrt{\frac{2}{\pi}} \frac{S_{f}(x, y)}{l+l_{1}} \quad \text { at } \quad x^{\prime}=-l
$$

Normal Dynamic Subsidence Velocity is,

$$
V\left(x^{\prime}, y\right)=\sqrt{\frac{2}{\pi}} \frac{v \cdot S_{f}(x, y)}{l+l_{1}} e^{-2\left(\frac{x^{\prime}+l}{l+l_{1}}\right)^{2}}
$$

Relationship: $\frac{i_{d}\left(x^{\prime}, y\right)}{V\left(x^{\prime}, y\right)}=-\frac{1}{v}$

Normal Dynamic Horizontal Displacement

$$
U_{d}\left(x^{\prime}, y\right)=\frac{R^{2}}{h} \cdot i_{d}\left(x^{\prime}, y\right)
$$

Maximum Dynamic Horizontal Displacement 


$$
U_{d \max }=\sqrt{\frac{2}{\pi}} \frac{R^{2}}{h} \frac{S_{f}(x, y)}{l+l_{1}} \quad \text { at } \quad x^{\prime}=-l
$$

Normal Dynamic Curvature

$$
K_{d}\left(x^{\prime} y\right)=\frac{d^{2} S_{d}}{d x^{\prime 2}}=4 \sqrt{\frac{2}{\pi}} \frac{S_{f}(x, y)}{\left(l+l_{1}\right)^{3}}\left(x^{\prime}+l\right) e^{-2\left(\frac{x^{\prime}+l}{l+l_{l}}\right)^{2}}=-4 \frac{x^{\prime}+l}{\left(l+l_{1}\right)^{2}} \cdot i_{d}\left(x^{\prime}, y\right)
$$

Maximum Convex Dynamic Curvature

$$
K_{d \max }^{+}(x, y)=0.968 \cdot \frac{S_{f}(x, y)}{\left(l+l_{1}\right)^{2}} \quad \text { at } \quad x^{\prime}=-\left(l-l_{1}\right) / 2
$$

Maximum Concave Dynamic Curvature

$$
K_{d \max }^{-}(x, y)=-0.968 \cdot \frac{S_{f}(x, y)}{\left(l+l_{1}\right)^{2}} \quad \text { at } \quad x^{\prime}=-\left(3 l+l_{1}\right) / 2
$$

Normal Dynamic Strain

$$
\varepsilon_{d}\left(x^{\prime}, y\right)=\frac{R^{2}}{h} \cdot K_{d}\left(x^{\prime}, y\right)
$$

Maximum Tensile Dynamic Strain

$$
\varepsilon_{d \max }^{+}(x, y)=0.968 \cdot \frac{S_{f}(x, y)}{\left(l+l_{1}\right)^{2}} \cdot \frac{R^{2}}{h} \quad \text { at } \quad x^{\prime}=-\left(l-l_{1}\right) / 2
$$

Maximum Compressive Dynamic Strain

$$
\varepsilon_{d \max }^{-}(x, y)=-0.968 \cdot \frac{S_{f}(x, y)}{\left(l+l_{1}\right)^{2}} \cdot \frac{R^{2}}{h} \quad \text { at } \quad x^{\prime}=-\left(3 l+l_{1}\right) / 2
$$

\subsection{Subsurface Subsidence}

Due to economical and operational reasons, field measurements for mining engineering studies are constrained to surface and in-mine levels. The subsurface strata movements, connecting the surface subsidence with in-mine level strata movements, are essential for evaluating coal mining ground control stability and assessing mining impacts on surface and subsurface hydrological systems. 


\subsubsection{Background}

At present, most research on subsidence has been directed towards the study of surface subsidence induced by underground mining. The state-of-the-art of evaluation and prediction of surface subsidence caused by mining operations in horizontal coal seam can be said to have reached a fairly mature stage. For this reason, subsidence prediction programs, such as CISPM (Luo, 1989; Peng and Luo, 1992; Luo et al., 2008) and SDPS (Agioutantis and Karmis, 2008) are extremely popular.

As the easily accessible seams are exhausted, mining companies will be forced into extracting deeper, underlying seams. To ensure the optimum longwall layout, and to minimize interaction effects, a better understanding of strata deformation above a large mine gob is required. This is essential in areas of high extraction, so as to minimize surface subsidence effects, aquifer disruption, and interaction between superincumbent mine workings. Over the past twenty years this problem has attracted the attention of many investigators. However, due to the high cost of subsurface instrumentation programs, majority of these investigations were confined to surface and in-mine measurements (Styler, 1984).

Therefore, more attention should be paid to the research on subsurface subsidence. This research includes: (1) development of comprehensive mathematical models for predicting subsurface subsidence, and (2) development of methodologies for applying the predicted subsurface deformations to studying the subsidence effects on subsurface water bodies, and subsurface structures such as shafts, pillars and openings (Shu and Bhattacharyya, 1993).

As in the instance of surface subsidence, numerous methods and models can be used to study subsurface subsidence. One of the most commonly used methods is direct field monitoring employing multi-anchor borehole wire extensometers. Field investigations of subsurface subsidence have been conducted by Gurtunca (1984), Holla and Armstrong (1986), and Holla and Hughson (1987). Most recently, Du (2010) and Shen et al. (2011) installed the borehole extensometers to monitor the subsurface movements and deformations. Field monitoring results in these studies provides us with a good understanding of the overburden strata movement above longwall mining panels. This technique may not, however, always be possible to use due to economic and operational reasons.

Other methods include theoretical analysis, and physical and numerical modeling. Each has its own advantages and disadvantages (Shu and Bhattacharyya, 1990). Kratzsch (1983) and 
Peng (1992) made some analytical and modeling studies on subsurface subsidence. Whittaker et al. (1990) have conducted some experiments employing physical modeling to study ground behavior above longwall faces in different geological conditions. They described the development of subsurface fractures from longwall mining, and the resulting principal strain patterns, and discussed the significance of the strain patterns in relation to the mining dimensions, and the geological setting in terms of rock strength. Finite element methods (Chen and Hu, 2009; Shen et al, 2011), finite difference method (Xie et al., 1999) and boundary element method (Akinkugbe, 2004; Akinkugbe and Heasley, 2004) have also been used to predict ground movements between the mining horizon and the ground surface. Kwinta (2012) had conducted a study to predict the horizontal and vertical strain around the mine shaft caused by subsurface subsidence and assessed their threats on the shaft stability.

\subsubsection{Subsurface Subsidence Prediction}

Shu and Bhattacharyya (1990) proposed a theoretical model relating subsurface subsidence to surface subsidence. For considering the extraction of a panel with width $W$ and depth $H$ below the ground surface as illustrated in Figure 2.5. The profiles of the five components of surface subsidence, namely subsidence, tilt, curvature, horizontal displacement and horizontal strain are respectively represented by $s_{o}\left(x_{o}\right), g_{o}\left(x_{o}\right), k_{o}\left(x_{o}\right), u_{o}\left(x_{o}\right)$ and $e_{o}\left(x_{o}\right)$ while the corresponding profiles at a sub-surface horizon at a depth $H_{s}$ below the ground surface are respectively represented by $s_{s}\left(x_{s}\right), g_{s}\left(x_{s}\right), k_{s}\left(x_{s}\right), u_{s}\left(x_{s}\right)$ and $e_{s}\left(x_{s}\right)$. According to the proposed model, the relationship between the components of sub-surface subsidence and the corresponding ones at the surface are as follows:

$$
\begin{aligned}
& s_{s}\left(x_{s}\right)=F s_{o}\left(x_{o}\right) \\
& g_{s}\left(x_{s}\right)=F^{2} g_{o}\left(x_{o}\right) \\
& k_{s}\left(x_{s}\right)=F^{3} k_{o}\left(x_{o}\right) \\
& u_{s}\left(x_{s}\right)=F^{2} u_{o}\left(x_{o}\right) \\
& e_{s}\left(x_{s}\right)=F^{3} e_{o}\left(x_{o}\right)
\end{aligned}
$$




$$
\begin{aligned}
& F=\frac{1+\lambda \frac{W}{H}}{1+\lambda \frac{W}{H}-\frac{H_{S}}{H}} \\
& x_{s}=\frac{x_{0}}{F} \\
& \lambda=\frac{1}{2} \cot \delta
\end{aligned}
$$

where:

$$
\begin{array}{ll}
x_{0} & =\text { the distance of a surface point to the center of the panel. } \\
x_{S} & =\text { the distance of a sub-surface point to the center of the panel. } \\
\delta & =\text { the angle of the draw relative to the vertical. }
\end{array}
$$

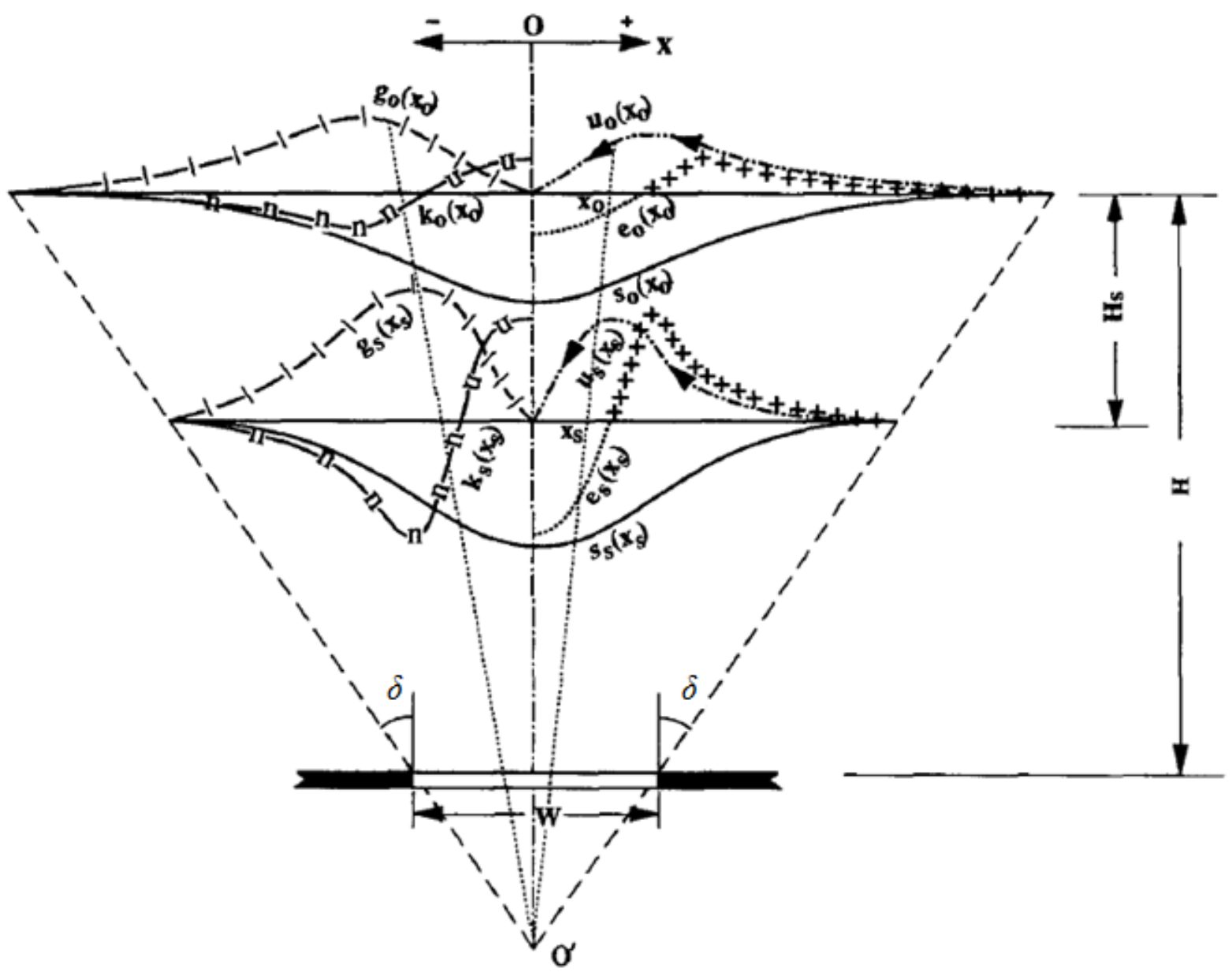

Figure 2.5 Components of surface and subsurface subsidence (after Shu and Bhattacharyya, 1990) 
The methods for predicting final and dynamic subsurface subsidence over full extraction mining methods have been developed by Luo and Peng (2000) using a large amount of surface and subsurface subsidence data over longwall panels. In addition to the traditional deformations used in surface subsidence (i.e., slope, horizontal strain and curvature), two new deformation terms, vertical strain and void intensity - that could be useful for assessing subsurface problems, can be also determined. The vertical strain is a term to express how severely the overburden strata at a point of interest is stretched or compressed along the vertical direction. The void intensity is a term combining the horizontal and vertical strains in a particular way to show the degree that the volume of a block of rock strata at a point expands or contracts under the influence of ground subsidence. When its volume expands, indicated by a positive value, its porosity and permeability increase. For example, in the study of subsidence influences to surface and subsurface water bodies, a contiguous zone of high positive void intensity may imply possibly connected fractures in that zone that could form channels for significant water flow. Therefore, the distributions of the void intensity during and after subsidence process are very useful information for assessing the potential of and identifying the possible routes for significant water leakage from the surface and subsurface water bodies or aquifers to the mine workings. The subsurface subsidence and horizontal displacement at a point of interest $(x, h)$ as shown in Figure 2.6 can be determined by the following two equations.

$$
\begin{aligned}
& S(x, h)=\frac{a m}{R} \int_{d-x}^{W-d-x} e^{-\pi\left(\frac{\varsigma}{R}\right)^{2}} d \varsigma \\
& U(x, h)=\frac{a m R}{h}\left[e^{-\pi\left(\frac{d-x}{R}\right)^{2}}-e^{-\pi\left(\frac{W-d-x}{R}\right)^{2}}\right]
\end{aligned}
$$

Where:

$$
\begin{array}{ll}
a & =\text { subsidence factor. } \\
R & =\text { radius of major influence. } \\
d & =\text { offset of inflection point. } \\
m & =\text { mining height. } \\
h & =\text { overburden depth. } \\
W & =\text { panel width. }
\end{array}
$$




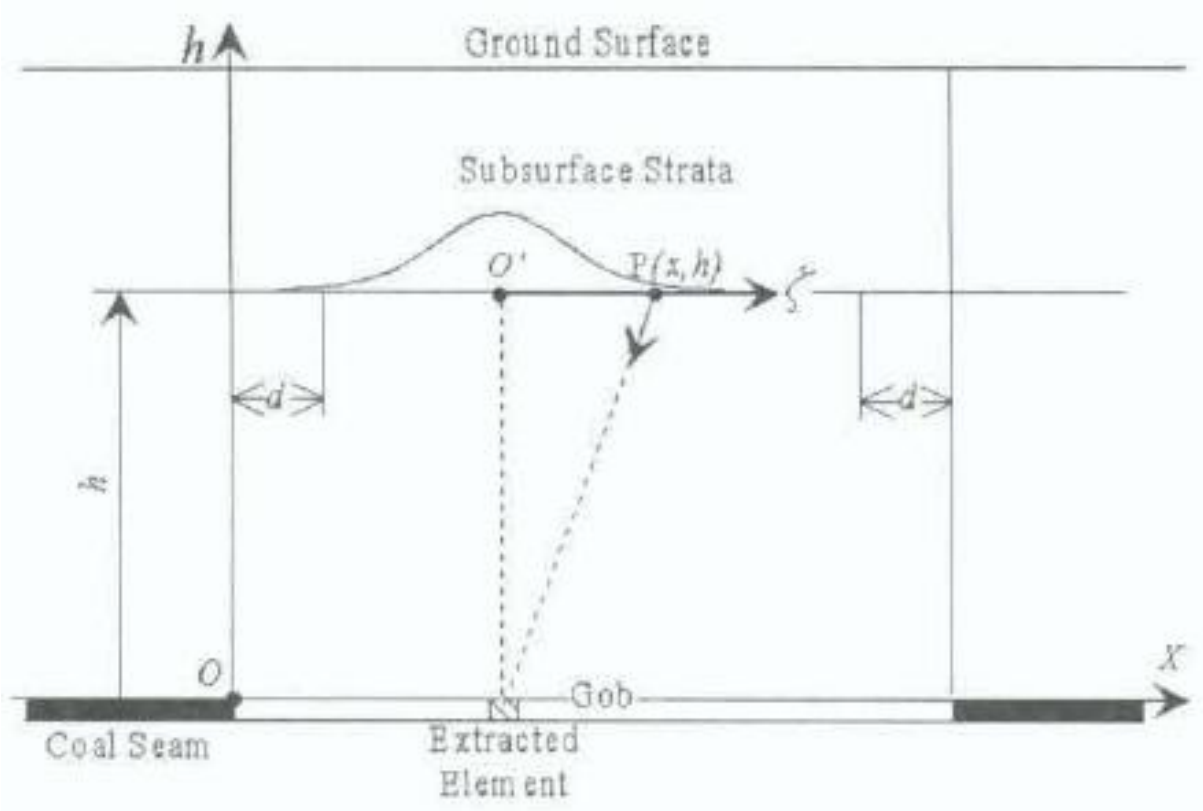

Figure 2.6 Schematic for influence function method (Luo and Peng, 2000)

\subsubsection{Stratification Influences}

The overburden stratification plays a significant role in the propagation of the subsurface subsidence. For example, a thick hard rock layer could significantly alter the distribution of subsurface and surface subsidence. However, the means to reflect the presence and effects of such hard layer are not well developed in the previous subsidence prediction models.

Research has been conducted to study the influence of the overburden stratifications on subsurface subsidence. The main observations are the progressive reduction in surface subsidence, a distinct change in break angle, and the increasingly blocky nature of failure, all associated with an increase in rock strength (Whittaker et al., 1990). The analytical model for calculating angle of draw proposed by Yao et al. (1991) indicates that the angle of draw is a function of overburden strength and stiffness properties. In order to ensure the accuracy of the subsurface subsidence prediction, the overburden stratification should be considered. Numerical studies had also been conducted on the key strata movement impact to overburden movement $\mathrm{Li}$ and Qiu (2012).

\subsection{Subsidence-related Ground Control Problems}


When either a total or high extraction mining method is employed in a coal seam, the overburden strata above the mined-out gob will move and deform. Such movements and deformations could affect the stability of the mine structures in overlying mines, causing roof falls or excessive roof-to-floor convergence or a combination of them (Peng, 2006). They could also induce ground water loss and/or cause water inrush into the mine openings (Zhang et al., 2001). Three specific subsidence related ground control problems, pre-driven longwall recovery room support design, multi-seam mining interactions and longwall mining subsidence influence on hydrological systems, will be discussed in this study.

\subsubsection{Pre-driven Longwall Recovery Room}

When a longwall panel is finished, the heavy and large longwall equipment (i.e., shields, AFC, shearer etc.) has to be removed from a small space surrounded with highly stressed and deformed rock strata then moved to the set-up room of a new panel. If not designed and implemented properly, this process can significantly affect the productivity of the longwall mine, and even cause loss of mining equipment and serious safety problems. The following two methods can be employed to conduct the longwall move.

\subsubsection{Conventional Methods}

Conventional methods require that a pre-determined location be established and preparations be made between 10 to 13 shear cuts before the stop line. After each cut is taken, the mine roof between the shield tips and the longwall face is supported with welded wire roof mesh or chain-link material. These materials are usually placed against the roof in conjunction with steel wire ropes that run the width of the longwall panel. This is a complicated process that slows down the rate of face advance considerably.

\subsubsection{Pre-driven Recovery Room}

In order to reduce the low-production period, the pre-driven open recovery room concept was developed in the late 1980s (Peng, 2006). A pre-driven longwall recovery room has the potential to speed up the non-productive recovery operation of the longwall face equipment upon completion of a panel. With this method, a recovery room is developed and supported ahead of time so that the required combination of standing and internal supports have been installed before the longwall face approaches. Compared with the traditional longwall recovery method, 
the required supports of the recovery room are installed prior to the adverse effects of the front abutment pressure, this limits the exposure of the operators to the hazards associated with roof bolt installation by hand-held equipment and slim line bolters under the unsupported roof. With the traditional method to move the longwall face from one panel to another normally takes about 20 days while move times as long as 30 days are recorded (Bauer et al. 1988 and 1989). When using the pre-driven recovery room, the face move time can be shortened by one to two weeks depending on the ground conditions (Thomas, 2008).

\subsubsection{Ground Control Support System}

However, the pre-driven longwall recovery room must be properly designed and adequately supported to ensure success. Failure to provide adequate ground control will not only reduce the productivity but also create an extremely hazardous environment that can lead to catastrophic results with injuries to mine workers and loss of mining equipment as shown in Fig. 2.7. Several incidents with serious failures have occurred when using the pre-driven recovery rooms in which rock falls or severe weighting pressures on the shields required weeks or even months to work through. In addition, the miners were exposed to extremely hazardous working conditions during these incidents (Tadolini, 2003).

There are several parameters that may affect the success of the pre-driven longwall recovery room, which include immediate roof characteristics, floor strength, overburden depth, seam thickness, mining advance rate, room width, room length, shield capacity, roof reinforcement, standing support and face-room angle. The study of a comprehensive international database of 131 case histories suggests two types of room failure mechanisms (Oyler et al., 2001). The first is a roof fall type failure caused by loading of the immediate roof at the face as the fender or remnant longwall panel narrows. The second is an overburden weighting type failure caused by the inability of the roof to bridge the recovery room and face area, and affecting rock well above the immediate roof. The data indicate that the roof fall type of failure is less likely when intensive roof reinforcement (bolts, cables and trusses) is employed together with higher-capacity shields. The overburden weighting failures, in contrast, occurred when the roof was weak and little standing support was used. Weighting failures were not greatly affected by the density of roof reinforcement. 


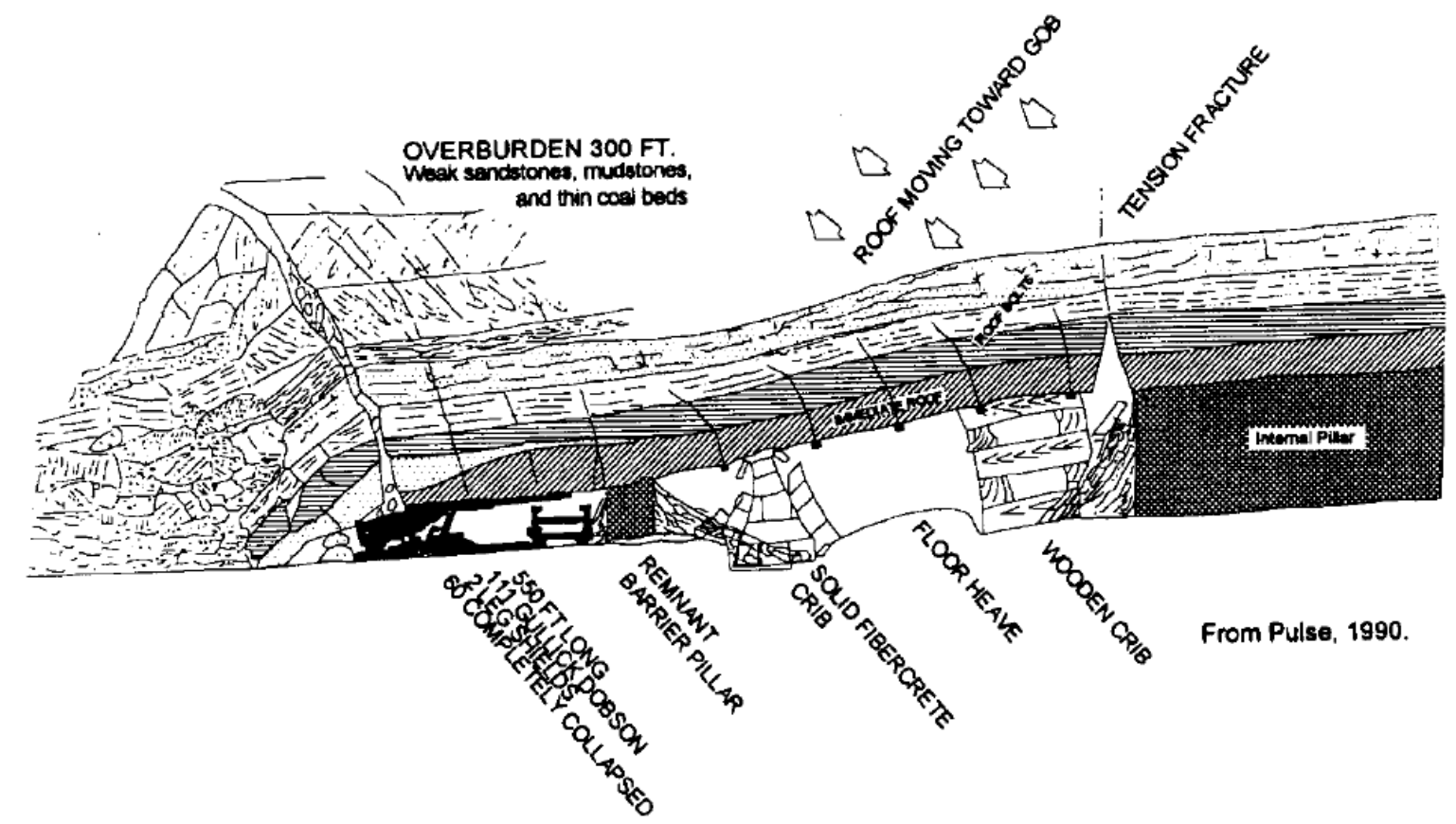

Figure 2.7 Weighting failure of the pre-driven room with a fracture observed at the front edge of the abutment pillar (Pulse, 1990)

Normally, the combination of the internal bolting system and the standing concrete supports are used for achieving successful and safe recovery of the longwall equipment. It was proven that the crib support stiffness and bolt length were the critical support parameters needed to achieve room stability (Tadolini, 2003). The STOP program was used for the design of the secondary supports (Barczak, 2001). The software includes a complete database of the support characteristics and loading profiles obtained through safety performance testing of these supports at the NIOSH Safety Structures Testing Laboratory (NIOSH, 2010). Pumpable cribs were frequently used in the pre-driven recovery rooms as standing supports because they can be cut by the longwall shearer. Zhang et al. (2012) conducted a comprehensive study of the performance and requirements of the pumpable cribs, and proposed the guidelines for determining the requirements of the crib stiffness, and the designing of the crib patterns and spacing.

\subsubsection{Standing Supports}

History has shown that it is very difficult to provide adequate support without the use of standing support to help control the large span of roof as the recovery room is mined into (Oyler et al., 1998 and 2001). The standing supports in the pre-driven recovery room have to be cut by the longwall shearer, to provide enough space for the removal of the shields. The yielding of the 
last section of the longwall panel due to abutment stresses produces a component of convergence that is sometime uncontrollable, requiring the standing supports to be able to yield accordingly and maintain support capability until the shields are fully into the room. Here too, history has shown that supports that are too stiff and non-yielding, despite their high capacity, fail prematurely and endanger ground control (Tadolini, 2003).

Properly design and analysis of the standing support systems and their effects on recovery room and roof support system behavior are critical in the success of pre-driven longwall recovery entry system. Laboratory testing has been conducted to study the load convergence characteristics of various types of standing supports (NIOSH, 2010). Calibrated 3-dimensional finite element models were developed to examine the convergence at the center of the recovery room, calculate the expected loads exerted on the standing supports, and finally, to evaluate the effects of standing support loading on the primary, and secondary bolting systems (Tadolini, 2003). The standing support does not take significant load before the longwall face advances forward into the recovery room. At this period, the coal pillars, primary, and secondary bolting systems control the initial movements. As the longwall face approaches the recovery room, pillars, roof, and the floor will be deformed under the abutment loads. When that occurs, the standing supports are subjected to high levels of forward abutment loading. The load applied to the standing support is dependent on the level of abutment pressure, the stiffness of the standing supports and pillars, the behavior of the roof and floor strata, and the bolt support system previously installed in the roof. The most critical component for a safe longwall system recovery appears to be the good stiffness and load carrying capacity of the selected cribbing system.

Successful longwall recoveries are largely dependent on the appropriate design of the cribs. For example, a stiff cribbing system would attract a large portion of the abutment load, possibly causing the cribs to fail before the longwall can safely enter the recovery room. Conversely, a soft crib system will attract less abutment load but may provide insufficient support to the immediate and main roofs, potentially causing the primary and secondary bolting systems to fail and the roof to fall before the longwall panel can safely enter the recovery entry.

\subsubsection{Instrumentations}

Field instrumentation provides direct information for the study of the pre-driven longwall recovery room. The field instrumentations for pre-driven longwall recovery rooms include the measurements of stresses with load cells and the monitoring of convergences with extensometers. 
The stress changes inside the fender pillar, barrier pillar and solid coal of longwall panel helps understanding of the loading conditions as the longwall face approaching the pre-driven recovery rooms. The measurement of the bolt/cable end load, and load of standing support provides information about the effectiveness of the supports. The roof-floor convergence and the standing support convergence provide information of the stability of roof, floor and standing support stability. Figure 2.8 shows the typical instrumentations of a pre-driven longwall recovery room case in a Pittsburgh seam mine (Oyler et al., 2001).

The room was instrumented on four sites: at both an intersection and a mid pillar site at mid face, a mid-face pillar site near the tailgate side of the panel, and a single sonic extensometer located in the room just off of the tailgate entry. The instruments installed included roof extensometers at all four sites installed to depths between 19 to $22 \mathrm{ft}$ (5.79 to $6.71 \mathrm{~m})$, load cells (hydraulic and strain gauge types) on roof bolts, strain gauges on roof bolts, strain gauges on roof trusses, roof to floor convergence sensors and vibrating wire stress cells installed in the panel and in the abutment pillar. Instrument installation began three months before the face reached the recovery room and all instruments were installed and connected to data recorders at least two weeks before the room was reached, when the remnant panel (inby fender pillar) was still over $800 \mathrm{ft}$ (244 m) wide.

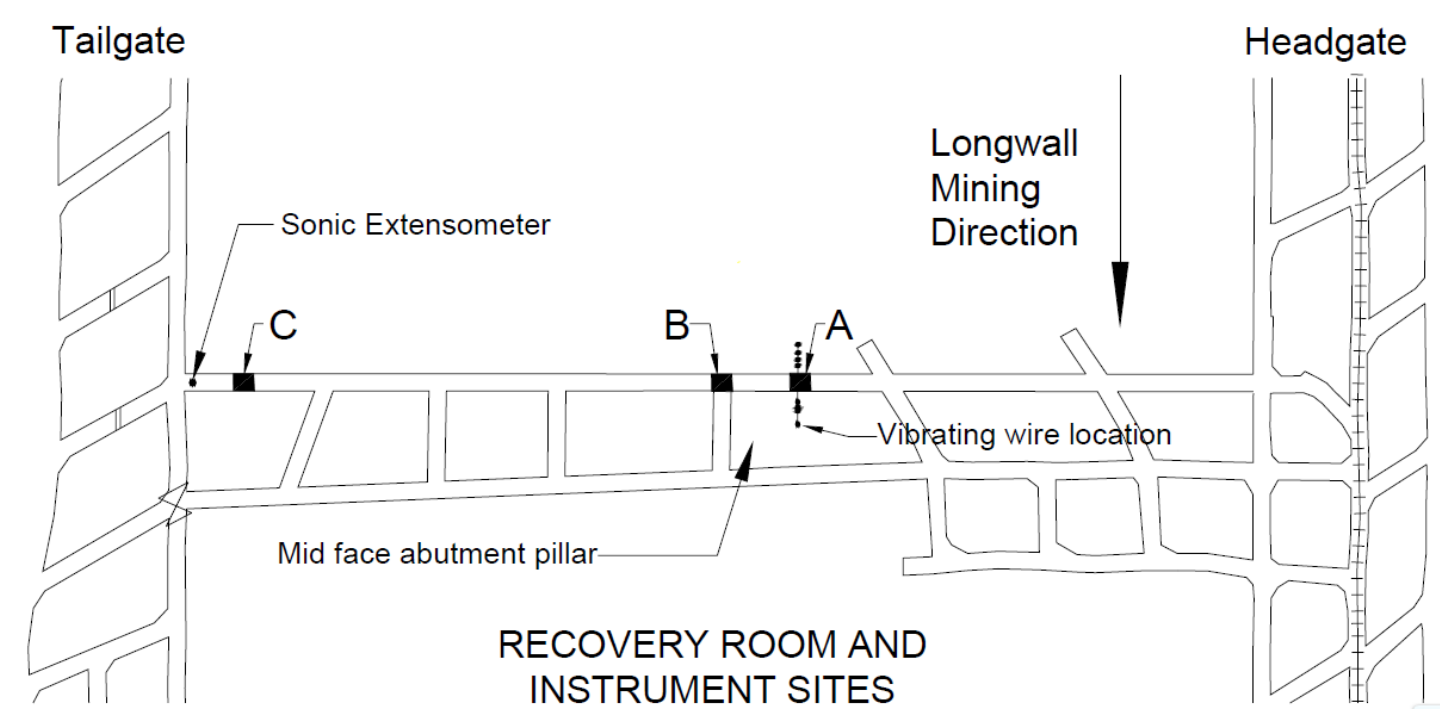

Figure 2.8 Full face recovery room showing instrumentation locations (Oyler et al., 2001)

Figure 2.9 shows the stress curves from the $19.66 \mathrm{ft}(6.00 \mathrm{~m})$ panel and $15 \mathrm{ft}(4.60 \mathrm{~m})$ pillar vibrating wire cells, sag from the $19.25 \mathrm{ft}(5.87 \mathrm{~m})$ anchor of extensometer, and convergence from the A site panel side sensor. The extensometer curve has been multiplied by a 
factor of ten to make it more readable. As the width of the fender was reduced, the rates of loading of the fender, and the front abutment pillars increased until the coal of the rapidly thinning fender yielded and failed. This interpretation is based upon the stress cell, convergence and extensometer data as shown in Fig. 2.9. The failure took place when the fender was about 35 $\mathrm{ft}(10.7 \mathrm{~m})$ wide. The yielding of the fender led to an abrupt increase in the rate of loading of abutment pillar and acceleration of the rates of roof sag and room convergence. At this point, despite the increased room convergence, the fender was probably still providing substantial roof support. Evidence for this comes from the stress measured by the $19.66 \mathrm{ft}(6 \mathrm{~m})$ vibrating wire cell which had precipitously dropped upon fender yield but began to increase again when the fender width was about $26 \mathrm{ft}(8 \mathrm{~m})$, and continued to increase until the cell was cut out by the shearer. Total failure of the fender as a roof support element probably took place when the fender width was about $10 \mathrm{ft}(3 \mathrm{~m})$, about the same width noted by observers in other open entry mine through. At the time of the total failure of the fender, convergence rates had increased to as much as $24 \mathrm{in} / \mathrm{hr}(600 \mathrm{~mm} / \mathrm{hr})$.

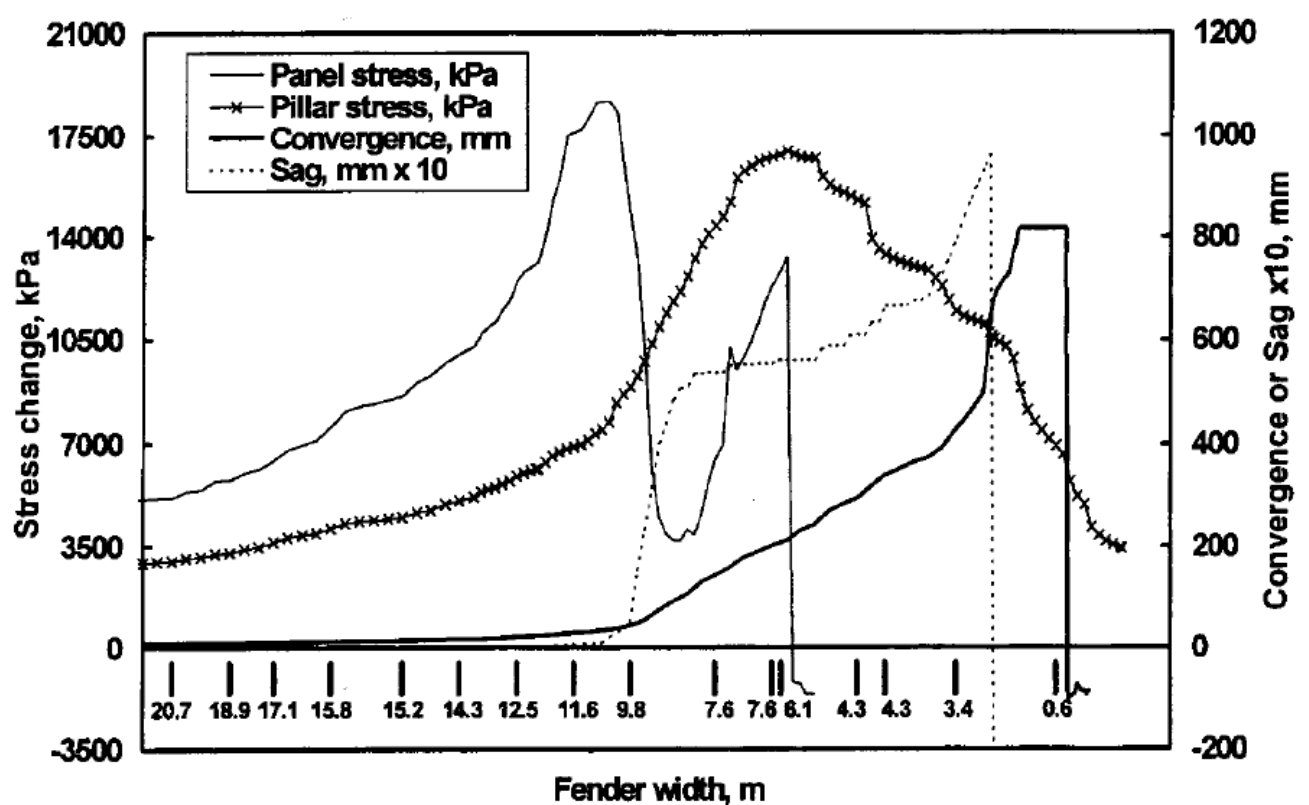

Figure 2.9 The changes of panel stress, abutment pillar stress and the convergences at the instrumentation site as fender pillar width decreasing (Oyler et al., 2001)

\subsubsection{Pre-driven Recovery Room Modeling}

Only when the loading and stress distribution in the pre-driven longwall recovery room system are thoroughly studied and the proper measures are taken to prevent the potential ground 
control risks, the full advantages of this process can be realized. Based on the study of the international pre-driven recovery room case histories by Oyler et al. (1998 and 2001), many predriven recovery rooms adopted in coal mines are reported with success while a few of them ended with failures. Recently, Zhang et al. (2006) and Stone (2012) reported some successful cases of mining into pre-driven recovery rooms and mains. Although other studies of pre-driven longwall recovery room operations have been conducted, questions regarding the loading mechanics and support design requirements remained unanswered as evidenced by premature support failures (Tadolini et al., 2003), roof falls, and loss of shields (Oyler et al., 1998), while other operations were successful (Wynne et al., 1993). One local roof fall and excessive roof sag occurred at the completion of the previous panel at this mine using this same recovery room design and support plan with only minor differences.

In the longwall operations using pre-driven recovery room, the front abutment pressures increase as the longwall face approaches to the recovery room. Consequently, the stress increases in the panel, the standing roof supports in the recovery room, and the barrier pillar indicates that the load has been bridged across the recovery room prior to the yielding of the fender pillar. Various studies including numerical simulations (Tadolini et al., 2002), case histories analysis (Oyler et al., 1998 and 2001), and field instrumentations (Barczak et al., 2007 and Stone, 2012) have been conducted to understand the development pattern of the loading and stress distribution and the research findings have been published. However, not all the field instrumentation findings can match well with existing theory (Zhang et al. 2006). Additional studies should be conducted to gain better understanding of the loading mechanics in and around the pre-driven longwall recovery rooms.

Griffith's crack theory can be utilized to model the mining induced stresses (Griffith, 1921). In this theory, the stresses at the edges of an elliptical crack, which represents the mine opening in this case, may represent the stresses occurring in pillars and in the ribs extending into the coal seam (Luxbacher et al., 2009). For the analysis of longwall chain pillar stress distribution, Kramer and Luo proposed a fracture mechanics approach (FMA) and developed a computer program to estimate stress distribution on the longwall chain pillar system (Kramer and Luo, 1998). The FMA approach provides the capacities to model various mine structures such as stiff and yield pillars, longwall gob materials, longwall supports, cribs, posts, hydrostatic loads, etc. The program can predict pillar stability by combining empirical pillar strength equations into the 
analytic analysis. This approach can be potentially employed to analyze the stress distribution for pre-driven longwall recovery room and facilitates the design of the pre-driven longwall recovery room support.

\subsubsection{Multi-seam Mining Interaction and Subsidence}

Multi-seam mining is one of the most chanlleging ground control problems in the mine industry. The multi-seam mining interaction, effects of the mining of one seam on the adjacent seams, could induce serious ground control safety problems to the mine operations. With proper planning, ground control issues associated with multi-seam mining can be avoided, minimized, or on occasion, utilized beneficially (Peng, 2008).

\subsubsection{Overview of Multi-seam Mining}

Coal deposits in the formation of multiple seams are very common in the U.S. It is estimated that the multi-seam coal reserves account for about $70 \%$ of the total reserves (Mark, 2007a). Particularly in central Appalachian and the Western coalfields, the majority of today's mines are operating above and/or beneath previously mined seams (Mark, 2007c). The effects of the mining of one coal seam on the other coal seam, which is so called multi-seam mining interactions, are the major ground control problem in the coal mining history (Mark et al, 2007a). As shown in Fig. 2.10, the two most common types of multi-seam mining interactions are (Mark et al, 2007b):
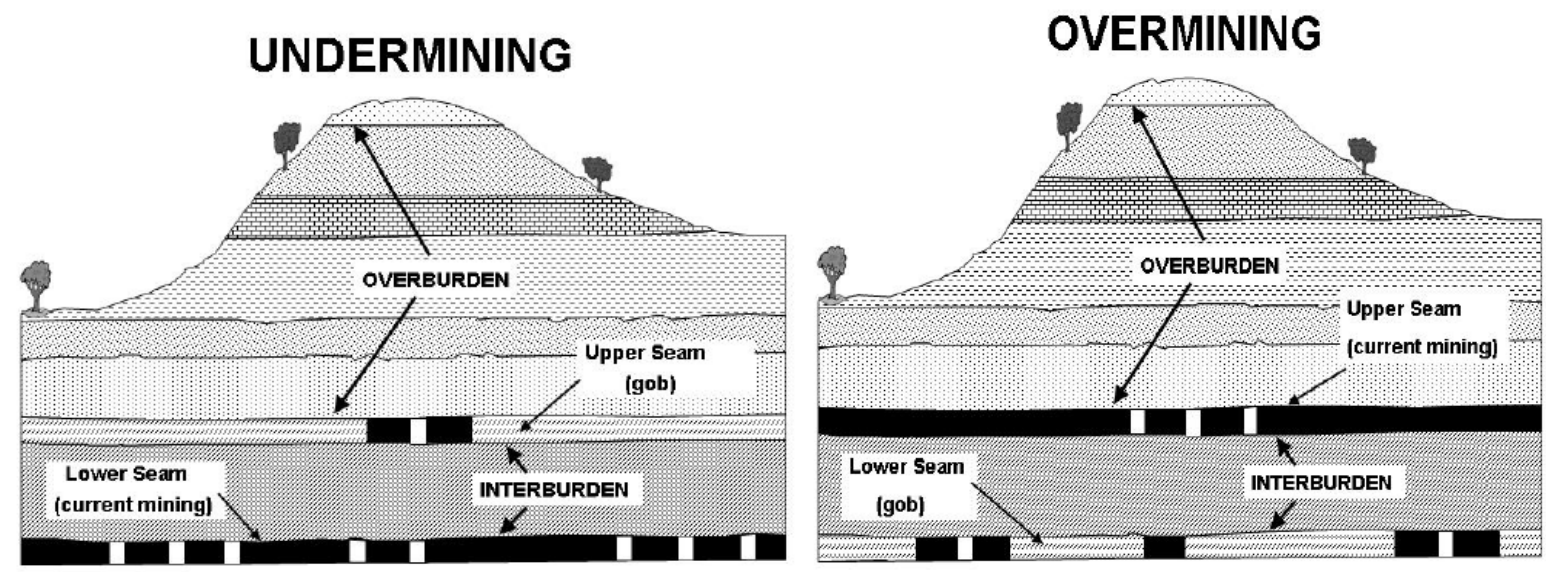

Figure 2.10 Undermining and overmining (Mark et al., 2007b)

- Undermining, where stress concentrations caused by previous full extraction in an overlying seam is the main concern; and 
- Overmining, where previous full extraction in an underlying seam can result in stress concentrations and rock damage from subsidence.

In the US, multi-seam coal mining operations have been more frequently conducted in the central Appalachian coal fields than any other coal producing regions, which is also the area with most mining accidents both in numbers and in severity historically. When mining operations are conducted in multiple coal seams, the mining interactions can greatly complicate the distribution fields of stress and deformations and induce significantly more hazardous conditions. This situation can reduce the mine production and increase the cost for roof support or even endanger the miner's safety. Coincidentally, most multi-seam mining operations in US are conducted in the Central Appalachian coal field (Mark, 2007c), and this area also has the most mining accidents and disasters in the history of U.S. coal industry. Since 1970, 13 out of 21 coal mine disasters (defined as five or more fatalities in an accident) have occurred in the Central Appalachian coal field. More recently, the multi-seam mining phenomenon heavily contributed to the Upper Big Branch mine explosion in West Virginia (Phillips, 2012).

\subsubsection{Multi-seam Mining Interactions}

Interaction effect exists when two or more neighboring seams are mined. The mining activity in one seam causes stress redistribution and strata movement in both the roof and floor. When the thickness of interburden between two neighboring seams is small, some hazardous situations like roof cutters, roof falls, floor heave and rib spalling in one seam may be encountered due to the effect of the mining activity in the other seam (Han et al., 2005). Stemple (1956) reported that the most common phenomenon observed in the upper seam mining operation affected by lower seam mining was cracking or horizontal parting of the overlying strata. The upper seam was often displaced vertically from a fraction of an inch to as much as a few feet. This bed separation caused either the floor to drop away from the coal or the coal to separate from the roof. Other disturbances caused by the extraction of the lower seam were roof falls, floor heaves, and pillar crushing or squeezing, which may be observed with single seam mining but are aggravated by overmining. Stemple also noted that maximum disturbance in the upper seam was generally observed when isolated pillars, groups of pillars, or solid coal (barrier pillars, chain pillars) were left in the lower seam. This caused the upper seam to shear along the coal line in the lower seam. However, Stemple reported that the maximum damage area often did not lie immediately over the edge of the coal but at a distance of 100 to 300 feet away, on the 
gob side. Figure 2.11 shows the disturbance in a superjacent seam. Violently rapid coal pillar failures like coal pillar bumps could also be encountered due to multi-seam mining interactions (Gauna and Phillipson, 2008).

When subsidence-induced fracture zones in the interburden strata connect the active mine to old mine workings or previously sealed mines, more severe safety problems, such as water inundations, sudden methane inrushes, and spontaneous combustions, can occur. These can seriously disrupt mining operations and threaten the safety of miners (Mark, 2007b). Most recently, Su et al. (2012) conducted a study to evaluate the multi-seam interactions between the two mine works in No.2 Gas seam and Powellton Seam. Studies for this case were aimed to evaluate the safety of mining under the potentially flooded mined out areas.

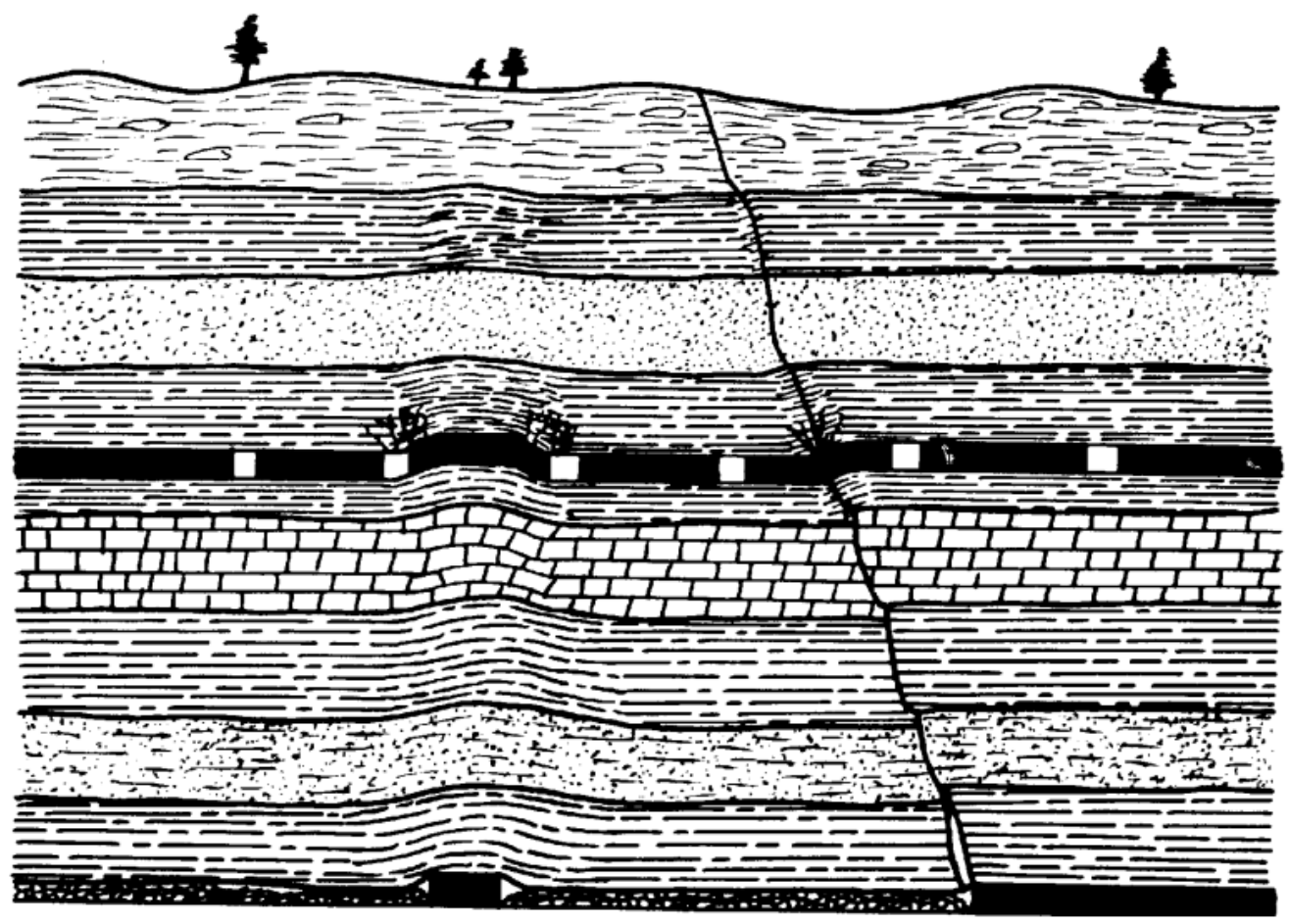

Figure 2.11 Disturbance in a superjacent seam (Stemple, 1956)

Multi-seam mining effects are closely related to interburden characteristics, mining sequence, seam heights and mining methods applied, time interval between the mining activities in neighboring seams and sometimes local topographic and hydrographic features. Among these factors, the interburden characteristics are the most critical factors in determining the potential for multi-seam interaction. Interburden characteristics include thickness, rock type, number of layers and percentage of hard rock. Within the interactive distance, interburden thickness determines the intensity and types of seam interaction. The thicker the interburden, the less 
intense the seam interaction (Munsamy et al., 2004). Strata in the interburden that have high elastic modulus, such as sandstone and limestone are stiffer and tend to bidge. Consequently they tend to dampen stress transfer. Conversely, softer strata such as shale tend to bend more readily, transferring the load. Therefore, the interactive distance decreases with increasing percentage of hardrock, such as sandstone and limestone, in the interburden (Haycocks et al., 1983).

\subsubsection{Mechanism of Multi-seam Mining Interaction}

Almost all of the above mentioned ground control problems experienced in multi-seam mining can be explained by four interaction mechanisms: trough subsidence, massive interseam shearing and load transfer. Holland (1951) stated that trough subsidence is responsible for most of the interaction effects on overlying seam.

\subsection{Trough Subsidence}

Longwall mining usually leads to uniform and predictable subsidence as documented by surface measurements. A surface profile for supercritical and critical panels consists of a subsidence trough, the outer limits defined by the angle of draw, and an area of maximum subsidence. As shown in Figure 2.12, the subsidence trough is identified by two zones of tension and compression. An inflection point, typically located directly superjacent to the ribline, distinguishes these two zones on the surface: the tension zone over the solid coal, and the compression zone over the mined-out panel.

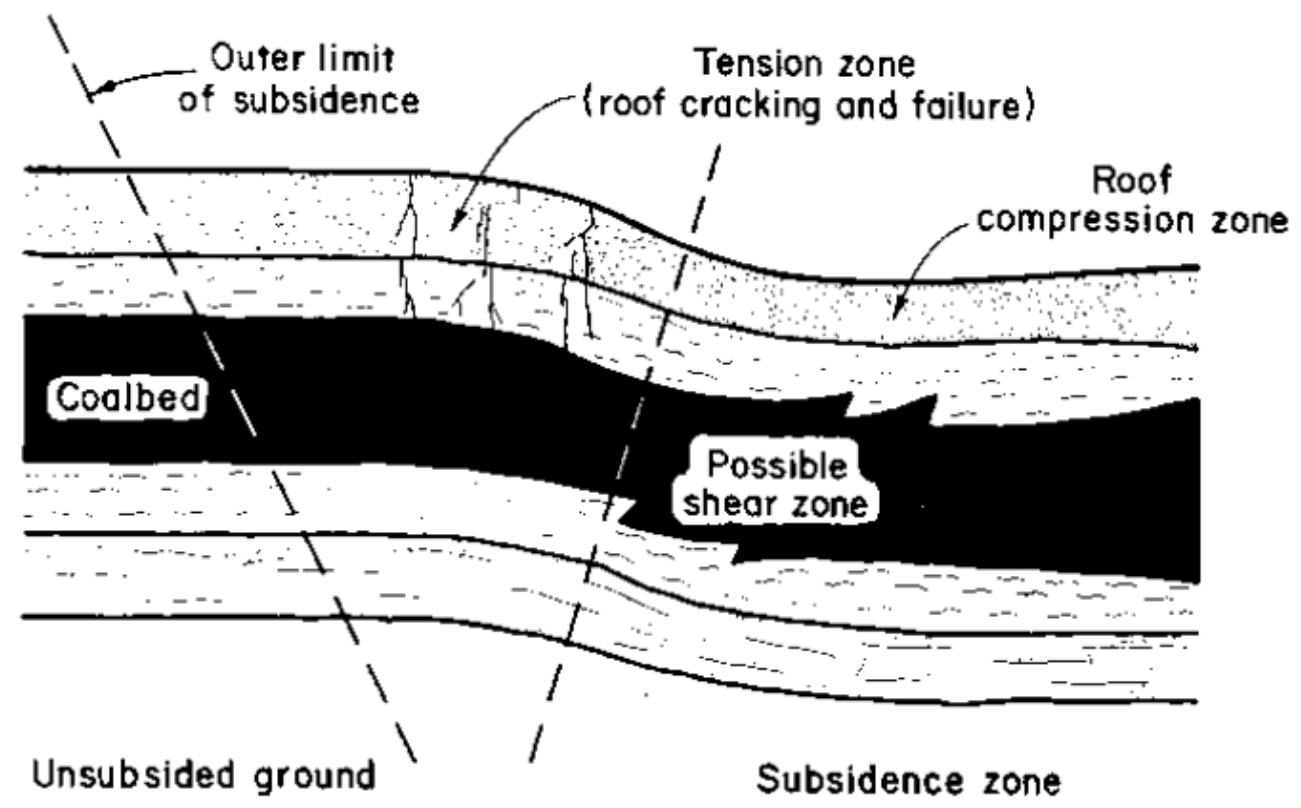

Figure 2.12 Formation of subsidence trough above mined-out panel (Haycocks et al., 1982) 
However, recent subsidence measurements over longwall panels in the Appalachian coal fields indicates that the inflection point actually develops over the mined-out panel, which means that the tension zone would also be located over the mined-out panel. Since the tensile strengths of the coal massive rocks are very low, strata crack or fracture easily under very small tensile stresses. The magnitude of ground control problems in the subsidence trough is dependent on the extent of the tension zone, which is responsible for the formation of fractures and opening of joints. The compression zone has been observed to cause only minor ground control problems related to pillar instability, mostly rib spalling (Hsiung and Peng, 1987). Beyond the subsidence trough is the zone of maximum subsidence. In this zone the extraction of the longwall in the lower seam allows the ground to subside uniformly, usually resulting in improved ground conditions (Chekan and Listak, 1993).

\subsection{Massive Interseam Shearing}

When an opening is excavated in the lower seam, the original stress equilibrium in the surrounding strata is disturbed. Under gravitational loading the interburden roof strata will deform and displace. As the width of the opening increases, these interburden roof strata are supposed to cave in, forming a subsidence trough. However, if the interburden strata are comprised of brittle-type rocks, such as sandstone, they have a higher resistance to deformation, bending and displacement and, thus, shear stress at the boundary of intradosal and extradosal ground accumulates as the opening widens. When the shear stress in the roof beds exceeds the shearing strength, shearing failure occurs. Such failure can eventually lead to massive failure of the entire interburden. In some extreme cases, the failure can extend through to the surface, cutting off large sections of coal, as shown in Figure 2.13.

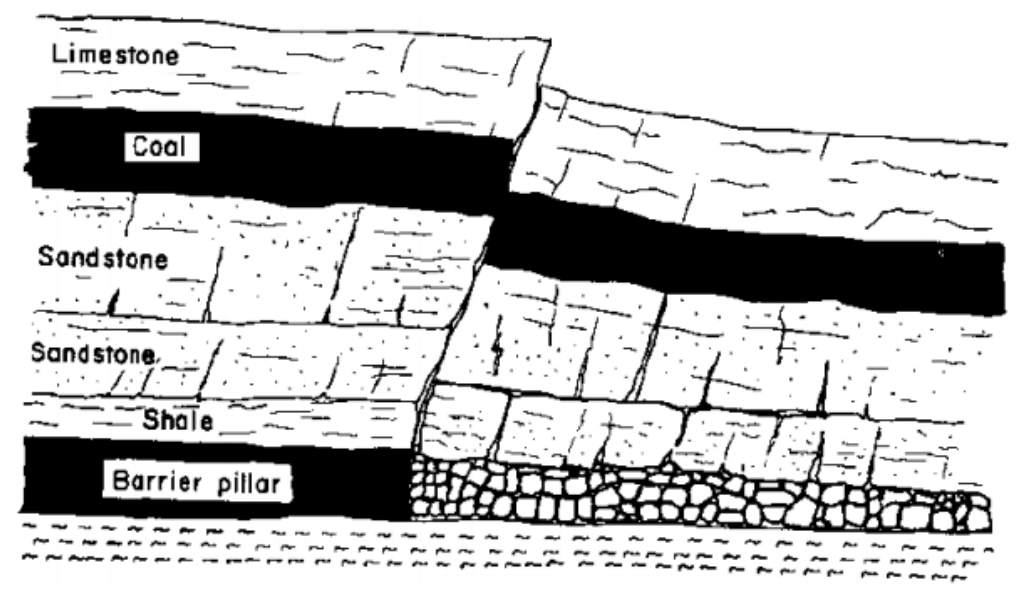

Figure 2.13 Interseam shearing (after Holland, 1951) 


\subsection{Load Transfer}

Two types of theories have been developed in the past to determine the magnitude and extent of load transfer due to the existence of remnant pillars and gob-solid boundaries, which are pressure arching theory and pressure bulb theory. They are based on conventional analytical solutions and as such do not account for the non-homogeneity and anisotropic nature of coal measure strata. However, the theories are simple to follow and, for homogeneous materials, are fairly accurate. On the other hand, it must be emphasized that with the advance of computer technology in recent years, numerical modeling of mine structures has been the preferred method for analyzing multi-seam mining interactions (Morsey et al., 2006; Zhang et al., 2005). The advantage with numerical modeling of mine structural analysis is that it can properly simulate, case by case, the detailed 3-dimentional mine layouts in both seams, considering all the factors. The disadvantage is that it is time consuming and highly sophisticated, requiring in-depth knowledge, experience, and special training (Peng, 2008).

For the pressure arching theory, before any excavation takes place, the ground at any depth is subject to a pressure equal to the weight of the column of the ground above. When an opening is excavated, strata directly over the opening lose the in-situ support and, thus, will deform and not be able to support loads from above. The weight of the ground above the opening originally supported by the material extracted will be transferred outward to the solid rock at both sides of the opening, forming a pressure ring around the opening. This pressure ring, usually referred to as pressure arch, is elliptical and exists both above and below the mine opening. Inside the pressure ring there is a core of decompressed or de-stressed and fractured ground which is called the intradosal ground (tensile zone). Around the intradosal ground is a zone of firmly compressed ground called the extradosal ground (compressive zone). Large abutment pillars or barriers support the extradosal ground and the pressure is known as abutment pressure.

The pressure bulb concept originated from the solution of the distribution of stress field under a point load in an elastic homogeneous semi-infinite plane. The only parameters in this solution were the magnitude of the point load and the vertical and horizontal coordinates of the points in question under the load. The integration of the point load solution over a surface boundary extends this concept to be used for the stress distribution in homogeneous elastic foundations provided that the load distribution over the foundation is known. When the load over the foundation is uniform, the stress contours formed in the foundation look like a series of bulb 
outlines and the magnitude of stress dissipates with depth. The vertical load may sectionally dissipate at a distance equal to three times the width of the uniform load. This theory was initially employed in civil engineering and later applied to mining engineering problems, in particular, pillar load transfer of the remaining pillars in the upper seam to the underlying seams (Luo, 1997).

\subsubsection{Multi-seam Mining Subsidence}

The subsidence caused by multi-seam mining attracted researchers' concern for a long time due to its complexity comparing with the subsidence caused by a single seam. Dyni (1991) monitored the subsidence induced by longwall mining operations in two seams in the central Utah coalfield. The subsidence factor was 0.68 and the angle of draw was $30^{\circ} \mathrm{Li}$ et al. (2011) reported seven cases of multi-seam mining subsidence which are divided into two groups. One is longwall mining under existing longwall gob with five cases, and the other one is longwall mining above existing gob with two cases. Based on case studies, Li et al. (2011) have identified and characterized additional subsidence arising from longwall mining above or under existing longwall gob. It suggests that the magnitude, mechanisms and prediction methods for such additional subsidence are different between the two mining configurations. Kook et al. (2008) conducted a study on the subsidence prediction for multi-seam extraction under consideration of time effects by the use of geomechanical numerical models.

Based on the subsidence measurements that covered a mining period of five seams, investigations have been made on the multi-seam mining subsidence characteristics. The investigations show that the value for the subsidence factor, the angle of main influence, and the time coefficient get larger in line with the increasing number of seams mined, meaning with increased multi-seam mining as shown in Fig. 2.14.

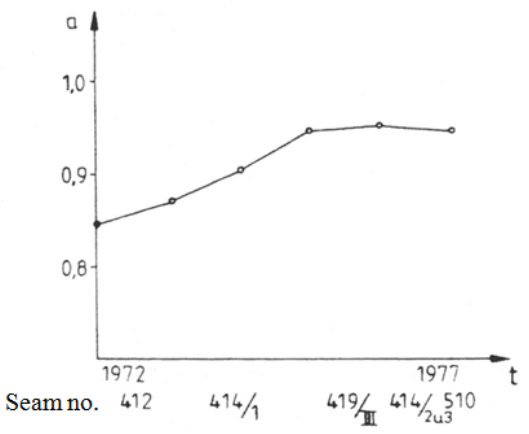

(a) subsidence factor

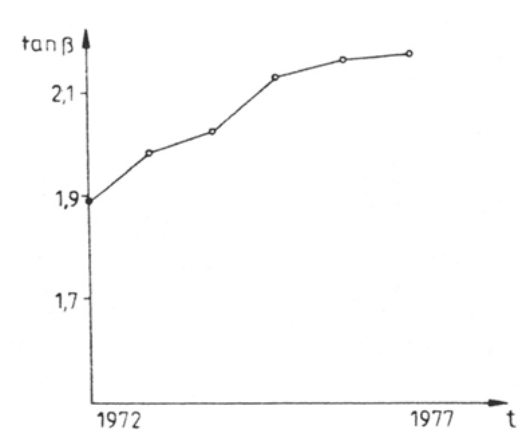

(b) angle of major influence

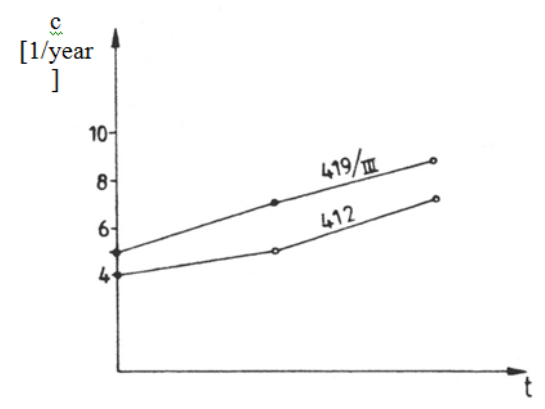

(c) time coefficient

Figure 2.14 Change of subsidence parameters (subsidence factor, angle of major influence and 
time coefficient) due to multi-seam mining (Preusse et al., 2012)

In practice, this means that the subsidence basin becomes deeper and deeper, the surface slopes increasingly steeper, and the surface movements even faster. These qualitative characteristics correspond fully to the phenomenon observed in the Ruhr region in German (Preusse et al., 2012).

\subsubsection{Multi-seam Mining Study}

The mining activity in one seam can cause stress redistribution and strata movements in coal seams both above and below. This stress and deformation change will affect the stability of the remnant pillar in the mined out seam. For example, the differential vertical and horizontal strain may reduce the confinement of the interfaces between the remnant pillars and roof and floor, this effect may reduce the strength of the remnant pillars, and may then cause the failure of the remnant pillars. If the failure of the remnant pillars occurs in a sufficiently large contiguous area, it may be able to induce additional surface subsidence other than that caused by the mining operations in the active mine. Most recently, Mark and Barker (2012) reported a case study that severe dynamic multi-seam interactions could occur when mine workings were subsided by underlying mining activity. This unexpected additional subsidence may cause many problems to the surface and subsurface structures, water bodies and highways, and also may affect the application process for the mine permit.

Many researchers and practitioners have conducted theoretical studies, numerical analysis and field cases studies for the multi-seam mining interactions. Luo (1997) conducted a study on the gateroad design in overlying multiple seam mines. Mark (2007b) summarized some ground control techniques based on case histories to avoid or mitigate multi-seam mining interactions, which include gate entry configuration, panel layout, roof strength, and pillar design etc. The numerical study conducted by Zipf (2007) suggested four factors that control multiple-seam mining interactions and should be considered explicitly in design guidelines: OB/IB thickness ratio, gob width-to-interburden thickness ratio, site-specific geology and horizontal stress to rock strength ratio. Heasley and Agioutantis (2007) employed the LaModel program to evaluate multiple-seam mining interactions.

The multiple-seam mining induced ground control problems occurred in many coal mines, and the case studies were conducted to analyze the mechanism of the ground control problems encountered. Case studies (Morsy et al., 2006; Chase et al., 2007) showed that the probability of 
a major multi-seam mining interaction occurring increased when: 1) the overburden depth to interburden thickness was greater, 2) the ALPS pillar stability factor was lesser, and 3) the multiseam mining effects on pillar SF were less than $40 \%$.

A multi-seam mining interaction analysis software program, UGLY (Upperseam Gateroad Longwall Stability), was developed by Luo et al., (1997) and Kaniganti, (1996) to determine the amount of damage in the upper seam when the lower seam had been mined out previously. The program is applicable to both room-and-pillar mining and longwall mining. The damage rating is defined by,

$$
D R=1.69\left[\frac{3 m_{\text {lower }}(H R) h}{H_{\text {in }}}\right]^{0.05} e_{l} T_{\text {lower }}^{0.07}
$$

where,

$$
\begin{array}{ll}
D R & =\text { damage rating (see Table } 2.1) \\
m_{\text {lower }} & =\text { lower seam height. } \\
h & =\text { overburden thickness }(\mathrm{ft}) . \\
H_{\text {in }} & =\text { interburden thickness }(\mathrm{ft}) . \\
H R \quad & =\text { percentage of hard rock in interburden }(\%) . \\
e_{l} & =\text { extraction ratio of lower seam. } \\
T & =\text { time delay between mining of the upper and lower seams (year). }
\end{array}
$$

Table 2.1 Upper seam damage rating system for overmining operations (Zhou, 1988)

\begin{tabular}{c|l}
\hline \hline \multicolumn{1}{c|}{ Damage Rating } & \multicolumn{1}{|c}{ Characteristics } \\
\hline 1.12 -- No Damage & $\begin{array}{l}\text { Normal conditions; conditions no worse than mining in } \\
\text { undisturbed areas. }\end{array}$ \\
\hline 1.56 -- Negligible Damage & $\begin{array}{l}\text { Fractures present in upper seam, but no associated roof } \\
\text { problems; no displacements; no difficulty of mining due to the } \\
\text { lower seam extraction. }\end{array}$ \\
\hline 2.00 -- Moderate Damage & $\begin{array}{l}\text { Fractures with visible movement; occasional broken roof and/or } \\
\text { coal; water entering; mined with minimum or no extra support. }\end{array}$ \\
\hline 2.44 -- Considerable Damage & $\begin{array}{l}\text { Roof problems encountered; seam broken; some bottom heaves } \\
\text { and pillar spalling; mined with increased timber support and } \\
\text { slate work; occasional loss of coal. }\end{array}$ \\
\hline 2.88 -- Severe Damage & $\begin{array}{l}\text { Major roof problems encountered; entire entry caved; bottom } \\
\text { heaved; top broken; coal crushed or cut out; mined with heavy } \\
\text { support or certain amount of coal lost. }\end{array}$ \\
\hline \hline
\end{tabular}




\subsubsection{Longwall Mining Impacts on Hydrological System}

Longwall mining operations in shallow areas could affect the surface streams, ponds, water table and subsurface aquifers to various degrees. As the methods to mitigate subsidence influences to surface structures mature, the potential influences of longwall subsidence on surface streams become a very urgent issue for many longwall mines in the coal fields of the eastern U.S. (Luo and Peng, 2010). However, the research on this topic is undeveloped.

\subsubsection{Conceptual Models}

The ground subsidence process associated with underground longwall mining operation could lead to the redistribution of stress, as well as the formation of new fractures in the overburden strata, which can significantly affect the surface and subsurface hydrological system (Luo and Peng, 2010). Subsidence influences to groundwater are an environmental constraint of longwall mining, whether considered as a problem for residents of mined areas or for companies in permit applications (Booth, 2006). Reliable prediction of groundwater flow due to mining is not only essential for improving mine safety and reduction of coal production costs, but also important for the assessment of environmental impact of mining.

The subsurface subsidence induces new vertical and horizontal fractures, enlarges bedding separations and changes the storativity, conductivity and transitivity of the overlying strata. These changes may cause the water level to lower in the overlying aquifers. One response is dewatering from confined to unconfined conditions in the overlying aquifers as a result of loss of water into new void spaces. Very few shallow aquifers or water bearing zones in the subsidence trough area will remain confined (Booth, 2007).

A conceptual model of the hydrogeological effects of longwall coal mining has gradually been developed from case studies by Booth (2002). All underground mines are potential groundwater drains, but subsidence and strata movement due to longwall mining affect the groundwater system separately from mine drainage (Booth, 2002).

In Fig. 2.15, there are five zones of overburden strata movement based mainly on groundwater effect (Kendorski, 2006): the caved zone is in the zone of complete disruption; the fractured zone has vertically transmissive fractures; the dilated zone has increased storativity 
with little or no vertical transmissivity; the constrained zone has no significant effect on transmissivity or storativity; and the surface fracture zone potentially has vertically-transmissive surface cracks and disruptions (Kendorski, 1993). The dilated zone consists of two zones, a lower dilated zone and an upper aquiclude zone. The dilated zone has increased storage potential and can impact well observation, but it has no direct connection to the lower strata. The upper aquiclude zone is unaffected by mining and has no change in permeability.

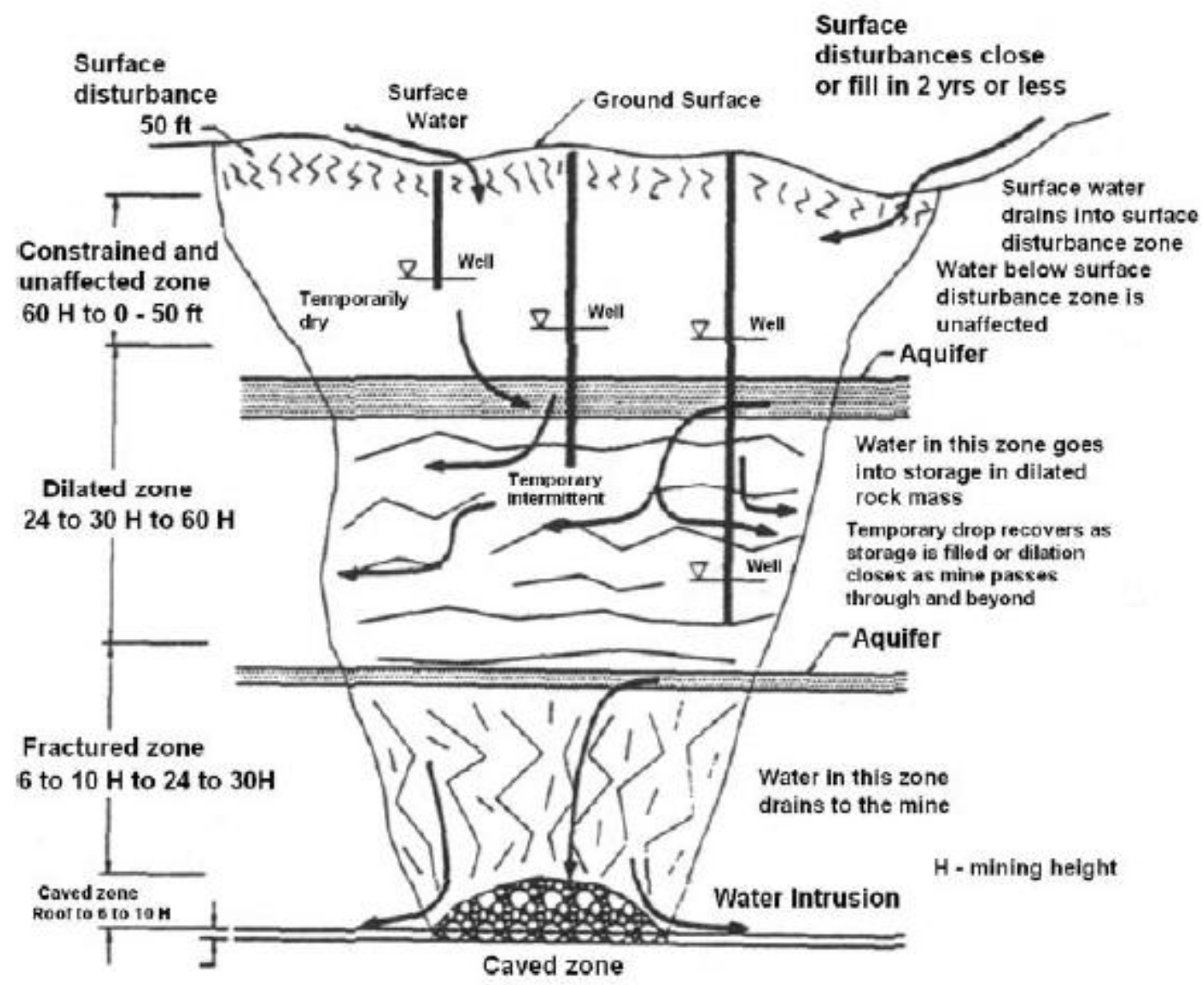

Figure 2.15 Hydrological changes in the overburden induced by longwall subsidence (modified from Kendorski, 2006)

Forster (1995) also divided the overburden movement into four zones for the central coast of New South Wales, Australia as shown in Fig. 2.16. In the surface zone, the depth of surface tensile cracks was less than $33 \mathrm{ft}(10 \mathrm{~m})$. The constrained zone is a relatively unfractured zone characterized by occasional shear dilation, bed separations and horizontal slippage along the weak-strong rock interfaces, with little vertical fracturing. This zone can form an effective barrier to prevent hydraulic connections between the overlying aquifers and the dewatered zone 
if its thickness is more than 12 times the mining height. The caved zone and fractured zone are located immediately above the coal seam. These two zones provide an effective conduit between the overlying aqui-fers and the gob, which is either directly intersected by or hydraulically connected to these two zones. The caved and fractured zones combined, up to 33 times of the mining height, are a dewatered zone assuming a dome shape (Li et al., 2006).

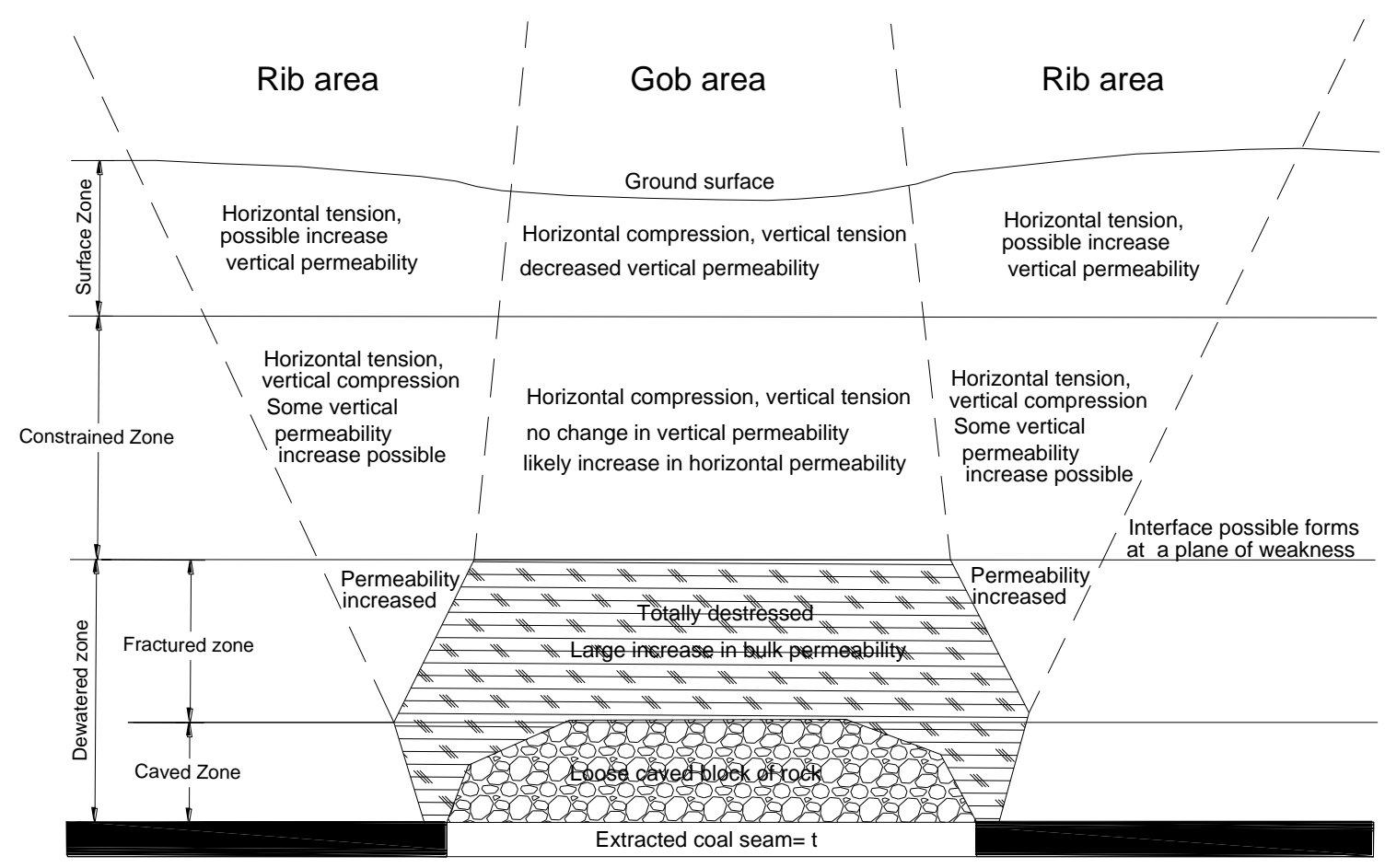

Figure 2.16 Conceptualized representation of overburden response (after Forster et al., 1995; Li, 2006)

\subsubsection{Stress Induced Overburden Permeability Change}

The hydrological and geomechanical characteristics are essential for studying the overburden hydrological system response to the longwall mining (Hasenfus et al., 1988). Many research works in this subject are focused on the modeling of the coupling of hydrological and geomechanical response of the overburden strata associated with longwall mining (Karacan and Goodman, 2009).

Matetic et al. (1995) established the formulas for calculating the hydraulic conductivities in $\mathrm{x}$ and $\mathrm{y}$ directions respectively,

$$
K_{x}=K_{x 0}\left[1+\frac{b+S\left(1-R_{m}\right)}{b} \Delta \varepsilon_{y}\right]^{3}
$$




$$
K_{y}=K_{y 0}\left[1+\frac{b+S\left(1-R_{m}\right)}{b} \Delta \varepsilon_{x}\right]^{3}
$$

where:

$$
\begin{array}{ll}
K_{x}, K_{y} & =\text { post-mining conductivities in the x-direction and the y-direction. } \\
K_{x 0}, K_{y 0} & =\text { pre-mining conductivities in the x-direction and the } \mathrm{y} \text {-direction. } \\
\Delta \varepsilon_{x}, \Delta \varepsilon_{y} & =\text { induced strains in the x and y directions. } \\
b & =\text { fracture aperture. } \\
s & =\text { fracture spacing. }
\end{array}
$$

When $R_{m}=1$, the mass modulus and intact material modulus are identical and the strain is uniformly distributed between fractures and matrix.

Luo et al. (2001) established the relationships between permeability and mean stress for three types of common coal-measure rocks (coal, shale and sandstone), which are shown in the following equations.

$$
\begin{aligned}
& K_{\text {coal }}=25\left(e^{-5.07 \times 10^{-3} \sigma_{m}}+5.85 \times 10^{-4} \sqrt[3]{\sigma_{m}}\right) \\
& K_{\text {shale }}=2.5\left(e^{-6.39 \times 10^{-3} \sigma_{m}}+2.71 \times 10^{-4} \sqrt[3]{\sigma_{m}}\right) \\
& K_{\text {sandstone }}=2.8\left(e^{-6.32 \times 10^{-3} \sigma_{m}}+2.82 \times 10^{-4} \sqrt[3]{\sigma_{m}}\right)
\end{aligned}
$$

Esterhuizen and Karacan (2005) proposed to use the following equations to determine the stress affected horizontal and vertical permeabilites respectively:

$$
\begin{aligned}
& K_{x}=K_{x 0} \times e^{-0.25\left(\sigma_{y y}-\sigma_{y y 0}\right)} \\
& K_{y}=K_{y 0} \times e^{-0.25\left(\sigma_{x x}-\sigma_{x x 0}\right)}
\end{aligned}
$$

where:

$$
\begin{array}{ll}
\sigma_{x x}, \sigma_{y y} & =\text { the horizontal and vertical stresses. } \\
\sigma_{x x 0}, \sigma_{y y 0} & =\text { the initial horizontal and vertical stresses. }
\end{array}
$$

\subsubsection{Modeling of Longwall Mining Impacts on Hydrological System}

Physical and numerical models were employed to represent an approximation of the ground water situation (Anderson et al., 1992). Physical models are to setup a similar simulation 
experiment in the laboratory to simulate the real-work groundwater system. A mathematical model simulates the groundwater flow system indirectly by means of governing equations thought to represent the physical processes that occur in the system, together with equations that de-scribe heads or flows along the boundaries of the model. Numerous numerical simulation techniques are employed to study the longwall mining impact on hydrological systems.

The general governing equation for transient, heterogeneous, and anisotrop-ic conditions with a source/sink term is:

$$
\frac{\partial h}{\partial x}\left(K_{x} \frac{\partial h}{\partial x}\right)+\frac{\partial h}{\partial y}\left(K_{y} \frac{\partial h}{\partial y}\right)+\frac{\partial h}{\partial z}\left(K_{z} \frac{\partial h}{\partial z}\right)=S_{s} \frac{\partial h}{\partial t}-R
$$

The general governing equation for steady-state, heterogeneous, and anisotropic conditions with a source/sink term is:

$$
\frac{\partial h}{\partial x}\left(K_{x} \frac{\partial h}{\partial x}\right)+\frac{\partial h}{\partial y}\left(K_{y} \frac{\partial h}{\partial y}\right)+\frac{\partial h}{\partial z}\left(K_{z} \frac{\partial h}{\partial z}\right)=-R
$$

Equation 2.42 is the general governing equation for steady-state, homogeneous, and isotropic conditions with a source/sink term. Steady flow means that the flow rate, piezometric head, and amount of fluid in storage do not change with time.

$$
K_{x} \frac{\partial^{2} h}{\partial x^{2}}+K_{y} \frac{\partial^{2} h}{\partial y^{2}}+K_{z} \frac{\partial^{2} h}{\partial z^{2}}=-R
$$

where:

$$
\begin{array}{ll}
h & =\text { piezometric head. } \\
K & =\text { hydraulic conductivity. } \\
S & =\text { storage coefficient, } S=b S s \\
b & =\text { aquifer thickness. } \\
S s & =\text { specific storage. } \\
T & =\text { transmissibility, } T=b K \\
t & =\text { time. } \\
R & =\text { recharge/ discharge rate. }
\end{array}
$$

Based on computer simulations and field measurements, Gale (2006 and 2010) concluded that flow into mines is typically via an interconnected network of preexisting and mining induced fractures. The height of the mining induced fractures above the coal seam is typically related to the width of the panel. However the potential for those fractures to form a connected network 
which can facilitate flow, is related to the amount of subsidence and the depth of mining. A three-dimensional numerical model, called COSFLOW is employed to Simulation of mine water inflow and gas emission during longwall mining. It uses a Cosserat continuum approach for the efficient description of mechanical stress changes and deformation in weak layered rock, typical of coal measures. This mechanical model is coupled with a two-phase dual porosity fluid flow model to describe flow of water and gas through porous rock, desorption and adsorption of gas from the matrix and subsequent flow of water and gas through the fracture network. The coupling includes simulation of permeability and porosity changes with rock deformation (Guo et al., 2009; 2012). Booth and Greer (2011) applied MODFLOW and Telescopic Mesh Refinement (TMR) to simulate hydrologic responses in the shallow aquifer system overlying longwall mining.

\subsubsection{Field Instrumentations}

Field instrumentations for studying the longwall mining impacts on the hydrological system include the measurement of surface subsidence and overburden movement, monitoring of ground water levels and overburden hydraulic conductivities. Hasenfus et al. (1988) conducted an extensive hydrological and gemechanical monitoring program at a longwall coal mine in West Virginia. The groundwater levels, overburden hydraulic conductivity, overburden movement and surface subsidence relative to the passage of the longwall face were monitored. In combination with the pre-mining overburden geology and rock strength characteristics and post-mining main roof fracturing, a conceptual overburden response model was proposed based on the correlations between hydrological and geomechanical data. Du (2010) conducted a comprehensive field monitoring of the surface and subsurface subsidence, surface and ground water tables and hydraulic conductivities over two longwall panels. The field data were analyzed and compared with numerical modeling results. Efforts were made to connect the subsurface movements and the groundwater flow characteristics and evaluate longwall mining impact on surface and subsurface water bodies.

Other field instrumentations, concerning more on the geological and environmental aspects, were conducted to monitor the flow characteristics of surface streams over the mining area. The surface stream flow measurements were then analyzed with respect to the mining activities, and to evaluate longwall mining impacts on surface hydraulic systems. Wade (2008) conducted a study on six streams in Ohio, Pennsylvania, and West Virginia to evaluate 
subsidence impacts from active and abandoned longwall coal mines on stream discharge. Mined longwall panels included in this study ranged in age from five months to fifteen years old and in depth from 100 to 600 feet $(30.5$ to $182.9 \mathrm{~m}$ ) beneath the studied streams. Significant stream flow losses and gains were detected in each stream studied. Comparing longwall panel locations to stream flow measurements, geophysical surveys, and geomorphology surveys, it was concluded that longwall mine subsidence caused some of the detected stream flow losses and gains. Data collected suggests that longwall mine subsidence can impact stream flow and that the impact can be different for different baseflow conditions. Iannacchione et al. (2008) conducted a study for PA DEP on the impacts of underground bituminous coal mining on surface water resources. They conducted independent stream surveys of flow and biological health for a subsample of the undermined streams, to determine the extent to which reported flow problems had resulted in decreased biological health and the extent to which stream biological health had recovered following mitigation.

\subsection{Summaries}

The extraction of coal underground, with longwall mining and high extraction room and pillar mining methods, will cause the caving of the immediate roof and propagate through the whole overburden strata up to the surface which will induce surface subsidence. The final surface subsidence basin and the dynamic surface subsidence basin are the two main types of surface subsidence. Final and dynamic surface subsidence can be predicted by the mathematical models developed based on influence function methods. Accurate surface subsidence predictions are essential for mine planning and designing when there are major surface facilities that need to be protected. Techniques to control the subsidence and mitigate subsidence influences are also based on solid surface subsidence predictions. With more than three decades' development, the surface subsidence theories are now well accepted by the coal mine industry and play an important role in mine planning and designing.

The subsurface strata movements, connecting the surface subsidence with in-mine level strata movements, are essential for evaluating coal mining ground control stability and assessing mining impacts on surface and subsurface hydrological systems. As field measurements of subsurface subsidence are of high cost and operational complexity, mathematical models are developed to predict subsurface subsidence. These models are successfully applied in many 
subsidence related projects. However, the means to reflect the presence and effects of such hard layer are missing in these subsurface subsidence prediction models. It is found that subsurface subsidence theories can be potentially employed to analyze several ground control problems, include pre-driven longwall recovery room support design, multi-seam mining interactions and longwall mining subsidence influence on hydrological systems.

A pre-driven longwall recovery room has the potential to speed up the non-productive recovery operation of the longwall face equipment upon completion of a panel. The recovery room is supported ahead of time with primary bolts and supplemental cables and standing supports to provide a safe space for longwall equipment removal. As the longwall face approaching the recovery room, front abutment load acted on the fender pillar and recovery room increases and the fender pillar converges. Subsequently, the immediate roof above the fender pillar sags the same amount as the pillar convergence. Generally, the barrier pillar is large enough to withstand the abutment load and resist any significant amount of convergence. The pre-driven longwall recovery room must be properly designed and adequately supported to ensure success. Field instrumentations are installed in many cases to monitor the roof-floor convergence, roof strata movement, fender pillar stress and barrier pillar stress. Statistical analysis based on case histories as well as numerical techniques are employed for the pre-driven longwall recovery room support design. However, there is no study conducted on analytical modeling of the dynamic loading and roof support interaction process as longwall face approaching recovery room.

Multi-seam mining is one of the most challenging ground control problems in the mine industry. The multi-seam mining interaction, effects of the mining of one seam on the adjacent seams, could induce serious ground control safety problems to the mine operations. There are three of multi-seam mining interaction mechanisms, the subsidence, massive interseam shearing and load transfer. Various theories and techniques are employed to analyze multi-seam mining effects. With the fast development of computer technology, numerical modeling of mine structures has been the preferred method for analyzing multi-seam mining interactions. The advantage with numerical modeling of mine structural analysis is that it can properly simulate, case by case, the detailed 3-dimentional mine layouts in both seams, considering all the factors. The disadvantage is that it is time consuming and highly sophisticated, requiring in-depth knowledge, experience, and special training. Multi-seam mining subsidence is different as single 
seam mining subsidence due to two reasons. One is the additional subsidence caused by the failure of remnant structures in sufficient area, and the other one is the recompaction of the gob material. Further study should be made on the physical mechanisms of multi-seam mining and modifications of the multi-seam mining subsidence prediction.

Longwall mining operations in shallow areas could affect the surface streams, ponds, water table and subsurface aquifers to various degrees. Reliable prediction of groundwater flow due to mining is not only essential for improving mine safety and reduction of coal production costs, but also important for the assessment of environmental impact of mining. Conceptual models of the hydrogeological effects of longwall mining have gradually been developed from case studies. The overburden strata above longwall mine gob are divided into different zones. In the surface zone, the depth of surface tensile cracks was less than $33 \mathrm{ft}(10 \mathrm{~m})$. The constrained zone, although there are minor bed separations, can serves as a water barrier if its thickness is more than 12 times the mining height. The caved and fractured zones combined, up to 33 times of the mining height, are a dewatered zone assuming a dome shape. Longwall mining induced stress and strain redistribution will change the overburden strata permeability. Several formulas are established for calculating the hydraulic conductivities change due to longwall mining. The groundwater flow in response to longwall mining effects can be modeled with various numerical techniques. Field instrumentations are very important to obtain groundwater flow parameters and the monitoring of groundwater flow fluctuations. However, since longwall mining induced overburden movements and deformations are pretty large, the stress related permeability change model seems not very accurate. Further study should be conducted on the strain related permeability change of the overburden strata in response to longwall mining. 


\section{CHAPTER 3 SUBSURFACE SUBSIDENCE PREDICTION}

The subsurface subsidence prediction is referred to the longwall mining induced overburden movement and deformation. Undermined by longwall panels, the overburden strata will subside from the immediate roof up to the ground surface. The movement of the immediate roof is essential for the ground control analysis of the pillar, roof and floor stability. The subsidence induced overburden movement will also disrupt the overlying coal seam, which may induce severe multi-seam interaction. To ensure the optimum longwall layout, to minimize interaction effects, and to improve the ground control safety, a better understanding of strata deformation above the longwall face is required (Styler, 1984). This problem has attracted the attention of many investigations. However, due to the high cost of subsurface instrumentation programs, the majority of these investigations were confined to surface and in-mine measurements. A good alternative for this problem is to predict the subsurface subsidence with solid mathematical models and empirical formulae deduced from field works.

\subsection{Introduction}

With the development of the mining industry, the importance of subsurface subsidence prediction and its broad applications in the mining industry is realized by the practitioners and researchers. The most obvious applications are to assess the mining effects on: (1) surface and subsurface water bodies, (2) methane emissions and migration in overburden strata for gob well degasification performance analysis, and (3) mine structures in multi-seam mining operations (Qiu and Luo, 2011).

Due to the limitations of numerical analysis methods in dealing with large deformation and discontinuity commonly encountered with coal mine ground control problems, and upon the success in developing and applying CISPM (Luo, 1989; Peng and Luo, 1992), the maturely developed surface subsidence theories are employed in developing a new subsurface subsidence prediction method. 


\subsubsection{Current Prediction Method}

In the subsurface subsidence prediction model previously developed by Luo and Peng (2000; 2010), a new deformation term, total strain or void intensity, has been introduced and can be determined from the predicted subsurface movements. This term reflects the volumetric expansion of overburden rock under the influence of mine subsidence. Figure 3.1 shows the predicted distribution of the final void intensity in overburden strata over a 1,000 $\mathrm{ft}$ wide longwall panel using Luo and Peng's prediction model (Luo and Peng, 2000). The strata zone with increased positive void intensity (shown in warm color) can induce higher permeability for water and methane gas to flow through. The reduced confinement pressure in such zone will make methane desorption from the methane containing coal or rock easier. The increased desorption and permeability can greatly accelerate the methane emission process. Higher void intensity also reduces the pillar strength and destabilizes the mine structures located in the overburden strata.

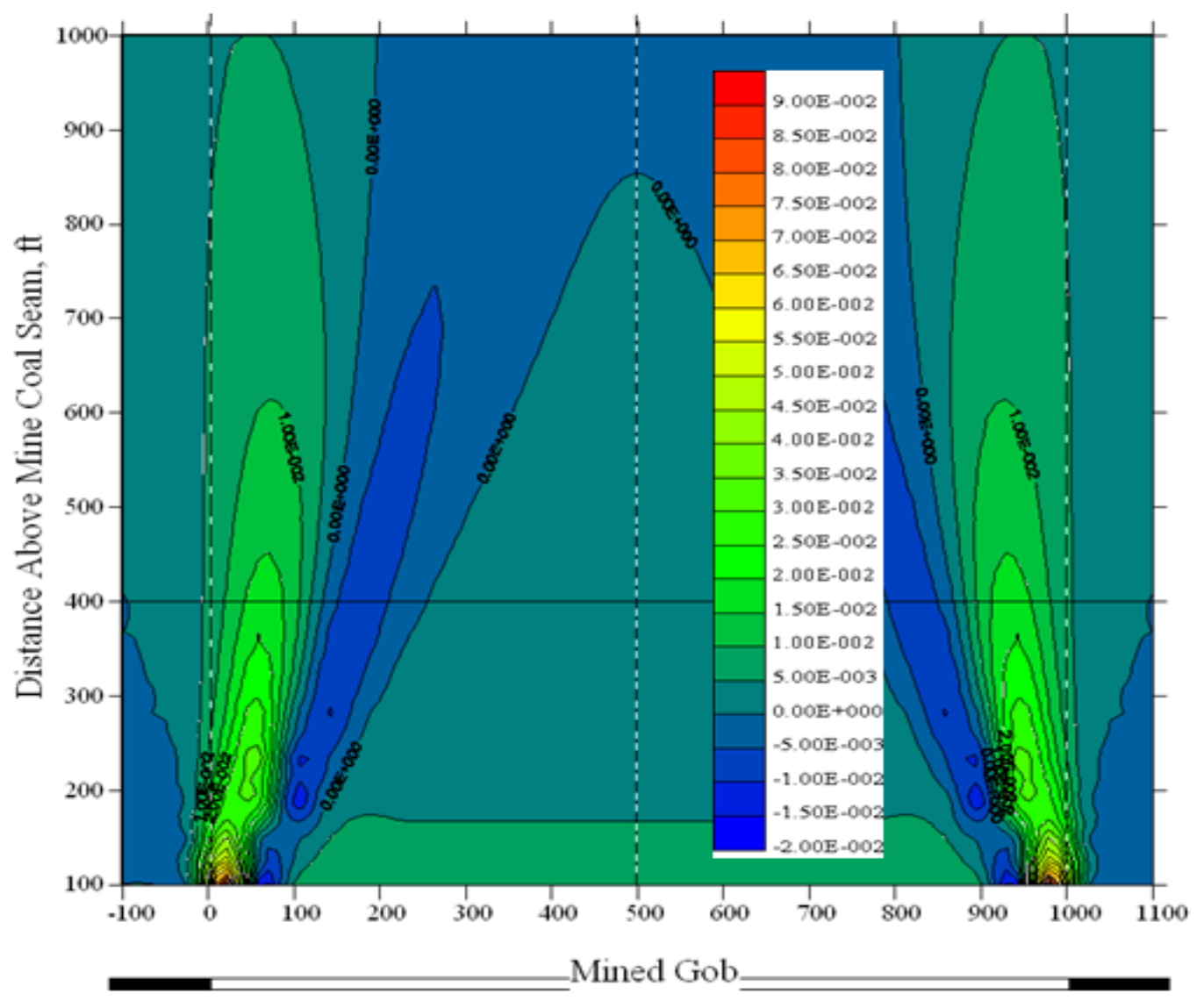

Figure 3.1 Void intensity distribution in overburden predicted by current subsurface subsidence prediction model (Luo and Peng, 2010) 
In the current subsurface subsidence prediction model, the stratification, particularly the massive hard rock (i.e., limestone and sandstone) layers, of the overburden were unable to be considered. The presence of massive hard rock layers in the overburden strata can greatly affect the magnitude and distribution of subsurface strata movements and deformations. An innovative approach to employ the influence function method while considering the hard rock layers will be applied in the development of a new subsurface subsidence prediction model.

\subsubsection{Potential Applications}

\subsubsection{Performance Management of Gob Well Degasification System}

In most of the US longwall mines, various methods for partially removing methane contained in the coal seam and surrounding rock strata have been employed to ensure mine safety and smooth mining operation. Gob well degasification system is one of the three methods to remove methane from entering the mine ventilation systems in longwall mines. The other two methods are pre-mining vertical hole drainage and in-seam horizontal hole drainage. It has been found that the gob well method is the most cost effective and often responsible for more than $70 \%$ of coal mine methane removed from longwall coal mines. The performance of the gob wells for a longwall panel can be affected not only by the well layout over the longwall panel and distance to the mined coal seam but also by how each of the wells is operated. Since most of the gob wells have a short degas life, it is desirable to remove as much methane through each of the wells as possible within its useful life.

The flow rate and the methane concentration of a gob well at a given time depend on the subsidence-induced permeability in the strata surrounding the bottom part of the well where the methane is collected. With some additional work, this subsurface subsidence prediction model can be extended to predict dynamic movements and deformations. The final and dynamic void intensity can be directly related to the permeability based on the findings from the laboratory studies on coal permeability for gases under various confining pressure by Somerton et al. (1974). Therefore, the subsurface subsidence prediction model can be used in the design and production management of the gob well degasification system. This is particularly important if the drained methane through the gob wells is required to be at a high concentration for utilization and marketing. In the design, the slotted well case located at the bottom part of the gob well for gas collection should be placed in the central part of a contiguous zone of high void intensity. The 
distance between the bottom of the gob well and the coal seam is an important factor to control the flow rate and the methane concentration in the degas flow. A larger distance would make the flow small but concentration high while a smaller distance will do the opposite. An optimum distance should be determined based on the distributions of the final and dynamic void intensity to achieve high flow rate and concentration. As a longwall operation is progressing through a panel, the productions of the gob wells placed over the panel should be carefully managed. The management of the gob well production includes using a vacuum pump and regulating the well flow to improve drainage efficiency. Therefore, the subsurface dynamic subsidence prediction model will have great potential to manage the gob well production.

\subsubsection{Subsidence Influences on Surface and Subsurface Hydrologic Systems}

As shown in Fig. 3.2, the subsurface subsidence process could affect surface and subsurface hydrological system in two ways: (1) temporary redistribution of hydrological system and (2) dewatering of surface streams and subsurface aquifers through connected paths to the longwall gobs. In the first case, the volume of the subsidence basin at different level above a mined longwall panel varies inversely with the depth. For an aquifer, the volume difference in the subsidence basins between its lower and upper aquifer boundaries has to be filled with water from other parts of the disturbed aquifer, other aquifers in the neighboring area or from surface water bodies. As a result, the water table of the subsurface aquifers will be lowered and the flow rate of surface streams could be reduced.

In the second case, the differential subsurface vertical and horizontal movements could create contiguous zones with high void intensity in the overburden strata near the edges of the longwall panel as well as a short distance behind the moving longwall face. When the void intensity is larger than certain critical value, it could lead to significant dewatering of water bodies connected to such zones. Since the lost water will flow to the mined gobs, the impacts of this type of subsidence influences will be more severe to the hydrological system than the other two types. If the connected surface and/or subsurface water bodies including old mine workings are large, it could lead to sudden water inrush and create a hazardous condition. Based on back

calculation, a critical void intensity leading to significant water seepage flow is about $4.1 \times 10^{-2}$ $\mathrm{ft} / \mathrm{ft}$ or $\mathrm{m} / \mathrm{m}$ (Luo And Peng, 2010). 

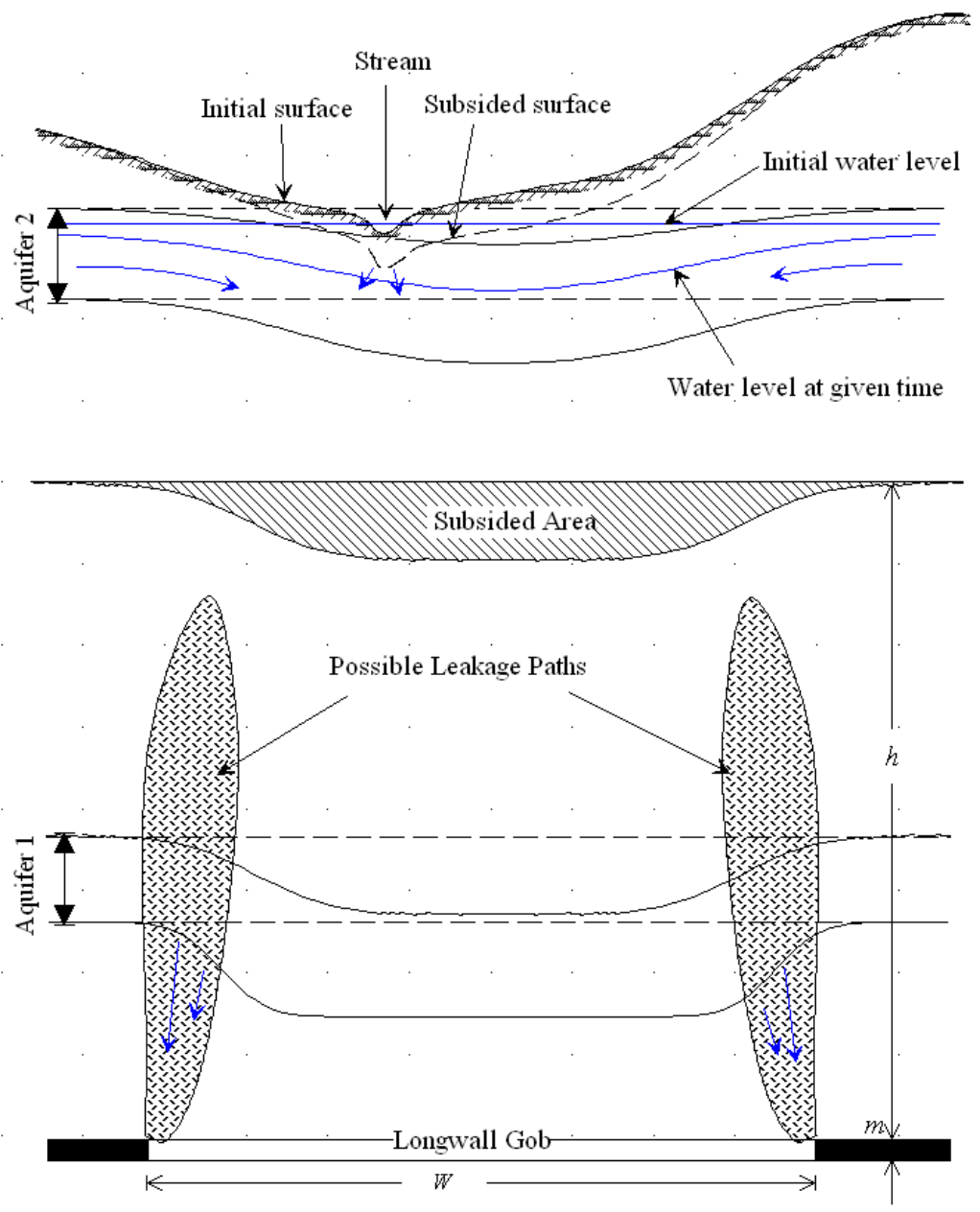

Figure 3.2 Subsidence effects on surface and subsurface hydrologic systems (after Luo and Peng, 2010)

\subsubsection{Pillar Stability under Influence of Subsurface Subsidence}

In areas with multi-seam mining, the mining activities conducted in underlying seam(s) could affect the stability of mine structures, (i.e., coal pillars, entry floor, and roof) in the seams above. Instable pillars, roof and floor can not only cause significant problems to mining operations but also present hazardous conditions to mine workers. The subsurface subsidence prediction model has the potential for the assessing the stabilities of mine pillars, roof and floor.

The stability of a mine pillar depends on and its strength and the load applied on it. Instable pillars in a large contiguous area could lead to cascading pillar events - a serious safety hazard to miners and mining operations. The pillar strength is a function of confinement normally reflected by the width to height ratio of the pillar in a single seam mining setting. However, when a pillar is disturbed by mine subsidence, both the pillar load and its strength 
could be affected. Change in pillar load can be related to the differential subsidence between the roof and floor line of the pillar. The pillar strength would decrease with the confinement pressure that is related to the increased void intensity caused by strata subsidence process.

Roof falls have been the No. 1 safety threat to underground miners. Common roof falls in coal mines are tensile failures and roof cutters. When an underground coal mine is affected by mining activities conducted in the underlying coal seam, the originally stable mine roof could become unstable. Roof tension cracks could be induced in zones with high void (expansive) intensity while roof cutters are more likely to occur in areas with high horizontal compressive strain. Since the subsurface subsidence prediction model has the capacity to predict the distribution of these subsurface deformations, the model can be used to guide mine design to avoid excessively disturbed zones and to plan ahead of any mitigation measures (e.g., supplementary roof supports) to minimize such influences.

Unstable mine floor are mainly shown in floor cracks and floor heaves. Though they more likely cause problems to mining operations, they might also bring serious safety problems. For examples, floor cracks could form connected channels for accumulated methane in the closed underlying coal mines to rush into the active working. The subsurface subsidence prediction model could be used in the similar way in assessing the stability of the mine floor as that for mine roof.

\subsection{Enhanced Subsurface Subsidence Prediction Model}

In this subsurface subsidence prediction model, the overburden strata over a longwall gob are divided into a finite number $(n)$ of layers of equal thickness. The layers are numbered from the immediate roof stratum to the surface by $1,2, \ldots, n$ as shown in Fig. 3.3. The subsidence on the top surface of a given layer can be determined in the following procedure: (1) transforming the overburden load above it into a uniform equivalent load on the layer; (2) defining the subsidence influence function at a prediction point using the equivalent load, layer thickness, percent of hard rock in the layer and vertical movement at the layer bottom directly under the prediction point, (3) integrating the influence function within a proper horizontal interval for the final subsidence on the top of the layer. This procedure is repeated from the mining horizon, layer by layer upwards, until the ground surface is finally reached. 


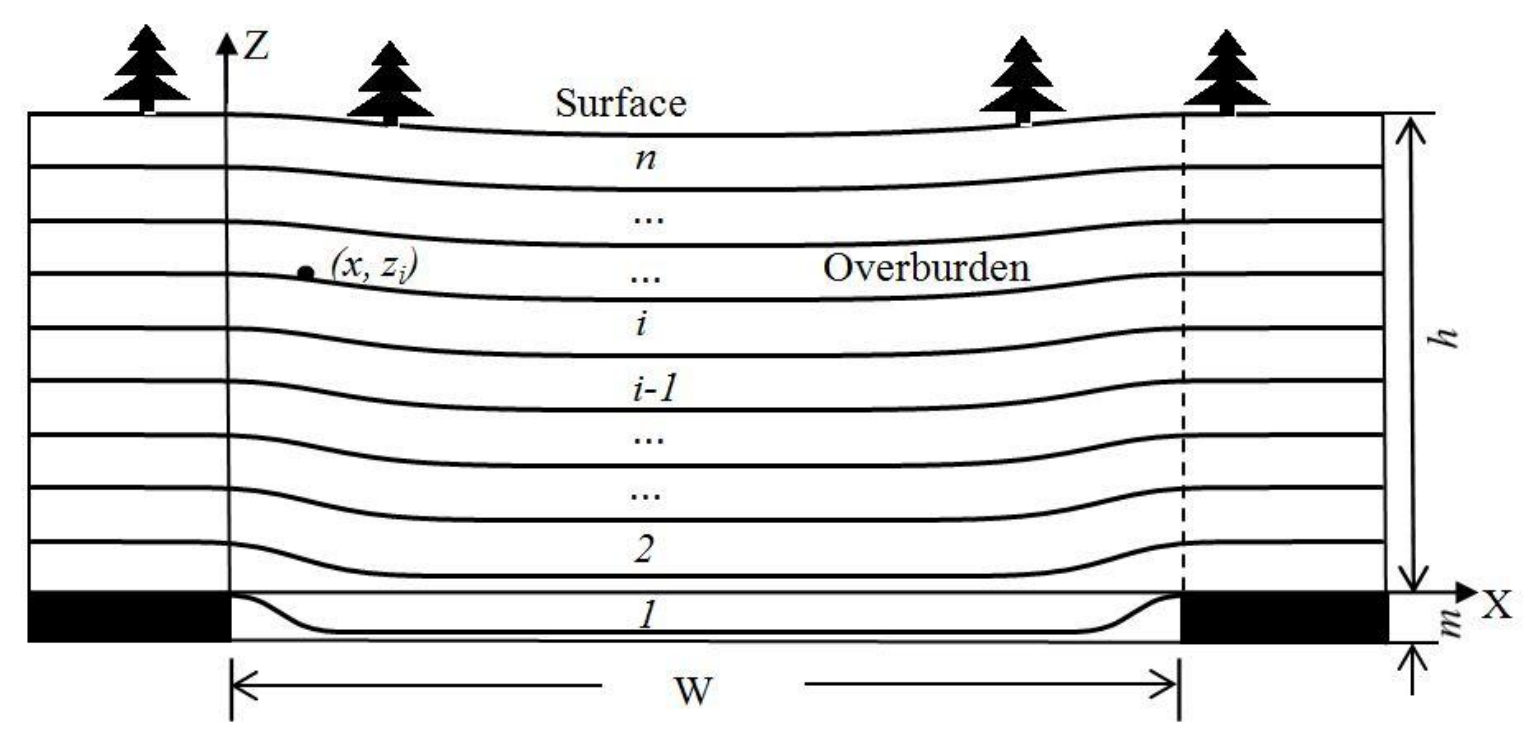

Figure 3.3 Subsurface subsidence prediction model

( $h$ - overburden depth; $m$ - mining height; $W$ - panel width; $n$ - number of overburden layers)

\subsubsection{Influence Functions}

The first step to apply influence function method for determining strata movements at a given point on the top surface of the $i$ th layer is to define the influence functions for vertical and horizontal displacement, respectively. The influence function for subsidence along a major crosssection is shown in the Eq. 3.1.

$$
f_{s}\left(x^{\prime}, z_{i}\right)=\frac{S\left(x+x, z_{i-1}\right) \cdot a_{i}}{R_{i}} e^{-\pi\left(\frac{x}{R_{i}}\right)^{2}} \quad i=1,2, \ldots, n
$$

In this equation, $x$ is the horizontal distance between the left panel edge and the prediction point while $z_{i}$ is the vertical distance between the top surface of the $i$ th layer and the mined coal seam as shown in Fig. 3.3. The term $S\left(x+x^{\prime}, z_{i-1}\right)$ is the predicted final subsidence on top surface of the underlying layer located $x$ ' distance on the left of the prediction point. For the first layer immediately above the mined coal seam, the mining height, $m$, should be used in the place of $S\left(x+x^{\prime}, z_{\mathrm{i}-1}\right)$ in the influence functions. Final subsidence parameters $a_{i}$ and $R_{i}$ are the subsidence factor and radius of major influence for the $i$ th layer, respectively. Coordinate $x^{\prime}$ is the horizontal distance between the point of "influence" to cause subsidence and the prediction point on the top surface of the layer. 
Based on the focal point theorem, the influence function for horizontal displacement along a major cross-section is derived from the influence function for subsidence (Eq. 3.1) as shown in the following equation. In the equation, $h$ is the overburden depth.

$$
f_{u}\left(x^{\prime}, z_{i}\right)=-2 \pi \frac{S\left(x+x, z_{i-1}\right) \cdot a_{i} \cdot n}{R_{i} \cdot h} x e^{-\pi\left(\frac{x^{*}}{R_{i}}\right)^{2}} \quad i=1,2, \ldots, n
$$

\subsubsection{Final Subsurface Strata Movements}

The final subsurface subsidence and horizontal displacement at a prediction point are determined by integrating the respective influence functions between the left and right inflection points as shown in Fig. 3.4. In the following two equations, $d_{i 1}$ and $d_{i 2}$ are the offset distances of inflection points on the left and right sides of panel for the $i$ th layer, respectively. The methods to determine the final subsidence parameters $\left(a_{i}, R_{i}, d_{i l}\right.$ and $\left.d_{i 2}\right)$ will be discussed in the next section.

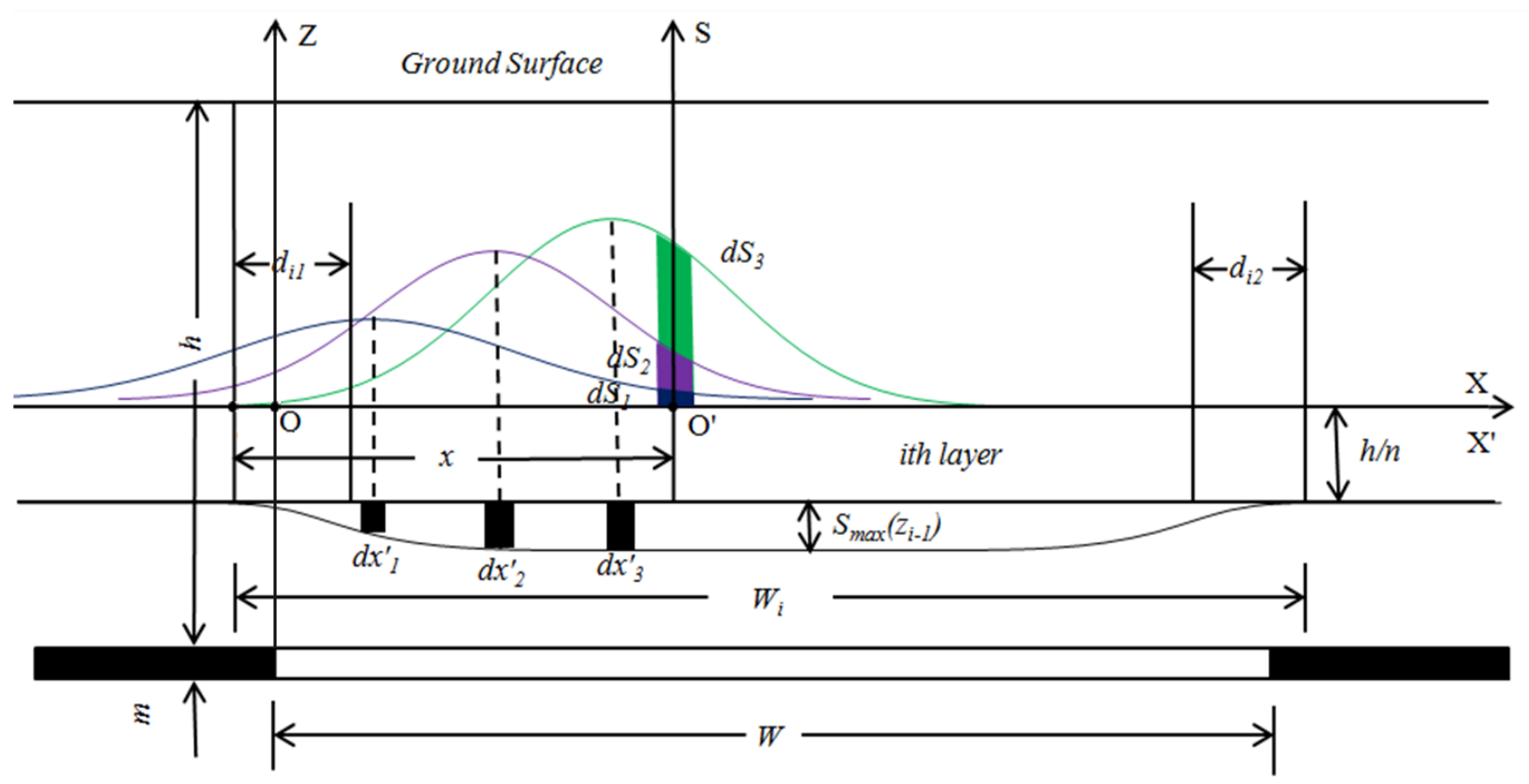

Figure 3.4 Schematic for influence function method

The final subsurface subsidence at a prediction point $\left(x, z_{i}\right)$ is obtained by integrating the influence function for subsidence (Eq. 1) between the left and right inflection points at top of $i$ th layer as shown in Eq. 3.3. In the equations, $W$ is the rib-to-rib width of the mined longwall panel.

$$
S\left(x, z_{i}\right)=\frac{a_{i}}{R_{i}} \int_{d_{i 1}-x}^{W-d_{i 2}-x} S\left(x+x, z_{i-1}\right) \cdot e^{-\pi\left(\frac{x}{R_{i}}\right)^{2}} d x, \quad i=1,2, \ldots, n
$$


The final subsurface horizontal displacement at prediction point $\left(x, z_{\mathrm{i}}\right)$ can be determined by integrating the influence function for horizontal displacement (Eq. 3.2) between the left and right inflection points as shown in Eq. 3.4.

$$
U\left(x, z_{i}\right)=\frac{a_{i} \cdot n \cdot R_{i}}{h} \int_{d_{i 1}-x}^{W-d_{i 2}-x} S\left(x+x, z_{i-1}\right) \cdot x^{\prime} \cdot e^{-\pi\left(\frac{x}{R_{i}}\right)^{2}} d x^{\prime} \quad i=1,2, \ldots, n
$$

\subsubsection{Final Subsurface Deformations}

The differential strata movements in both horizontal and vertical directions will cause deformations in the subsurface strata. In surface subsidence studies, the surface deformations are traditionally described by slope, strain and curvature. However, for applications dealing with subsurface subsidence, the distributions of horizontal, vertical and total strains in the overburden strata could be much more valuable for assessing the subsidence influences to subsurface structures, hydrological system and gob well degasification operations.

The horizontal strain $\left(\varepsilon_{\mathrm{x}}\right)$ is defined as the first derivative of horizontal displacement with respect to $x$ (Eq. 3.5). Sufficient horizontal strain could cause vertical fractures or even cracks in the strata. The vertical strain $\left(\varepsilon_{\mathrm{z}}\right)$ is defined as the first derivative of subsurface subsidence with respect to $z$ (Eq. 3.6). Sufficient vertical strain could cause bed separations along the strata bedding planes or even step cracks. The total strain $\left(\varepsilon_{t}\right)$, defined in Eq. 3.7, is an indicator of the severity of expansion or shrinkage of a volume of rock strata under the influence of subsidence process. It should be noted that the expansive type of total strain (in positive value), reflecting the intensity of voids, is an indicator of the increase in porosity and permeability for seepage flows of gases or water in the subsurface strata. For simplicity, the expansive total strain is also called void intensity.

$$
\begin{aligned}
& \varepsilon_{x}(x, z)=\frac{d U(x, z)}{d x} \\
& \varepsilon_{z}(x, z)=\frac{d S(x, z)}{d z} \\
& \varepsilon_{t}(x, z)=\varepsilon_{x}+\varepsilon_{z}+\varepsilon_{x} \cdot \varepsilon_{z}
\end{aligned}
$$




\subsection{Subsurface Subsidence Parameters}

Similar to any other prediction models, the accuracy of this proposed model largely depends on the final subsurface subsidence parameters, $a_{i}, R_{i}, d_{i l}$ and $d_{i 2}$. Previous studies have shown that the magnitudes of the final subsidence parameters are affected by the geological, geomechanical and mining factors. In this section, empirical formulae for the final subsurface subsidence parameters have been proposed. The past subsidence research works (Luo, 1989; Peng et al, 1995) and mechanical analysis form the basis for these empirical formulae.

\subsubsection{Collected Subsurface Subsidence Cases}

In order to calibrate the subsurface subsidence parameters, the data from three sites of extensometer monitoring holes drilled over two longwall panels published by Luo and Peng (2000) have been collected. Extensometers have been used in various research projects to measure the lowering of the subsurface strata in relation to the ground surface. With the measured surface subsidence at the top of the extensometer borehole, the subsurface subsidence along the borehole at different strata levels above the mined coal seam can be determined. The general information about each of the data collection sites is shown in Table 3.1.

Both sites 1 and 2 were located along the longitudinal center line of one single langwall panel but separated by a distance of 3,300 ft. At these two sites, the overburden depth was about $480 \mathrm{ft}$ and the mining height was about $13.78 \mathrm{ft}$. In the overburden strata over this longwall panel, a thick alluvial deposit of about $100 \mathrm{ft}$ was located from the surface down while strong sandstone strata ranging from 80 to $100 \mathrm{ft}$ thick, either massive or thickly bedded was located an average of $15 \mathrm{ft}$ above the mined coal seam. Seven extensometers were installed in seven closely drilled boreholes reaching different distances above the mined coal seams. The lowest extensometers were located about $16 \mathrm{ft}$ above the coal seam while the uppermost extensometers were $183 \mathrm{ft}$ from the mining level. At site 3, the overburden was $670 \mathrm{ft}$ thick and the mining height was about $10.83 \mathrm{ft}$. The alluvial deposit was even thicker. Eight extensometers were installed into a single borehole at varying depths. The lowest extensometer was located about $16 \mathrm{ft}$ above the coal seam while the uppermost point was about $476 \mathrm{ft}$ above the mining level. The average face advance rates when the extensometers were actively affected by the mining activities have been calculated and listed in Table 3.1. 
Table 3.1 Subsurface subsidence monitoring sites

\begin{tabular}{ccccccc}
\hline $\begin{array}{c}\text { Site } \\
\text { No. }\end{array}$ & $\begin{array}{c}\text { Mining } \\
\text { Depth, Mining } \\
m\end{array}$ & $\begin{array}{c}\text { Advance } \\
m\end{array}$ & $\begin{array}{c}\text { Rate, } \\
m / d a y\end{array}$ & $\begin{array}{c}\text { No. } \\
\text { Holes }\end{array}$ & $\begin{array}{c}\text { No. } \\
\text { Extens. }\end{array}$ & $\begin{array}{c}\text { Extensometers Anchor } \\
\text { Locations*, } m\end{array}$ \\
\hline 1 & 146 & 4.2 & 6.2 & 7 & 7 & $\begin{array}{l}4.9,9.8,14.9,19.8,27.7, \\
36.9,55.8\end{array}$ \\
\hline 2 & 146 & 4.2 & 7.7 & 7 & 7 & $\begin{array}{l}4.9,9.8,14.9,19.8,27.7, \\
36.9,55.8\end{array}$ \\
\hline 3 & 204 & 3.3 & 11.1 & 1 & 8 & $\begin{array}{l}4.9,25.0,45.1,67.7,89.0, \\
105.5,122.2,145.1\end{array}$ \\
\hline \hline
\end{tabular}

${ }^{*}$ Vertical distance above the coal seam

\subsubsection{Subsidence Factors}

Among the final subsurface subsidence parameters, the subsidence factor is the most important parameter in subsidence prediction. Previous studies on the subsidence factors are based on the regression study of the case data. A nonlinear regression performed on 135 data points, including 22 subsurface subsidence case data points and 113 surface subsidence case points as shown in Fig. 3.5, suggested the following empirical formula (Eq. 3.8) be one of the best to represent the relationship between $h$ and the subsidence factors for both subsurface and surface cases (Luo and Peng, 2000).

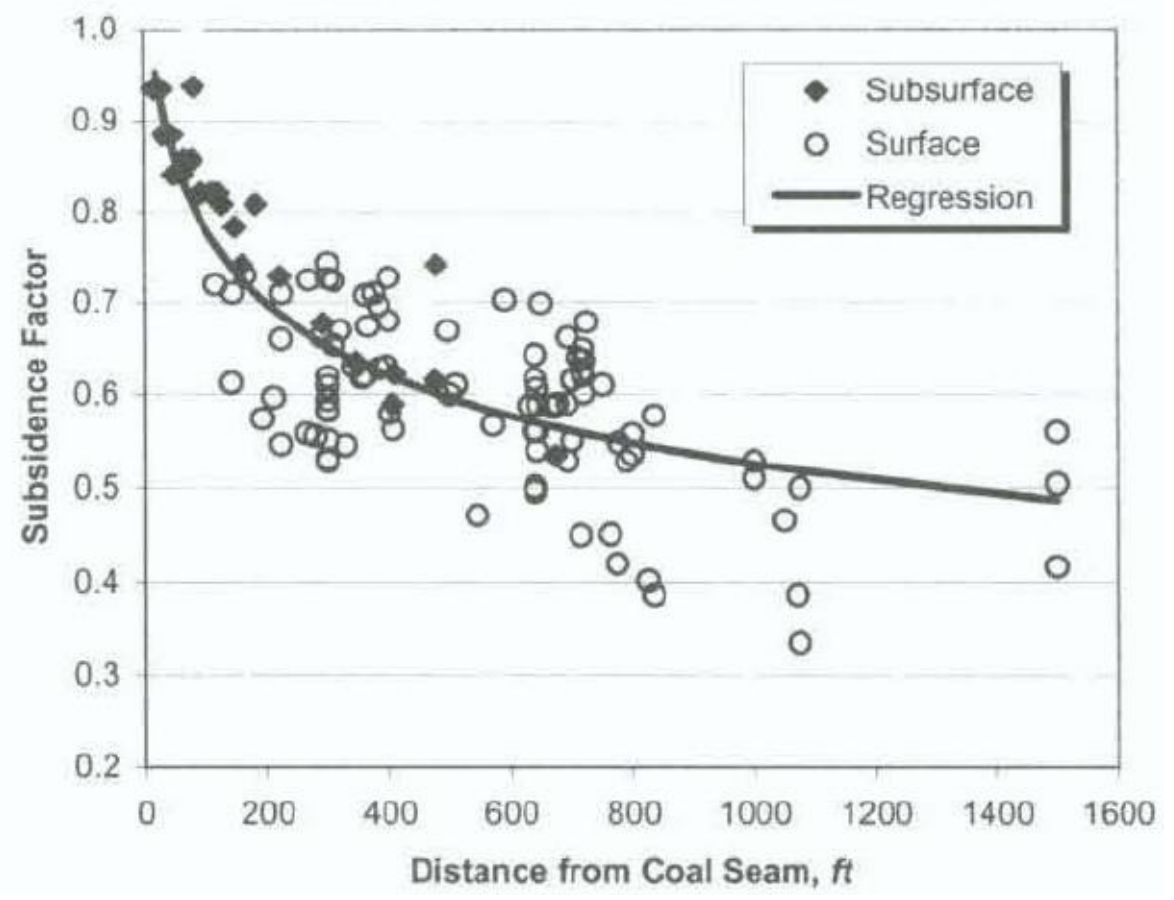

Figure 3.5 Surface and subsurface subsidence factors (after Luo and Peng, 2000) 


$$
a_{i}=1.9381\left(\frac{h i}{n}+23.4185\right)^{-0.1884}
$$

For the enhanced subsurface subsidence prediction models, it is believed that the hard rock percentage has some influence on the subsurface subsidence factor. The following empirical equation relates subsidence factor of a layer with the percent of hard rock in it $\left(\eta_{i}\right)$ and the distance between the coal seam and it $(h i / n)$.

$$
a_{i}=1.9381\left(\frac{h i}{n}+23.4185\right)^{-0.1884} e^{\left.0.0000535-\eta_{i}\right)} \quad i=1,2, \ldots, n
$$

\subsubsection{Radius of Major Influence}

The radius of major influence is the half width of the major influence zone where the final subsidence varies from the recognized "edge" of subsidence basin to the "full" subsidence point as shown in Fig. 3.6. To determine the radius of major influence for the $i$ th layer, the layer is treated as an overhang beam of thickness of $h / n$. It is vertically restricted on the left side by an elastically fixed end while the overhanging beam on the right is restricted by the maximum possible subsidence on the top surface of the previous layer, $S_{\max }\left(Z_{\mathrm{i}-1}\right)$. The deflection of the $i$ th layer of the overburden strata can be seen as a cantilever beam with the maximum deflection of $a_{i} S_{\max }\left(Z_{\mathrm{i}-1}\right)$ as shown in Fig. 3.6. The maximum deflection of the beam can be determined by Eq. 3.10a based on the beam theory.

$$
a_{i} \cdot S_{\max }\left(Z_{i-1}\right)=\frac{q_{i} L_{i}^{4}}{8 E_{i} I_{i}}
$$

The magnitude of the overburden load, $q_{i}$, is also an important factor for the radius of major influence of the $\underline{i}$ th layer. $E_{i}$ and $I_{i}$ in this equation are the Young's modulus and the area moment of inertia respectively. $L_{i}$ is the length of the beam that have the maximum deflection of $a_{i} S_{\max }\left(Z_{\mathrm{i}-1}\right)$ under the distributed load. $L_{i}$ can be used to determine the radius of major influence of the $i$ th layer. Based on the subsidence field data, the subsidence initiation point is normally located a short distance outside the panel edge. In order to match the mathematical model with the field data, the analytically derived formula should be modified to fit the empirically derived values on ground surface with similar condition as Eq. 3.10b. The proposed empirical formula for radius of major influence for the $i$ th layer is shown in Eq. 3.10c. 
$R_{i}=\frac{L_{i}+0.13 \frac{h}{n}}{2}$

$\left.R_{i}=0.5\left\{\frac{2 \cdot S_{\max }\left(Z_{i-1}\right) \cdot a_{i}\left(\frac{h}{n}\right)^{3} \frac{K_{E}}{Q_{i}^{2}}}{3 q_{i}}\right]^{0.25}+0.13 \frac{h}{n}\right\} \quad i=1,2, \ldots, n$

$q_{i}=\frac{\gamma \cdot h \cdot(n+1) \cdot(n-i+1)}{288 \cdot n \cdot i} \quad i=1,2, \ldots, n$

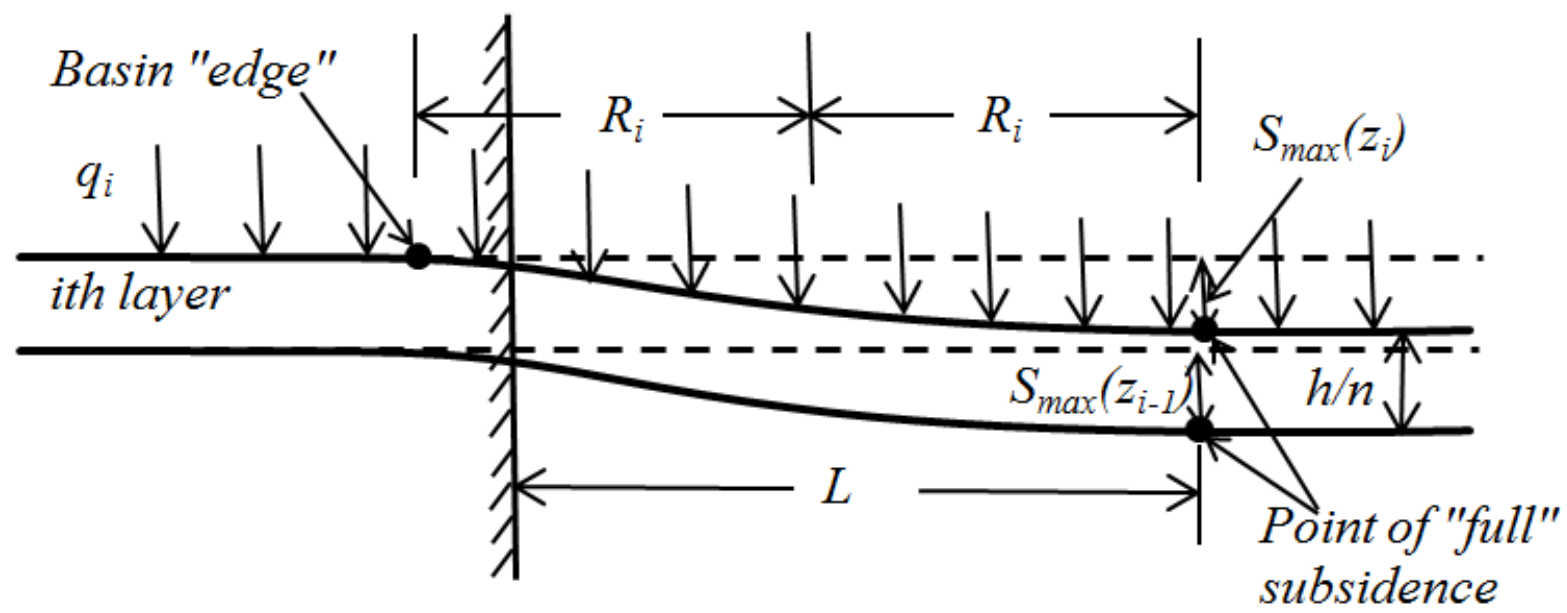

Figure 3.6 Determination of the radius of major influence

In Eq. 3.10, $\gamma$ is the average unit weight of the overburden strata. $K_{E}$ is a factor related to the Young's modulus of the rock strata, which can be estimated to be 0.49 times the average Young's modulus of the soft rock strata. The overburden load on the $i$ th layer can be estimated by Eq. 3.11. The rock factor for the $i$ th layer, $Q_{i}$, can be found by Eq. 3.12. In this equation, the percent of hard rock (consisting of limestone and sandstone) for each layer, $\eta_{i}$, should be determined first. If the determined radius of major influence for $i$ th layer $\left(R_{\mathrm{i}}\right)$ is smaller than that for the underlying layer $\left(R_{\mathrm{i}-1}\right)$, it forces $R_{i}=R_{i-1}+0.2 \mathrm{~h} / \mathrm{n}$.

$$
Q_{i}=\sqrt{\frac{\left(0.08 \cdot \eta_{i}\right)^{2}+\left[0.7 \cdot\left(1-\eta_{i}\right)\right]^{2}}{\eta_{i}{ }^{2}+\left(1-\eta_{i}\right)^{2}}} \quad i=1,2, \ldots, n
$$

\subsubsection{Offset of Inflection Point}

The offset distance of inflection point of the first layer can be determined by the empirical formulae of surface subsidence prediction. 


$$
d_{i}=0.382075 \times 0.999253^{\frac{i h}{n}} \times \frac{i h}{n} \quad(i=1,2,3, \cdots, n)
$$

It should be noted that the units for overburden depth $(h)$, radius of major influence $\left(R_{i}\right)$ and offset distance of inflection point $\left(d_{i}\right)$ in the empirical equations 8, 9,10,11, 12 and 13 are in feet $(\mathrm{ft})$ and $1 \mathrm{ft}=0.3048 \mathrm{~m}$.

\subsection{Dynamic Subsurface Subsidence}

The dynamic subsidence process is the complicated subsidence development process, in which the movement direction and magnitude at the point change with time. When a longwall face moves forward, the ground at the edge of the solid coal and some distance behind the longwall face will subside accordingly, which will experience tension and then compression.

\subsubsection{Mathematical Model}

Similar as surface dynamic subsidence, the subsurface dynamic subsidence can be predicted based on accurately defined subsidence velocity. Figure 3.7 shows the schematic drawing for the model and the moving coordinate system used in the model development. It is assumed that the subsidence velocity at a point in the subsurface strata can be represented by a mathematical function similar to the normal probability distribution function as shown in Fig. 3.7 if the advance rate of the longwall face $(v)$ is fairly constant.

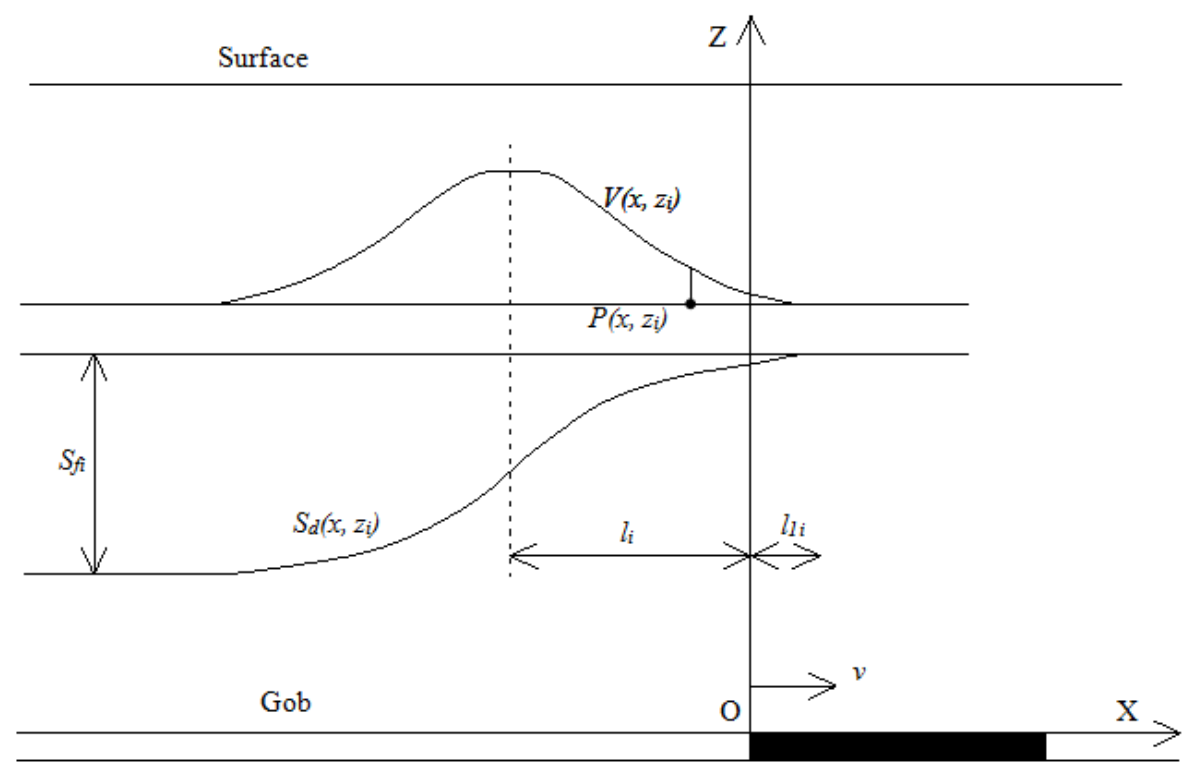

Figure 3.7 Schematic for dynamic subsurface subsidence associated with longwall mining 
With similar formula derivations, the subsurface dynamic subsidence of the $i$ th layer in the overburden strata can be expressed by the following equation.

$$
S_{d}\left(x_{p}, z_{i}\right)=\frac{1}{2} S_{f}\left(x, z_{i}\right)+\sqrt{\frac{2}{\pi}} \frac{S_{f}\left(x, z_{i}\right)}{l_{i}+l_{1 i}} \int_{x_{p}}^{-l_{i}} e^{-2\left(\frac{x^{\prime}+l_{i}}{l_{i}+l_{i i}}\right)^{2}} d x^{\prime} i=1,2, \ldots, \mathrm{n}
$$

The subsurface dynamic horizontal displacement can be predicted based on the subsurface dynamic subsidence and it is shown in the following equation.

$$
U_{d}\left(x_{p}, z_{i}\right)=-\sqrt{\frac{2}{\pi}} \frac{R^{2}}{h} \frac{S_{f}\left(x, z_{i}\right)}{l_{i}+l_{1 i}} e^{-2\left(\frac{x^{\prime}+l_{i}}{l_{i}+l_{1 i}}\right)^{2}} \quad i=1,2, \ldots, \mathrm{n}
$$

\subsubsection{Dynamic Subsurface Subsidence Parameters}

Two additional parameters, $l_{i}$ and $l_{l i}$, other than the final subsidence parameters mentioned before appear in both Eqs. 3.16 and 3.17. $l_{i}$ is the offset of velocity peak or offset of dynamic inflection point at the $i$ th layer of the overburden strata, and $l_{l i}$ is the offset of subsidence initiation point where about $2 \%$ of the final subsidence has accumulated at the $i$ th layer of the overburden strata. These two parameters are called the dynamic subsidence parameters because of their important roles on the prediction accuracy of dynamic subsidence process. Both $l_{i}$ and $l_{l i}$ are mainly depending on the advance rate of the longwall face $(v)$ and the distance above the mined coal seam $\left(z_{i}\right)$. The determined offset of peak velocity at different subsurface levels from the dynamic subsidence development curves in the subsurface subsidence cases are plotted along with those from surface subsidence cases in Fig. 3.8.

The two important subsurface dynamic subsidence parameters can be determined by regression study, and they are shown in the following two equations.

$$
\begin{gathered}
l_{i}=(2.7645+0.8472 \sqrt{v}) \sqrt{h_{i}} \quad i=1,2, \ldots, \mathrm{n} \\
l_{1 i}=\frac{0.113 h_{i}}{1+0.1825 \sqrt{v}} \quad i=1,2, \ldots, \mathrm{n}
\end{gathered}
$$

Figure 3.9 shows the $l$ - $h$ relationship defined by the empirical formula for face advance rates ranging from 6.1 and $30.5 \mathrm{~m} /$ day (20 to $100 \mathrm{ft} /$ day). Lower advance rate results in a shorter $l$ at a given $h$. 


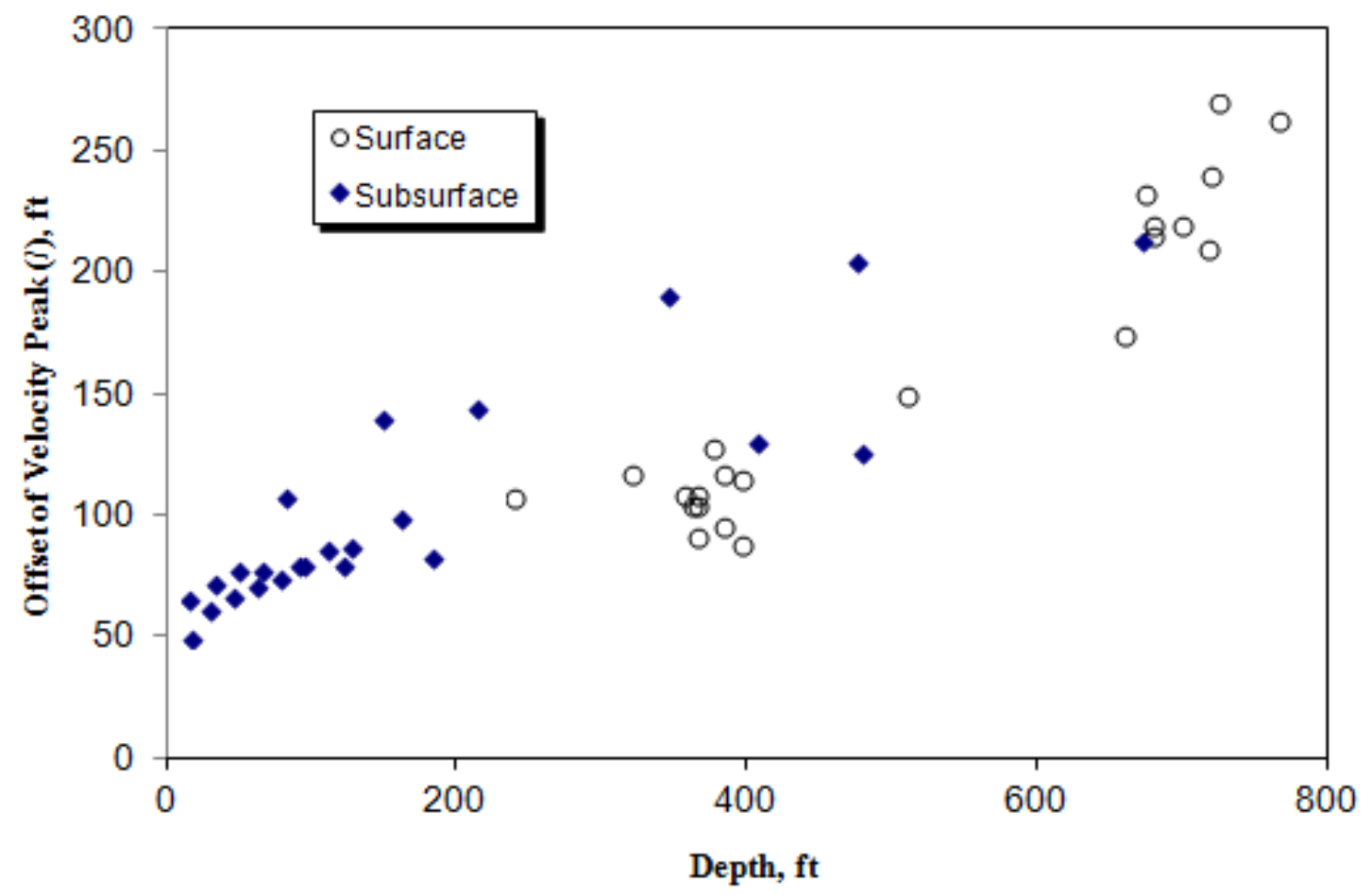

Figure 3.8 Offset of subsidence velocity peak vs. distance above the seam (Luo and Peng, 2000)

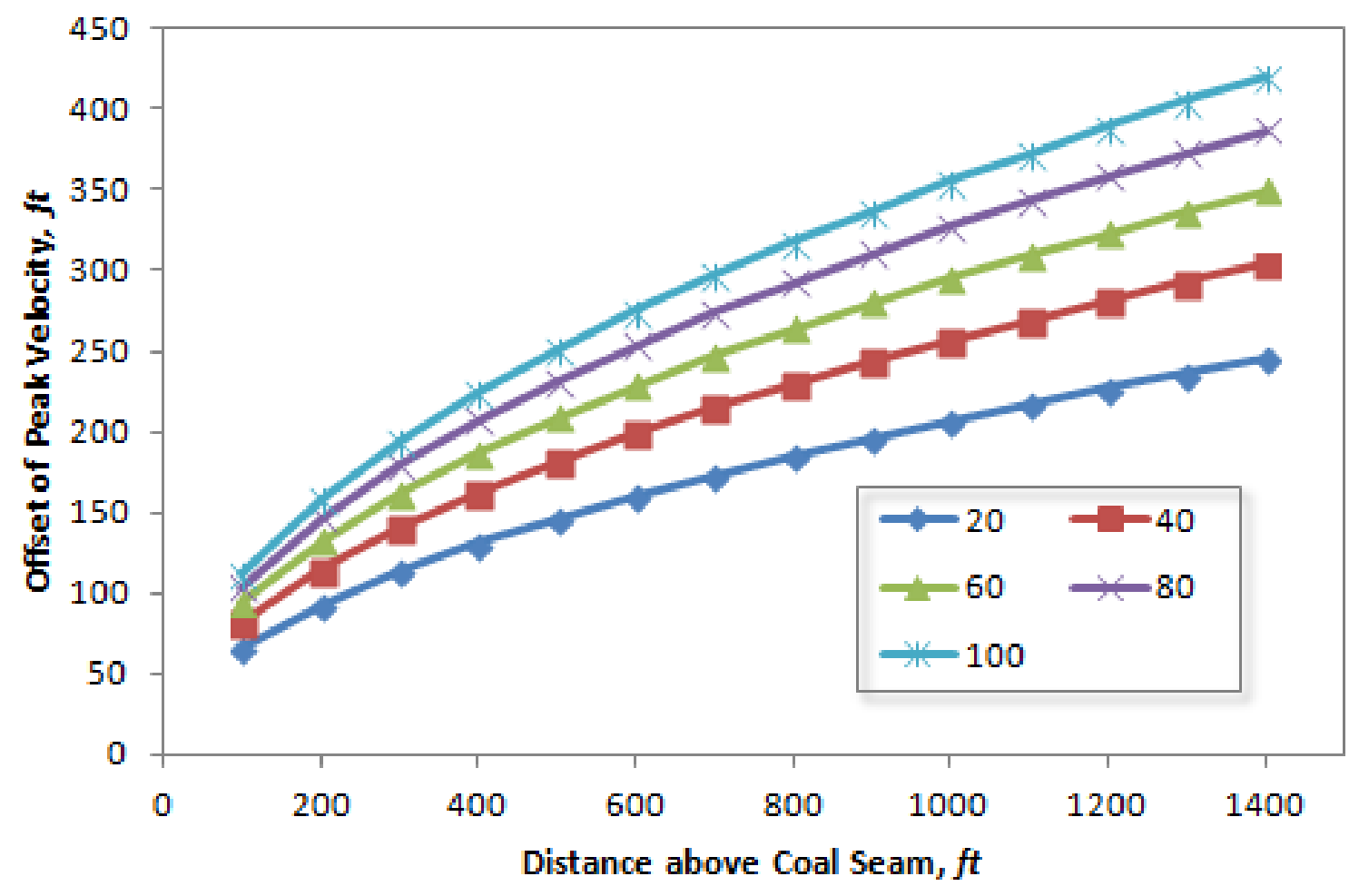

Figure 3.9 Calculated offset of peak velocity using Eq. 3. 16 


\subsection{Case Study}

A longwall mine case in which both surface and subsurface subsidence has been monitored is selected for demonstrating the proposed mathematical model and the computer program. The site is located in the northern Appalachian coal fields.

\subsubsection{Case Mine Conditions}

The longwall panel of the study area is $437 \mathrm{~m}(1,433 \mathrm{ft})$ wide and the overburden depth is $187 \mathrm{~m}(612 \mathrm{ft})$. A mining height of $2.3 \mathrm{~m} \mathrm{(7.7} \mathrm{ft)} \mathrm{is} \mathrm{used} \mathrm{in} \mathrm{the} \mathrm{prediction.} \mathrm{Table} 3.2$ shows the geological column of the overburden strata. To perform the subsurface subsidence prediction with the program, the overburden is divided into 20 equal layers, and the determined percent of the hard rock in each layer is shown in Fig. 3.10. Two layers with high percentages of hard rock strata (99\% and 100\%) are presented at 65 and $121 \mathrm{~m} \mathrm{(214} \mathrm{and} 398 \mathrm{ft})$ below the ground surface.

Table 3.2 Geological column of the overburden

\begin{tabular}{|l|c|c||l|l|l||l||l||l|l|}
\hline Rock Type & Thickness $(\mathrm{m})$ & Depth $(\mathrm{m})$ & Rock Type & Thickness $(\mathrm{m})$ & Depth $(\mathrm{m})$ & Rock Type & Thickness $(\mathrm{m})$ & Depth $(\mathrm{m})$ \\
\hline Top Soil & 4.3 & 4.3 & Sandstone & 12.7 & 78.1 & Sandstone & 0.6 & 159.4 \\
\hline Shale & 15.0 & 19.4 & Shale & 4.1 & 82.1 & Shale & 1.2 & 160.6 \\
\hline Sandstone & 1.3 & 20.7 & Coal & 1.1 & 83.2 & Coal & 0.2 & 160.8 \\
\hline Shale & 2.6 & 23.2 & Shale & 2.0 & 85.2 & Shale & 1.4 & 162.3 \\
\hline Sandstone & 1.8 & 25.0 & Sandstone & 5.5 & 90.7 & Limestone & 9.9 & 172.2 \\
\hline Shale & 4.0 & 29.0 & Limestone & 0.7 & 91.4 & Shale & 1.2 & 173.4 \\
\hline Coal & 0.5 & 29.5 & Shale & 3.5 & 94.9 & Limestone & 2.3 & 175.7 \\
\hline Shale & 9.9 & 39.4 & Sandstone & 15.9 & 110.8 & Shale & 1.1 & 176.8 \\
\hline Sandstone & 3.2 & 42.6 & Shale & 2.1 & 112.9 & Limestone & 0.6 & 177.4 \\
\hline Shale & 1.9 & 44.5 & Limestone & 3.1 & 116.0 & Shale & 5.0 & 182.3 \\
\hline coal & 0.3 & 44.8 & Sandstone & 2.0 & 118.0 & Coal & 0.1 & 182.4 \\
\hline Shale & 3.8 & 48.6 & Shale & 1.8 & 119.8 & Shale & 0.2 & 182.6 \\
\hline Sandstone & 1.1 & 49.7 & Limestone & 14.7 & 134.5 & Coal & 0.4 & 183.0 \\
\hline Shale & 9.5 & 59.3 & Shale & 2.1 & 136.6 & Shale & 3.2 & 186.2 \\
\hline Limestone & 0.6 & 59.9 & Limestone & 10.5 & 147.1 & Coal & 0.2 & 186.4 \\
\hline Shale & 1.0 & 60.9 & Shale & 8.9 & 156.0 & Shale & 0.1 & 186.5 \\
\hline Coal & 0.4 & 61.3 & Coal & 1.7 & 157.7 & Coal & 2.3 & 188.9 \\
\hline Shale & 4.1 & 65.4 & Shale & 1.1 & 158.8 & & & \\
\hline
\end{tabular}

\subsubsection{Subsurface Subsidence Prediction}

The program determines the final subsidence parameters for each layer based on the proposed empirical equations. The profiles of the predicted final subsurface subsidence on the top surface of the layers are plotted in Fig. 3.11. In the plotting, the vertical subsidence is exaggerated by 10 times so that the displacements can be visually observable. Due to the symmetrical features of the subsidence profiles, only the subsidence profiles over one half of the 
longwall panel are plotted in the figure. It shows that the subsidence profiles formed at all layers exhibits the super-critical nature with a flat basin bottom as indicated by the high width/depth ratio of 2.34, significantly higher than the value for a critical subsidence basin of 1.2 in the same region. The flat bottom portion in a lower layer is wider than that an upper layer as expected. Though not very easily discernible from the plot, there is a significant differential subsidence between the layers when a strong layer lays over significant weak layers.

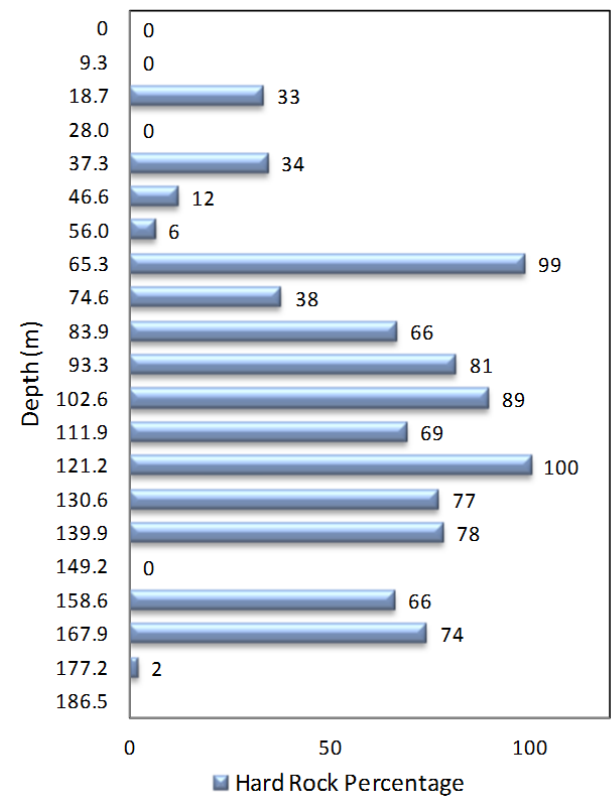

Figure 3.10 Percent of hard rock in the overburden layers

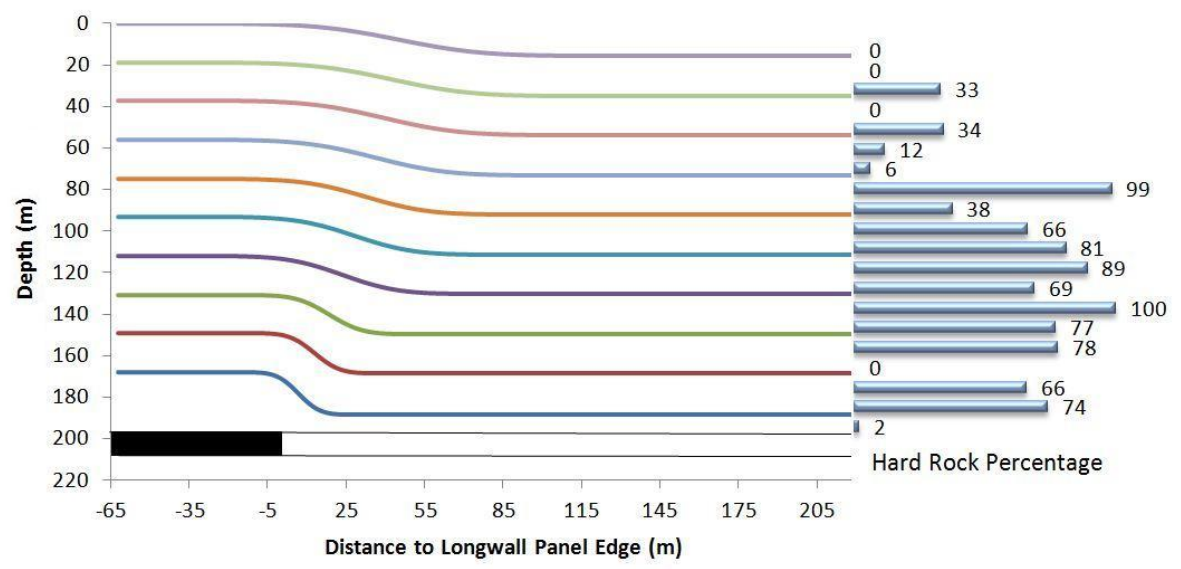

Figure 3.11 Final subsurface subsidence profiles formed at different levels above the longwall panel

Figures 3.12 and 3.13 show the contour plots of the predicted final vertical and total strain, respectively. Because of the differential strata movements in both horizontal and vertical 
directions, deformations are induced in the subsurface strata. In these plots, the strain distribution, especially that of the total strain, changed the patterns considerably in the level with harder rock layers at the depths of 65 and $121 \mathrm{~m}$ (214 and $398 \mathrm{ft})$. The presence of the thick hard rock layers will reduce the peak total strains above them but spread them in a larger area.

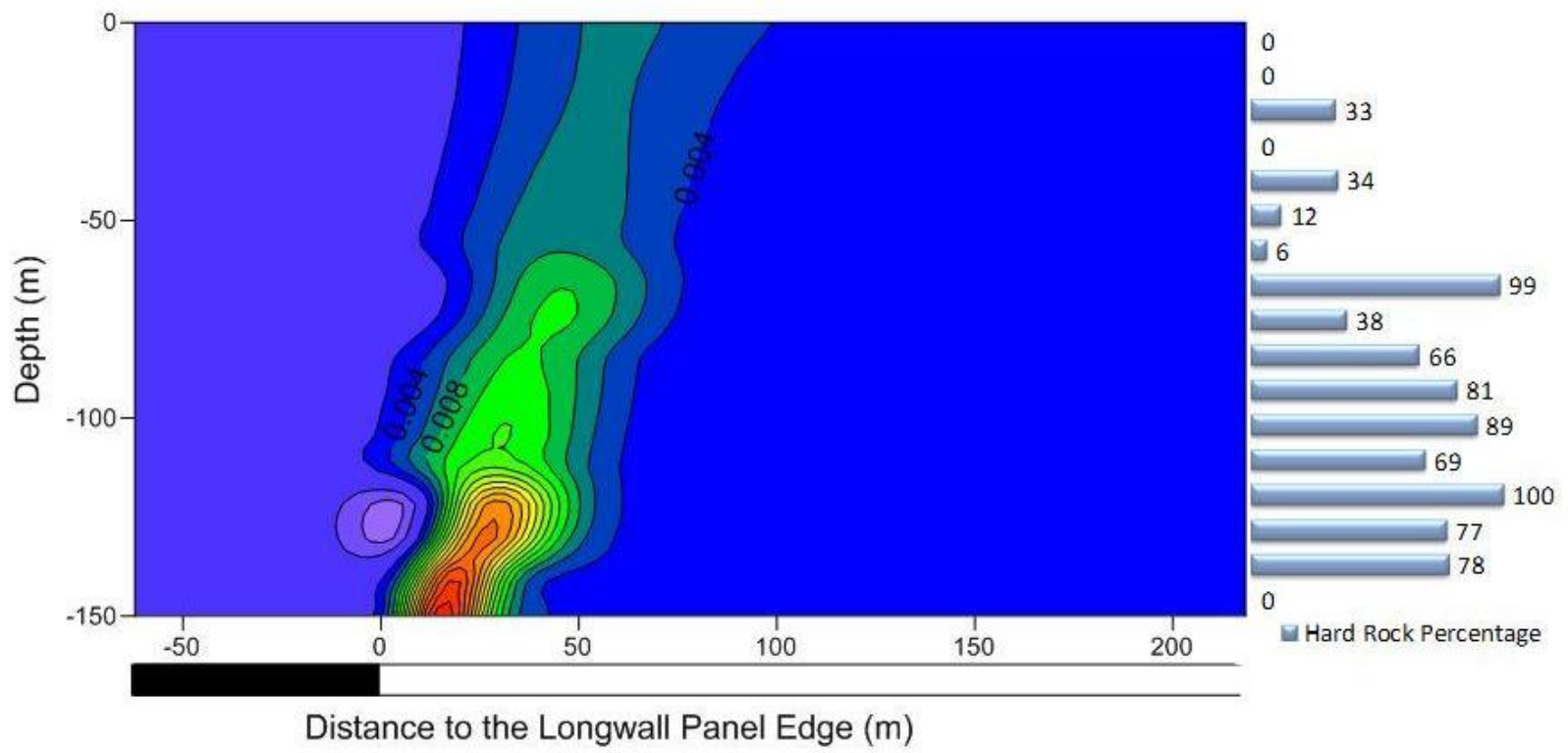

Figure 3.12 Contour plot of final subsurface vertical strain above the longwall panel

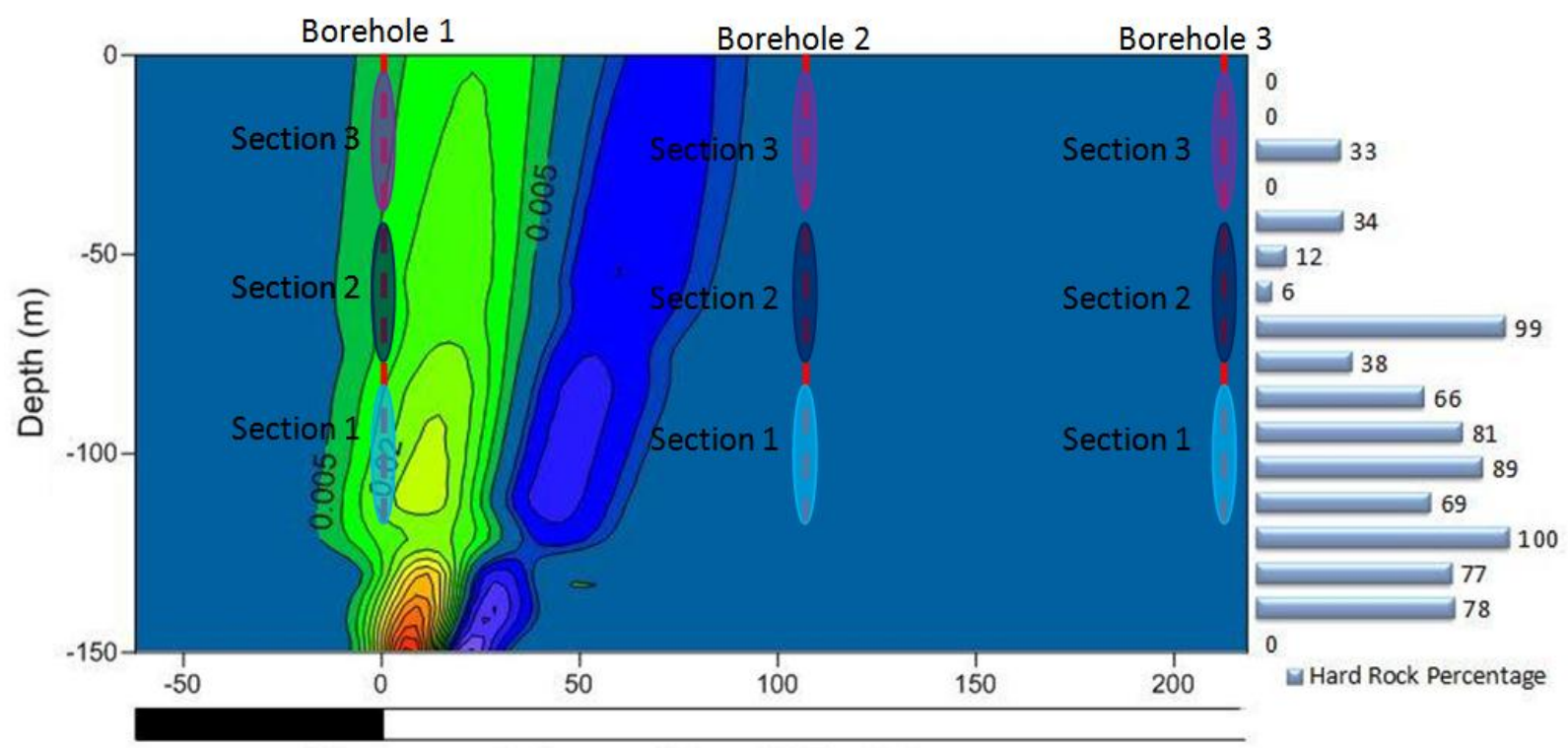

Distance to the Longwall Panel Edge $(\mathrm{m})$

Figure 3.13 Contour plot of final subsurface void intensity above the longwall panel 


\subsubsection{Comparison with Field Monitoring Results}

In order to study the subsidence process of the subsurface strata associated with longwall mining operations, the data from three sites of extensometer monitoring holes drilled over the longwall panel have been collected. Extensometers have been used in various research projects to measure the lowering of the subsurface strata in relation to the ground surface. With the measured surface subsidence at the top of the extensometer borehole, the subsurface subsidence along the borehole at different strata levels above the mined coal seam can be determined. The general information about each of the data collection sites is shown in Table 3.3. The three sites were located at the panel edge, quarter panel width to the edge and panel center, which are about $0 \mathrm{~m}(0 \mathrm{ft}), 106.7 \mathrm{~m}(350 \mathrm{ft})$ and $213.4 \mathrm{~m}(700 \mathrm{ft})$ from the panel edge respectively. For each borehole, 18 anchors were installed in different levels over the coal seam. The lowest anchors were located about $64.6 \mathrm{~m}(212.0 \mathrm{ft})$ above the coal seam while the uppermost anchors were

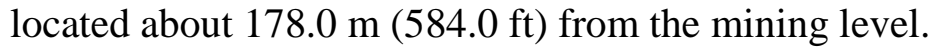

Table 3.3 Subsurface subsidence monitoring site anchor locations*

\begin{tabular}{|c|l|c|c|c|c|c|c|}
\hline \multicolumn{2}{|c|}{ Anchor Number } & 1 & 2 & 3 & 4 & 5 & 6 \\
\hline \multirow{3}{*}{ Borehole 1 } & Section 1 & 62.90 & 69.57 & 76.22 & 82.89 & 89.57 & 96.24 \\
\cline { 2 - 8 } & Section 2 & 102.89 & 109.56 & 116.24 & 122.88 & 129.56 & 136.23 \\
\cline { 2 - 8 } & Section 3 & 142.91 & 149.55 & 156.23 & 162.90 & 169.58 & 176.22 \\
\hline \multirow{4}{*}{ Borehole 2 } & Section 1 & 64.61 & 71.28 & 77.96 & 84.60 & 91.28 & 97.95 \\
\cline { 2 - 8 } & Section 2 & 104.63 & 111.27 & 117.95 & 124.62 & 131.30 & 137.94 \\
\cline { 2 - 8 } & Section 3 & 144.62 & 151.29 & 157.94 & 164.61 & 171.29 & 177.96 \\
\hline \multirow{3}{*}{ Borehole 3 3} & Section 1 & 69.42 & 76.10 & 82.77 & 89.42 & 96.09 & 102.77 \\
\cline { 2 - 8 } & Section 2 & 109.44 & 116.09 & 122.76 & 129.44 & 136.11 & 142.76 \\
\cline { 2 - 8 } & Section 3 & 149.43 & 156.11 & 162.75 & 169.43 & 176.10 & 182.78 \\
\hline
\end{tabular}

*Vertical distance above the coal seam, $\mathrm{m}$

In order to validate the subsurface subsidence prediction model, the borehole extensometer monitoring results were analyzed in comparison with the predicting results. Due to some installation problems and adverse strata movements, the section 1 of borehole 1 and section 1, 2 of borehole 2 were damaged, and the results were unreliable. The comparison of the final subsurface subsidence prediction results and borehole extensometer monitoring results were shown in Table 3.4. It shows that the final surface subsidence prediction for the three borehole locations matches the borehole extensometer monitoring results pretty well. 
The measured subsurface subsidence and surface subsidence at the location of borehole 3 is plotted against the distance that the longwall face has passed the extensometer boreholes in Fig. 3.14. The subsidence process at all the subsurface and surface points develops when the face is about $27.4 \mathrm{~m}$ (90 ft) inby the borehole location. Then the subsidence process accelerated before the longwall face reached a distance between 12.2 and $18.3 \mathrm{~m} \mathrm{(40} \mathrm{and} 60 \mathrm{ft}$ ) outby the borehole locations. Figure 3.14 also shows that the lower level strata subside earlier and more than the upper strata.

Table 3.4 Comparison of subsurface subsidence prediction and field monitoring results

\begin{tabular}{|c|c|c|c|c|c|c|c|c|c|}
\hline \multirow{2}{*}{ Anchor } & \multicolumn{3}{|c|}{ Borehole 1 } & \multicolumn{3}{c|}{ Borehole 2 } & \multicolumn{3}{c|}{ Borehole 3 } \\
\cline { 2 - 11 } & Field & Prediction & Error & Field & Prediction & Error & Field & Prediction & Error \\
\hline 18 & 0.122 & 0.110 & $9.4 \%$ & 1.402 & 1.588 & $-13.3 \%$ & 1.560 & 1.597 & $-2.4 \%$ \\
\hline 17 & 0.122 & 0.115 & $5.3 \%$ & 1.547 & 1.610 & $-4.1 \%$ & 1.613 & 1.617 & $-0.3 \%$ \\
\hline 16 & 0.122 & 0.121 & $1.1 \%$ & 1.547 & 1.630 & $-5.4 \%$ & 1.626 & 1.636 & $-0.6 \%$ \\
\hline 15 & 0.122 & 0.126 & $-3.7 \%$ & 1.547 & 1.649 & $-6.6 \%$ & 1.689 & 1.654 & $2.1 \%$ \\
\hline 14 & 0.147 & 0.133 & $9.5 \%$ & 1.547 & 1.666 & $-7.7 \%$ & 1.689 & 1.670 & $1.1 \%$ \\
\hline 13 & 0.150 & 0.141 & $6.0 \%$ & 1.547 & 1.683 & $-8.8 \%$ & 1.689 & 1.685 & $0.2 \%$ \\
\hline 12 & 0.151 & 0.149 & $1.4 \%$ & N/A & 1.698 & N/A & 1.709 & 1.700 & $0.5 \%$ \\
\hline 11 & 0.154 & 0.160 & $-3.9 \%$ & N/A & 1.713 & N/A & 1.735 & 1.715 & $1.2 \%$ \\
\hline 10 & 0.165 & 0.171 & $-3.8 \%$ & N/A & 1.727 & N/A & 1.735 & 1.728 & $0.4 \%$ \\
\hline 9 & 0.165 & 0.177 & $-7.4 \%$ & N/A & 1.741 & N/A & 1.735 & 1.742 & $-0.4 \%$ \\
\hline 8 & 0.165 & 0.168 & $-1.7 \%$ & N/A & 1.756 & N/A & 1.735 & 1.756 & $-1.2 \%$ \\
\hline 7 & 0.165 & 0.183 & $-10.6 \%$ & N/A & 1.769 & N/A & 1.758 & 1.769 & $-0.7 \%$ \\
\hline 6 & N/A & 0.202 & N/A & N/A & 1.783 & N/A & 1.758 & 1.783 & $-1.4 \%$ \\
\hline 5 & N/A & 0.224 & N/A & N/A & 1.797 & N/A & 1.821 & 1.797 & $1.3 \%$ \\
\hline 4 & N/A & 0.252 & N/A & N/A & 1.812 & N/A & 1.821 & 1.812 & $0.5 \%$ \\
\hline 3 & N/A & 0.286 & N/A & N/A & 1.828 & N/A & 1.847 & 1.828 & $1.0 \%$ \\
\hline 2 & N/A & 0.325 & N/A & N/A & 1.844 & N/A & 1.847 & 1.844 & $0.1 \%$ \\
\hline 1 & N/A & 0.372 & N/A & N/A & 1.861 & N/A & 1.847 & 1.861 & $-0.8 \%$ \\
\hline
\end{tabular}

\subsubsection{Sensitivity Analysis of Layer Thickness}

As discussed in the previous sections that the subsurface subsidence parameters are determined by hard rock percentage of the layer and the layer thickness. Hard rock percentage is the percentage of hard rock (i.e. sandstone and limestone) in the layer which can be easily calculated based on the geological column. The layer thickness has the same or even more influence on the subsidence parameters as well as the computing time of the model. In order to improve the accuracy of the prediction, the sensitivity of the layer thickness should be discussed. 


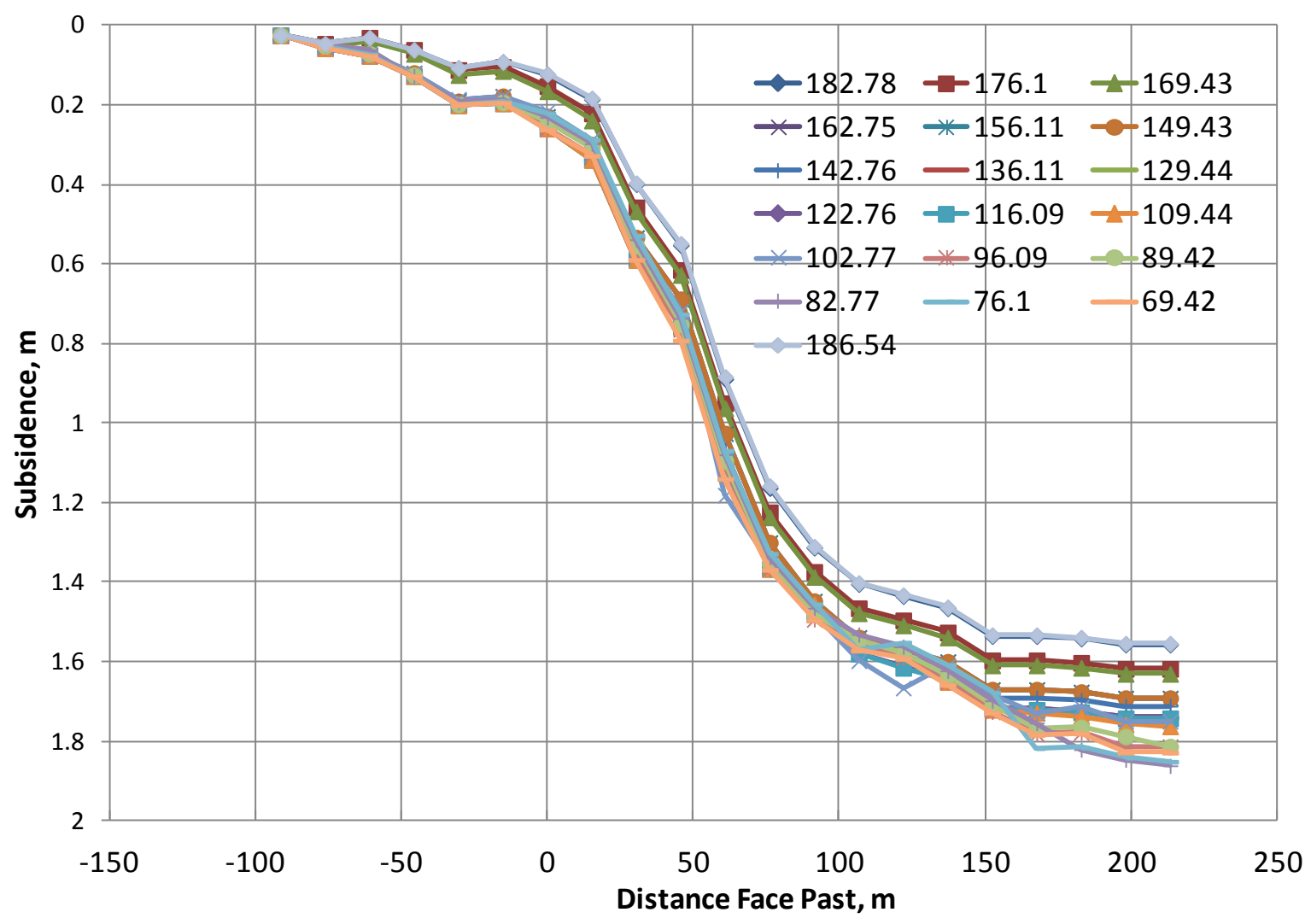

Figure 3.14 Subsidence development curves at borehole 3

Smaller layer thickness yields higher accuracy of the prediction, but requires more computing time. For example, if this model is applied in the analysis of the multi-seam mining interactions with thin interburden thickness, the layer thickness for subsurface subsidence prediction should be, at least, less than the interburden thickness. If the layer thickness is too small, the layers will be high and the computing time of the subsurface subsidence prediction will be increased considerably. Larger layer thickness means the layer will be harder to deflect. With the same amount of maximum deflection of a layer, the layer with larger thickness will have larger radius of major influence.

\subsection{Summaries}

An enhanced subsurface subsidence prediction model considering overburden stratifications is proposed. The model employs the influence function method for subsurface subsidence prediction layer by layer from the immediate roof to the ground surface. The final subsurface subsidence parameters (i.e., subsidence factor, offset distance of inflection point, radius of major influence) are determined by empirical formulae based on collected subsurface subsidence measurements. A case study is conducted for the verification of the model. The 
predicted subsurface movements and deformations agree well with the general observation over longwall mining operations. The influence of the thick hard rock layers on the subsurface subsidence can be easily identified from the prediction results.

The model can help us to gain a better understanding about the distributions of subsurface movements and deformation in the overburden strata above a longwall panel. Such understanding will help guiding the designs of gob well methane recovery, studies of mining effects on surface and subsurface hydrologic systems, and assessment of mine structural stability in the overburden strata. Efforts are continuing to improve the accuracy of the final subsurface subsidence prediction model. 


\section{CHAPTER 4 PRE-DRIVEN LONGWALL RECOVERY ROOM}

Longwall face move when a panel is completed is critical for the longwall mining operation. Severe ground conditions will be met when moving the longwall equipment from the recovery line of one panel to the setup line of the new panel. This is the non-production period that all coal mine companies want to minimize. The pre-driven longwall recovery room method is proposed for this purpose. The practices show very good benefits from this method. However, some weighting failures and roof falls of the pre-driven longwall recovery rooms did happen in some coal mines (Oyler et al., 2001). A good understanding of the mechanism of the loading, roof deflection and support interaction will be beneficial for the design and practice of pre-driven longwall recovery rooms.

\subsection{Introduction}

\subsubsection{Pre-driven Longwall Recovery Room}

The pre-driven longwall recovery room is a method that employed to facilitate the longwall face equipments move, which has the potential to speed up the non-productive longwall face move operation. Compared to the traditional method, the required supports for the recovery room are installed prior to the adverse effects of the abutment pressure in front of the longwall face. The pre-driven longwall recovery room method can save up to one to two weeks production time depending on the ground conditions (Thomas, 2008).

As shown in Fig. 4.1, the pre-driven recovery rooms are located on the recovery end of the panel and they are normally supported by some forms of standing supports in combination with roof /rib bolts.

However, the design of the pre-driven recovery room is a complicated process because the stress distribution in the barrier pillar, standing supports, fender pillar and the immediate roof changes as the longwall face approaches the pre-driven recovery room. The understanding of the dynamic loading and the support interaction is essential for the ground control design of the predriven longwall recovery room (Qiu and Luo, 2012). The currently available techniques of numerical analysis (e.g. large scale finite element models) allow a rigorous solution of this 
problem, minimizing the number of necessary approximations, which allow a detailed analysis to be performed, including essential material and geometric nonlinearities (Zhang et al., 2006).

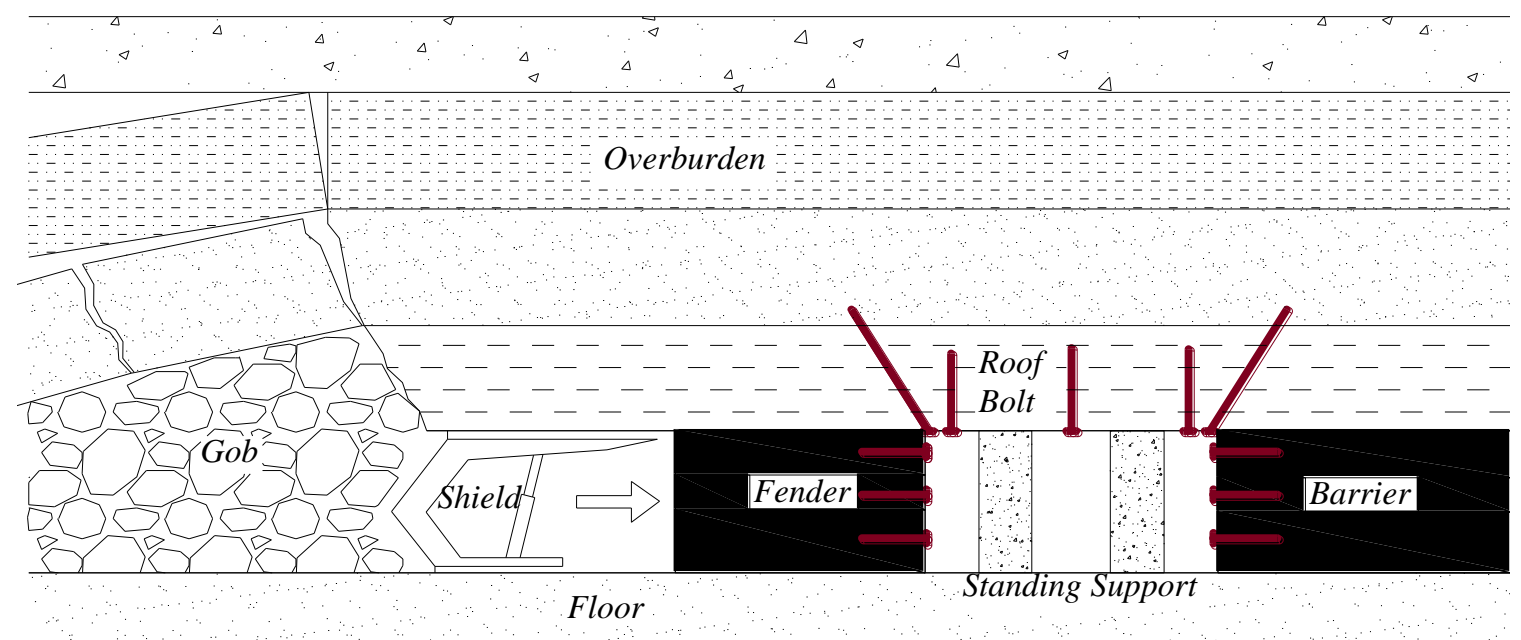

Figure 4.1 Schematic of Pre-driven Recovery Room for Longwall Mining Operation

\subsubsection{Support Design}

Pre-driven longwall recovery room has been used for efficient longwall recovery under weak roof conditions. The success of this plan is largely depending on the stability of the predriven recovery room, which is normally supported by standing supports and supplementary roof and/or rib bolts. Insufficient design of the combined support system can result in premature failure of the fender pillar and standing supports, as well as excessive closure of the recovery room. These conditions would make the recovery of the longwall equipment difficult. On the other hand, excessive design can result in significantly increased labor and costs.

The design of the pre-driven recovery room is not an easy task because the stress distribution in the barrier pillar, standing supports, fender pillar and the immediate roof is changing as the longwall face approaches the pre-driven recovery room. An analytical approach is proposed to determine the stress distribution in the barrier pillars, fender pillars, standing supports and immediate roof of the recovery room based on the fracture mechanics approach. This approach can simulate the impact of approaching longwall face on the stability of the predriven recovery room and calculate the overall stability factor of the combined support system. In the mathematical model, the recovery room and longwall gobs are treated as Mode I cracks in an infinite plate. The resistance of gob material, pillar yield zones and load capacity of the standing supports are considered as the distributed forces on the surface of the cracks. 
The movement of the immediate roof over the pre-driven longwall recovery room is essential for the support design. It was found that the movement of the immediate roof had some relationship with the surface subsidence. Heasley and Saperstein (1987) proposed to use an inverse application of the traditional influence-function surface subsidence prediction technique to analyze some of the complicated, expensive, and difficult-to-measure movements of the intermediate roof strata in a longwall. The subsurface subsidence prediction model provides a better way of connecting the immediate roof movement with the surface subsidence. Therefore, a great potential exists for the application of subsurface subsidence models in analyzing some of the ground control problems related to immediate roof movement.

Based on the developed mathematical model, a stand-alone computer program has been developed to facilitate the required computations. The parameters such as overburden depth, recovery room width, mining height, shield and standing support capacities are incorporated into this program to access the feasibilities of pre-driven recovery room designs.

\subsection{Stress Analysis and Load Transferring}

\subsubsection{FMA for Stress Analysis}

As compared to overburden strata, an underground mine opening is relatively small, and it can be treated as a thin crack in a large rock mass. According to Kramer and Luo (1998), the FMA approach provides a much simpler alternative to the numerical analysis methods (e.g., finite element method) in targeted stress analysis problems in underground coal mines. It also provides useful and accurate tools for users with limited resources in expertise, computer hardware and software.

The fundamental Westergaard and the Green functions from fracture mechanics are applied for stress analysis. A particular form of the Westergaard function ( $\phi=0$ and $y=0)$ in Eq. 4.1 is used to express the vertical stress distribution adjacent to a thin elliptical crack in an infinite plate (Fig. 4.2), a mode I crack problem. The origin of the coordinate system is located at the center of the crack while $\sigma_{\mathrm{y}}(x)$ is the vertical stress at a given point in the coal seam adjacent to the mine opening.

$$
\sigma_{y}(x)=\frac{\sigma_{i} x}{\sqrt{x^{2}-a_{0}^{2}}} \quad|x| \geq a_{0}
$$

where: 


$$
\begin{array}{ll}
a_{0} & =\text { half width of the crack. } \\
\sigma_{\mathrm{i}} & =\text { in-situ vertical stress, } \sigma_{i}=h \gamma . \\
x & =\text { distance from the center of the crack. }
\end{array}
$$

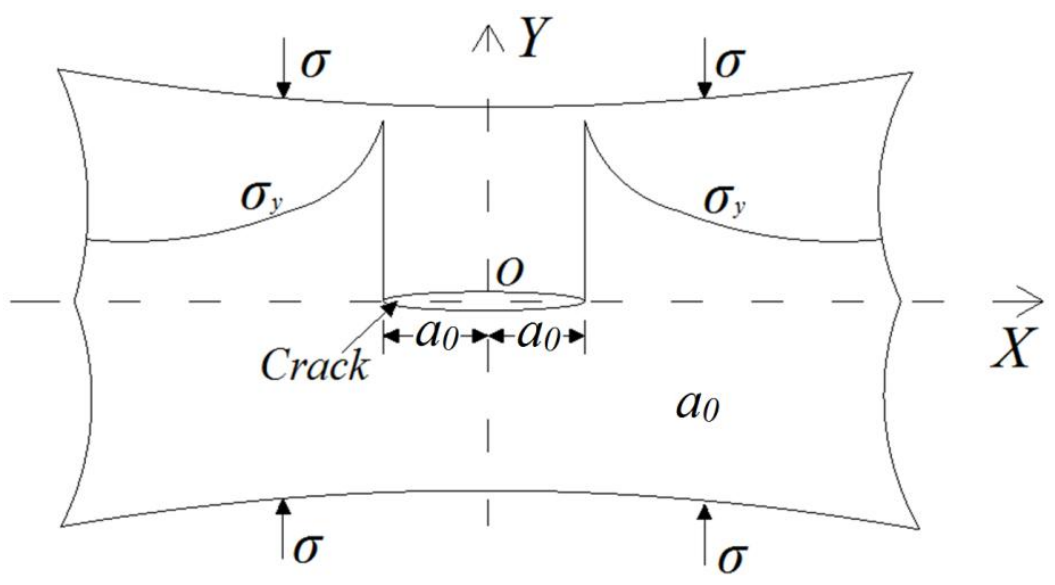

Figure 4.2 Stress distributions adjacent to a crack of width of $2 \mathrm{a} 0$ within a uniform in-situ stress field

The Green function is used as another basic function that allows the determination of the stress intensity factors at the tips of the crack caused by a wedge force $P$ that pushes against the crack surface (Fig. 4.3). The stress intensity factors at the tip points A and B of a crack are determined by the following two equations:

$$
\begin{aligned}
& K_{A}=\frac{P}{\sqrt{\pi a_{0}}} \sqrt{\frac{a_{0}+x}{a_{0}-x}} \\
& K_{B}=\frac{P}{\sqrt{\pi a_{0}}} \sqrt{\frac{a_{0}-x}{a_{0}+x}}
\end{aligned}
$$

where:

$P \quad=$ point force per unit plate thickness.

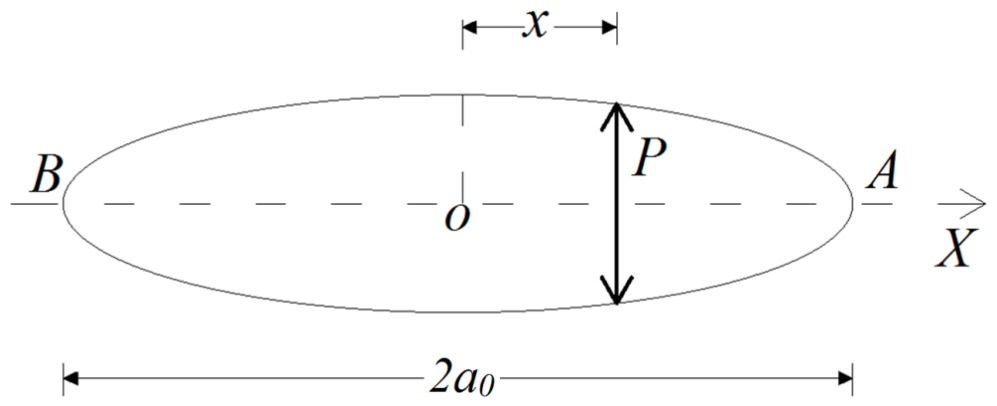

Figure 4.3 Crack with wedge force $\mathrm{P}$ located at $\mathrm{x}$ from its center 
To use a pre-driven system, an extra entry (i.e., recovery room) is driven at the location of the predetermined recovery line. The recovery room is heavily supported with primary, standing and supplemental roof and rib bolts. The longwall face is then able to extract the remaining fender pillar at full speed before it moves into the recovery room. Figure 4.1 shows a cross-sectional view of a typical pre-driven recovery room system.

\subsubsection{Gob Material Support}

To mathematically represent the load and stress distributions in the system, the supporting force to the overburden by the gob material is assumed to be linearly distributed that equals to zero at the face and to the full overburden load at a sufficient distance behind the face. The stress intensity factor due to the distributed support force of the gob material behind the shield can be determined as shown in Equation 4.4 (Kramer et al., 1998).

$$
K_{g o b}=\frac{P_{0}}{2} \sqrt{\pi a_{g}}
$$

where:

$P_{o} \quad=$ supporting force at the origin of coordinate system, $P_{o}=\frac{\gamma h}{2}$.

$a_{g} \quad=$ one half of the distance between longwall face and the point where the gob material begins to take the full overburden load along the longitudinal center line. According to field studies of the longwall dynamic subsidence process, a surface point normally reaches its quasi-final subsidence at a distance about 0.8 to 0.9 times of the overburden depth behind the longwall face. Therefore, a value of $a_{g}=0.4 h$ would be preferred for the predicted stress.

\subsubsection{Yield Pillar Analysis}

A yield zone will be formed near the pillar rib and its depth depends on many factors. The yield zone retains a residual strength that offers confinement to the core of the pillar. The distribution of the residual strength can be estimated by the following empirical formula proposed by Karabin and Evanto (1994).

$$
S_{R}(x)=[0.1385 \cdot \ln (x)+0.413] \cdot S_{p}(x)
$$

Where:

$$
S_{R}(x)=\text { residual stress level. }
$$


$x \quad=$ distance from pillar rib.

$S_{P}(x)=$ coal peak strength determined by empirical Mark-Iannacchione formula (1992).

$$
S_{P}(x)=S_{i} \cdot\left(0.78+1.74 \frac{d_{y}}{H_{p}}\right)
$$

$S_{i} \quad=$ in-situ coal strength.

$d_{y} \quad=$ depth of the yield zone.

$H_{p} \quad=$ height of the pillar.

The stress intensity factor caused by the residual strength of the yield zone can be determined by the following equation and the depth of the yield zone $(d)$ can be determined through an iterative process.

$$
K_{A}=\int_{-\frac{d}{2}}^{\frac{d}{2}}\left[\frac{S_{R}(x)}{\sqrt{\frac{\pi d}{2}}} \sqrt[\sqrt{\frac{d}{2}+r}]{\frac{d}{2}-r}\right] d r
$$

If the total width of the yield zones on both sides of the fender pillar is equal to or greater than the actual width of the pillar, the fender pillar is fully yielded. In this situation, the two openings adjacent to the yielded pillar and the pillar itself are combined into one single opening with the resistance of the yielded pillar being treated in the similar way as the supporting force of the gob material. The distribution of the supporting force provided by the yielded pillar is symmetrical to its center with each half being expressed by Eq. 4.5 .

\subsubsection{Stress Distribution}

Without considering the yielding characteristics of the coal pillar, the elastic solution of the vertical stress at a point in a pillar can be determined by superimposing the vertical stresses caused by different mine openings (i.e., entries and longwall gobs). The three distinctive mining stages in terms of the stress changes that a pre-driven longwall recovery room system will experience are: (1) normal production before full yield of the fender pillar, (2) normal production after the full yield of the fender pillar, (3) the standing supports in the recovery room are gone and the immediate roof on the face side rests on the longwall powered supports.

In the first mining stage or the normal mining stage, the vertical stress at a given point in the pillar can be determined by the following equation. The terms of $\left(\sigma_{y}\right)_{G o b}$ and $\left(\sigma_{y}\right)_{\text {Room }}$ are the 
vertical stresses caused by the presence of the longwall gob and the pre-driven recovery room, respectively.

$$
\sigma_{y}=\left(\sigma_{y}\right)_{G o b}+\left(\sigma_{y}\right)_{\text {Room }}
$$

As the longwall face moves toward the pre-driven recovery room, the fender pillar becomes narrower. After the fender pillar is fully yielded, the longwall gob and the pre-driven recovery room are combined into one single opening and the vertical stress at a given point in the barrier pillar can be determined as,

$$
\sigma_{y}=\left(\sigma_{y}\right)_{G o b}
$$

\subsection{Dynamic Loading Process Simulation}

\subsubsection{Roof Deflection Simulation}

It is a dynamic loading process over the pre-driven longwall recovery room when the longwall face is advancing towards and mining into it. As the width of the fender pillar decreases, the load on it increases and the fender pillar converges. Subsequently, the immediate roof above the fender pillar sags the same amount as the pillar convergence. Generally, the barrier pillar is large enough to withstand the abutment load and resist any significant amount of convergence. Under this condition, the immediate mine roof above the longwall shields, fender pillar, predriven recovery room and barrier pillar deflect vertically like a dynamic subsidence development curve along the mining direction as shown in Fig. 4.4.

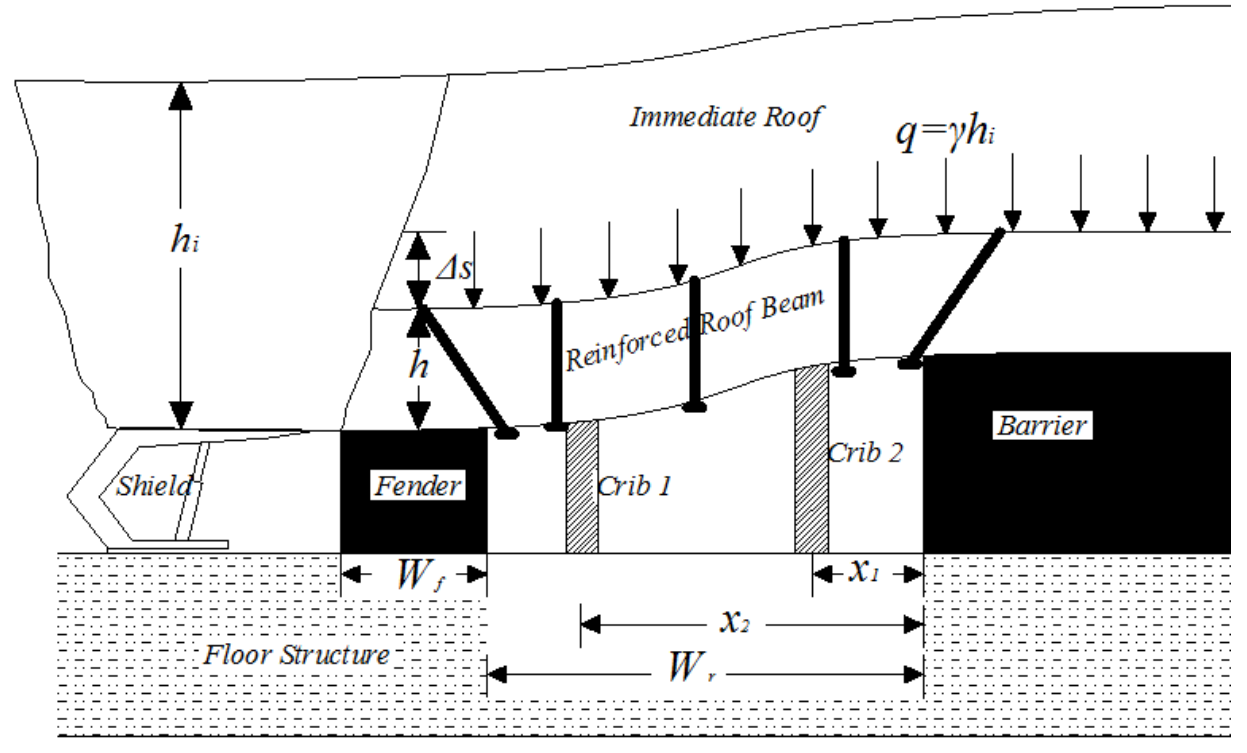

Figure 4.4 Mechanics of roof behavior and manifestation of shield and fender pillar loading 
For demonstrating that the deflection of the immediate roof can be represented by a dynamic subsidence development curve, the measured roof-to-floor convergence in a pre-driven recovery room at different times as the longwall face moves toward it (Bauer et al., 1988) is shown in Fig. 4.5. The average overburden depth and the mining height in this case were 173.0 $\mathrm{m}(567.5 \mathrm{ft})$ and $1.68 \mathrm{~m}(5.5 \mathrm{ft})$, respectively. The width of the recovery room is $5.5 \mathrm{~m}(18 \mathrm{ft})$.

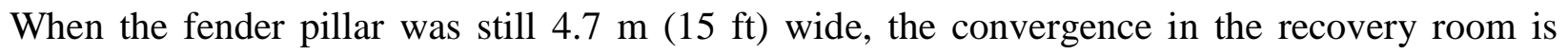
nearly a uniform $20 \mathrm{~mm}$ ( 0.7 inches). The subsequent profiles show non-uniform roof sagging similar to that in a residual dynamic subsidence process (Luo and Peng, 1991). When the longwall face moved into the recovery room, the convergence on the fender pillar side was about $155 \mathrm{~mm}$ (6.1 inches) while that at the edge of the barrier pillar was about $90 \mathrm{~mm}$ ( 3.5 inches). To simulate the dynamic loading process of the pre-driven longwall recovery room, the dynamic subsidence development curve can be employed to simulate the roof line deflection.

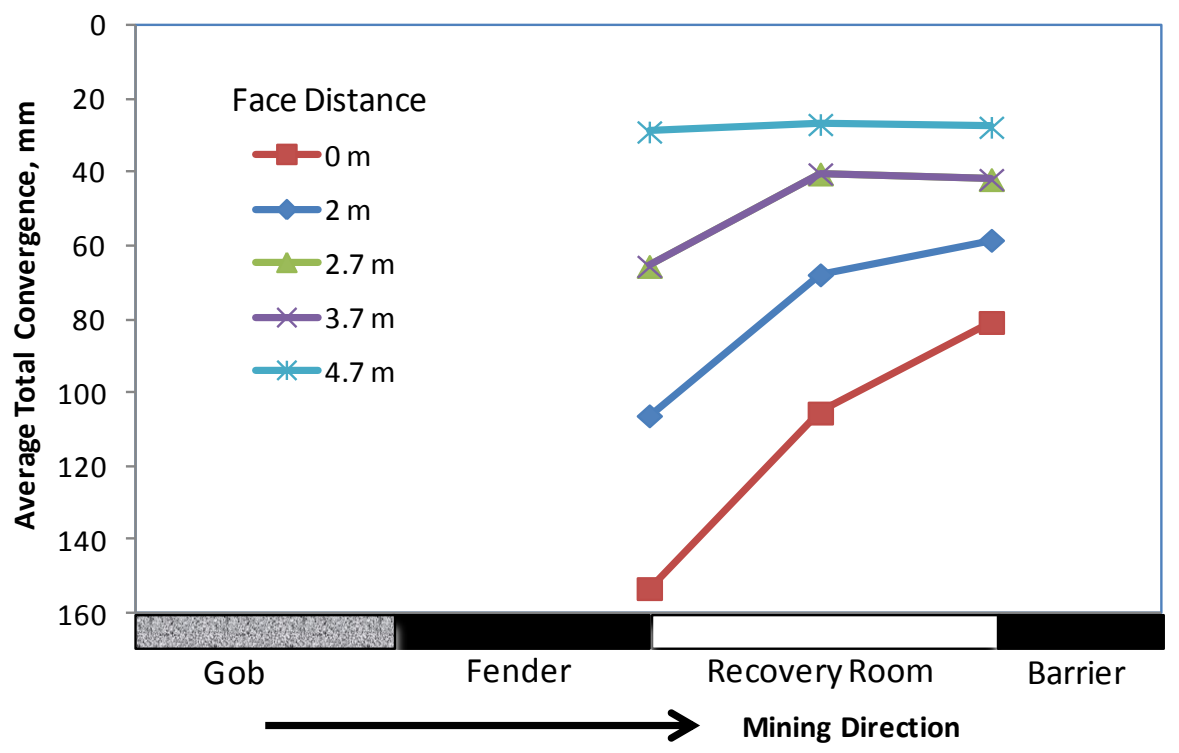

Figure 4.5 Measured roof-to-floor convergence on pre-driven recovery room in a US mine

In order to mathematically represent the roof deflection, the coordinate system $\mathrm{O}^{\prime}-\mathrm{X}^{\prime}$ is shown in Fig. 4.6. Based on the dynamic subsidence prediction theory (Luo and Peng, 1991), the sag of the immediate roof line at a given point over the pre-driven recovery room and fender pillar can be determined using Eq. 4.10 as the shaded area in Fig. 4.6.

$$
S_{d}\left(x_{p}\right)=\frac{1}{2} \Delta s+\sqrt{\frac{2}{\pi}} \cdot \frac{\Delta s}{l+l_{1}} \cdot \int_{x_{p}}^{-l} e^{-2\left(\frac{x^{\prime}+l}{l+l_{1}}\right)^{2}} d x^{\prime}
$$


In these equations, $h$ is the thickness of the bolted horizon in the immediate roof as shown in Fig. 4.4 and $R$ can be defined to be one third of $h$ as a normal practice in mine subsidence prediction. Term $l$ is the offset of the dynamic inflection point, $l_{l}$ is the offset of subsidence initiation point where detectable roof deflection is initiated. The dynamic subsidence process occurs in a distance of $2\left(l+l_{1}\right)$. In this model, parameter $l_{l}$ is assumed to be the depth of yield zone in barrier pillar beside the recovery room. The parameter, $l$, can be estimated by Eq. 4.11 assuming that the dynamic deflection process of the immediate roof ends at the center of the fender pillar before it fully yields. In this equation, $W_{f}$ is the width of the fender pillar and $W_{r}$ is the width of the recovery room. It should be noted as the fender pillar becomes narrower, $l$ decreases (Eq. 4.11) resulting in a higher maximum tensile strain on the roof.

$$
l=\frac{1}{2}\left(\frac{W_{f}}{2}+W_{r}-l_{1}\right)
$$

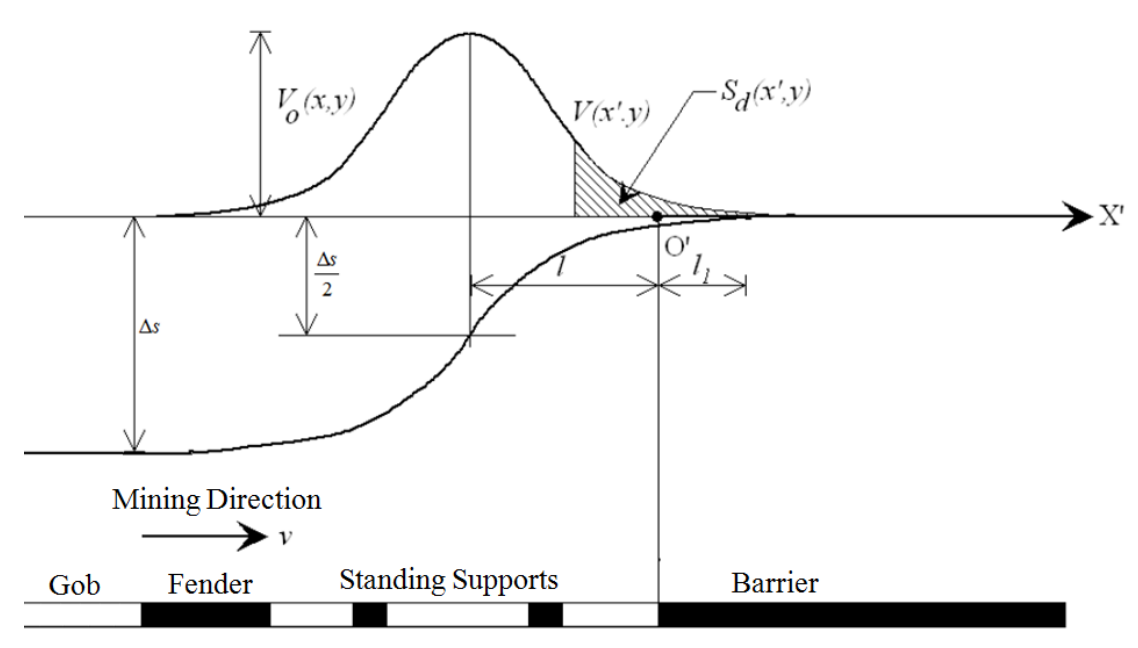

Figure 4.6 Global and dynamic coordinate system for roof floor convergence prediction

The most important parameter in the above equations is the maximum convergence of the immediate roof $(\Delta s)$. Its amount depends on the overburden load, the strengths of the longwall supports, the fender pillar, the standing supports and the barrier pillar. Before the total yield of the fender pillar, the fender pillar should be stiffer than the longwall powered supports. Thus $\Delta s$ equals to the amount of the convergence of the fender pillar determined by Eqs. 4.12 and 4.13.

However, after the fender pillar is totally yielded, the fender pillar can only take a part of the abutment load with its residual strength. The other abutment load is transferred to the longwall shields and the standing supports. Under this condition, the determination of $\Delta s$ should consider the stiffness of the powered supports, residual strength of the yielded fender pillar and 
load-displacement characteristics of the standing supports through an iterative process. The stiffness of the longwall powered supports and the performance curve of the standing support are incorporated in the determination of the recovery room support system design. A powered support is assigned to carry the dead load of the immediate rood as shown in Fig. 4.4.

With the stress distributions in the fender pillar determined by the FMA method, the average vertical stress in the fender pillar can be obtained using Eq. 4.12 and the total convergence of the fender pillar by Eq. 4.13.

$$
\begin{aligned}
& \sigma_{\text {ave }}=\frac{\int_{0}^{W_{f}} \sigma_{y}(x) d x}{W_{f}} \\
& \Delta s=\frac{\sigma_{\text {ave }}}{E} \cdot m
\end{aligned}
$$

Using Eq. 4.10, the roof to floor convergences at the locations of the standing supports, also the vertical displacements of the supports, can be determined as $S_{d}\left(-x_{i}\right)$. Based on the loaddisplacement performance curves of various kinds of supplemental supports determined by NIOSH laboratory tests (Barczak, 2001), the loads on the standing supports can be determined. The determined support loads are in-turn used in the determination of the vertical stress distribution using the FMA method (Eqs. 4.2 and 4.3). The new vertical stress distribution is then used to determine the roof convergence and the load of the standing supports in the next iteration. At the time the iteration converges, the stress distribution, roof convergence, support loads and the roof strain are finally determined. By choosing different performance curves in the NIOSH standing support database in the design process, a suitable standing support system could be selected to ensure that the recovery room will not fail prematurely.

\subsubsection{Powered Support Simulation}

A realistic simulation of the complex loading behavior of powered roof support is very important. The powered roof support modeled in this model comprises of a canopy, a base and four support members interacting between the canopy and base against roof and floor at the coal face. The stiffness of powered roof support is estimated using Eq. 4.14 considering the bulk modulus of water-mineral oil mixture as $1.94 \mathrm{GPa}$ (Singh and Singh, 2009).

$$
k_{P}=n_{s} \frac{k_{w} A_{p}}{h_{f}}
$$


Where:

$K_{P} \quad=$ powered support stiffness.

$n_{s} \quad=$ number of legs working in parallel in between canopy and base of the support.

$A_{p} \quad=$ area of cross-section of the leg piston.

$h_{f} \quad=$ fluid column height in the hydraulic leg.

$k_{w} \quad=$ bulk modulus of the water-oil mixture.

\subsection{Stability Analysis and Evaluation}

\subsubsection{Stability Analysis}

The past case studies by Oyler et al. (2001) on the usage of pre-driven recovery rooms suggest two types of pre-driven recovery room failures mechanism. The first type is the roof fall failure at the longwall face as the fender pillar narrows. This type of roof fall failure is less likely when intensive roof reinforcement (bolts, cables and trusses) is employed together with highercapacity shields. The second type is overburden weighting failure caused by the inability of the roof to bridge the recovery room and face area due to the face supports, fender pillar and the standing supports to carry the excessive loads from the main roof during a periodic weighting event. This type of failure occurs when the immediate roof is weak and insufficient standing supports are used. Therefore, providing sufficient supports to the immediate roof is the key to avoid failure of the pre-driven recovery room.

The maximum strain on the roof line can be employed to evaluate the possibility of the first type of instability (roof fall). Based on the subsurface dynamic subsidence prediction models, the strain distribution along the roof line is expressed by Eq. 4.15. The maximum tensile strain along the roof line and the occurring location is determined by Eq. 4.16.

$$
\begin{aligned}
& \varepsilon_{d}\left(x_{p}\right)=-\sqrt{\frac{32}{\pi}} \cdot \frac{R^{2}}{h} \cdot \frac{\Delta s\left(x_{p}+l\right)}{\left(l+l_{1}\right)^{3}} \cdot e^{-2\left(\frac{x_{p}+l}{l+l_{1}}\right)^{2}} \\
& \varepsilon_{d \max }=0.968 \cdot \frac{\Delta s}{\left(l+l_{1}\right)^{2}} \cdot \frac{R^{2}}{h} \quad \text { at } \quad x=-\frac{3 l+l_{1}}{2}
\end{aligned}
$$

If the maximum roof strain, most importantly the tensile strain, is larger than the maximum critical strain for tensile failure of the roof rock (e.g., $2 \times 10^{-3} \mathrm{~m} / \mathrm{m}$ for hard shale or soft sandstone), vertical crack could start to form in the immediate roof. As this occurs, difficult working condition may be encountered in the recovery room. 


\subsubsection{Support Intensity Evaluation}

As for the second type of instability (overburden weighting failure), the Ground Support Rating (GRSUP) system can be used.

$$
G R S U P=\frac{L_{b} N_{b} C_{b}}{14.6 S_{b} w}+\frac{L_{b} N_{t} C_{t}}{14.6 S_{t} w} \quad k N / m
$$

Where:

$L_{b} \quad=$ the thickness of the bolted horizon defined by roof bolts.

$N_{b} \quad=$ the average number of roof-bolts in each bolt row.

$C_{b} \quad=$ the ultimate tensile strength of roof-bolts.

$S_{b} \quad=$ the spacing between roof-bolt rows.

$N_{t} \quad=$ the average number of cables in each cable row.

$C_{t} \quad=$ the ultimate tensile strength of cables.

$S_{t} \quad=$ the spacing between cable rows.

$w \quad=$ the entry width.

The constant 14.6 is a constant that is needed to convert from the original NIOSH equation, which was in Imperial units, to SI units; this will allow for compatibility with all USA data using the standard NIOSH equation (Lawrence, 2009).

\subsection{Case Demonstration}

The developed program is demonstrated with a case using pre-driven longwall recovery room in the Pittsburgh seam. This case is similar to a published case by Zhang et al. (2006).

\subsubsection{Case Mine Conditions}

In the case study mine, the overburden depth, mining height and the thickness of the immediate roof are 183.0, 2.4, $10.1 \mathrm{~m}(600,8$ and $33 \mathrm{ft})$, respectively. The recovery room width is $4.9 \mathrm{~m}(16 \mathrm{ft})$. The in-situ coal strength $6.2 \mathrm{MPa}(900 \mathrm{psi})$ is used. The primary supports are roof bolts and cable bolts, and the thickness of bolted horizon is $2.4 \mathrm{~m}(8 \mathrm{ft})$ thick. In the published case, three rows of standing supports were used. In this demonstration case, two rows of pumpable concrete cribs spaced $3.0 \mathrm{~m}(10 \mathrm{ft})$ apart along the face direction are used as standing supports for practical consideration. The load-displacement performance curves of the selected standing support in two sizes (61 and $76 \mathrm{~cm}$ or 24 and 30 inches in diameter) are shown in Fig. 4.7 (NIOSH, 2010). Each of the longwall shields has a load capacity of $635 \mathrm{t}$ (700 tons). 


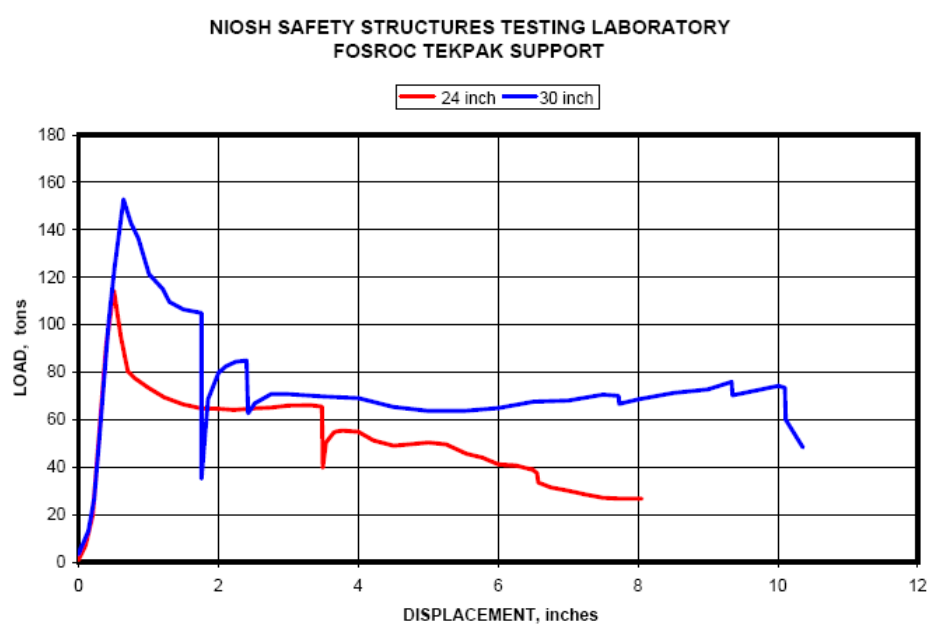

Figure 4.7 NIOSH Safety structures testing laboratory fosroc tekpak support, units in this figure are English units, 1 ton $=907.2 \mathrm{~kg}, 1$ inch $=2.54 \mathrm{~cm}(\mathrm{NIOSH}, 2010)$

\subsubsection{Dynamic Loading Simulation}

The simulation using the developed program starts with a $30.5 \mathrm{~m}(100 \mathrm{ft})$ fender pillar and progresses to the time when the standing supports are removed by the longwall shearer. Figure 4.8 shows the vertical stress profiles for the pre-driven longwall recovery room system as the width of the fender pillar narrows. As the fender pillar becomes narrower, higher loads are transferred to the barrier pillar. When the width of the fender pillar is about $15.2 \mathrm{~m} \mathrm{(50} \mathrm{ft),} \mathrm{the}$ vertical stress on the fender pillar increased significantly. The significant abutment pressure begins to influence the pre-driven recovery room system. When the width of the fender pillar is

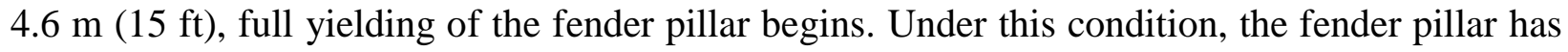
lost most of its capability to support the roof. The roof load begins to transfer to the barrier pillar, standing supports and the longwall shields. An abrupt stress increase will occur on the barrier pillar at this moment signifying that this is the critical time for the control of the pre-driven recovery room.

\subsubsection{Stress Developments}

Figure 4.9 shows the vertical stress variations at different points in the barrier pillar as the longwall face approaches the recovery room. When the longwall face reaches about $30.5 \mathrm{~m}$ (100 $\mathrm{ft}$ ) to the recovery room, the vertical stress at each observation points in the barrier pillar starts to increase gradually. When the fender pillar is less than $4.6 \mathrm{~m}(15 \mathrm{ft})$ wide, the fender pillar fully yields, and the stress on the barrier pillar starts to increase abruptly. Meanwhile, more loads will 
act on the standing supports in the pre-driven recovery room. The convergence of the recovery room will increase, and the load on the standing supports will increase too.

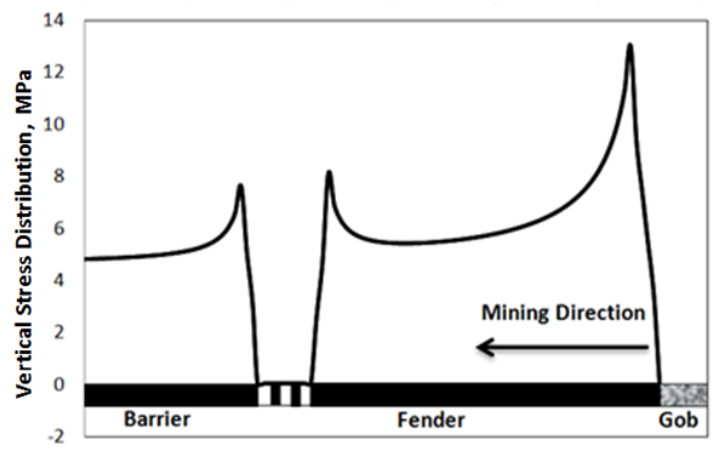

(a) Fender pillar width $30.5 \mathrm{~m}$

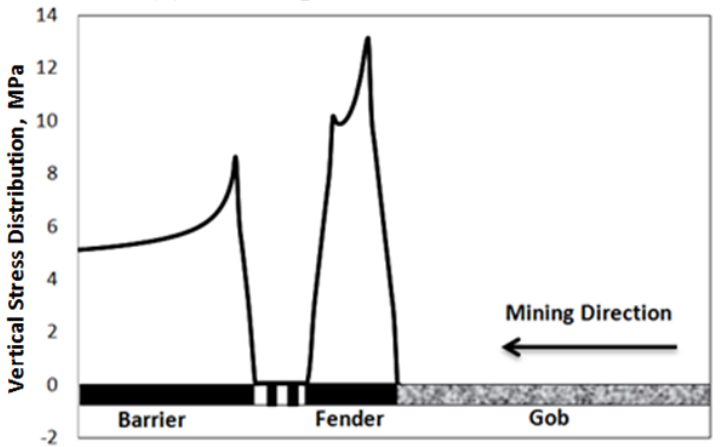

(c) Fender pillar width $7.6 \mathrm{~m}$

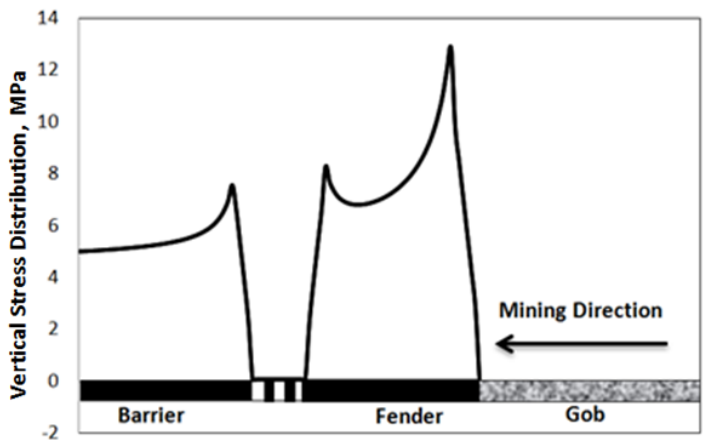

(b) Fender pillar width $15.2 \mathrm{~m}$

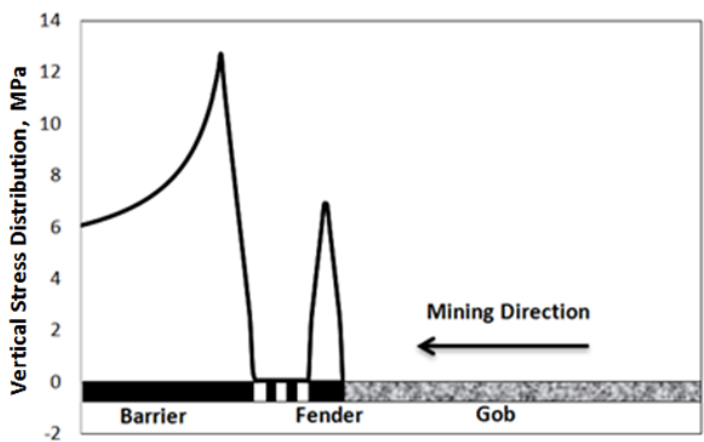

(d) Fender pillar width $3.1 \mathrm{~m}$

Figure 4.8 Vertical stress profiles for the pre-driven longwall recovery room system for various fender pillar width

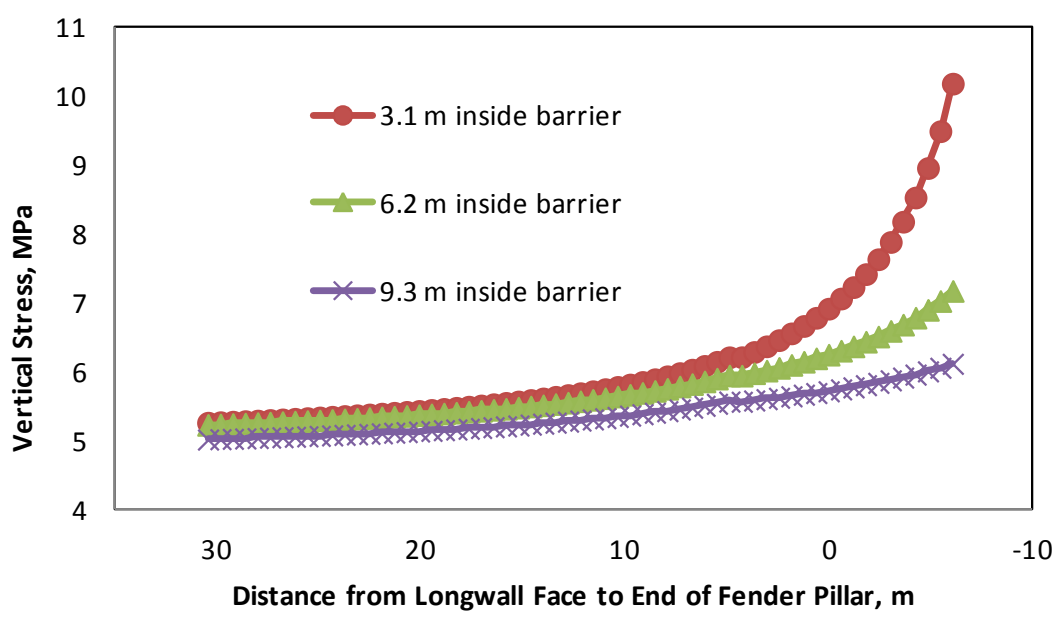

Figure 4.9 Vertical stress variations of the points at different depths in the barrier pillar as longwall face approaches the recovery room

The development curves of the load on the two rows of $76 \mathrm{~cm}$ (30-inch) diameter standing supports as well as the maximum tensile roof strain as the longwall face moves into the pre-driven recovery room are plotted in Fig. 4.10. The maximum loads on the cribs Nos. 1 and 2 
are about $137 \mathrm{t}$ (151 tons). It shows that crib 1 has yielded with a residual strength of $125 \mathrm{t}$ (138 tons) before it is cut by the longwall shearer. Crib 2 has not yielded yet before it is cut. The maximum tensile roof strain is about $1.868 \times 10^{-3} \mathrm{~m} / \mathrm{m}(\mathrm{ft} / \mathrm{ft})$ at the final stage. The tensile strain at such magnitude is unlikely to create fractures in the immediate roof. Therefore, the recovery room should be able to provide a good working condition for the face move operation.

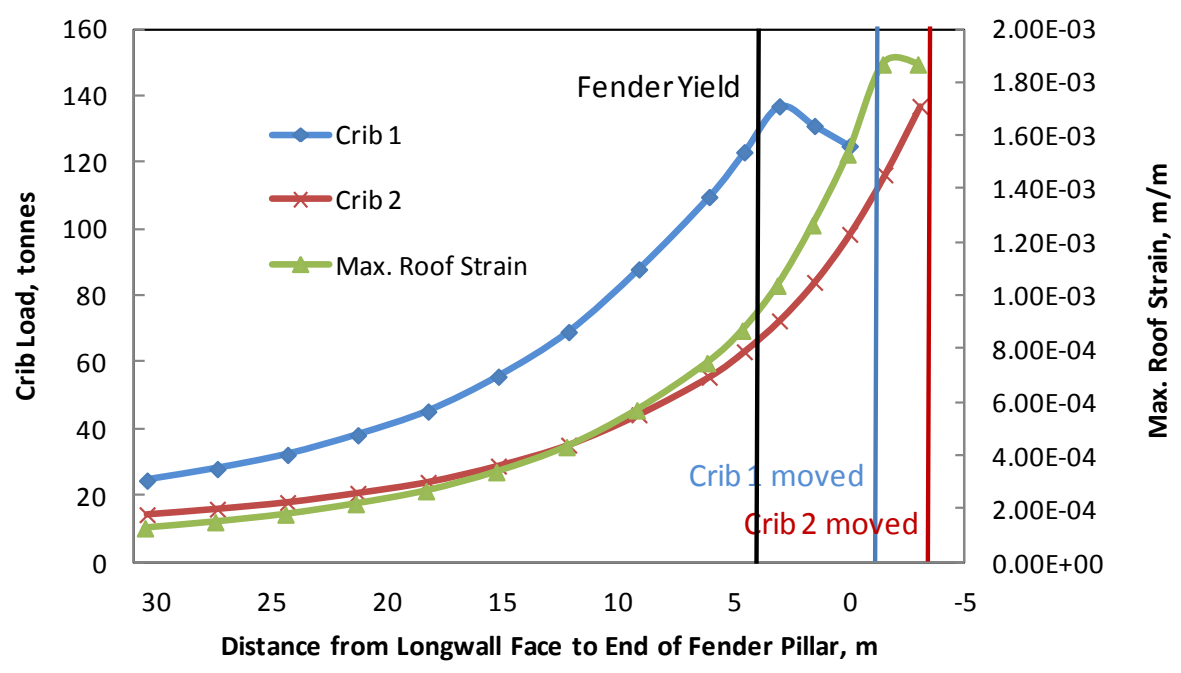

Figure 4.10 Crib load variations as longwall face approaches to recovery room (Crib diameter 76 $\mathrm{cm})$

For demonstration purposes, smaller $61 \mathrm{~cm}$ (24-inch) diameter pumpable concrete cribs are also simulated. The results are plotted in Fig. 4.11. The maximum crib strength of $100 \mathrm{t}$ (110 tons) at crib 1 is reached when the fender pillar is still $7.6 \mathrm{~m}(25 \mathrm{ft})$ wide. The loads on the crib No. 2 reached the maximum when the shearer has cut into the recovery room for a distance of $1.2 \mathrm{~m}(4 \mathrm{ft})$. Then these two sets of cribs show the yielding characteristics afterwards. The residual strengths of the two cribs before being cut are 71 and $83 \mathrm{t}$ (78 and 92 tons), respectively. Figure 4.11 also shows a rapid increase in roof strain when the fender pillar is reduced to less than $4.6 \mathrm{~m}(15 \mathrm{ft})$. At the time the fender pillar is completely cut, the roof strain is about $1.2 \times 10^{-3}$ $\mathrm{m} / \mathrm{m}(\mathrm{ft} / \mathrm{ft})$. The maximum roof strain of $2.177 \times 10^{-3} \mathrm{~m} / \mathrm{m}(\mathrm{ft} / \mathrm{ft})$ is reached when both cribs have been cut. Therefore, vertical fractures may be induced in the immediate roof of the recovery room and difficult conditions may encounter in the face move operations. In comparison to the previous case, the smaller standing supports used in this case are the main contributing factor to the higher strain and undesirable working condition in the pre-driven recovery room. 


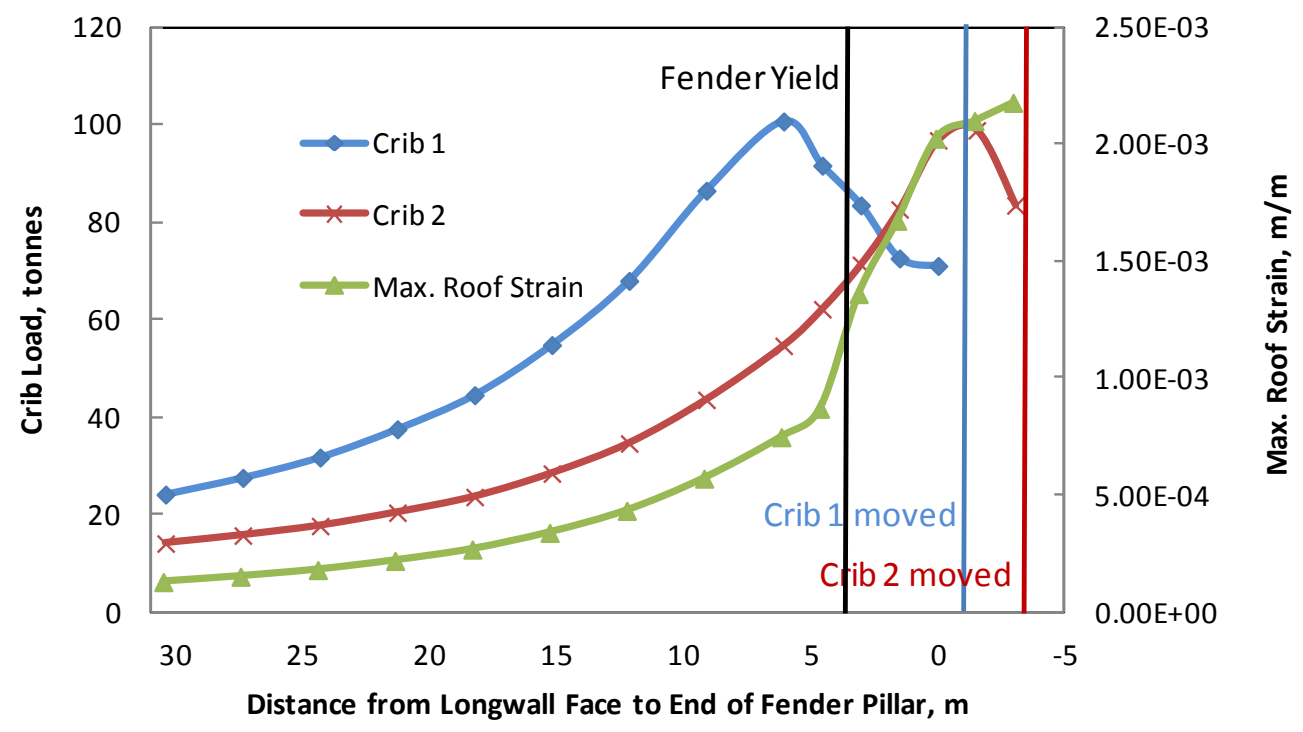

Figure 4.11 Crib load variations as longwall face approaches to recovery room (Crib diameter 61 $\mathrm{cm})$

\subsubsection{Roof Deflection Analysis}

Field monitoring data of the roof-to-floor convergence in this case are presented here to verify the model. Eight roof-floor convergence stations are installed on the cribs in the recovery room near the headgate ( 3 stations), middle ( 3 stations) and near the tailgate of the panel ( 2 stations). These stations on the headgate and middle panel sites are installed at the outby rib, center, and inby rib of the recovery room. The two stations near the tailgate of the panel are installed with a short distance inby the recovery room. The roof-to-floor convergences were measured as the face was approaching the recovery room. Figure 4.12 shows the average roof-tofloor convergence at the monitoring sites as the width of the fender pillar narrows. Among the three, the convergences near the two ends of the panel were small initially. Sudden increases occurred when the fender pillar was cut to less than $12 \mathrm{~m}$ (39 ft) wide. The roof-to-floor convergence at tailgate side increases faster than the middle and the headgate side. The final measured roof-to-floor convergence in the recovery room when the longwall face is still about $5.8 \mathrm{~m}(19 \mathrm{ft})$ to the end of the fender pillar ranges from 10 to $16.5 \mathrm{~mm}$ (0.4 to 0.65 inches).

Using the proposed model, the calculated roof-floor convergence at the location of crib 1 in the case where two rows of $76 \mathrm{~cm}$ (30-inch) diameter standing supports are used, are also plotted in Fig. 4.12 for comparison showing comparable roof-to-floor convergence in the recovery room. The model also predicts a rapid increase in roof convergence after the width of 
fender pillar is reduced to less than $4.6 \mathrm{~m}(15 \mathrm{ft})$. When the fender pillar is completely cut, the roof-to-floor convergence is about $28 \mathrm{~mm}$ (1.1 inches).

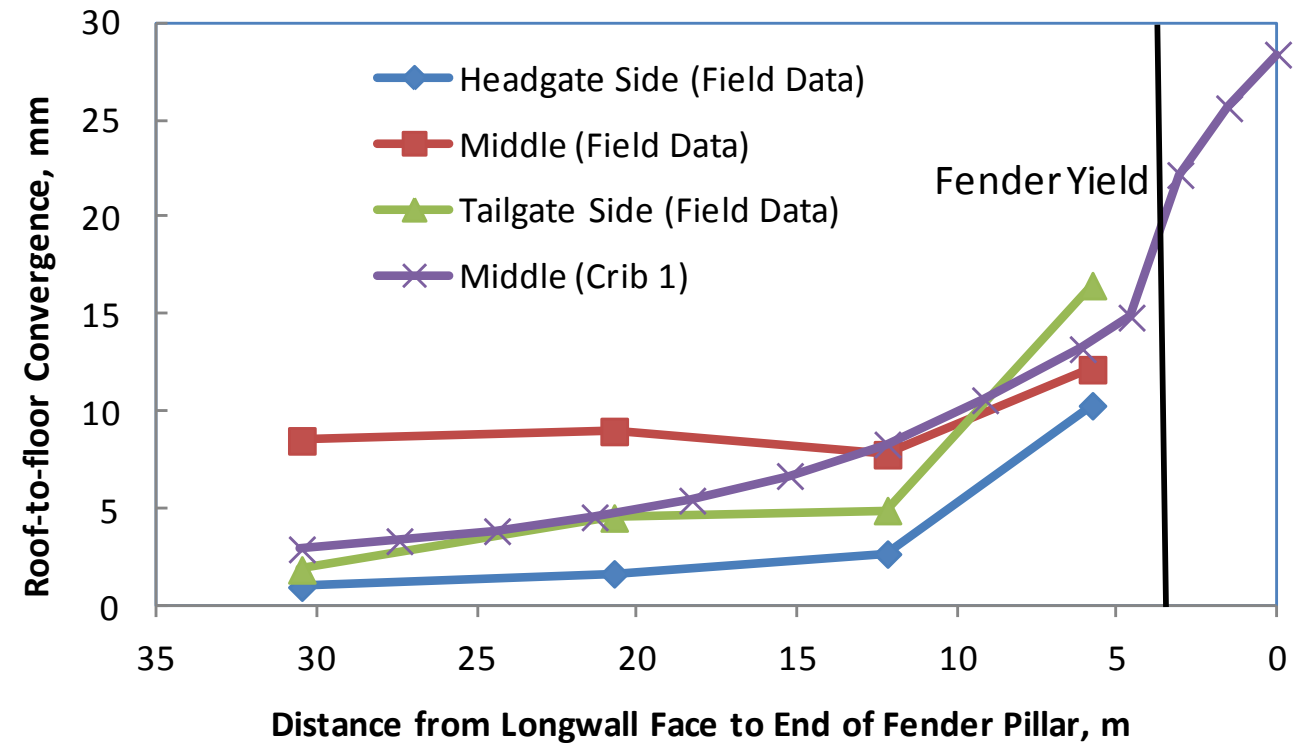

Figure 4.12 Cumulative Roof-to-floor Convergence

\subsection{Summaries}

The fracture mechanics approach have been applied to analyze the performance of predriven recovery room system (including the longwall powered supports, the fender pillar, the standing supports and barrier pillars) in longwall mining operations. This approach provides a much simpler alternative to the numerical analysis methods, especially for those with limited resources.

The dynamic subsidence development curve is adopted here to describe the immediate roof line deflection. This curve is very useful in determine the support load and evaluate the support and roof condition. The load-displacement characteristic curves of the longwall supports and standing supports are also considered in the design process.

This analytical model is able to consider the dynamic loading process and the roofsupport interactions as the longwall face is approaching the pre-driven longwall recovery room. It can be used to facilitate the pre-driven longwall recovery room design and to assess the performance of the system. A case similar to a published one is simulated with the model showing a good agreement between the simulation and field measurements. 


\section{CHAPTER 5 MULTI-SEAM MINING INTERACTION AND SUBSIDENCE}

Longwall and/or room-and-pillar mining operations in multiple coal seams could not only induce subsurface and surface subsidence but also cause interactions between these mined coal seams. The interaction might destabilize mine structures and cause additional strata movements, which can subsequently induce ground control stability and potential safety problems. In the last three decades, researches conducted in this area have raised awareness of the existence of and problems associated with multi-seam mining. A good understanding of the multi-seam mining interactions and the quantifying of subsidence influence on mine structures stability are essential for the multi-seam mining operations planning and designing.

\subsection{Introduction}

\subsubsection{Multi-seam Mining in the United States}

Coal reserves generally exist in multiple seam formations, that is, one seam overlays another seam. Depending on coal fields, these multiple coal seams might be closely spaced such as those in the Central Appalachian coal field and the others could be spaced in larger distances such as that in the Northern Appalachian coal field. Mining operations in closely spaced multiple coal seams can cause significant interactions and considerably more potential problems to mining operations and to miner safety than operating in a single coal seam. The most common safety problems associated with multi-seam mining operations are: water inundations, sudden methane inrushes, spontaneous combustions, large-scale roof falls, and coal bumps. The first three types of problems are related to subsidence-induced fracture zones in the interburden strata that connect the active mine to old mine workings or previously sealed mines (Michalek, and $\mathrm{Wu}, 2000)$. The last two types of problems are related to mining-induced stress redistribution in the surrounding strata.

Coincidentally, most multi-seam mining operations in US are conducted in the Central Appalachian coal fields, and this area also has the most mining accidents and disasters in the history of the U.S. coal industry. Since 1970, 13 out of 21 coal mine disasters (defined as five or more fatalities in an accident) have occurred in the Central Appalachian coal fields. More 
recently, the multi-seam mining phenomenon heavily contributed to the Upper Big Branch mine explosion in West Virginia.

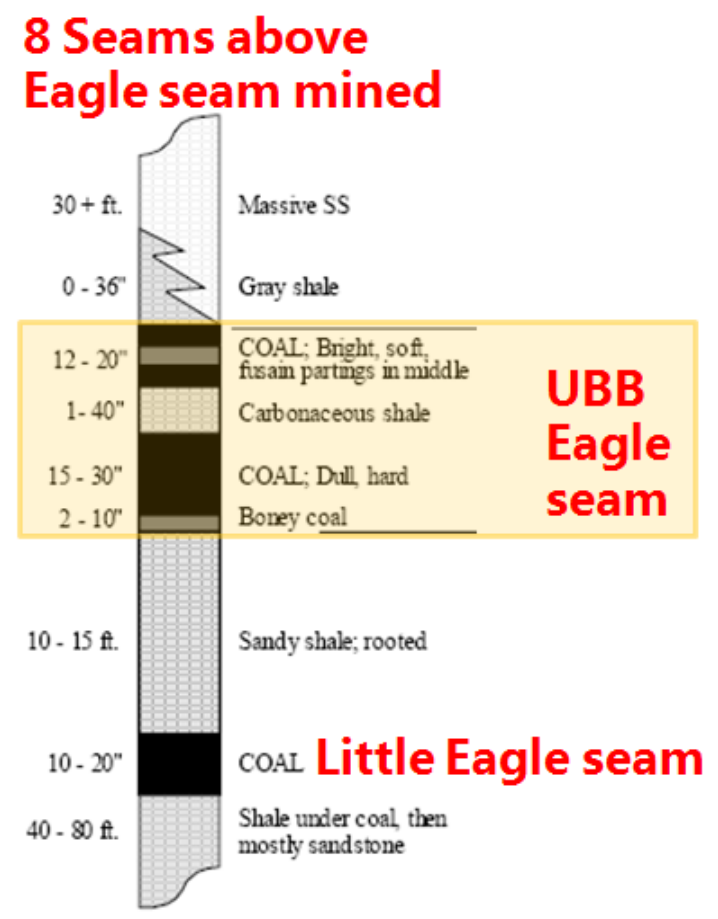

Figure 5.1 Intensive multi-seam mining conditions of Upper Big Branch Mine

Unlike many other major coal producing countries, the high degree of privatization of coal reserves in most U.S. coal fields often limits a company's mining right to only one single coal seam. U.S. coal mining operations in multiple seams are often conducted in an uncoordinated manner by different mining companies without due consideration of potential interactions to mining operations in adjacent coal seams. In most U.S. mining, research the mine design methods are developed for mining operations in a single coal seam. On the other hand, if a company owns the mining rights to a group of consecutive coal seams, a good coordination to avoid significant mining interactions will be built into its mine design and operation schedule.

\subsubsection{Multi-seam Mining Interactions}

In areas with multi-seam mining, the mining activities conducted in underlying seam(s) could affect the stability of mine structures, (i.e., coal pillars, entry floor, and roof) in the seams above and interburden strata. Instable pillars, roof, floor and interburden can not only cause significant problems to mining operations but also present hazardous conditions to mine workers. 
The interactions induced by mining operations in multiple coal seams often create operational and safety problems. Multi-seam mining effects are closely related to interburden thickness and properties, mining sequence, seam heights and mining method applied, time interval between the mining activities in neighboring seams, and sometimes local topographic and hydrographic features. The mining activity in one seam can cause stress redistribution and strata movements in the coal seams both above and below (Morsy et al., 2006). The redistributed stress and deformation will affect surface and subsurface structures, water bodies, and could even induce unexpected additional surface subsidence. In order to gain good understanding of and to control the multi-seam mining interactions, there is a need for a tool that can accurately predict surface and subsurface subsidence and assess interactions caused by mining operations in multiple coal seams.

\subsection{Multi-seam Mining Interactions}

The subsurface deformations due to mining operations in underlying seam have the potential to cause stability problems to mine structures (i.e., coal pillars, entry floor, and roof) in the upper seams (Fig. 5.2). Unstable pillars, roof and floor can not only cause significant problems to mining operations but also create hazardous working conditions.

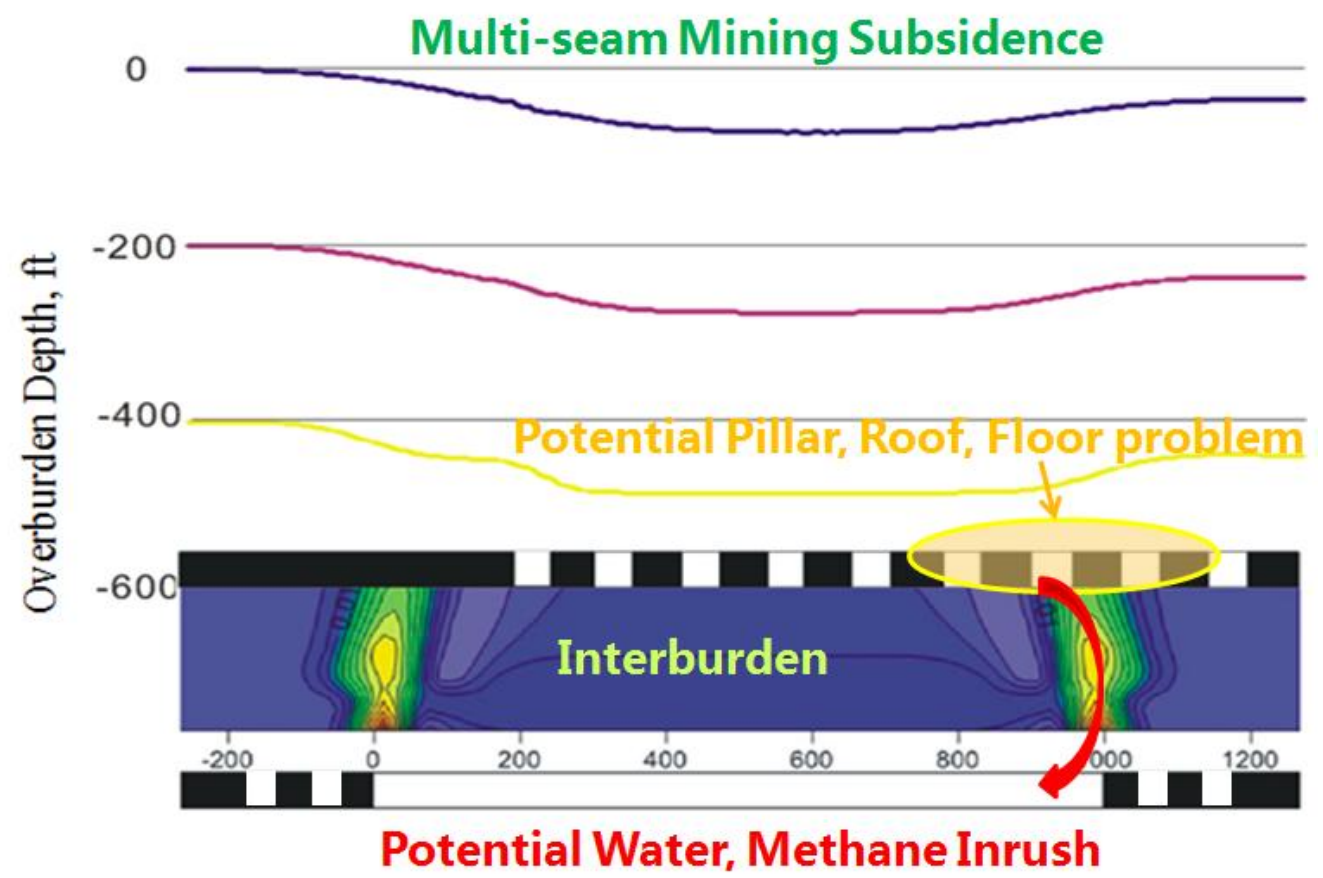

Figure 5.2 Subsurface Subsidence Profile and Multi-seam Mining Interactions 


\subsubsection{Characterization of Multi-seam Mining Interactions}

There are two common types of interactions that occur in multi-seam mining operations, one is subsidence and the other one is load transfer. Through understanding of the mechanism of these two types of multi-seam mining interactions is essential for the study and practice of the multi-seam mining operation.

\subsubsection{Pillar Load Transfer}

Pillar Load Transfer is an interaction that occurs as a result of load transfer through pillars in overlying or underlying mining operations as shown in Fig. 5.3. This interaction occurs particularly when coal seams are in close proximity, less than $33.3 \mathrm{~m}$ (110 ft), Stemple (1956), Haycocks et al. (1982), Haycocks et al. (1983) and either isolated, remnant pillars (barriers) or many strong, competent pillars are present in the upper or lower workings. This type of multi-seam mining interaction exists, lightly or severely, in most of the multi-seam mining operations. It can occur in overmining, simultaneous mining as well as undermining conditions.

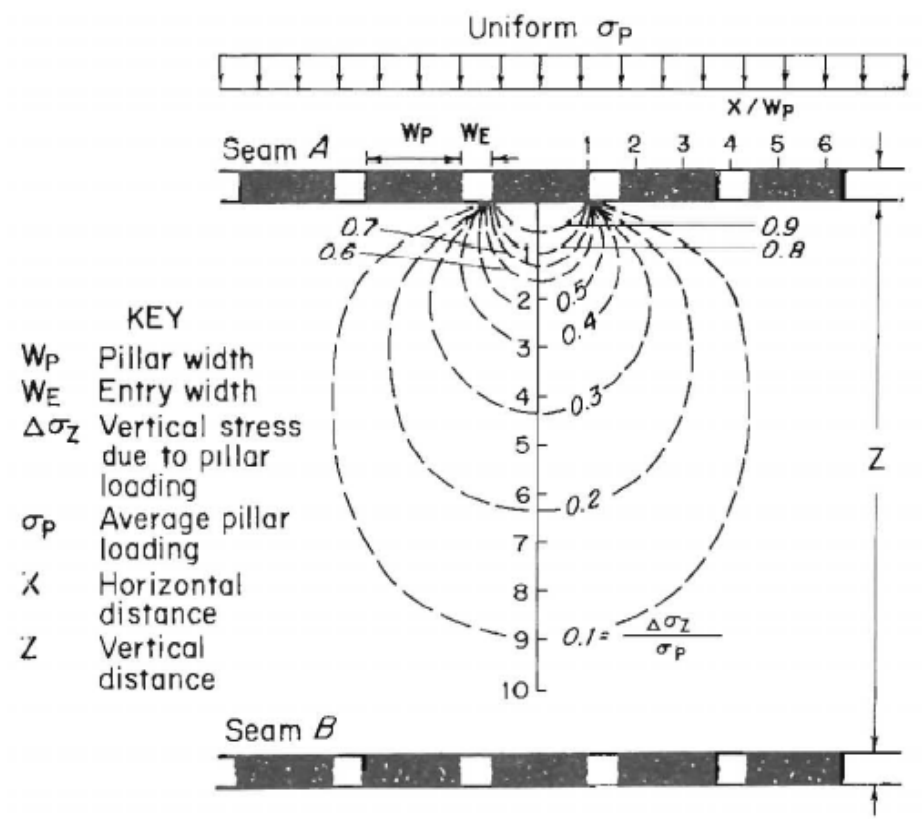

Figure 5.3 Typical pillar load transfer of multi-seam mining (after Peng and Chandra, 1980)

This type of multi-seam mining interaction may serve to concentrate stresses in the interburden causing ground instability in the upper or lower workings. Typical ground control problems caused by this type of multi-seam mining interaction are related to the overloading of the pillars, such as pillar failures, bumps, rib spalling and floor heave. Some of the areas with 
overloaded pillars also have roof cutter and roof fall problems, but not very frequently. The severity of this type of multi-seam mining interaction will increase as the overburden depth increases. Field monitoring shows a very high load increase of the pillars and relatively small roof-floor convergences of the entries for this type of multi-seam mining interaction.

This type of multi-seam mining interaction is the stress-related problem, in which most of the ground control problems are related to the multi-seam mining stresses. Therefore, the prediction and evaluation of this type of multi-seam mining interaction can be done based on comprehensive stress analysis. Most of the research works are focused on this type of multiseam mining interactions, and numerous tools are available for solving this problem.

\subsubsection{Subsidence}

The other type of the multi-seam mining interaction is the subsidence, which is as important as or even more severe than the load transfer type of interaction as shown in Fig. 5.4. Strata interactions due to subsidence result when an underlying bed is extracted first. Undermining subjects the strata above the coal seam to a mining induced movements and deformations, King et al. (1972). The movements and deformations within the strata is a function of the subsidence process and is most damaging to overlying coal seams after the critical to supercritical subsidence phase has been reached Haycocks et al. (1983), King et al. (1972), Haycocks et al. (1981). Depending upon the uniformity of lower coal seam extraction, there exists a relatively destressed zone toward the middle of the subsidence area. Most ground disturbances in overlying coal seams occur toward the boundaries of the subsidence basin. Within the subsidence basin, strata flexure creates zones of tensile and compressive stress Haycocks et al. (1981). The extent of this zone is defined by the angle of draw which is dependent upon the geologic and physical characteristics of the strata. As mining develops through the trough, these stresses have a severe effect on the entry stability, particularly on the integrity of the roof.

Typical ground control problems caused by this type of multi-seam mining interaction are related to the high strains on the roof and floor, such as roof tensile failure, roof fall, roof cutter and floor heave. Some of the pillars located at the edge of the subsidence basin will also be over loaded due to the strata movements. These pillars will also have the problems of pillar failure, bump and rib spalling. The severity of this type of multi-seam mining interaction depends mostly on the interburden properties, while has very small relationship with the 
overburden depth. Field monitoring shows that the roof-floor convergence of the entries located inside the subsidence basin is four times larger than the entries located above stiff pillars.

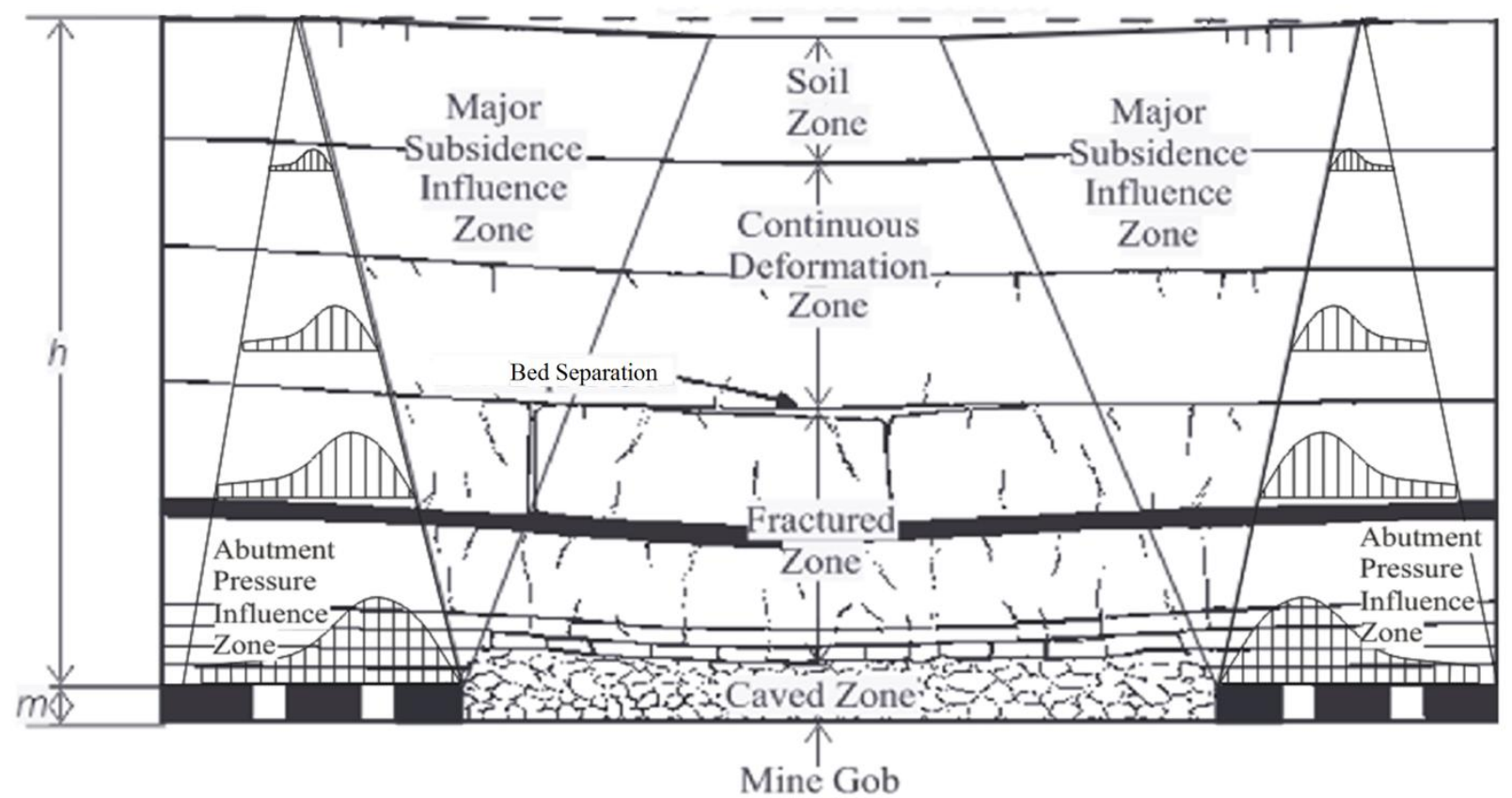

Figure 5.4 Subsidence type of multi-seam mining interaction and subsurface abutment load distribution

This type of multi-seam mining interaction is the strain-related problem, in which most of the ground control problems are related to the subsidence induced strains. After the mining of the lower seam, the caving zone, fracture zone, continuous deformation zone and soil zone will be formed in the overburden strata. As this problem is complicated with the existence of the caving and fracturing process in the strata above the lower seam, traditional stress analysis and numerical simulations seem not very accurate in dealing with this type of large deformation problems. The subsurface subsidence model will be a good alternative for solving this type of multi-seam mining interaction problems.

Most of the overmining cases with high extraction ratio of the lower seam will have the subsidence type of multi-seam mining interactions. The load transfer type of interaction will exist simultaneously with the subsidence type of interaction, which is located within a short distance outside of the subsidence basin. This is due to the subsurface abutment load cause by longming mining subsidence. As shown in Fig. 5.4, two abutment pressure influence zones are located near the longwall panel edge and above the chain pillar system in the overburden. As the 
distance to the mine gob increases, the magnitude and extent of the subsurface abutment load decrease.

\subsubsection{Multi-seam Mining Pillar Stability}

The stability of a mine pillar depends on its strength and the load applied on it. The pillar strength is a function of confinement that is indirectly reflected by the pillar width to height ratio in a single seam mining setting. However, when a pillar is disturbed by mine subsidence, both the pillar load and its strength could be affected (Lee, 2005).

\subsubsection{Pillar Stability Factor}

Change in pillar load can be related to the differential subsidence between the roof and floor line of the pillar. The pillar load under the influence of subsurface subsidence, $\sigma_{p}$, can be calculated by the following equation,

$$
\sigma_{p}^{\prime}=\sigma_{p}-E_{c} \cdot \varepsilon_{v}
$$

where,

$\sigma_{p} \quad=$ the pillar load prior to the subsurface subsidence influence which is normally determined using the tributary load method.

$E_{c} \quad=$ the Young's modulus of the coal pillar.

$\varepsilon_{v} \quad=$ the subsidence-induced vertical strain at pillar location.

The pillar strength would decrease with the confinement pressure that is related to the increased void intensity in the subsurface subsidence process. The pillar strength under the influence of subsurface subsidence, $S_{p}{ }^{\prime}$, is calculated by the following equation.

$$
S_{p}^{\prime}=\lambda S_{p}
$$

where,

$S_{p} \quad=$ the pillar strength prior to the subsurface subsidence influence which can be determined by Bieniawski's formula as shown in Eq. 5.3.

$\lambda=$ the pillar strength reduction factor, and the determination of this factor will be discussed in a later section.

$$
S_{p}=\sigma_{1}\left(0.64+0.36 \frac{W_{p}}{H_{p}}\right)
$$

where, 
$\sigma_{1} \quad=$ the in-situ coal strength, recommended 6.2 $\mathrm{MPa}(900 \mathrm{psi})$.

$W_{p} \quad=$ the pillar width.

$H_{p} \quad=$ the pillar height.

Subsequently, the safety factor of a pillar under the disturbance of subsurface subsidence can be determined by Eq. 5.4.

$$
S F^{\prime}=\frac{S_{p}^{\prime}}{\sigma_{p}^{\prime}}
$$

If the pillar safety factor under the disturbance of mine subsurface subsidence is less than a critical value, the pillar could fail. Based on the published investigation cases, it is proposed that a critical safety factor for pillars to fail in a large area is 1.0.

\subsubsection{Void Intensity and Pillar Strength}

The Bieniawski's formula (Eq. 5.3) is widely used to estimate the pillar strength in the process of pillar design and pillar stability analysis. The pillar width to height ratio $(\mathrm{W} / \mathrm{H})$ is an indirect measure of the confinement level of the pillar. However, the pillar strength is also affected by other factors, such as the structure and surface conditions of the discontinuities inside the pillar, and the roof and floor conditions. In order to account for the effects of subsurface subsidence on the pillar strength, the Hoek-Brown failure criterion is adopted here to evaluate the pillar strength. The generalized Hoek-Brown (1997) failure criterion for jointed rock masses is defined by Eq. 5.5. The $m_{b}, s$ and $a$ in this equation are material constants.

$$
\sigma_{1}^{\prime}=\sigma_{3}^{\prime}+\sigma_{c i}\left(m_{b} \frac{\sigma_{3}^{\prime}}{\sigma_{c i}}+s\right)^{a}
$$

where,

$\sigma_{1} \quad=$ the major effective principal stress at failure.

$\sigma_{3}{ }^{\prime}=$ the minor effective principal stress at failure.

$\sigma_{c i} \quad=$ the uniaxial compressive strength of the intact rock material.

When considering the strength of a pillar, it is useful to have an estimate of the overall strength of the pillar rather than a detailed knowledge of the extent of fracture propagation in the pillar. This leads to the concept of a global "rock mass strength" that could be estimated by the following Mohr-Coulomb relationship as proposed by Hoek and Brown (2002). 


$$
S_{p}=\frac{2 c^{\prime} \cos \phi^{\prime}}{1-\sin \phi^{\prime}}
$$

where,

$c^{\prime}=$ the cohesion.

$\phi^{\prime} \quad=$ angle of internal friction.

Equation 5.6 can be further derived into Eq. 5.7 in the stress range of $\sigma_{t}<\sigma_{3}{ }^{\prime}<\sigma_{c i} / 4$.

$$
\begin{aligned}
& S_{p}^{\prime}=k \sigma_{c i} \\
& k=\frac{\left[m_{b}+4 s-a\left(m_{b}-8 s\right)\right]\left(m_{b} / 4+s\right)^{a-1}}{2(1+a)(2+a)} \\
& \lambda=\frac{S_{p}^{\prime}}{S_{p}}=\frac{k^{\prime} \sigma_{c i}}{k \sigma_{c i}}=\frac{k^{\prime}}{k}
\end{aligned}
$$

In Eq. 5.9, $K$ and $K^{\prime}$ are the pillar strengths when the pillar is undisturbed and disturbed by multi-seam mining, respectively. The reduced material constant $m_{b}$ is a function of the material constant $m_{i}$ in original condition, the rock's geological strength index (GSI) and the degree of disturbance $(D)$ as shown in Eq. 5.10. The coefficients $s$ and $a$ for the rock mass are determined by Eqs. 5.11 and 5.12, respectively.

$$
\begin{aligned}
& m_{b}=m_{i} \cdot e^{\left(\frac{G S I-100}{28-14 D}\right)} \\
& s=e^{\left(\frac{G S I-100}{9-3 D}\right)} \\
& a=\frac{1}{2}+\frac{1}{6}\left(e^{-G S I / 15}-e^{-20 / 3}\right)
\end{aligned}
$$

Coefficient $D$ is a factor reflecting the degree of disturbance to which the rock mass has been subjected by blasting damage and stress relaxation. It varies from 0 for undisturbed in situ rock masses to 1 for very disturbed rock masses. The significance of the parameters and their values can be found in a publication by Hoek (2004).

The Geological Strength Index (GSI), introduced by Hoek (1994) and Hoek et al. (1995), provides a system for estimating the reduction in rock mass strength for different geological conditions. The GSI takes into account of the geometrical shape of intact rock fragments as well as the condition of joint faces. For underground structures such as tunnels, slopes and mine 
openings that are easy to access and observe the geological conditions, the GSI is determined using the method proposed by Hoek and Brown (1997). However, in this research, the geological conditions of the subsurface structures under the disturbance of the subsurface subsidence are very hard to observe. The subsurface total strain in the rock mass can be considered as a mininginduced geological condition of the rock mass. An empirical formula is established here to estimate the GSI for the subsurface structures based on the subsurface total strain distribution.

$$
G S I=75-0.95\left(\varepsilon_{t} \cdot 10^{3}\right)
$$

\subsubsection{Numerical Study of the Effect of Subsurface Deformation on Pillar Strength}

In order to calibrate the empirical formula, numerical simulations are also performed. The Fast Lagrangian Analysis of Continua (FLAC) program package, capable for elasto-plastic analysis of rock excavations with strain softening using the linear Mohr-Coloumb failure criterion, is used in the simulation (Jaiswal and Shrivastva, 2009). A FLAC3D model is developed to study the coal pillar strength under the influence of subsurface subsidence. The model consists of $8 \mathrm{ft}$ of coal seam, $30 \mathrm{ft}$ of roof strata and $36 \mathrm{ft}$ of floor strata (Fig. 5.5).

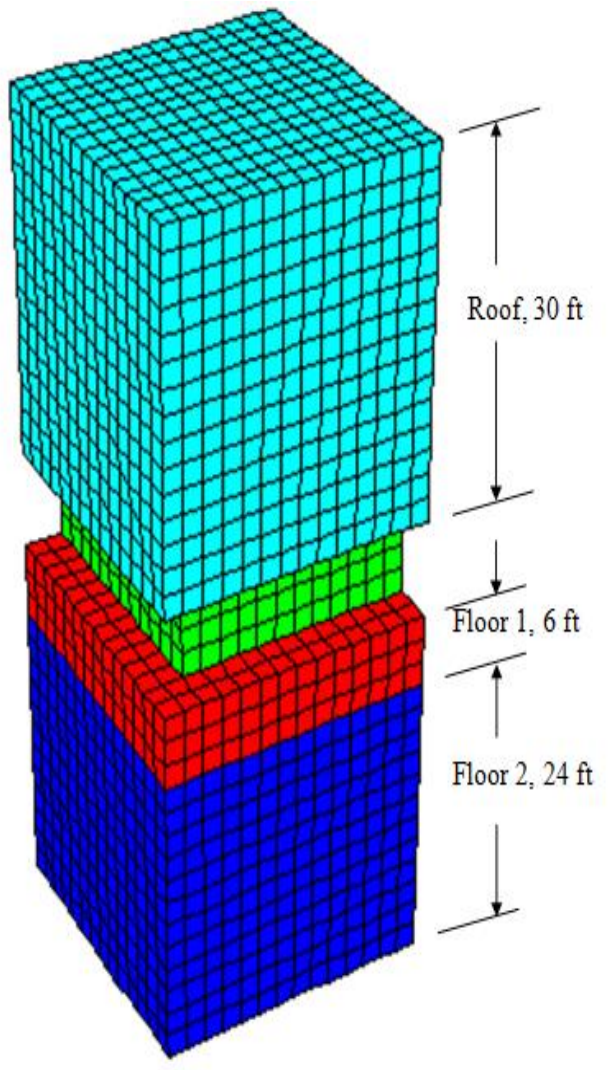

Figure 5.5 The three-dimensional discretized view of quarter pillars $(\mathrm{w} / \mathrm{h}=5)$ 
The entry and crosscut are $20 \mathrm{ft}$ wide. Elastic perfectly plastic Mohr-Coulomb model is assigned for the rock strata. Strain softening Mohr-Coulomb model is assigned for the coal seam. Roller boundary conditions were assigned along the sides and bottom of the model. In order to establish the peak load for the pillar to carry, the velocity of the vertical displacement on top of the model is fixed at a constant value of $-1 \times 10^{-5} \mathrm{ft} / \mathrm{sec}$. The sum of the reaction forces at the base of the model is obtained via a FISH function (Itasca, 2006) to estimate the average vertical stress developed in the pillar. The input geo-mechanical properties are the same as one used by Lu et al. (2008). Four pillar widths of 24, 40, 56, and $80 \mathrm{ft}$ reflecting the pillar width to height ratio $(W / H)$ of 3, 5, 7 and 10 are simulated. The resulting stress strain relationships are plotted in Fig. 5.6.

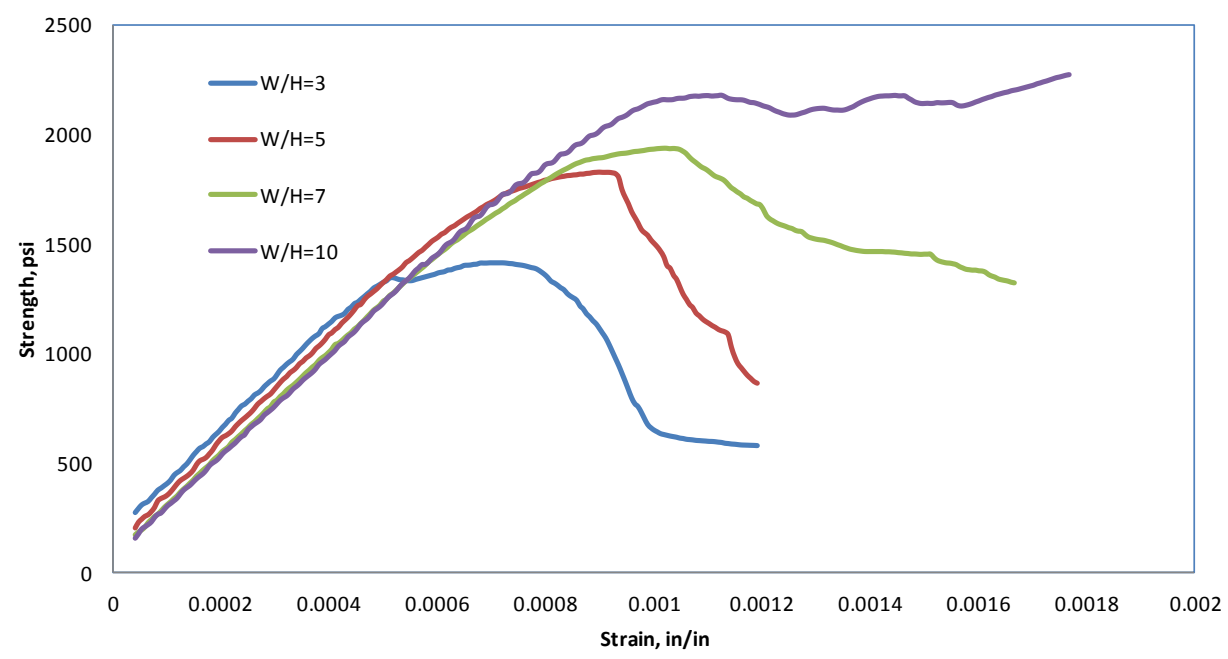

Figure 5.6 Stress strain curves under different W/H ratios

In order to simulate the subsurface subsidence effect on the pillar strength, the horizontal strain and vertical strain are simulated by applying the displacements on the side and the top of the model respectively at a constant value of $-1 \times 10^{-5} \mathrm{ft} / \mathrm{sec}$. Different subsurface deformation values are simulated with this model. The numerical simulation results are compared to the results of the previous analytical model for validation purpose in Fig. 5.7. It shows the proposed pillar strength formula to consider the subsurface subsidence effects agree well with the numerical simulation results. 


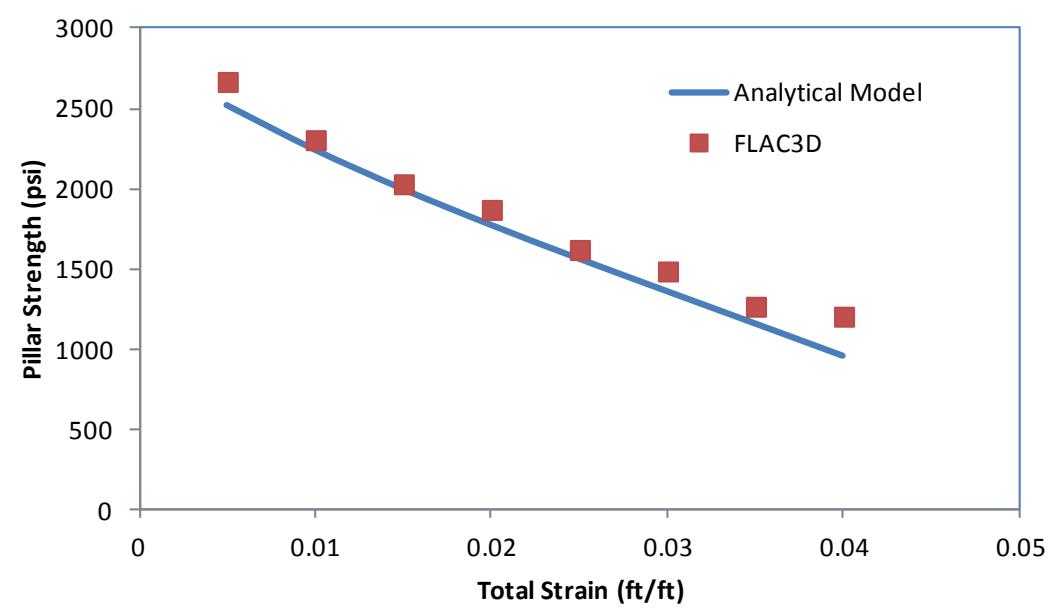

Figure 5.7 Comparison between proposed pillar strength formula and FLAC modeling results

\subsubsection{Simplified Model}

The pillar strength would decrease with the confinement pressure that is related to the increased void intensity caused by the subsurface subsidence process. To link the subsurface void intensity to the pillar strength, the Hoek-Brown (1997) failure criterion for jointed rock masses is employed to estimate the strength reduction factor under the multi-seam mining influence.

However, this method is kind of complicated with too many equations. To be simple, the pillar strength change is related to the total strain caused by mine subsidence. Based on the analytical model and the numerical simulation results (Luo and Qiu, 2012b), an equation of exponential relationship is proposed here to calculate the pillar strength under multi-seam mining influence. In this equation, $\varepsilon_{t}$ is the total strain, $S_{p}$ is the strength of the pillars without multi-seam mining influence, $S_{p}$ ' is the strength of the pillars with multi-seam mining influence and $a$ is the strength reduction coefficient that can be determined based on regression studies of case data, it is recommended to be in the range of $-30 \sim-10$ for the coal mines in the eastern US.

$$
S_{p}^{\prime}=S_{p} e^{a \varepsilon_{t}}
$$

The pillar stability factors under multi-seam influence can be calculated based on the calculations of the pillar load and pillar strength. If the pillar stability factor under the disturbance of mine subsurface subsidence is less than a critical value, the pillar could fail. Based on the published investigation cases (Morsy et al., 2006; Mark and Barker, 2012), it is proposed that a critical stability factor for pillars to fail in a large area is 1.0. When the failure of 
the pillars occurs in a sufficiently large contiguous area, it could induce additional surface and subsurface subsidence other than that caused by the active mine alone.

\subsubsection{Multiple-seam Mining Roof Stability}

Roof falls have been the No. 1 safety threat to underground miners. Common roof falls in coal mines were resulted from roof tensile failures and roof cutters. Except for the geologic effects, the induced stress by surface sharp valley and multi-seam mining is the main cause of roof instability (Moebs and Stateham, 1986). In multi-seam mining operations, when an underground coal mine is affected by mining activities conducted in the underlying coal seam, the originally stable mine roof could become unstable. Roof tension cracks could be induced in zones with high void intensity zones while roof cutters are more likely to occur in high lateral stress areas. Roof tension cracks and cutters do not always lead to roof falls. Many roof tension cracks and cutters stayed the same throughout the whole entry/crosscut life as they were found, while others progressed to various stages and stopped. The rate of propagation of tension cracks and cutters from stage to stage also varies (Peng, 2007).

The changes of the strains on the roof of the upper seam panels caused by subsurface deformations can be predicted by the previous described model. The predicted horizontal strain of the roof can be used to assess the stability of the roof. Based on the subsidence investigation experience, tensile strain higher than $2 \times 10^{-3} \mathrm{~m} / \mathrm{m}$ is capable of causing cracks in the immediate mine shale roof that could lead to roof failure (Luo and Qiu, 2012b). Except for the tensile strain, the compressive strain and shear strain are also contributing to the roof failures. The total strain can be a good indicator of the severity of multi-seam mining disturbances on the roof. Stronger roof support or supplemental supports should be installed at the areas with high subsidence induce void intensity. The Ground Support Rating (GRSUP) system as described in Eq.4.17 can be used to calculate the ground control support intensity. Further investigation can be made to study the relationship of the roof support intensity and the subsidence induced void intensity for multi-seam mining operations.

\subsubsection{Multiple-seam Mining Floor Stability}

The mine subsidence caused by the extraction of the lower seam could also destabilize

the floors of the entries in the upper seam mine operations. Unstable mine floors are mainly shown in floor cracks in high tension zones and floor heaves in high compression zones. 
The floor cracks themselves maybe not dangerous for the mine operations. However, if the floor cracks are deep enough to connect the pressurized aquifer, gassy coal seams and/or gassy shale strata, the gas and/or water may burst into the mine openings which could be hazardous to coal mine safety. The size and distribution of these floor cracks depend on the tensile strains on the floor strata and the geological properties. Similar to the roof stability, tensile strain higher than $2 \times 10^{-3} \mathrm{~m} / \mathrm{m}$ is capable of causing cracks in the immediate mine shale floor.

Floor heaves could be experienced in both the strong and weak floor strata. The weak floor such as shale or claystone, being a low modulus material, could result in "hump-like" floor heaves. Whereas, a strong floor such as sandstone and limestone, being a high modulus material, could result in a "buckling” type floor heave as shown in Fig. 5.8 (Matetic et al., 1987).

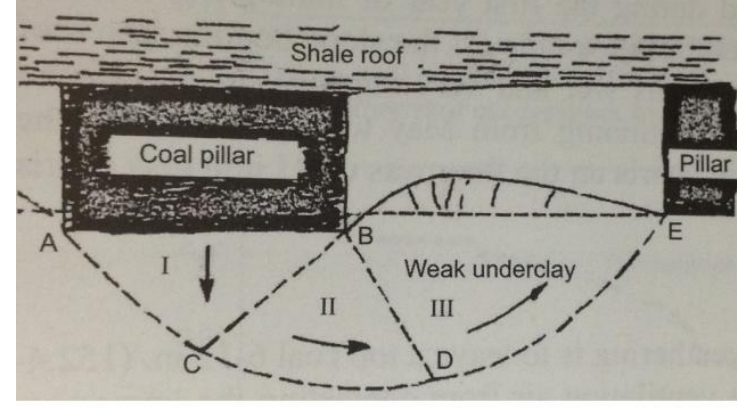

"hump-like" floor heave

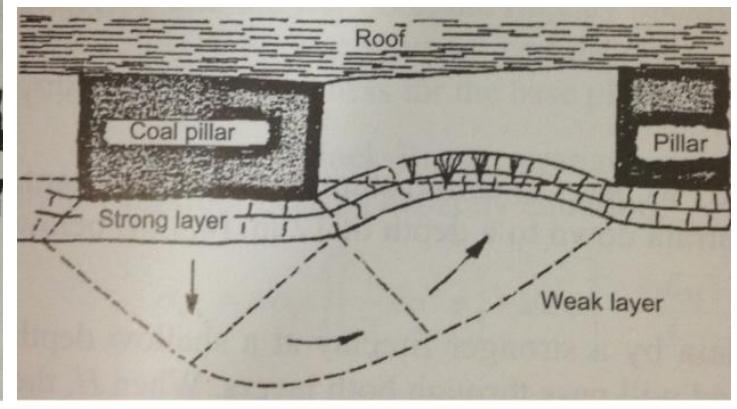

"buckling" floor heave

Figure 5.8 Two types of floor heaves (after Peng, 2008)

For the first type of floor heave, when the pillars are stronger than the underlying floor rock and have sufficient overburden loads, they have the potential to punch into the floor strata. The applied load will have only a local effect on deflection and stresses, and local shear failure will occur near both ribs of the pillar. When the foundation under a pillar ruptures and fails, the floor material either squeezes or heaves into the adjacent mine openings (Iannacchione et al., 2011). The coal pillar on weak floor strata may be considered as a shallow strip, square or rectangular foundation on cohesive rock. The theory of bearing capacity and settlement of shallow foundations may therefore be applied for assessing the propensity of floor heave. If the overburden loads plus the multi-seam mining loads acted on the pillar are larger than the floor bearing capacity, floor heave will occur. For this case, the floor bearing capacity can be determined by the following two equations (Chandrashehar et al., 1987). 


$$
\begin{aligned}
& q_{0}=S_{1} \frac{\omega N_{c}^{\prime}\left(N_{c}^{\prime} \beta-1\right)\left[(\omega+1) N_{c}^{\prime}+(1+\omega \beta) N_{c}^{\prime}+\beta-1\right]}{\left[\omega(\omega+1) N_{c}^{\prime}+\omega+\beta-1\right]\left[\left(N_{c}^{\prime}+\beta\right) N_{c}^{\prime}+\beta-1\right]-\left(\omega N_{c}^{\prime}+\beta-1\right)\left(N_{c}^{\prime}+1\right)} \\
& \beta=\frac{W_{p} L_{p}}{2\left(W_{p}+L_{p}\right) t_{w}}
\end{aligned}
$$

where,

$S_{1} \quad=$ the unconfined shear strength of the soft stratum.

$\omega=\quad=$ the ratio of the unconfined shear strength of the lower hard layer to the upper weak layer.

$N_{c}{ }^{\prime} \quad=$ the bearing capacity factor for the weak layer.

$W_{p} \quad=$ the pillar width.

$L_{p} \quad=$ the pillar length.

$t_{w} \quad=$ the thickness of the weak layer.

For the "buckling" type floor heave, the immediate floor is very strong in comparison with the main floor. In the subsidence induced compressive zone, the compressive load applied to the immediate floor will cause deflections of the immediate floor and the main floor and the main floor in a much larger area. The deflection curve is usually a smooth curve without abrupt changes in slope. Under such conditions, the tensile stress will most likely develop in the immediate floor and as soon as it reaches its tensile strength, tensile failure of the floor will initiate in the entries. This is the initial stage of the floor heaving process (Tsang and Peng, 1992). Based on the buckling failure theory, the critical compressive strain to cause "buckling" type floor heave can be estimated by the following equation.

$$
\varepsilon_{c}=\frac{\pi^{2} t_{f}^{2}}{3 W_{e}^{2}}
$$

where,

$$
\begin{array}{ll}
\varepsilon_{c} & =\text { the critical compressive stress to cause floor heaves. } \\
t_{f} & =\text { the thickness of the immediate floor. } \\
W_{e} & =\text { the width of the entry. }
\end{array}
$$

\subsubsection{Multiple-seam Mining Interburden Stability}

In cases of undermining, the mine gob of the upper seam is always flooded or filled with explosive gases. The mine subsidence caused by the extraction of the lower seam will induce fractures in the interburden near panel edges. The connected fracture zone between the mined 
coal seams induced by subsurface subsidence process could channel the accumulated methane or water in the sealed mine areas to rush into the active working to create a dangerous condition. Since the subsurface subsidence prediction model can predict the magnitude and distribution of various subsurface deformations, the model can be used to guide mine design to avoid excessively disturbed zones and to plan ahead of any mitigation measures to minimize such influences.

The subsurface subsidence will cause the redistribution of the stresses in the interburden strata. Tension zones and compression zones will be created in the interburden near the edges of the panel, whereas, the interburden over the center of the panel will be distressed. In the area of tension zones and distressed areas, the permeability will be increased, whereas, the permeability will be decreased in the compression zones. The most possible water and/or gas flow path is along the subsidence induced tension zone. The following equation can be used to evaluate the subsurface subsidence influence on the permeability change in the interburden strata (Qiu and Luo, 2013). Detailed derivation of this equation will be discussed in Section 6.3.

$$
K=K_{o}\left(\frac{1+\frac{\varepsilon_{t}}{\phi_{0}}}{1+\varepsilon_{t}}\right)^{3}
$$

where,

$$
\begin{array}{ll}
K & =\text { the permeability under mining influence. } \\
K_{0} & =\text { the initial permeability. } \\
\varepsilon_{t} & =\text { the total strain caused by mine subsidence. } \\
\phi_{0} & =\text { the initial porosity. }
\end{array}
$$

When the void intensity is larger than the certain critical value, it could lead to significant dewatering of water bodies connected to the upper seam mine gob. Since the lost water will flow to the active mine workings, the impacts of this type of subsidence influences will be more severe to multi-seam mining safety. Based on back calculation, a critical void intensity leading to significant water seepage flow is about $4.1 \times 10^{-2} \mathrm{~m} / \mathrm{m}\left(4.1 \times 10^{-2} \mathrm{ft} / \mathrm{ft}\right)($ Luo and Peng, 2010).

\subsection{Multi-seam Mining Subsidence}

It was recognized several decades ago that, in areas of intense multi-seam mining, 
significant differences have been observed between the predicted subsidence and the field measurement (Dyni, 1991). The main reason for these deviations is the multi-seam mining interaction. As discussed previously, the multi-seam mining interaction will affect the stability of the coal pillars and the failure of the coal pillars may cause additional subsidence on the surface.

\subsubsection{Mathematical Model}

For those multi-seam mining cases with insignificant multi-seam interaction, where the remnant coal pillars in the upper seam remain intact, there will be no additional subsidence caused by the upper seam. However, for those multi-seam mining cases with a large area of coal pillar failure, the final surface subsidence should be the superposition of the subsidence caused by the individual mine gobs and that caused by the failure of the coal pillars. The pillar failure area could be treated as an irregular mine gob, and the subsidence calculation for the pillar failure area can use the method proposed by Luo and Peng (1993). The superimpositions of the subsidence caused by two different coal seams can be represented by the following equations. Equation 5.19 shows the final subsidence caused by the coal seams. Equations 5.20 to 5.21 are the superimposition of the final horizontal displacement and the specified direction. The superimpositions of the final slope, strain and curvature are similar as the horizontal displacement.

$$
\begin{aligned}
& S_{m}(x, y)=\sum_{i=1}^{N} S_{i}(x, y) \\
& U_{m x}(x, y)=\sum_{i=1}^{N} U_{i x}(x, y) \\
& U_{m y}(x, y)=\sum_{i=1}^{N} U_{i y}(x, y) \\
& U_{m}(x, y)=\sqrt{U_{m x}(x, y)^{2}+U_{m y}(x, y)^{2}} \\
& \phi_{m}(x, y)=\tan ^{-1}\left(\frac{U_{m y}(x, y)}{U_{m x}(x, y)}\right)
\end{aligned}
$$

where,

$$
\begin{aligned}
& S_{m} \quad=\text { the final subsidence caused by multi-seam mining. } \\
& S_{i} \quad=\text { the final subsidence caused by the } i \text { th seam. }
\end{aligned}
$$


$U_{m} \quad=$ the final subsidence caused by multi-seam mining.

$U_{m x} \quad=x$ component of the final horizontal displacement caused by multi-seam mining.

$U_{m y} \quad=$ y component of the final horizontal displacement caused by multi-seam mining.

$\phi_{m} \quad=$ the principal direction of the final horizontal displacement.

$U_{i} \quad=$ the final horizontal displacement caused by the $i$ th seam.

\subsubsection{Multi-seam Mining Subsidence Cases}

Other than the obvious additional subsidence caused by the pillar crush in multi-seam mining, further modification should be made for multi-seam mining subsidence due to the recompaction of the existed mine gob that was caused by the subsurface subsidence. Based on Australia case studies, it is proposed that the subsidence factor for two seam mining should be about 0.8 and the subsidence factor for repeated mining (more than two seams) should be in the range of 0.8 0.95 ( $\mathrm{Li}$ et al., 2011). The subsidence measurements over two seams in the western United States show a subsidence factor of 0.73 for multi-seam mining, which is higher than the subsidence factor of the single seam mining of 0.68 (Dyni, 1991). The international cases of multi-seam mining subsidence measurements are listed in table 5.1.

Table 5.1 Cases of multi-seam mining subsidence (Li et al., 2011; Dyni, 1991; Kook et al., 2008)

\begin{tabular}{|c|c|c|c|c|c|c|c|c|c|c|}
\hline Case & $* m_{1}$ & $* * m_{2}$ & $h_{1}$ & $h_{2}$ & $I B$ & $S_{1}$ & $S_{2}$ & $a_{1}$ & $a_{2}$ & $a_{m}$ \\
\hline$S A-1$ & 2.8 & 3.0 & 133 & 148 & 15 & 1.1 & 2.3 & 0.40 & 0.96 & 0.69 \\
\hline$A U-1$ & 3.4 & 3.2 & 60 & 75 & 15 & 2.0 & 3.0 & 0.60 & 0.95 & 0.77 \\
\hline$A U-2$ & 2.4 & 2.0 & 160 & 200 & 40 & 1.6 & 2.1 & 0.65 & 1.05 & 0.83 \\
\hline$A U-3$ & 3.3 & 2.8 & 260 & 345 & 85 & & 2.8 & & 0.98 & \\
\hline$A U-4$ & 3.3 & 2.6 & 95 & 160 & 65 & & 2.5 & & 0.98 & \\
\hline UK-1 & & & & & & & & 0.80 & 0.90 & 0.85 \\
\hline$U S-1$ & 2.4 & 2.4 & 457 & 472 & 15 & 1.7 & 1.9 & 0.68 & 0.77 & 0.73 \\
\hline$D E-1$ & & 1.7 & & 850 & & & 1.4 & & 0.82 & \\
\hline
\end{tabular}

$*_{m}$ - mining height, $h$ - overburden depth, $I B$ - interburden thickness, $s$ - subsidence, $a$ - subsidence factor ** Subscript: 1 - upper seam, 2 - lower seam, $m$ - multiple seam

Based on the assessment of the difference between the surface subsidence prediction in Australia and US coal mines, we suggest a multi-seam mining subsidence factor $\left(a_{m}\right)$ of 07 0.8 for two seam mining for the US coal mines. It is found that the differential of the multi-seam subsidence factor $\left(a_{m}\right)$ and the single seam mining subsidence factor $\left(a_{1}\right)$ has a certain relationship with the severity of multi-seam mining disturbances, which are related to the interburden thickness, geological properties, and mining height etc. Further investigations into 
the physical processes that cause such modifications will be fundamental to the understanding and management of multi-seam mining subsidence (Li et al., 2011).

\subsection{Case Study of Remnant Structure}

To demonstrate the CISMP-MS program, a multi-seam mining case shown in Fig. 5.9 that cause both caused damages to subsurface mine structures and to surface structures is modeled using the program.

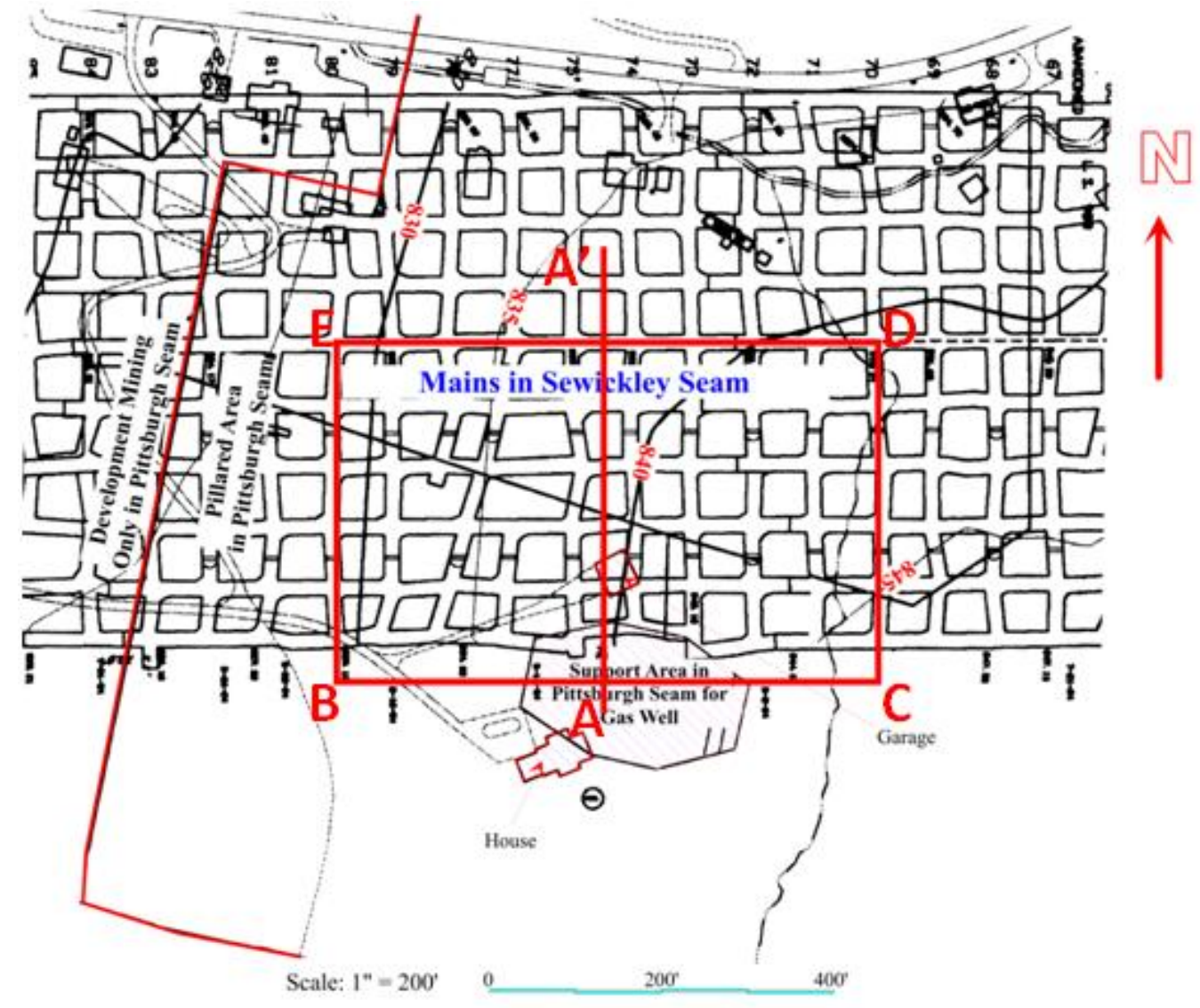

Figure 5.9 Spatial relationships among surface structures and mains in the mines in the Sewickley and Pittsburgh Seams

\subsubsection{Case Mine Conditions}

The active room and pillar mine was developing its mains in the Sewickley seam. A portion of the Pittsburgh seam, about $27.4 \mathrm{~m}$ (90 ft) below the Sewickley seam at this site, had been mined in the 1960's using the room and pillar method with pillaring and closed afterwards. The most noticeable mine structure left in the Pittsburgh seam near the two surface structures was a support area left around a gas well. The irregularly shaped support area was about $76.2 \mathrm{~m}$ 
(250 ft) long and $45.7 \mathrm{~m}(150 \mathrm{ft})$ wide. The spatial relationship between the two residential structures (the house and workshop), the layout of the active mine in the Sewickley seam are shown in Fig. 5.9. The support area left in the Pittsburgh seam around a gas wells and the boundary between the pillared area and the area with development mining only in the Pittsburgh seam are also shown in this figure.

\subsubsection{Surface and Underground Observations}

During surface observations, a ground crack and a depression zone were reported near the surface structures. Underground observations made in the active mine indicate that rib spall and cutters are more prevalent in the area above and around the boundary line in the Pittsburgh seam. The large roof fall in the entries in the active mine appeared to coincide with the edge of the support pillar area with the west end of the roof fall extended further away from the support area.

\subsubsection{CISPM-MS Analysis}

In order to study the subsurface subsidence effects of the Pittsburgh seam on the Sewickley seam mine pillars and entries, predictions are performed along the cross-section A-A' and in a rectangular area of BCDE as shown in Fig. 5.9.

The predicted subsurface subsidence and subsurface void intensity distribution in the Sewickley seam in over the specified rectangular area of BCDE are plotted in Figs. 5.10 and 5.11, respectively. The subsurface subsidence along the prediction line A-A' at the Sewickley seam around the support pillar area of the Pittsburgh seam is predicted using CISMP-MS and the results are shown in Fig. 5.12.

The subsurface subsidence prediction indicates that the subsurface deformation can reduce the average safety factor of the upper Sewickley seam pillars by $11.68 \%$. The original pillar safety factor for the Sewickley seam mine was about 8.56 , and the pillar safety factor under the subsurface subsidence influence is 7.56 which agrees well with the underground observation that the pillars in the active mine were still intact. The resulting high pillar safety factors strongly suggested that the mining operation in the Sewickley seam is not the cause for the reported surface subsidence events. However, the reported subsidence events could be caused by the water issue, since the Pittsburgh seam under the site is mined with room and pillar mine method in the 1960's.

The maximum strain of the mine roof in the Sewickley seam at the location near the edge

of the support pillar is $1.96 \times 10^{-2} \mathrm{~m} / \mathrm{m}\left(1.96 \times 10^{-2} \mathrm{ft} / \mathrm{ft}\right)$. This is significantly higher than the 
proposed critical tensile strain for roof cracking, $2 \times 10^{-3} \mathrm{~m} / \mathrm{m}\left(2 \times 10^{-3} \mathrm{ft} / \mathrm{ft}\right)$ and more than sufficient to cause the roof failure in the active mine. Figure 5.11 shows the most of the observed massive roof falls (in cross hatch pattern) and roof cracks in the active mine in the Sewickley coal seam are located in the zones of high void intensity.

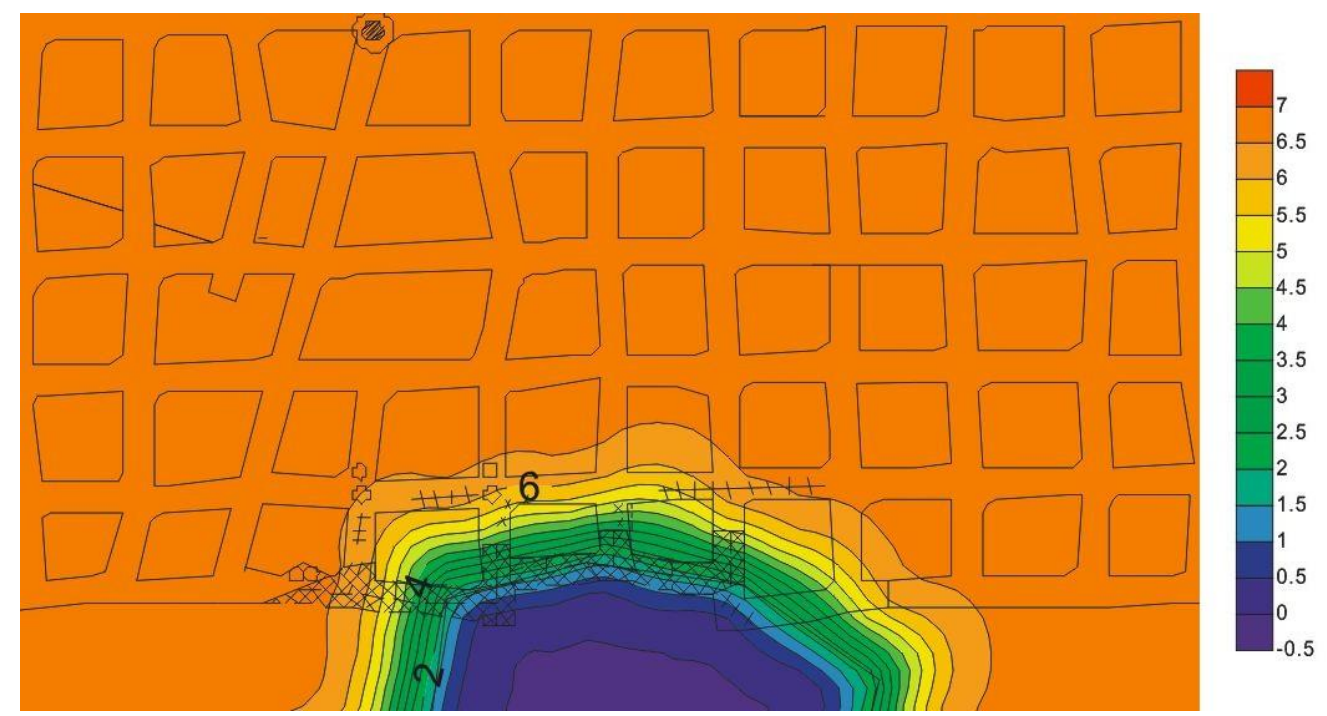

Figure 5.10 Predicted subsurface subsidence in the Sewickley seam in rectangular area BCDE

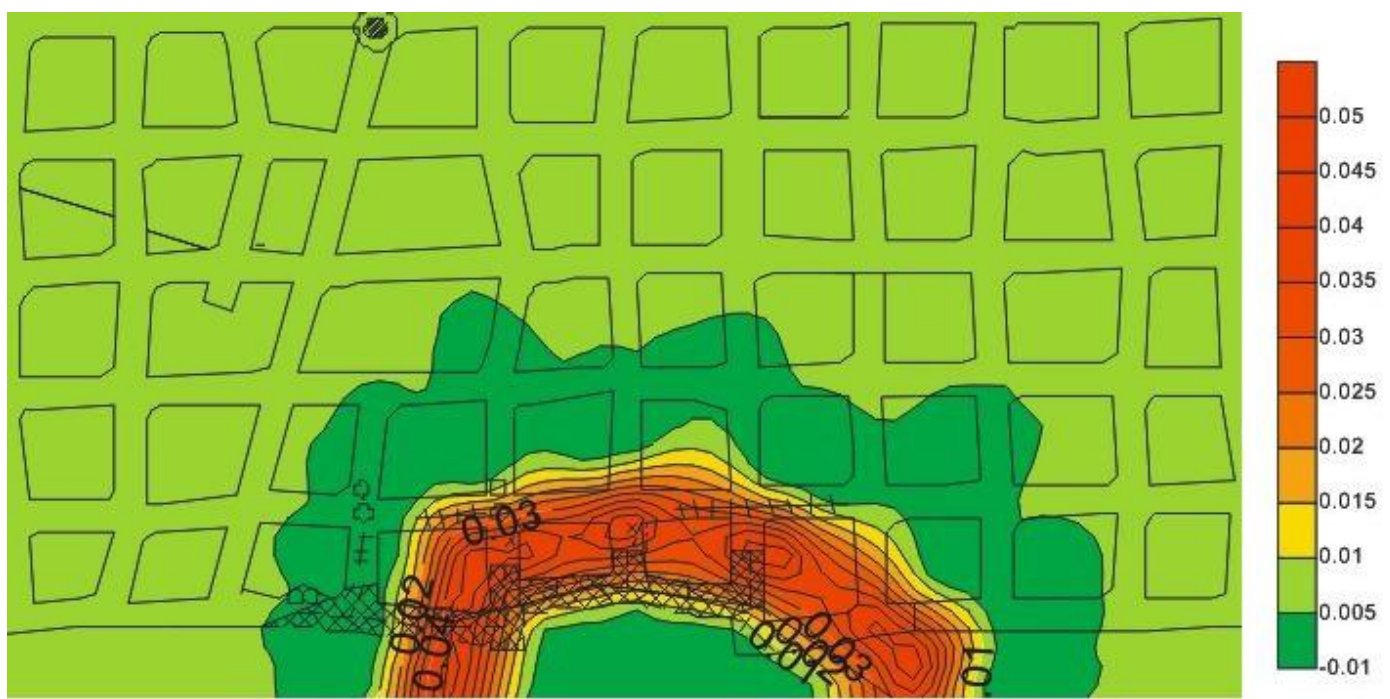

Figure 5.11 Predicted subsurface void intensity in the Sewickley seam in rectangular area BCDE 


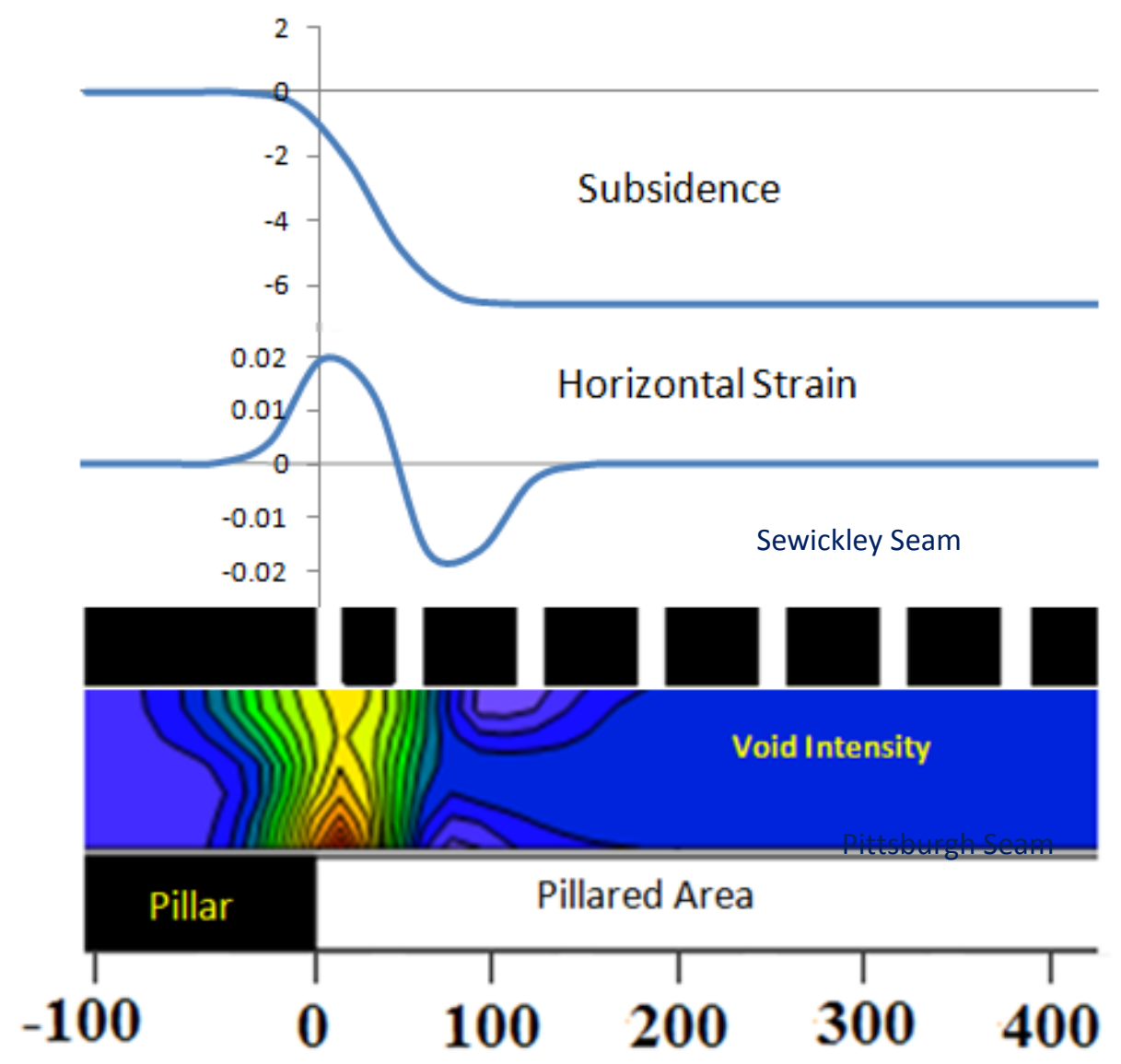

Figure 5.12 Predicted Subsurface subsidence and horizontal strain along A-A' cross-section in the Sewickley seam above the Pittsburgh seam

\subsection{Case Study of Overmining Stability}

A case study of mining inside subsidence influence zone was conducted to verify the models. The field investigation results as well as the analysis with the developed models are presented in this section.

\subsubsection{Case Mine Conditions}

The mine currently extracts the Sewickley seam using the room-and pillar mining method. The mains were consisted of 8 entries when it was at the right side of the Pittsburgh seam longwall panel, and were consisted of 6 entries when it was above and at the left side of the Pittsburgh seam longwall panel (Fig. 5.13). The pillars used in the mains were $18.3 \mathrm{~m}$ (60 ft) wide and 18.3 to $36.6 \mathrm{~m}$ (60 to $120 \mathrm{ft}$ ) long. The pillars used in the panels were $13.7 \mathrm{~m} \times 24.4 \mathrm{~m}$ $(45 \mathrm{ft} \times 80 \mathrm{ft})$. Entries and cross-cuts were $5.5 \mathrm{~m}(18 \mathrm{ft})$ wide. The overburden above the 
Sewickley seam in the studied area ranges from 121.9 to $243.8 \mathrm{~m}$ (400 to $800 \mathrm{ft}$ ). The thickness of Sewickley seam was $1.5 \mathrm{~m}(5 \mathrm{ft})$.

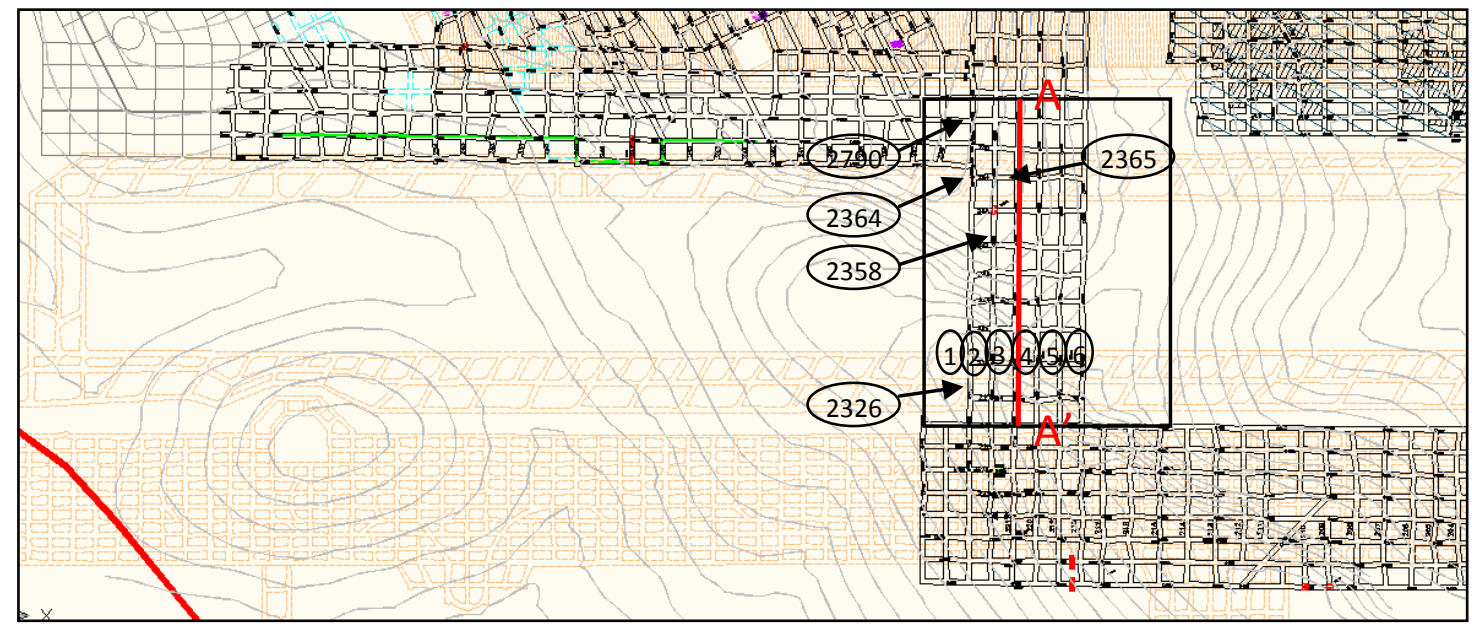

Figure 5.13 Mine layout and topographic map at study site

The Pittsburgh seam was mined about $25.9 \mathrm{~m}(85 \mathrm{ft})$ underneath the Sewickley seam by longwall and room-and-pillar mining methods. At the study site, longwall panel was completely mined out 14 years ago. The thickness of the Pittsburgh seam was $2.4 \mathrm{~m}(8 \mathrm{ft})$. At the study area, 3-entry gateroad system (stiff-yield) pillar design was implemented for the Pittsburgh seam longwall panel gateroad where the stiff pillar dimensions were $21.3 \mathrm{~m} \times 51.8 \mathrm{~m}(70 \mathrm{ft} \times 170 \mathrm{ft})$ while the yield pillars were $10.7 \mathrm{~m} \times 19.8 \mathrm{~m}(35 \mathrm{ft} \times 65 \mathrm{ft})$. Entries and crosscuts were $6.1 \mathrm{~m}(20$

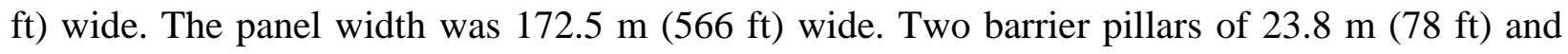

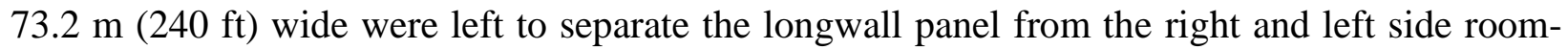
and-pillar panels in the Pittsburgh seam respectively.

The room-and-pillar section utilized an 8-entry mains system for Pittsburgh seam (Fig.

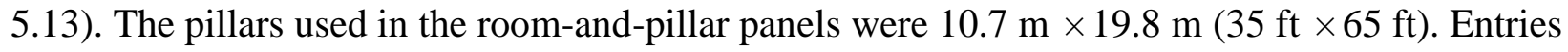

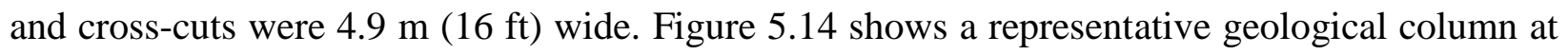
the study site. The inter-burden between Sewickley and Pittsburgh seams was composed of shaly limestone, sandstone and limestone. These strong rocks represent about $41 \%$ of the inter-burden. The immediate roof and floor of Sewickley seam were gray shale of $0.5 \mathrm{~m}(1.76 \mathrm{ft})$ and $0.4 \mathrm{~m}$ (1.4 ft), respectively. 


\begin{tabular}{|c|c|c|c|c|c|c|c|c|c|c|}
\hline Shale & & Lithology & \begin{tabular}{|c}
$\begin{array}{c}\text { Thickness } \\
(\mathrm{m})\end{array}$ \\
\end{tabular} & $\begin{array}{c}\text { Depth } \\
(\mathrm{m})\end{array}$ & Lithology & \begin{tabular}{|c|}
$\begin{array}{c}\text { Thickness } \\
\text { (m) }\end{array}$ \\
\end{tabular} & \begin{tabular}{|c} 
Depth \\
(m)
\end{tabular} & Lithology & \begin{tabular}{|c|}
$\begin{array}{c}\text { Thickness } \\
(\mathrm{m})\end{array}$ \\
\end{tabular} & $\begin{array}{c}\text { Depth } \\
(\mathrm{m})\end{array}$ \\
\hline \multirow{4}{*}{ Shale } & & Clay & 1.1 & 1.1 & Sandstone & 9.2 & 119.8 & Shale & 1.7 & 191.1 \\
\hline & & Shale & 40.0 & 41.1 & Shale & 0.9 & 120.8 & Limestone & 12.1 & 203.1 \\
\hline & & Fireclay & 0.9 & 42.0 & Limestone & 5.8 & 126.5 & Shale & 1.7 & 204.8 \\
\hline & S & Shale & 0.4 & 42.4 & Shale & 11.9 & 138.5 & Limestone & 5.3 & 210.1 \\
\hline \multirow{2}{*}{$\begin{array}{l}\text { Sandstone } \\
\text { WB. Coal } \\
\text { Sandstone }\end{array}$} & s & Sandstone & 1.2 & 43.6 & Limestone & 2.4 & 140.9 & Shale & 1.6 & 211.7 \\
\hline & 4 & Shale & 34.6 & 78.3 & Sandstone & 2.9 & 143.8 & Limestone & 1.3 & 213.0 \\
\hline Shale & 西 & Limestone & 0.7 & 78.9 & Shale & 6.4 & 150.3 & Slate & 0.9 & 213.9 \\
\hline Shale & & Fireclay & 2.3 & 81.2 & Limestone & 1.2 & 151.5 & P2 Coal & 0.4 & 214.3 \\
\hline Limestone & 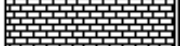 & Shale & 3.0 & 84.2 & Shale & 1.1 & 152.6 & Slate & 0.3 & 214.6 \\
\hline \multirow{3}{*}{$\begin{array}{l}\text { Sw. Coal } \\
\text { Limestone } \\
\text { Limestone } \\
\text { Pitt. Coal }\end{array}$} & & Sandstone & 22.5 & 106.7 & Limestone & 28.5 & \begin{tabular}{|l|}
181.1 \\
\end{tabular} & P1 Coal & 0.4 & 215.0 \\
\hline & 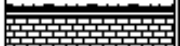 & WB Coal & 2.1 & 108.8 & Shale & 6.6 & 187.6 & Slate & 0.3 & 215.3 \\
\hline & 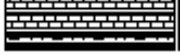 & Shale & 1.9 & 110.7 & SW Coal & 1.7 & 189.4 & & & \\
\hline
\end{tabular}

Figure 5.14 Geological column at study site

\subsubsection{Field Investigations}

The field investigation started at intersection \#2326 (Fig. 5.15) where the upper seam mains starts to change direction and passes over the lower seam longwall panel. Going inby the mains from intersection \#2326 to intersection \# 2790, some water came out of the left side rib of entry No. 1. Near the intersection \#2326, it was obvious that the entry was dipping downward towards inby the mains (Fig. 5.16). Based on the measurements, the subsidence of the entries in the Sewickley seam started to dip towards Pittsburgh seam mine gob at about $16.8 \mathrm{~m}$ (55 ft) from the panel edge. The roof was bended obviously due to the subsidence caused by the longwall mining in the Pittsburgh seam. At the high tension zone of the subsidence trough, "V" shape cracks were formed on the shoulder of the entries (Fig. 5.17). Near the intersection of \#2358, we were informed by the mine operator that there was a small area of roof fall that occurred in 2008. 


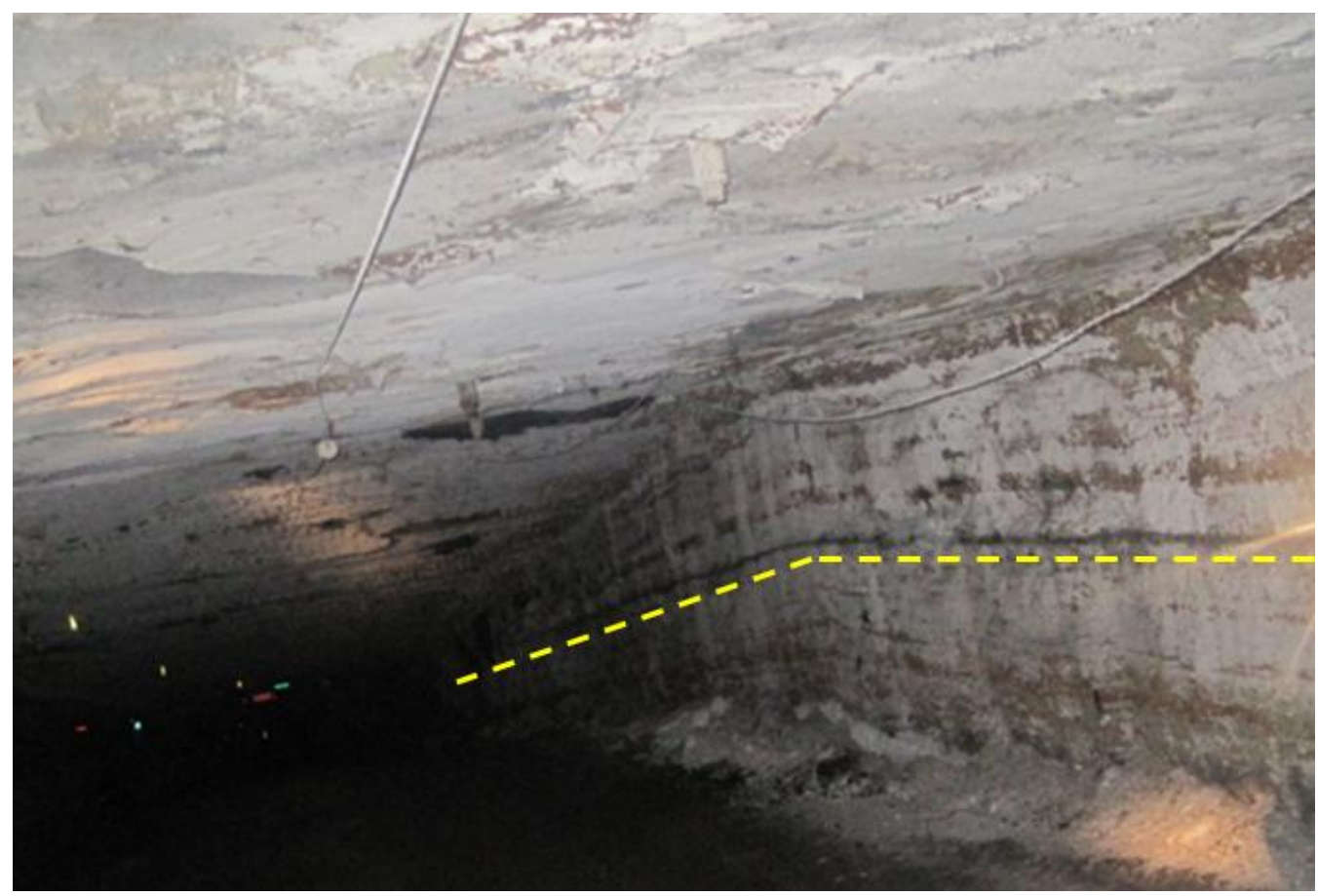

Figure 5.15 Subsidence downhill from right to left

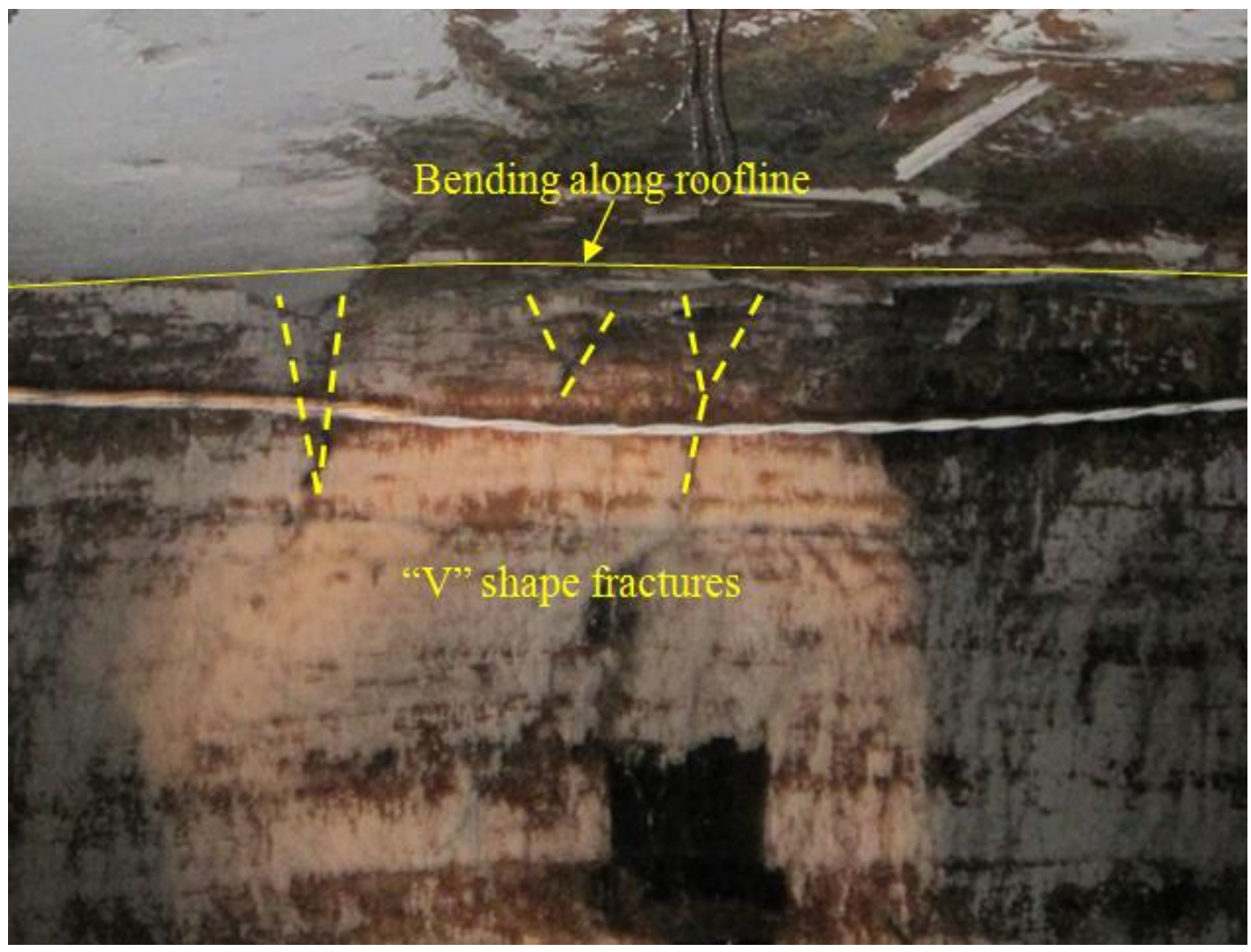

Figure 5.16 Cracks caused by subsidence induced tension 


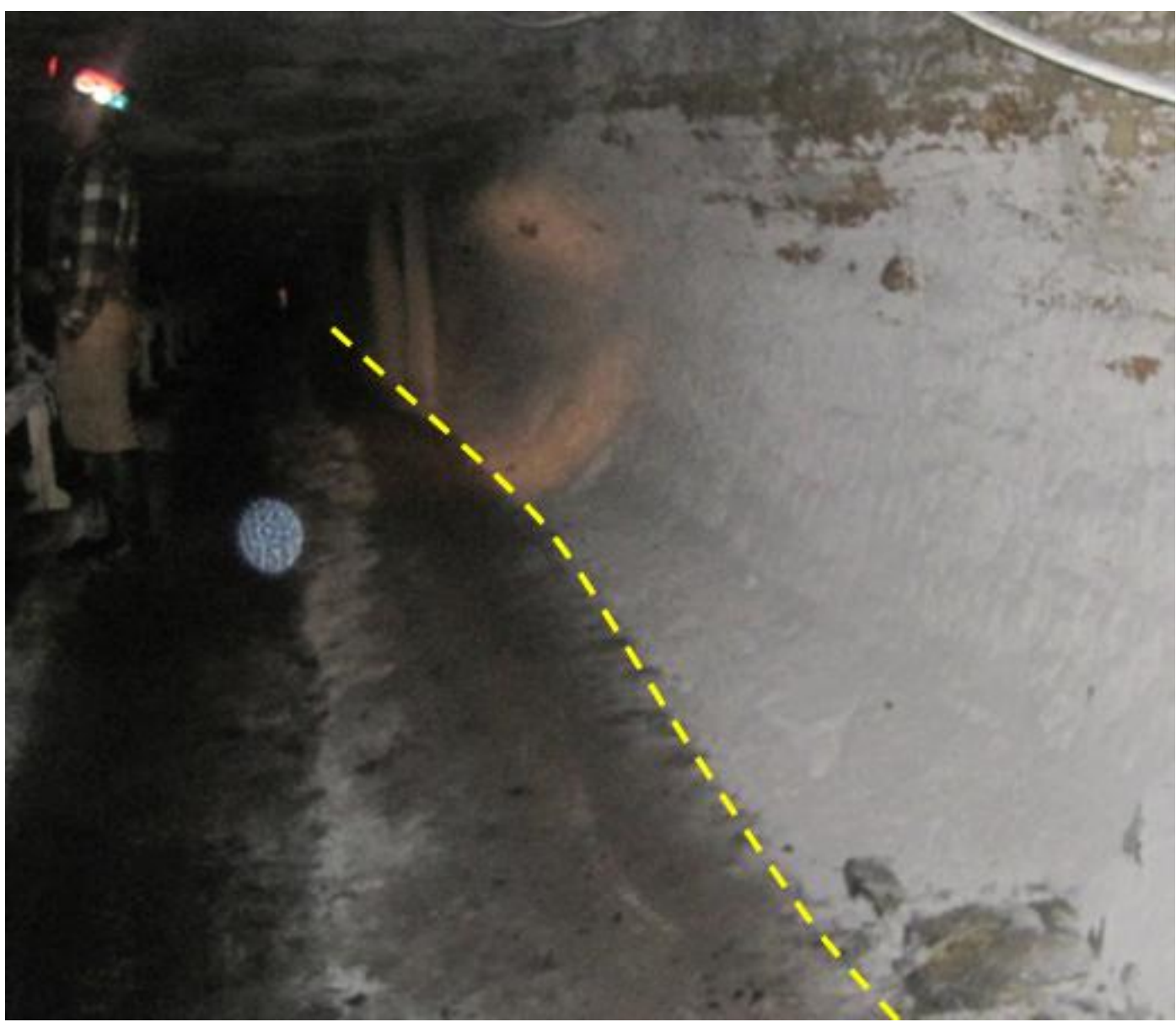

Figure 5.17 Subsidence up dip in the belt entry

Near the intersection \#2364, the floor was dipping upward and it went uphill on solid at about $41.8 \mathrm{~m}$ (137 ft) from the panel edge. The investigation ended at the intersection \#2790 and switched to the belt entry to go backwards outby the mains. Additional investigations were conducted along this entry. The same subsidence induced roof and floor bend line was observed in the belt entry near the intersection \#2365 (Fig. 5.17). Simultaneously, it was observed that the pillars at the left side of the belt entry were in depression, which was possible to cause pillar failure.

The results of the field investigation for the mains in the Sewickley seam can be summarized in the following, and they are all marked on the mine map (Fig. 5.18).

- In the area that the Sewickley seam mains pass over the previously mined Pittsburgh seam longwall panel, more ground control problems occurred there than in other areas.

- The subsidence caused by the Pittsburgh seam longwall mining induced the roof and floor bending of the entries of the Sewickley seam mains. 
- Groundwater came out of the rib of the solid coal side of No. 1 entry.

- The pillars at the left side of the belt entry near the intersection \#2365 were in depression, which was possible to cause pillar failure.

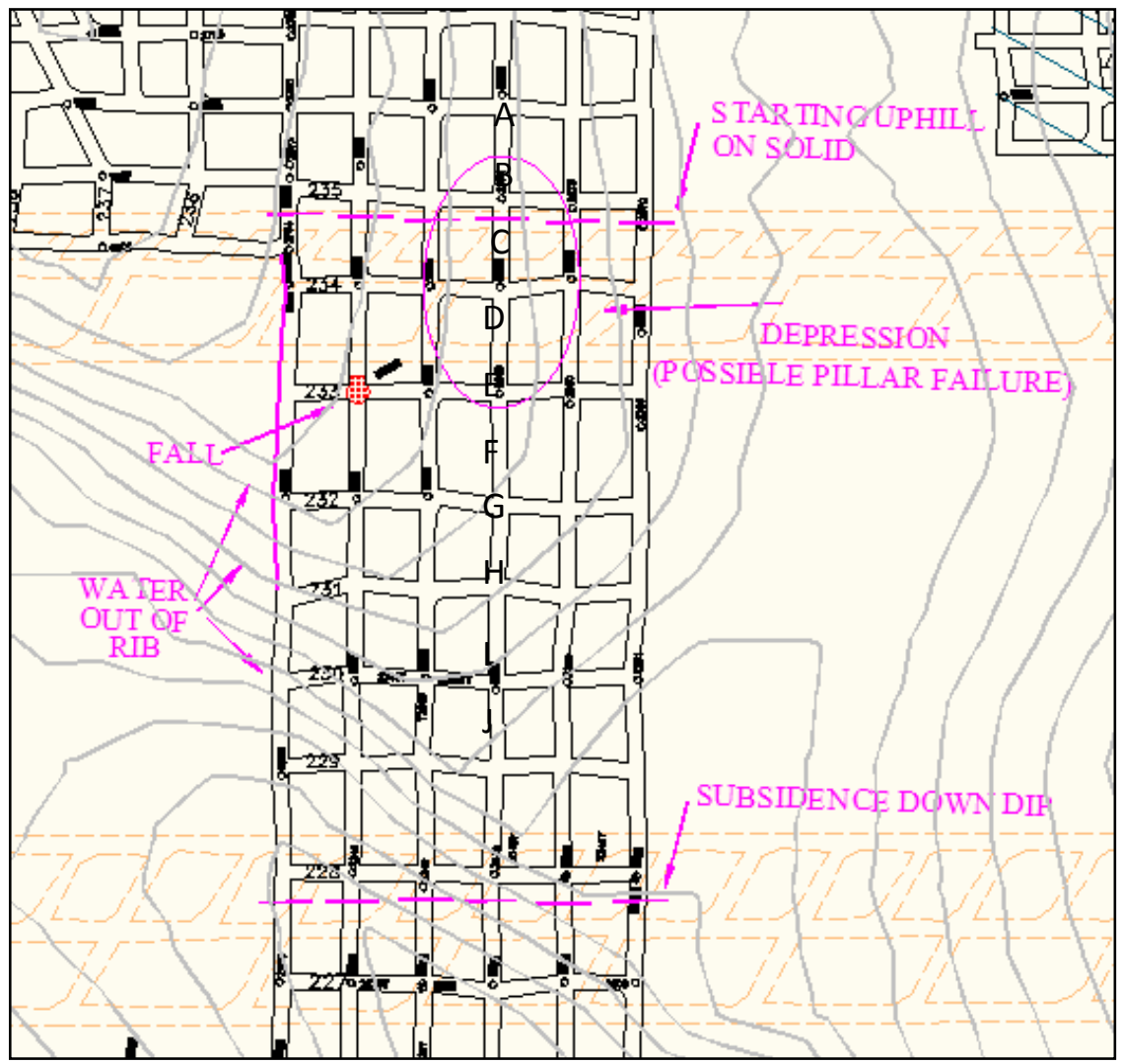

Figure 5.18 Field investigation results at study site

\subsubsection{CISPM-MS Analysis}

In order to study the subsurface subsidence effects of the Pittsburgh seam on the Sewickley seam mine pillars and entries, predictions were performed along the cross-section A$A^{\prime}$ as shown in Fig. 5.13. The predicted subsurface vertical strain and subsurface void intensity distribution along the cross-section A-A' are plotted in Figs. 5.19 and 5.20, respectively.

In Figs 5.19 and 5.20, the strain distribution patterns, especially that of the void intensity, varied considerably in locations with harder rock layers overlying the weak layers at the depths of 46 and $122 \mathrm{~m}$ ( 150 and $400 \mathrm{ft}$ ), respectively. The presence of the thick hard rock layers will prevent high void intensity developed in the underlying weak layers from propagating directly upwards while spread them in a larger area. The Sewickley seam pillars C, D, G and H are located in the major influence zone of the subsidence basin, which are endangered by severe multi-seam mining interactions. 


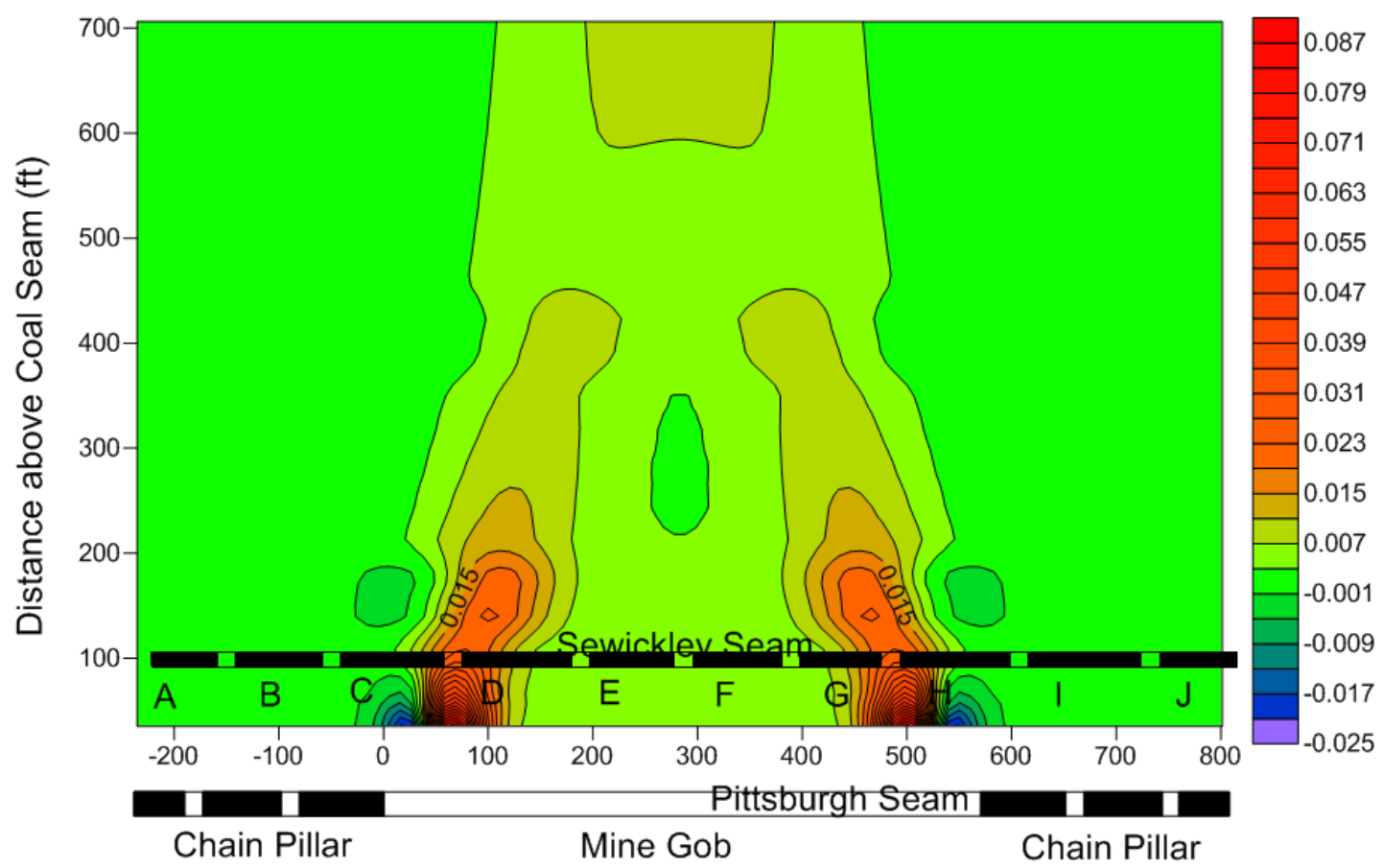

Figure 5.19 Subsurface vertical strain distribution along the cross-section A-A'

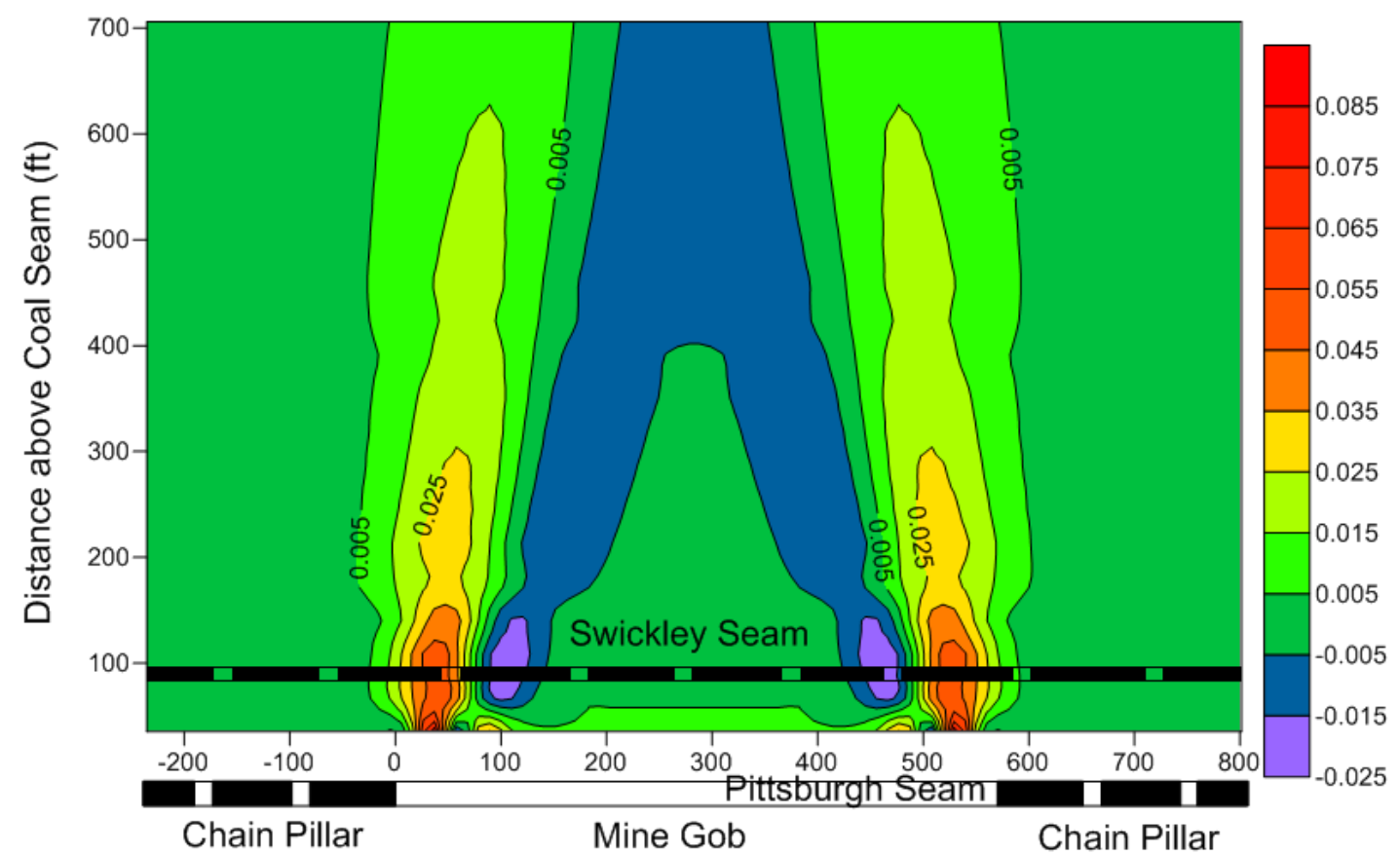

Figure 5.20 Subsurface void intensity distribution along the cross-section A-A'

Table 5.2 shows the calculations of the stability factors of the pillars $\mathrm{A} \sim \mathrm{J}$ at the Sewickley seam mains. And the stability factors of pillars A J with/without multi-seam mining interactions are plotted in Fig. 5.21. Due to the longwall mining in the lower seam, the stability 
factors of pillars D and G were increased. This was because of the relief zone created above the longwall of the lower seam. However, the multi-seam mining had negative effects on the stability factors of pillars C, E, F and H. Especially for pillars C and H, the stability factors were reduced from 5.0 to 2.8 and from 5.1 to 2.4 respectively. Through the pillars were endangered by the multi-seam mining interactions, the stability factors were all large enough to keep the pillars from failure, which agrees well with the underground observation that the pillars in the active mine were still intact.

Table 5.2 Stability factors calculations of the pillars at the upper seam mains

\begin{tabular}{|c|c|c|c|c|c|c|c|c|c|c|c|c|c|}
\hline \multirow[b]{2}{*}{ Pillar No. } & \multicolumn{4}{|c|}{ Dimensions } & \multicolumn{3}{|c|}{ No Multi-seam Interaction } & \multicolumn{6}{|c|}{ With Multi-seam Interaction } \\
\hline & $\begin{array}{c}\mathrm{L} \\
(\mathrm{m}) \\
\end{array}$ & $\begin{array}{l}\mathrm{W} \\
(\mathrm{m}) \\
\end{array}$ & $\begin{array}{c}\mathrm{h} \\
(\mathrm{m})\end{array}$ & \begin{tabular}{|c|}
$\begin{array}{c}\text { Entry } \\
(\mathrm{m})\end{array}$ \\
\end{tabular} & $\begin{array}{c}\text { Pillar Strength } \\
(\mathrm{MPa})\end{array}$ & $\begin{array}{c}\text { Load } \\
(\mathrm{MPa}) \\
\end{array}$ & $\mathrm{SF}$ & $\begin{array}{c}\text { Vertical Strain } \\
(\mathrm{m} / \mathrm{m}) \\
\end{array}$ & \begin{tabular}{|c}
$\begin{array}{c}\text { Horiz. Strain } \\
(\mathrm{m} / \mathrm{m})\end{array}$ \\
\end{tabular} & \begin{tabular}{|c|}
$\begin{array}{c}\text { Void Inten. } \\
(\mathrm{m} / \mathrm{m})\end{array}$ \\
\end{tabular} & \begin{tabular}{|c|}
$\begin{array}{c}\text { Pillar Strength } \\
(\mathrm{MPa})\end{array}$ \\
\end{tabular} & $\begin{array}{c}\text { Load } \\
(\mathrm{MPa})\end{array}$ & $\mathrm{SF}$ \\
\hline $\mathrm{A}$ & 26.4 & 18.3 & 1.5 & 5.5 & 34.9 & 7.3 & 4.8 & $0.00 \mathrm{E}+00$ & $0.00 \mathrm{E}+00$ & $0.00 \mathrm{E}+00$ & 34.9 & 7.3 & 4.8 \\
\hline $\mathrm{B}$ & 25.2 & 18.3 & 1.5 & 5.5 & 34.5 & 7.4 & 4.7 & $0.00 \mathrm{E}+00$ & $0.00 \mathrm{E}+00$ & $0.00 \mathrm{E}+00$ & 34.5 & 7.4 & 4.7 \\
\hline $\mathrm{C}$ & 30.0 & 18.3 & 1.5 & 5.5 & 36.0 & 7.2 & 5.0 & $1.73 \mathrm{E}-03$ & $2.00 \mathrm{E}-02$ & $2.18 \mathrm{E}-02$ & 20.2 & 7.2 & 2.8 \\
\hline $\mathrm{D}$ & 31.7 & 18.3 & 1.5 & 5.5 & 36.4 & 7.1 & 5.1 & $1.64 \mathrm{E}-02$ & $-2.19 \mathrm{E}-02$ & $-5.91 \mathrm{E}-03$ & 44.9 & 7.1 & 6.3 \\
\hline $\mathrm{E}$ & 24.5 & 18.3 & 1.5 & 5.5 & 34.2 & 7.4 & 4.6 & $4.57 \mathrm{E}-03$ & $0.00 \mathrm{E}+00$ & $4.57 \mathrm{E}-03$ & 29.6 & 7.4 & 4.0 \\
\hline $\mathrm{F}$ & 25.9 & 18.3 & 1.5 & 5.5 & 34.7 & 7.4 & 4.7 & $4.56 \mathrm{E}-03$ & $0.00 \mathrm{E}+00$ & $4.56 \mathrm{E}-03$ & 30.1 & 7.4 & 4.1 \\
\hline $\mathrm{G}$ & 24.4 & 18.3 & 1.5 & 5.5 & 34.1 & 7.4 & 4.6 & $8.87 \mathrm{E}-03$ & $-1.57 \mathrm{E}-02$ & $-7.02 \mathrm{E}-03$ & 43.8 & 7.4 & 5.9 \\
\hline $\mathrm{H}$ & 31.9 & 18.3 & 1.5 & 5.5 & 36.5 & 7.1 & 5.1 & $1.27 \mathrm{E}-02$ & $1.71 \mathrm{E}-02$ & $2.98 \mathrm{E}-02$ & 17.1 & 7.1 & 2.4 \\
\hline $\mathrm{I}$ & 32.9 & 18.3 & 1.5 & 5.5 & 36.7 & 7.1 & 5.2 & $-7.12 \mathrm{E}-07$ & $5.78 \mathrm{E}-05$ & $5.71 \mathrm{E}-05$ & 36.7 & 7.1 & 5.2 \\
\hline $\mathrm{J}$ & 23.0 & 18.3 & 1.5 & 5.5 & 33.5 & 7.5 & 4.5 & $0.00 \mathrm{E}+00$ & $0.00 \mathrm{E}+00$ & $0.00 \mathrm{E}+00$ & 33.5 & 7.5 & 4.5 \\
\hline
\end{tabular}

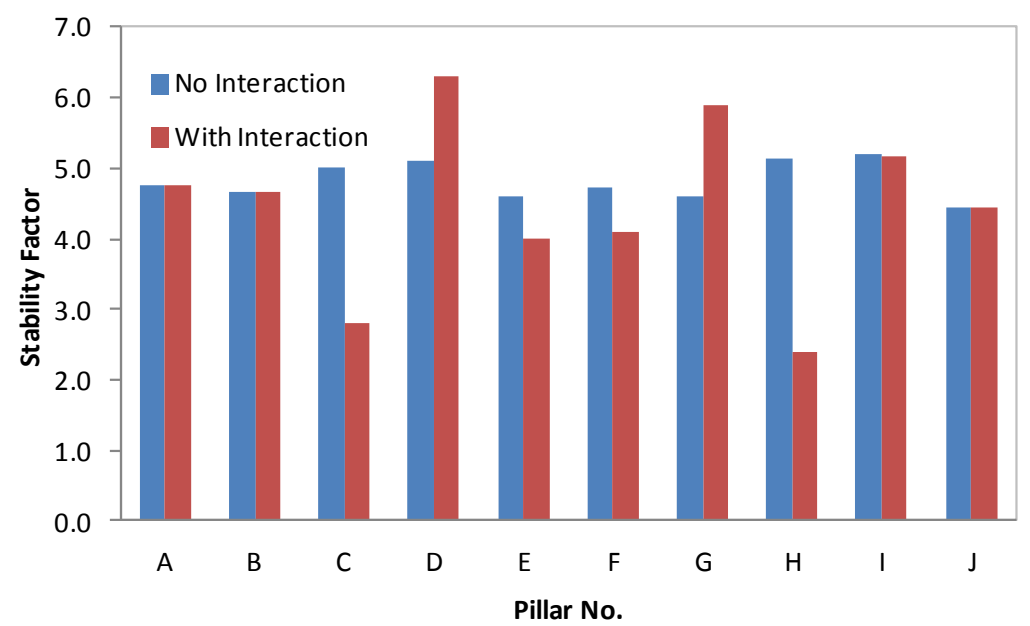

Figure 5.21 Stability factors of the pillars at the upper seam mains with and without multi-seam mining interaction

The entry between pillars C and D was located in the high void intensity zone (Fig. 5.20), where the multi-seam interaction would have had severe effects on the roof of this entry. The maximum strain of the mine roof in the Sewickley seam at the location near the edge of the support pillar was $4.24 \times 10^{-2} \mathrm{~m} / \mathrm{m}$. This was higher than the proposed critical tensile strain for 
roof cracking, $2 \times 10^{-3} \mathrm{~m} / \mathrm{m}$ and more than sufficient to cause the roof failure in the active mine. The roof support in this area should be stronger than other areas. This agrees well with the field investigations that there was a roof fall that occurred at the crosscut between pillars C and D (Fig. 5.18).

\subsection{Summaries}

The enhanced subsurface subsidence prediction model can be used to analyze the interactions in multi-seam mining operations. A number of important parameters to quantify the subsurface subsidence influences to subsurface mine structures have been proposed. They include: (1) the critical strain for causing tensile cracks in the mine roof and floor, (2) the method to determine subsidence induced pillar load, and (3) the failure criteria based method to determine pillar strength under the influence of subsurface subsidence. The methodology to assess the multi-seam mining interactions has been incorporated in the subsidence prediction model CISPM-MS for multi-seam mining operations.

CISPM-MS successfully incorporated the four models, subsurface subsidence predictions, multi-seam interaction, mine structure stability evaluations and multi-seam mining subsidence predictions, and was capable of predicting multi-seam mining subsidence as well as evaluating multi-seam mining interactions. With easy input/output interfaces and fast computation speeds, this program can serve as a great tool for mine designing and ground control works for multiseam mining operations.

Two case studies, a case of remnant structure and a case of mining inside subsidence influence zone, were conducted to illustrate CISPM-MS's capability to assess the multi-seam mining interactions, which showed a good agreement with the field observations. Multi-seam mining interactions may affect the stability of the roof, floor, rib and pillars, and induce high cost of supplemental supports or even more severe ground control problems. Understanding of the mechanism of these multi-seam mining interactions will greatly help mitigate the negative effects of these interactions. Assessing the multi-seam mining interactions with reliable tools before and during the mining operation is essential for the planning and designing of multi-seam mining operations. A profitable and safe multi-seam operation can be achieved through this process. 


\section{CHAPTER 6 LONGWALL MINING IMPACTS ON HYDROLOGICAL SYSTEM}

Mining operations under surface water bodies (lakes, streams, and impoundments) and subsurface water bodies (flooded mine workings and subsurface aquifers) become more and more common due to the depletion of easy-to-mine coal seams (Michalek, and Wu, 2000). The longwall mining subsidence could affect the surface streams, ponds, water table and subsurface aquifers to various degrees. More severe safety problems of sudden water inrushes could occur when subsidence induced fractures connect the surface and subsurface water bodies with active mine workings. The sudden release of water could easily flood the current active mine workings with possible fatalities (Vutukuri, and Singh, 1995). Attempts will be made in this study to explore the mechanisms involved in longwall subsidence's impact on surface and subsurface hydrological systems.

\subsection{Introduction}

\subsection{Impacts on Hydrological System}

Other than disturbances to surface structures, longwall mining operations in shallow underground coal mines (depth less than $500 \mathrm{ft}$ ) can have significant influences on surface and subsurface hydraulic system. The potential influences on the hydraulic system include: (1) water pooling on the surface area, (2) temporary redistribution of the hydrological system, and (3) dewatering of surface streams and subsurface aquifers (Luo and Peng, 2010). In order to protect the water resources and to avoid significant mining influences on the environment, it is very important to have a tool to quantify the impacts of longwall subsidence on the surface and subsurface hydraulic system.

The water pooling is a simple subsidence-induced surface phenomenon under certain surface topography conditions. If the gradient of the surface stream bed is less than the subsidence-induced maximum surface slope, water pools will be formed along the surface stream. The extent and depth of the water pools depend on the surface topography and the characteristics of the surface subsidence basin. 
The later two types of problems depend on subsurface deformations, the geological and the hydrological system of the overburden strata. The third one could have a significant impact on mine safety, especially when new mines are placed under flooded old mines. In recent years, a number of feasibility studies had been conducted for mining under flooded old mines. The previous version of the subsurface subsidence prediction model developed by the Luo and Peng (2000) has been used in the studies. The critical void intensity that could lead to significant water leakage has also been deducted and the results agreed with observed heights of fractured zones over the longwall gobs well.

\subsection{Methodology of the Study}

The newly developed subsurface subsidence prediction model can be applied in the studies of the effects of longwall mining on the hydrological system. This model is able to consider the effects of the massive hard strata on the distributions of subsidence and total strain in the overburden strata. The voids created by differential subsurface subsidence in the upper aquifer strata can serve as additional storages for water from surface water streams and subsurface aquifers. The differential subsurface vertical and horizontal movements can create contiguous zones with high void intensity in the overburden strata near the edges of the longwall panel as well as a short distance behind the moving longwall face. The subsidence-induced total strain would change the hydraulic conductivity in the overburden strata.

This paper attempts to link the predicted subsurface total strain to the hydraulic conductivity. A numerical simulation model incorporating the distribution field of intact and disturbed hydraulic conductivity is developed for studying the longwall subsidence effects of the hydrological system. The model is examined and compared with various case studies.

\subsection{Temporary Redistribution of Hydrological Systems}

The volume of the subsidence basin at different levels above a mined longwall panel varies inversely with the depth. For an aquifer, the volume difference in the subsidence basins between its lower and upper aquifer boundaries has to be filled with water from other parts of the disturbed aquifer, other aquifers in the neighboring area or from surface water bodies. As a result, the water table of the subsurface aquifers will be lowered and the flow rate of surface streams could be reduced. 


\subsubsection{Temporary Water Level Change}

This type of influence is induced by the differential volume of subsidence basins between the lower and upper boundaries of an aquifer. For a longwall panel with a width of $W$, the final subsided area along a transverse cross section at a level of $h$ distance above the mined coal seam can be simply determined by Eq. 6.1. Since final subsidence parameters $a$ and $d$ vary with depth (h), as shown in Eqs. 3.3 and 3.4, the subsided area also depends on the depth.

$$
A(h)=a \cdot m \cdot(W-2 d)
$$

For a confined aquifer with its lower and upper boundaries being $h_{1}$ and $h_{2}$ above the mined coal seam, the volume of void created in this aquifer for a unit length along the panel's longitudinal direction can be determined by Eq. 6.2. It should be noted that Eq. 6.2 shows the effect of mining a single longwall panel only.

$$
\Delta A\left(h_{1-2}\right)=A\left(h_{1}\right)-A\left(h_{2}\right)
$$

If an $L$ length of the longwall panel is located under the aquifer, the total void that subsidence will create in the aquifer is about $L \times \Delta A\left(h_{1-2}\right)$. If this aquifer is not communicative with the overlying and underlying aquifers, it will become unsaturated and the water level will be lowered by $x$ amount as determined by Eq. 6.3.

$$
x=h_{2}-h_{1}-\frac{V \phi\left(h_{2}-h_{1}\right)}{V \phi+L \cdot \Delta A\left(h_{1-2}\right)}
$$

In Eq. 6.3, $V$ and $\phi$ are the total volume and porosity of this confined and saturated aquifer strata before being affected by the subsidence process, respectively. For an unconfined aquifer near the ground surface, the total void and the lowering of the water level under the subsidence influence can be determined in a similar way. The symbol $h_{2}$ represents the original water level in the aquifer before subsidence. If the resultant water level is lower than a surface stream flowing through the area, the stream water will be drawn to fill the created void. If the flow of the stream is small, the stream could experience temporary flow loss. The time length for the recovery of the stream will depend largely on weather conditions.

\subsubsection{Subsided Area over Longwall Panels}

Figure 6.1 shows the calculated subsided areas for four typical longwall panel widths, 244, 305, 366 and $457 \mathrm{~m}(800,1,000,1,200$ and 1,500 ft), at different distances above a $2.1 \mathrm{~m}(7$ $\mathrm{ft}$ ) high mined coal seam. This figure can be used to estimate the total void created in an aquifer. For example, a sandstone aquifer is located from 110 to $125 \mathrm{~m} \mathrm{(360} \mathrm{ft} \mathrm{to} 410 \mathrm{ft}$ ) above a 
longwall panel, with its width and mining height being $366 \mathrm{~m}(1,200 \mathrm{ft})$ and $2.1 \mathrm{~m}(7 \mathrm{ft})$, respectively. Using Fig. 6.1, the subsided areas at the lower and upper boundaries of the aquifer are determined to be 407 and $389 \mathrm{~m}^{2}\left(4.38 \times 10^{3}\right.$ and $\left.4.19 \times 10^{3} \mathrm{ft}^{2}\right)$, respectively. If a $610 \mathrm{~m}(2,000$ $\mathrm{ft}$ ) long section of the longwall panel is located under the aquifer, it would create a void of $10,760 \mathrm{~m}^{3}\left(3.8 \times 10^{5} \mathrm{ft}^{3}\right)$ in this aquifer after the subsidence process is complete. If it is an unconfined aquifer near ground surface, this newly created void will have to be filled by surface water bodies. If it is a confined aquifer, the water level will be lowered to some degree, affecting some domestic wells.

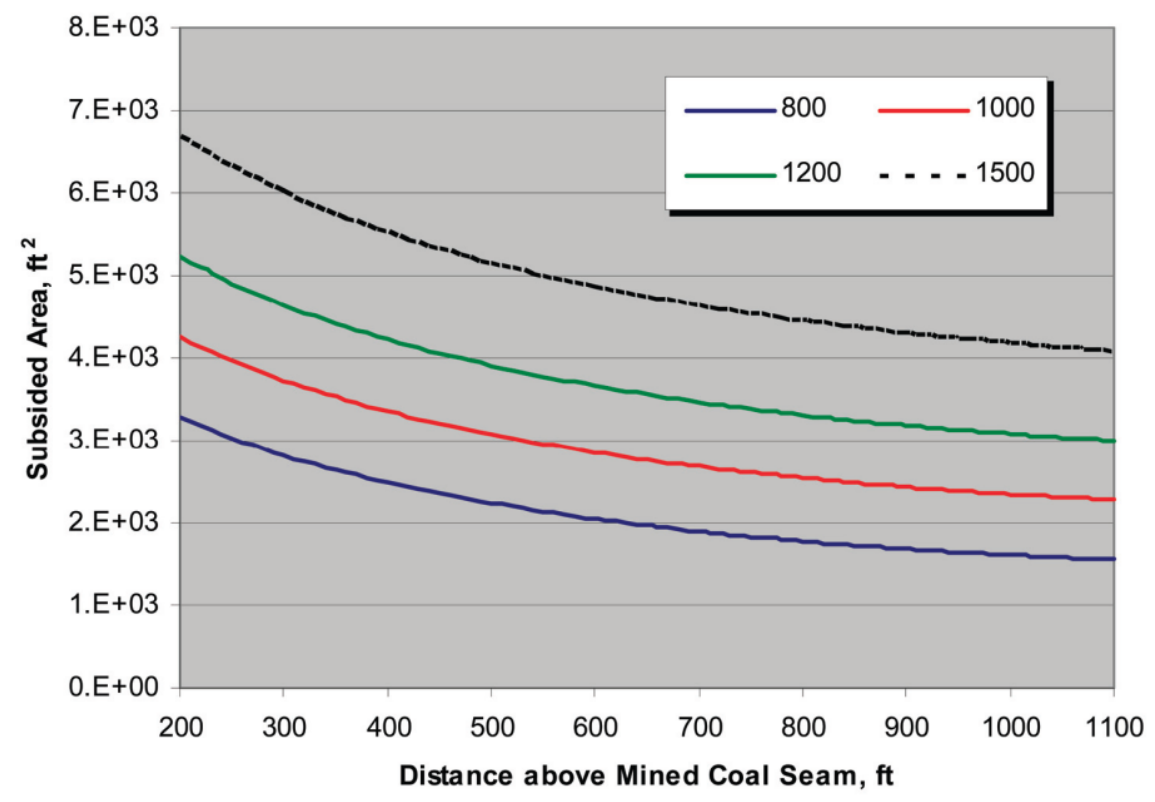

Figure 6.1Predicted final subsided area for four panel widths

\subsection{Mining Induced Subsurface Permeability Change}

Permeability is a property of soil or rock, which describes the ease with which water can move through the pore spaces or fractures. In Darcy's law, it relates the water flow rate through a unit cross-sectional area under a unit gradient of hydraulic head. The permeability for groundwater flow in a particular rock is heavily dependent both on the type and micro-structure of the rock as well as the stress conditions applied to rock (Rutqvist and Stephansson, 2003). It is apparent that a sufficient tensile stress applied could increase the porosity of the rock and consequently its permeability (Singhal and Gupta, 2010). Therefore, the stress effects on the permeability should be considered in the groundwater flow simulations. 


\subsubsection{Conceptual Model}

To examine the effects of subsurface subsidence on overburden hydrological system, the first effort is to establish the stress-permeability relationship (Bai and Elsworth, 1994). Longwall mining induces stress and strain changes in the overburden strata. Tension and compression zones will be formed around the edges of the panel from the mining horizon to the ground surface. Consequently, additional pores will be created in the tension zones while the original pores will be shrunk in the compression zones. These changes can have a profound effect on the rock mass permeability. Field studies have shown both increase and decrease of approximately one order of magnitude in the permeability of the rock mass above a longwall panel (Hasenfus et al., 1988; Esterhuizen and Karacan, 2005).

Longwall subsidence can cause varying degrees of disturbance to the overburden strata as shown in Fig. 6.2. The caved zone ranges in thickness from two to ten times of the mining height (Peng, 2006). It is characterized by irregular rock fragments as well as high void ratios and permeability. Laboratory tests have shown that the void ratio in the caved zone can be in the order of 30\%-45\% (Esterhuizen and Karacan, 2005).

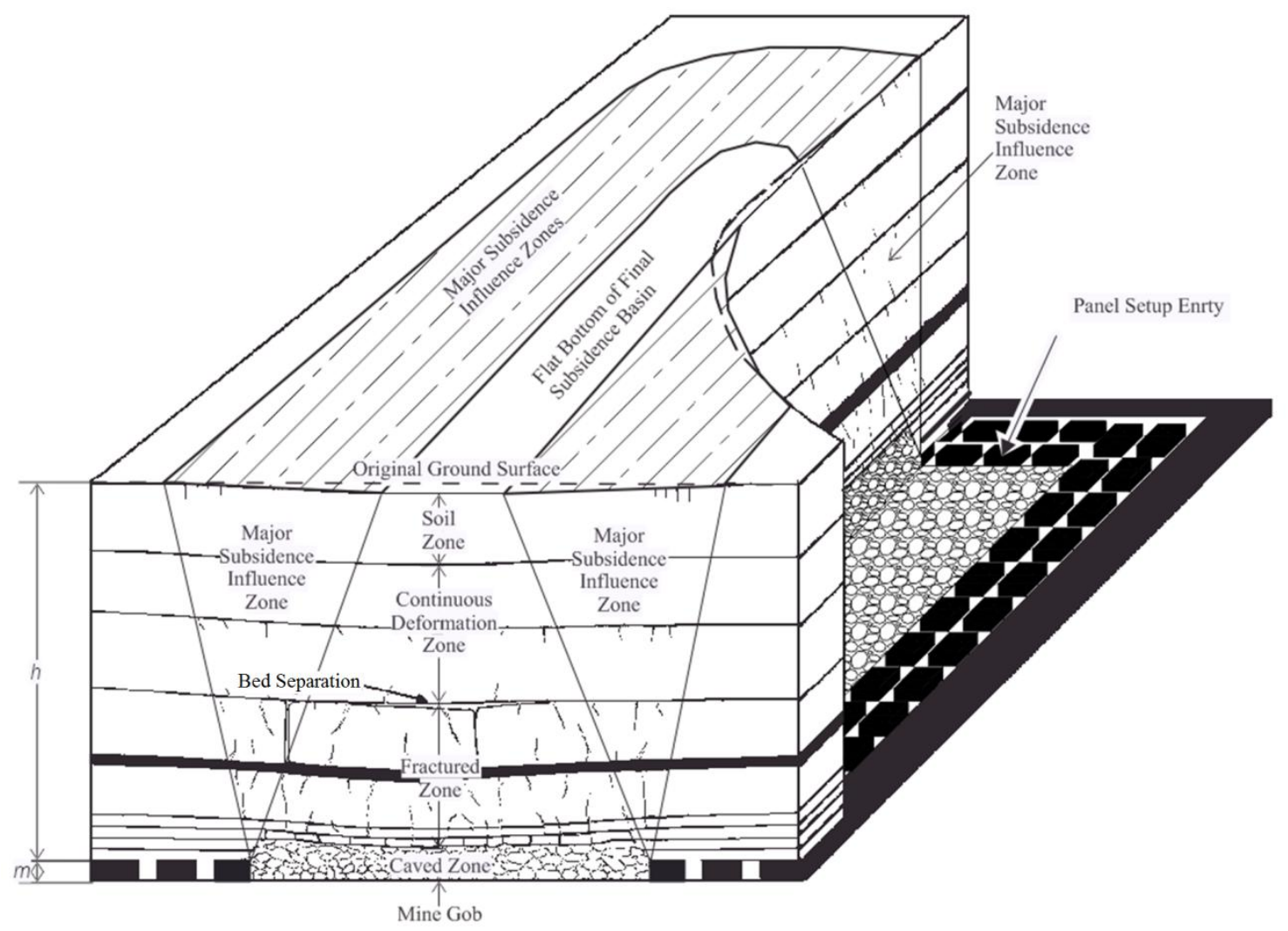

Figure 6.2 Overburden deformation zones caused by longwall subsidence 
The fractured zone is located above and around the caved zone which ranges in thickness from 28 to 52 times the mining height. It is characterized by vertical and/or sub-vertical fractures and horizontal cracks due to bed separation. In this zone, water can drain directly into the caved zone and then to the mine gob. Measurements of permeability in the fractured rock have shown up to forty fold increases in permeability (Hasenfus et al., 1988).

Between the fractured zone and the ground surface is the continuous deformation zone. In this zone, the strata deform gently without causing any major cracks that extend long enough to cut through the thickness of the strata, as in the fractured zone. The mine subsidence has insignificant effects on permeability and water storage in this zone.

On the surface, there is a soil zone of varying depth depending on the location. In this zone, cracks open and close as the longwall face comes and goes. In general, cracks on and near the panel edges tend to remain open permanently, whereas those in and around the center of the panel will close back up when the longwall face has passed for a sufficient distance. The surface fracture zone potentially has vertically-transmissive surface cracks and disruptions, which can cause the dewatering of the surface water bodies (Kendorski, 2006).

\subsubsection{Mathematical Model}

The differential subsurface vertical and horizontal movements could create contiguous zones with high void intensity in the overburden strata near the edges of the longwall panel as well as a short distance behind the longwall face. When the void intensity is larger than the certain critical value, it could lead to significant dewatering of water bodies connected to such zones. Since the lost water will flow to the mined gobs, the impacts of this type of subsidence influences will be more severe to the hydrological system than the other two types. If the connected surface and/or subsurface water bodies including old mine workings are large, it could lead to sudden water inrush to the longwall workings and create a hazard condition.

Under increased compressive stress, the voids in and the permeability of an elastic rock will be reduced. However, when the stress on the rock exceeds the elastic limit the rock will behave plastically, in which state the stress changes insignificantly while the strain increases quickly. Therefore, most of the stress-permeability models can not accurately predict the permeability change for large deformation conditions such as those in the caved and fractured zones. For this reason, the strain-permeability model is a better approach for estimating the permeability change in problems dealing with large rock deformation. 
Reiss (1980) links a rock's permeability to its porosity by Eq. 6.4. In the equation, $K$ is the permeability under mining influence, $K_{0}$ is the initial permeability, $\phi$ is the porosity under mining influence, $\phi_{0}$ is the initial porosity.

$$
\frac{K}{K_{o}}=\left(\frac{\phi}{\phi_{0}}\right)^{3}
$$

The porosity under mining influence can be determined by the initial porosity and the total strain $\left(\varepsilon_{t}\right)$ using the following equation.

$$
\phi=\frac{\phi_{0}+\varepsilon_{t}}{1+\varepsilon_{t}}
$$

By combining Eqs. 6.4 and 6.5, the resulting mathematical formula to determine the permeability change at a given subsurface point is shown as Eq. 6.6. In this equation, the total strain $\left(\varepsilon_{t}\right)$ at the specified point can be predicted using the subsurface subsidence prediction model.

$$
K=K_{o}\left(\frac{1+\frac{\varepsilon_{t}}{\phi_{0}}}{1+\varepsilon_{t}}\right)^{3}
$$

Figure 6.3 shows the relationship between the subsidence-induced total strain and the permeability under different initial porosity conditions $(0.05,0.10,0.15$, and 0.20$)$. The permeability increases with the total strain. The permeability of the rock with lower porosity will be more significantly affected by the total strain.

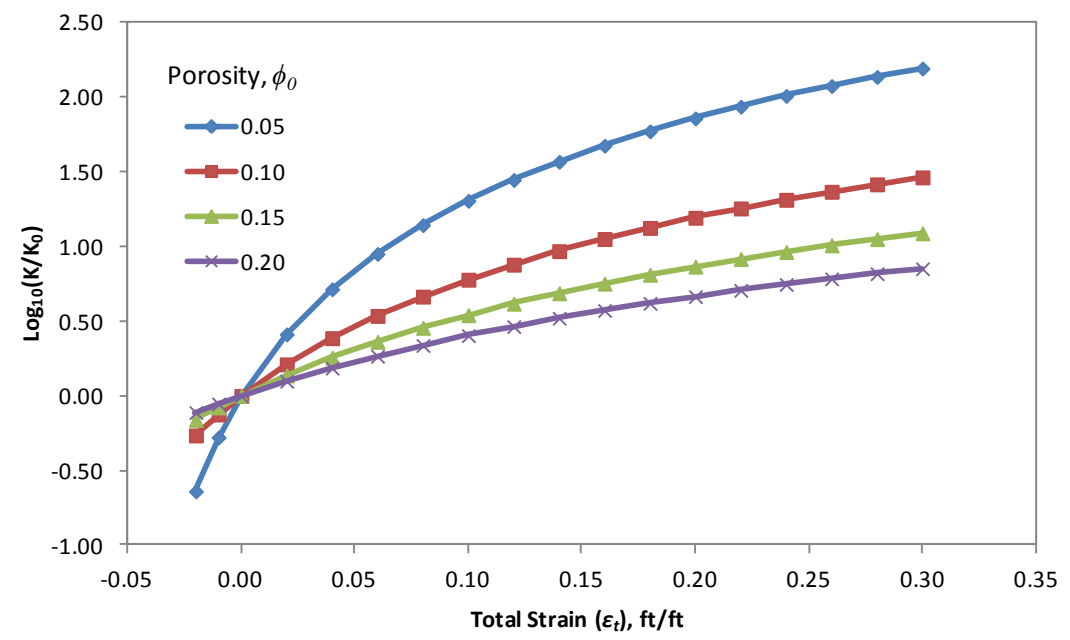

Figure 6.3 Relationship of total strain and permeability 


\subsection{Groundwater Flow Modeling}

A numerical groundwater flow model is the mathematical representation of an aquifer in a computer. Groundwater models describe groundwater flow and transport processes using mathematical equations based on certain simplifying assumptions. These assumptions typically involve directions of flow, geometries of the aquifers, the heterogeneity or anisotropy of sediments or bedrocks within the aquifers. Because of the simplifying assumptions embedded in the mathematical equations and many uncertainties in the values of data required by the model. The models were viewed as an approximation and not an exact duplication of field conditions (Mandle, 2002).

\subsubsection{Darcy's Law}

Water flows from high elevation to low elevation. In 1856, a French hydraulic engineer named Henry Darcy investigated the flow of water through porous medium. His experiments demonstrated that the rate of flow i.e. volume of water per unit time, $Q$ is directly proportional to the cross-sectional area, $A$, and head loss, $h_{L}$, and inversely proportional to the length of the flow path, $L$. By introducing proportionality constant $(K)$, the Darcy's law can be written as,

$$
Q=K A \frac{d h}{d l}
$$

where,

$$
\begin{aligned}
& K \quad=\text { the hydraulic conductivity of the porous medium. } \\
& d h / d l=\text { the hydraulic gradient. }
\end{aligned}
$$

\subsubsection{General Equations of Flow}

Ground water satisfies the equation of continuity. It expresses the principle of conservation of mass, i.e. the net inward flux through an element volume of an aquifer in the flow field must be equal to the rate at which matter is accumulating within the element as shown in Fig. 6.4. For the incompressible fluid and using Darcy's law, Eq. 6.8 can be obtained and it represents transient flow through a saturated anisotropic medium (Singhal, and Gupta, 2010).

$$
\frac{\partial}{\partial x}\left(K_{x} \frac{\partial h}{\partial x}\right)+\frac{\partial}{\partial y}\left(K_{y} \frac{\partial h}{\partial y}\right)+\frac{\partial}{\partial z}\left(K_{z} \frac{\partial h}{\partial z}\right) \pm \bar{W}=S_{s}^{\prime} \frac{\partial h}{\partial t}
$$

Where,

$\bar{W} \quad=$ the volume of flux per unit volume of the porous medium (a positive sign for the inflow and negative sign for the outflow). 
$S_{s}{ }^{\prime} \quad=$ specific storage, which is defined to be the volume of water released from storage per unit in head $(h)$ per unit volume of aquifer.

For a homogeneous and isotropic medium, Eq. 6.8 can be reduced to,

$$
\frac{\partial^{2} h}{\partial x^{2}}+\frac{\partial^{2} h}{\partial y^{2}}+\frac{\partial^{2} h}{\partial z^{2}}=\frac{S_{s}}{K} \frac{\partial h}{\partial t}
$$

In a horizontal confined aquifer of thickness, $b$, the storage coefficient, $S$ will be equal to $S_{s} b$ and $T=K b$. Therefore, Eq. 6.9 can be reduced to,

$$
\frac{\partial^{2} h}{\partial x^{2}}+\frac{\partial^{2} h}{\partial y^{2}}+\frac{\partial^{2} h}{\partial z^{2}}=\frac{S}{T} \frac{\partial h}{\partial t}
$$

This is the partial differential equation, governing non-steady state groundwater flow in a confined aquifer.

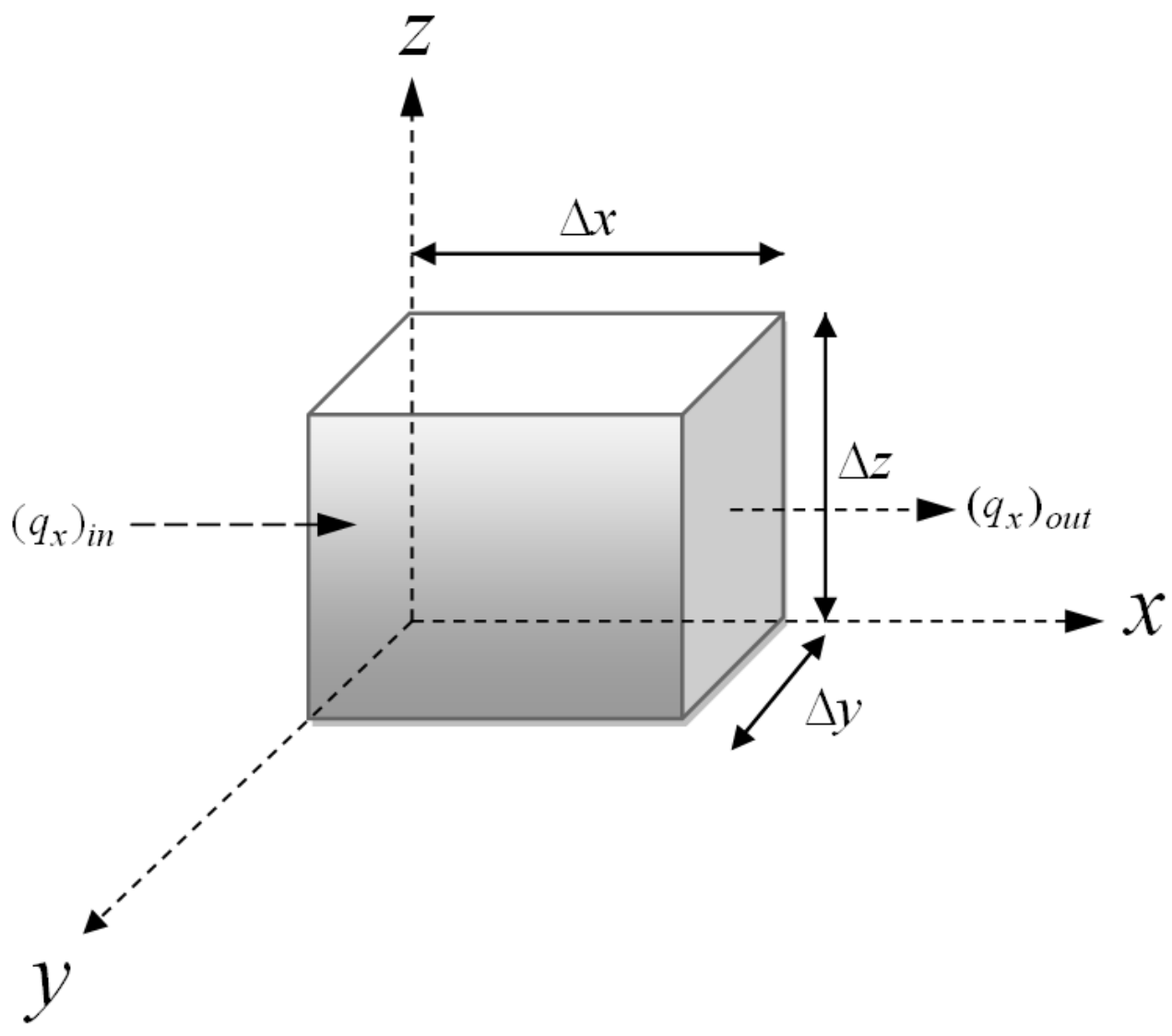

Figure 6.4 Net flow of the representative elementary volume

If the flow is steady, $\partial \mathrm{h} / \partial \mathrm{t}=0$, i.e. velocity and pressure distribution do not change with time, Eq. 6.10 changes to, 


$$
\frac{\partial^{2} h}{\partial x^{2}}+\frac{\partial^{2} h}{\partial y^{2}}+\frac{\partial^{2} h}{\partial z^{2}}=0
$$

\subsection{Application Case}

The proposed methodology is applied to assess the subsidence influence to a large water reservoir that provides water needs to a nearby small city.

\subsubsection{Case Mine Conditions}

Mining operation in one longwall panel is planned to be conducted directly under the tail half of the reservoir while its earth dam is located beyond the panel over the solid coal as shown in Fig. 6.5. The longwall panel width is $434 \mathrm{~m}(1,425 \mathrm{ft})$. The smallest overburden depth under the reservoir area is about $219 \mathrm{~m}(720 \mathrm{ft})$.

Two main important concerns for this project are: (1) whether the longwall mining subsidence can induce leakage problems and change the water-holding capacity of the reservoir, and (2) whether water leaked from the reservoir would affect the underground longwall operation. In order to address these two concerns, a comprehensive subsidence study is conducted. In the study, it is important to find out whether contiguous highly-fractured zones will be formed in the overburden strata to connect the surface reservoir and the underground longwall gobs.

After the construction of the reservoir, a layer of silt with varying thickness, up to $4.6 \mathrm{~m}$ $(15 \mathrm{ft})$, has been deposited on the bottom of the reservoir after its construction decreasing its water-holding capacity. The provided core log information from a nearby geological exploration

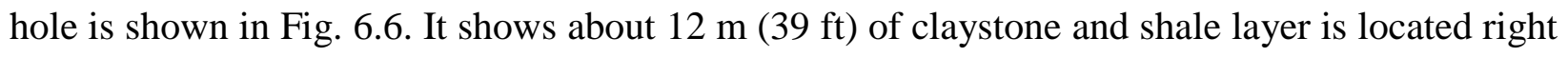
below the reservoir bottom as shown in Fig. 6.6. After a $2.4 \mathrm{~m}(7.9 \mathrm{ft})$ sandstone layer, another $11 \mathrm{~m}$ (36 ft) of claystone layer follows. The next $46 \mathrm{~m}(150 \mathrm{ft})$ overburden strata contains claystone layers of 4.3, 3.0, 2.7 and $8.5 \mathrm{~m}(14,10,9$ and $28 \mathrm{ft})$ thick. Therefore, the impermeable claystone layers account for about $58 \%$ of the top $70 \mathrm{~m}(230 \mathrm{ft})$ overburden strata. Two layers of sandstone 8.5 and $18.3 \mathrm{~m}$ (28 and $60 \mathrm{ft}$ ) thick are located about 73 and $122 \mathrm{~m} \mathrm{(240} \mathrm{and} 400 \mathrm{ft}$ ) below the bottom of the reservoir, respectively. It is also important to note that the presence of substantial limestone beds in the roof of the coalbed. From bottom up, the maximum height of the coal seam to be mined is $2.8 \mathrm{~m}(9.1 \mathrm{ft})$. Three limestone layers, 9.1, 36.6 and $2.4 \mathrm{~m}(30,120$ 
and $8 \mathrm{ft})$ thick, are located about 12, 27, $76 \mathrm{~m} \mathrm{(40,90} \mathrm{and} 250 \mathrm{ft})$ above the coal seam. The limestone is stiffer and stronger than the shale, claystone and siltstone strata.

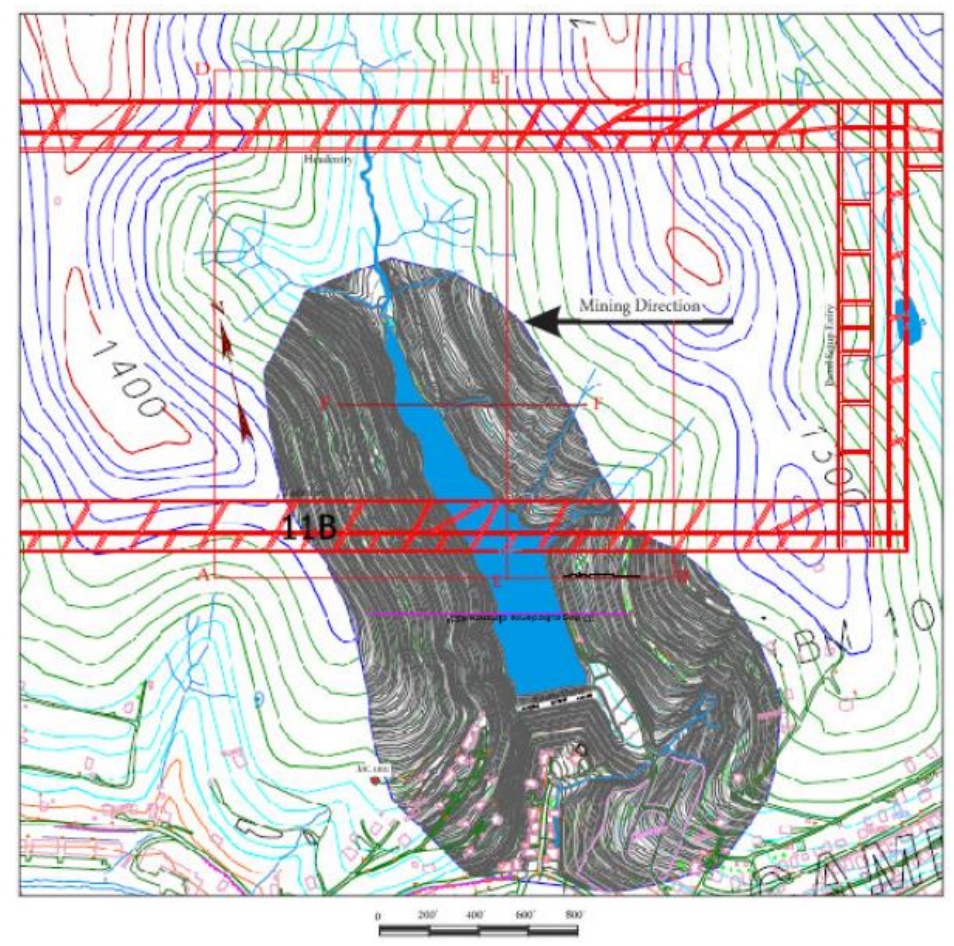

Figure 6.5 The reservoir and the longwall panels under it

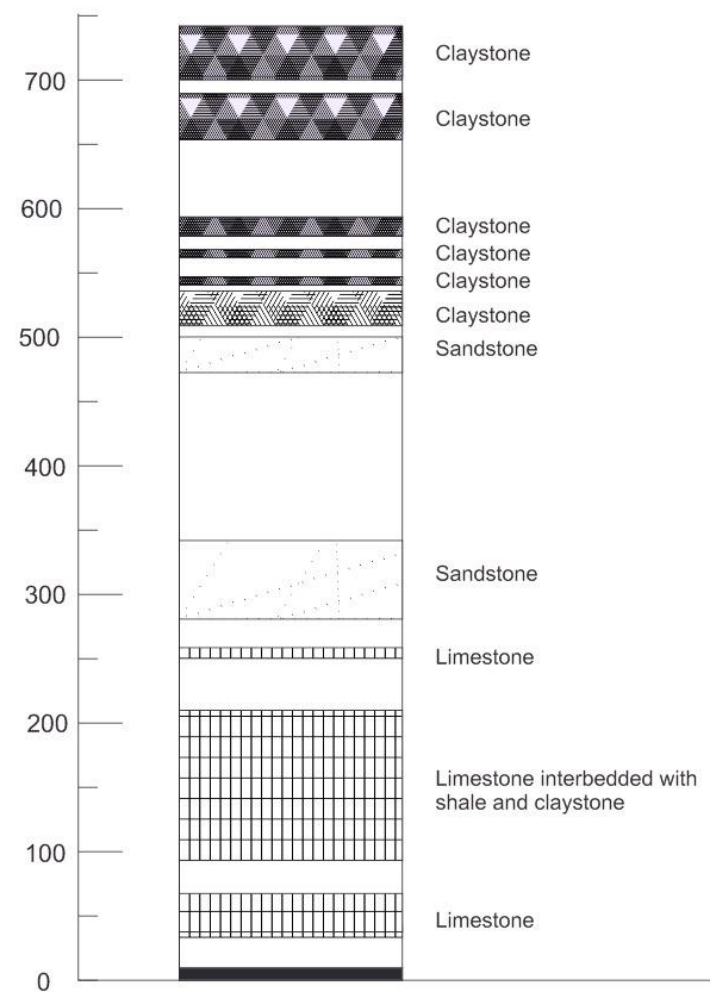

Figure 6.6 Geological column at mine site 


\subsubsection{Surface and Subsurface Subsidence Predictions}

In the study, surface final and dynamic predictions using CISPM-W, a comprehensive surface subsidence program package, are performed. The predicted maximum final and dynamic surface tensile strains at the bottom of the reservoir are just capable of initiating hairline cracks on the ground surface. However, due to the thick silt deposit on the reservoir bottom, such hairline cracks are likely to be filled with the silt once they are created.

Using the new subsurface subsidence prediction model, the final movements and deformations in the subsurface strata are predicted. After substituting the predicted final void intensity into Eq. 10, the subsidence influence to the permeability of overburden strata under the reservoir can be determined and the results are plotted in Fig. 6.7. The bridging effect of the 36.6 m (120 ft) thick limestone layer located about $27 \mathrm{~m} \mathrm{(90} \mathrm{ft)} \mathrm{above} \mathrm{the} \mathrm{coal} \mathrm{seam} \mathrm{is} \mathrm{clearly} \mathrm{shown}$ in the figure. This thick competent rock layer considerably changes the distribution patterns of strata deformations and the permeability below and above it. The prediction shows that the maximum subsidence influence on the strata permeability at the bottom of reservoir is that the initial permeability will be doubled. A zone of high permeability increase occurred in the area a short distance inside the longwall panel edge.

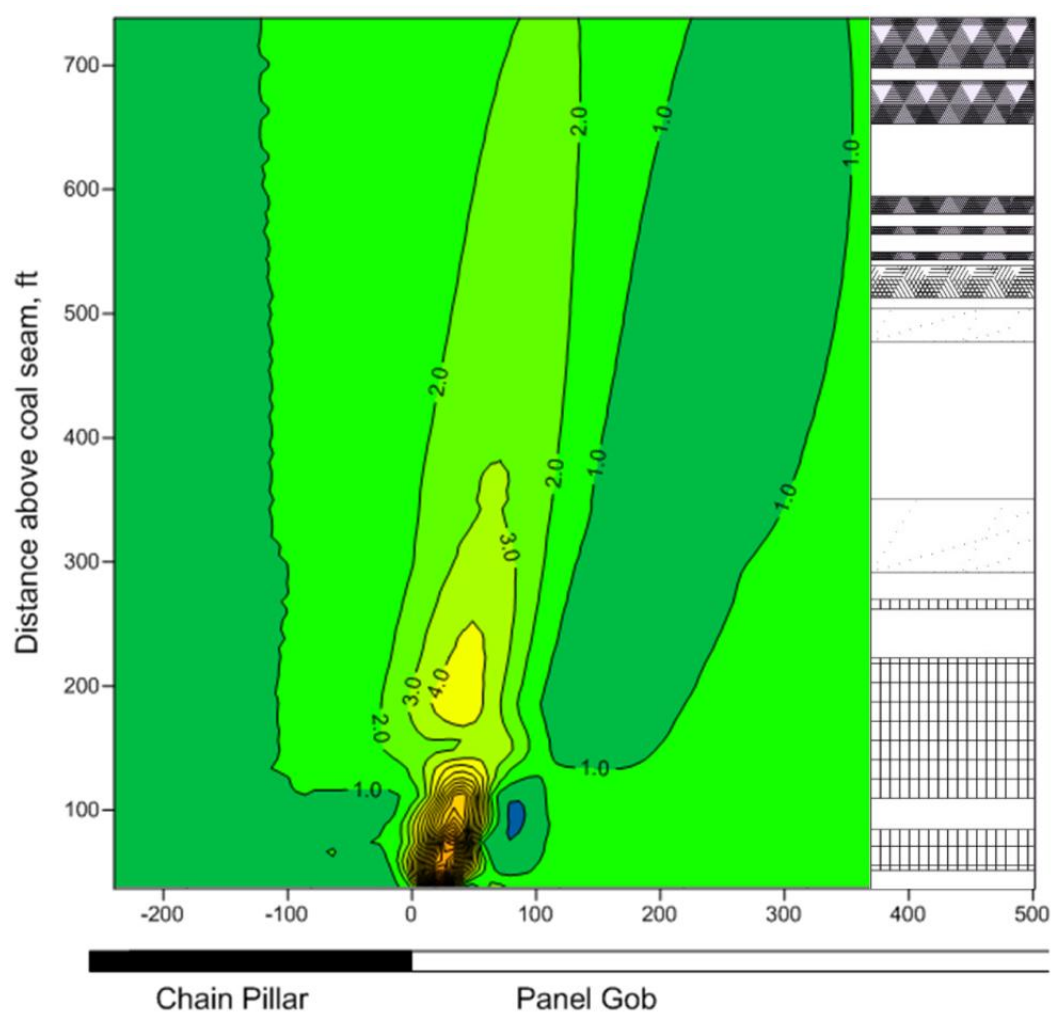

Figure 6.7 Permeability change $\left(k / k_{0}\right)$ caused by the mining of the longwall panel 


\subsubsection{Subsidence Induced Ground Water Flow}

In order to assess the possibility for the reservoir water to leak into the longwall gob in large quantity, a numerical simulation study has been conducted. As shown in Fig. 6.7, the most possible water leakage path is along the high permeability increase zone from the surface to the mine level near the panel edge. The numerical study focused on assessing the possibility of the water leakage through this path. One half width of the longwall panel was selected for the numerical simulation. The 2-D numerical model consisted of about 2,300 finite elements and simulated a $228 \mathrm{~m}(748 \mathrm{ft})$ in width and $225 \mathrm{~m}$ (738 ft) in depth of the overburden above the longwall panel as shown in Fig. 6.8. Element sizes varied, but were selected so that the element

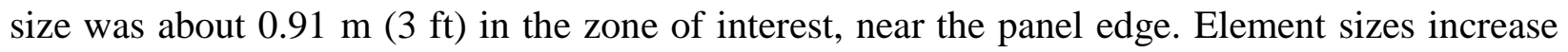
with increasing distance from the area of interest.

In building the numerical model, the ground water elevation at the mine gob was set to be zero, and the ground water elevation at the surface equaled to the reservoir water elevation minus the coal seam elevation $225 \mathrm{~m}$ (738 ft). The vertical boundaries of the model were set to be impermeable. The actual overburden sequence has been simplified, combining lithological layers to represent rock characteristics of primary importance to obtain an average response. Two numerical models were built to represent the pre-mining and post-mining conditions respectively.

Table 6.1 presents the initial hydraulic property of the coal measure rocks used in the numerical simulation, which is determined from published values (Esterhuizen, and Karacan, 2005). The hydraulic permeability of the overburden strata after mining is calculated based on the predicted final total strain distribution and the results are plotted in Fig. 6.8. It shows that a zone of high permeability is located in the sandstone strata between 61 and $91 \mathrm{~m} \mathrm{(200} \mathrm{and} 300 \mathrm{ft}$ ) above the coal seam. The longwall subsidence induces a high total strain and high permeability in the area located near but inside the longwall panel edge. In this area, the zones with high permeability are limited within the $106 \mathrm{~m}$ (350 ft) from the coal seam. Above this level, the subsidence influence to the permeability is insignificant due to much lower total strain and the low permeability of the claystone strata and thick silt at the bottom of the reservoir. The maximum vertical permeability after mining reaches $54.86 \mathrm{~mm} / \mathrm{day}(0.18 \mathrm{ft} /$ day $)$ in the area directly above the longwall panel edge. However, the vertical permeability in most of the other areas is less than $27.43 \mathrm{~mm} /$ day $(0.09 \mathrm{ft} /$ day $)$. 
Table 6.1 Initial hydraulic property of coal measure rocks

\begin{tabular}{l|c|c|c}
\hline \multirow{2}{*}{ Rock Types } & \multicolumn{2}{|c|}{ Permeability, ft/day (mm/day) } & \multirow{2}{*}{ Porosity, \% } \\
\cline { 2 - 4 } & Horizontal & Vertical & \\
\hline Soil & $2.74 \mathrm{E}-04(0.08)$ & $2.74 \mathrm{E}-04(0.08)$ & 0.15 \\
\hline Claystone & $5.48 \mathrm{E}-04(0.17)$ & $5.48 \mathrm{E}-04(0.17)$ & 0.10 \\
\hline Shale & $2.74 \mathrm{E}-03(0.83)$ & $1.37 \mathrm{E}-03(0.42)$ & 0.05 \\
\hline Coal & $2.74 \mathrm{E}-03(0.83)$ & $2.74 \mathrm{E}-04(0.83)$ & 0.05 \\
\hline Limestone & $5.47 \mathrm{E}-03(1.67)$ & $5.47 \mathrm{E}-03(1.67)$ & 0.10 \\
\hline Sandstone & $2.74 \mathrm{E}-02(8.35)$ & $2.74 \mathrm{E}-02(8.35)$ & 0.15 \\
\hline
\end{tabular}

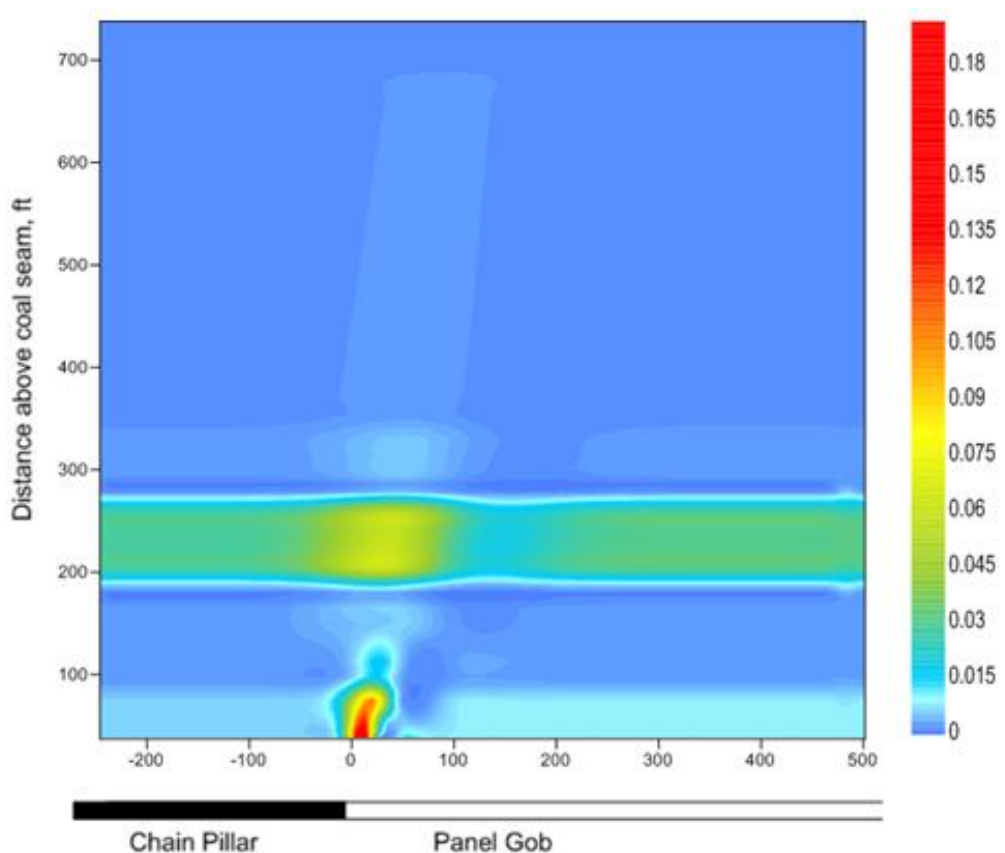

Figure 6.8 Post-mining vertical hydraulic permeability distribution over the longwall panel

The distribution of the simulated post-mining ground water pressure head in reference to the mine level is plotted in Fig. 6.9. In the zone where the increased permeability and water flow are induced by mine subsidence, the water head contour lines bent upward. It shows that the head at a point has decreased from its original level. The vectors of water flow velocity in the overburden strata after subsidence are also plotted in Fig. 6.9. The zone with higher flow velocities are located in a short distance inside the panel edge. Based on the simulation, the water leakage rate from the surface reservoir to the mine gob is about $0.132 \mathrm{~m}^{3} /$ day per meter $(1.42$ $\mathrm{ft}^{3} /$ day per foot) of distance along the panel longitudinal direction. From Fig. 6.5, the equivalent average width of the reservoir water surface along the panel longitudinal direction is determined to be $25.5 \mathrm{~m}(83.8 \mathrm{ft})$. The daily water leakage from the reservoir to underground longwall gob is estimated to be $3.4 \mathrm{~m}^{3} /$ day $\left(119 \mathrm{ft}^{3} /\right.$ day $)$. For the underground mining operation, the increased in- 
flow of water $0.0024 \mathrm{~m}^{3} / \mathrm{min}(0.62$ gallons $/ \mathrm{min})$ to the mine from the surface reservoir is very insignificant to the mine pumping system. Therefore, the water leaked from the reservoir to the underground mine through the subsidence-disturbed overburden strata should not create a safety concern.

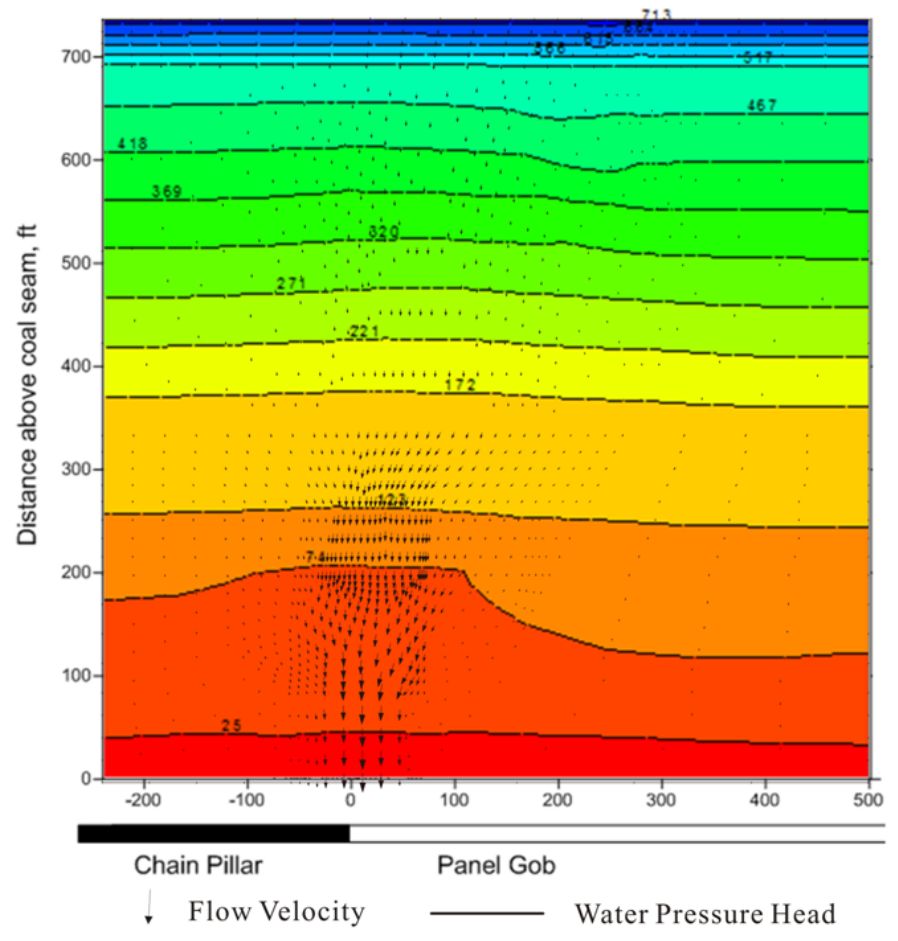

Figure 6.9 Post-mining ground water pressure head and flow velocity distribution over the longwall panel

\subsubsection{Assessment of Water Holding Capacity}

As shown in the previous simulation, the longwall subsidence is very unlikely to draw any significant water from the reservoir in comparison to its water supplies. The only remaining question is whether the subsidence would reduce the water-holding capacity of the reservoir. For this assessment, the final subsidence prediction is performed in a rectangular area around the reservoir. The surface coordinates and elevations at a large number of selected points in the specified area before mine subsidence are read from the mine map. After the predicted final subsidence at each of the selected points is subtracted from its original elevation, it results in the new elevation at that point after subsidence. The surface topography contour lines before (light blue) and after (black) subsidence are plotted in Fig. 6.10. The subsidence event moves the surface contour lines in the area above the longwall panel away from the reservoir. 


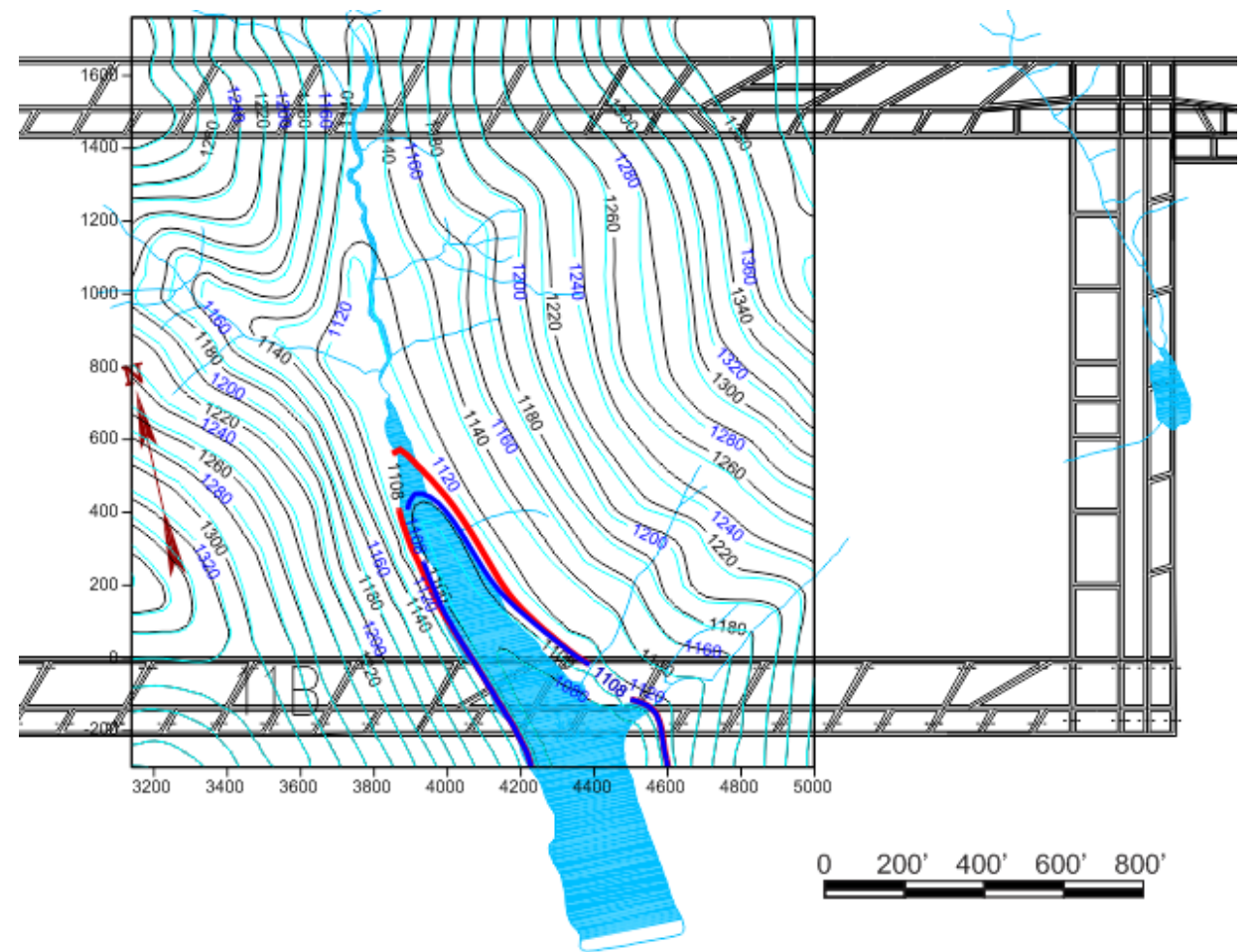

Figure 6.10 Surface elevation contours before (light blue) and after (black) mine subsidence

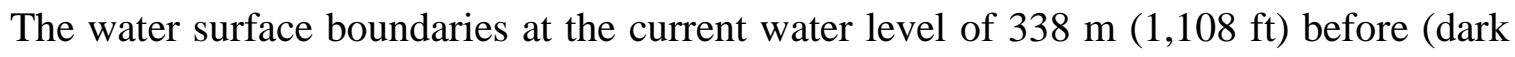
blue) and after (red) mine subsidence are also plotted in Fig. 6.10. It shows that the elevation changes would expand the tail water side of the reservoir edge for a distance of about $46 \mathrm{~m}$ (150 $\mathrm{ft}$ ) to the upper stream. The volume calculation performed shows that the longwall subsidence event will increase the water-holding capacity of the reservoir by $8,265 \mathrm{~m}^{3}\left(291,863 \mathrm{ft}^{3}\right)$ if the water surface level is maintained at the current level. The increased capacity should be actually an added benefit to the nearby city.

\subsection{Summaries}

The enhanced subsurface subsidence prediction model provides a good tool for analyzing the longwall mining influence on surface and subsurface hydrological systems. The total strain calculated in the subsurface subsidence prediction represents the shrinkage or expansion of the rock volume in the overburden strata. Such change would affect the permeability of the overburden strata. The relationship between the total strain and the permeability change is established. A case study is presented to demonstrate the capability of the subsurface subsidence prediction model and its application in studying the subsidence effects on surface and subsurface 
hydrological systems. Due to relatively large overburden depth and overburden composition in the case, the longwall mining operation will have a very insignificant influence to the surface reservoir and the underground mining operation. 


\section{CHAPTER 7 PROGRAMMING AND SOFTWARE DEVELOPMENT}

As discussed in the previous chapters, the subsurface subsidence prediction model and its applications in solving ground control problems can be used to facilitate the mine planning and ground designing works. In order to provide an easy-to-use tool for mining engineers to conduct their jobs more efficiently, a computer program is developed to predict the final surface and subsurface movements and deformations over longwall mining panel. The applications of the subsurface subsidence prediction results on, pre-driven longwall recovery room support design, multi-seam mining interaction assessment and multi-seam mining subsidence prediction and longwall mining impacts on overburden hydrological systems, are also incorporated in this program.

Visual Basic will be used for programming the previous developed models. This program will provide a user-friendly working environment. The subsurface subsidence prediction model and its three application models are sharing the same inputs for the project, such as overburden depth, mining height, panel geometries, etc. The three application models also have their own specific inputs, such as support load displacement characteristics for the pre-driven longwall recovery room support design model. Each of these three application models can work independently for its own purpose.

\subsection{Subsurface Subsidence Prediction}

In comparison to surface subsidence prediction, the subsurface subsidence prediction model involves considerably more computations. The computer program is developed to facilitate the required computation. The basic input information includes panel width $(W)$, mining height $(m)$ and overburden depth $(h)$ required for surface subsidence prediction. The input information to specify the subsurface stratification includes the number of layers $(n)$ to equally subdivide the overburden strata and the percent of hard rock in each layer $\left(\eta_{\mathrm{i}}\right)$. Figure 7.1 shows the interface of the subsurface subsidence prediction program. 


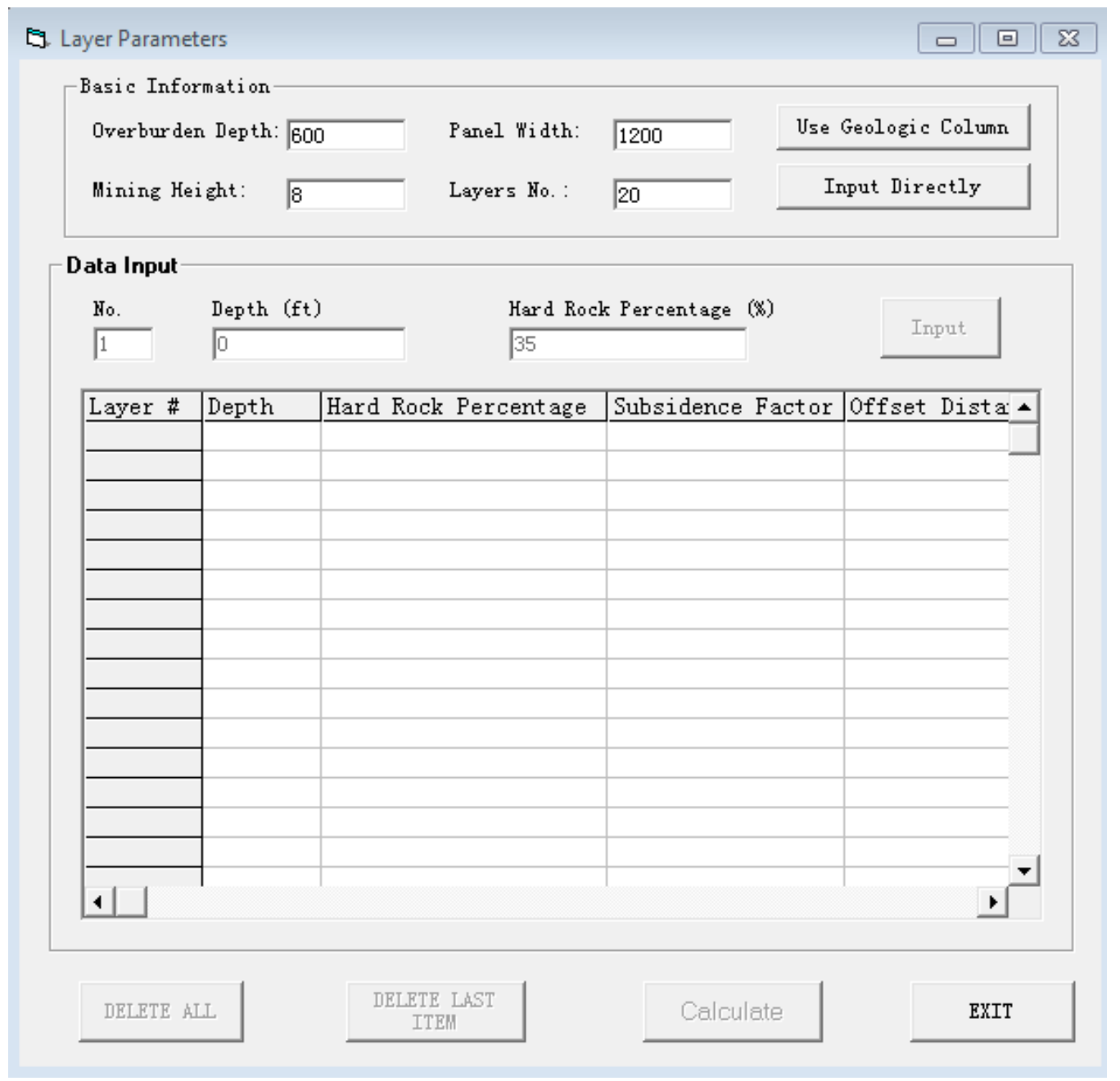

Figure 7.1 Interface of the subsurface subsidence prediction program

The output will be the subsurface movements (i.e., subsidence and horizontal displacement) and deformations (i.e., slope, curvature, as well as horizontal, vertical and total strains) in all overburden layers over the longwall panel. The output data are in tabular format that can be export to excel for further analysis. The post-processing of the output data are shown in the case studies in the previous chapters.

\subsection{Pre-driven Longwall Recovery Room Support Design}

Based on the mathematical model developed in Chapter 4, a computer program has been developed to facilitate the simulation of the performance of the pre-driven recovery room system in the final stage of mining a longwall panel. Figure 7.2 shows the development of pre-driven longwall recovery room support design model. To use the program, the user should input the overburden depth, mining height, width of the pre-driven recovery room and in-situ coal strength 
as the general information. Figure 7.3 shows Interface of the program. The stiffness of the longwall powered supports should be specified. For the standing supports in the recovery room, the type, density, placement and load-displacement performance curve should be provided. The width of the fender pillar can be changed by the user, with the minimum to be zero, to simulate the longwall retreating operation.

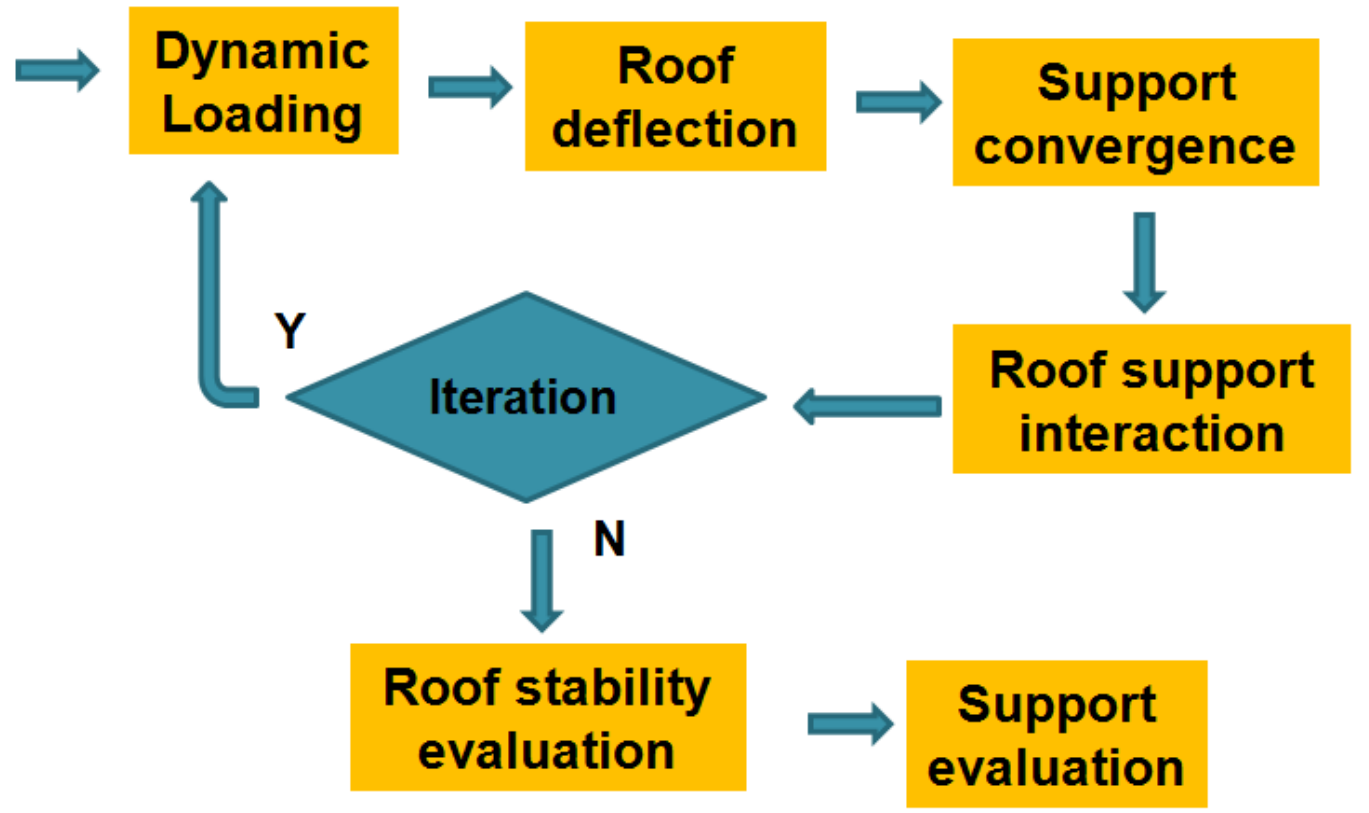

Figure 7.2 Development of pre-driven longwall recovery room support design model

Once the data input is done, the program performs the required computations, through an iterative process as shown in Fig. 7.2, to establish a pseudo-equilibrium condition. The major calculation tasks include determining various stress intensity factors, the depths of yield zones in the fender and barrier pillars, superimposing the stress functions, determining the deflection of the immediate roof, etc. When the process converges, the simulation results can be output in graphical and tabular forms.

The output of this program will be (1) the stress distributions over the fender pillar and barrier pillar, (2) stress variation history in fender and barrier pillars as longwall face advancing toward recovery room, (3) support loads of the cribs, (4) roof strain distribution, and (5) roof deflection. Further analysis can be made based on these results for the aim of selecting sufficient supports to maintain the recovery room stability. The post-processing of the program results are demonstrated in the case study in Chapter 4. 


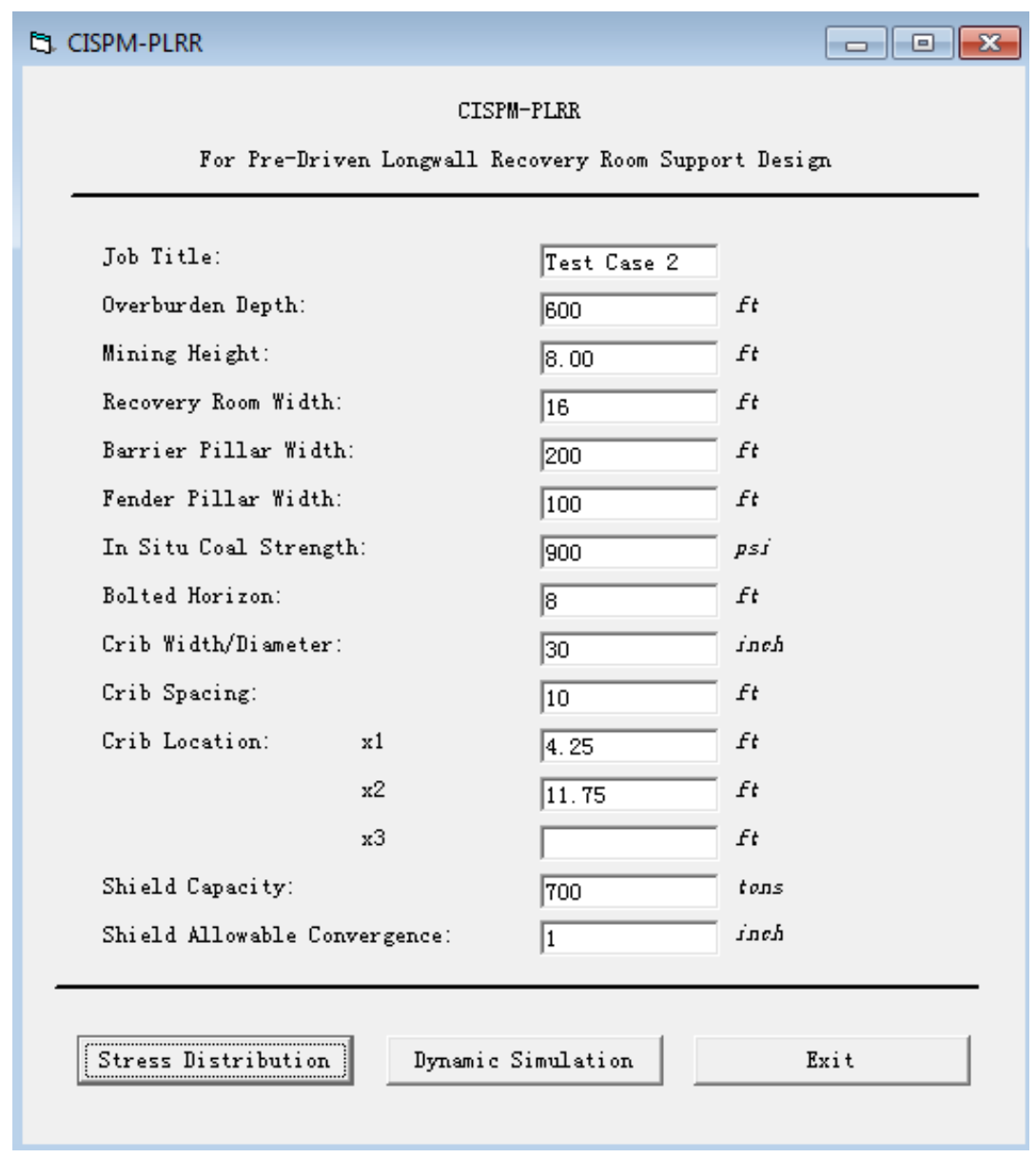

Figure 7.3 Interface of the pre-driven longwall recovery room support design program

\subsection{Development of CISPM-MS}

A computer program, CISPM-MS (Comprehensive and Integrated Subsidence Prediction Model - Multiple Seam), has been developed for the multi-seam mining interaction assessment and multi-seam mining subsidence prediction. This program provides a userfriendly working environment for specifying the layout of mine panels in different coal seams and the subsidence prediction points on surface in AutoCAD. A numerical procedure is designed and implemented in the program to perform the considerable amount of computations quickly and accurately for subsidence caused by mine gobs that are rectangular or irregular shapes in different coal seams. It also provides convenient tools for data output and post analysis.

It is well known that surface subsidence caused by multi-seam mining is not simply superposition of the subsidence caused by mining in each individual coal seam but also that caused by possible multi-seam mining interactions. In order to accurately predict multi-seam 
mining subsidence, multi-seam mining interaction should be evaluated first. If such interactions are insufficient to cause additional surface subsidence, the effects of multi-seam interactions will be disregarded in subsidence prediction. Otherwise, the additional subsidence caused by the failed mine structures in sufficiently large continuous areas will be determined and included in the final surface subsidence. The subsurface subsidence prediction model (Luo and Qiu, 2012a) is employed here for assessing the multi-seam mining interactions. The decision and computation flow chart of program CISPM-MS is shown in Fig. 7.4. Figure 7.5 shows the interface of the CISPM program.

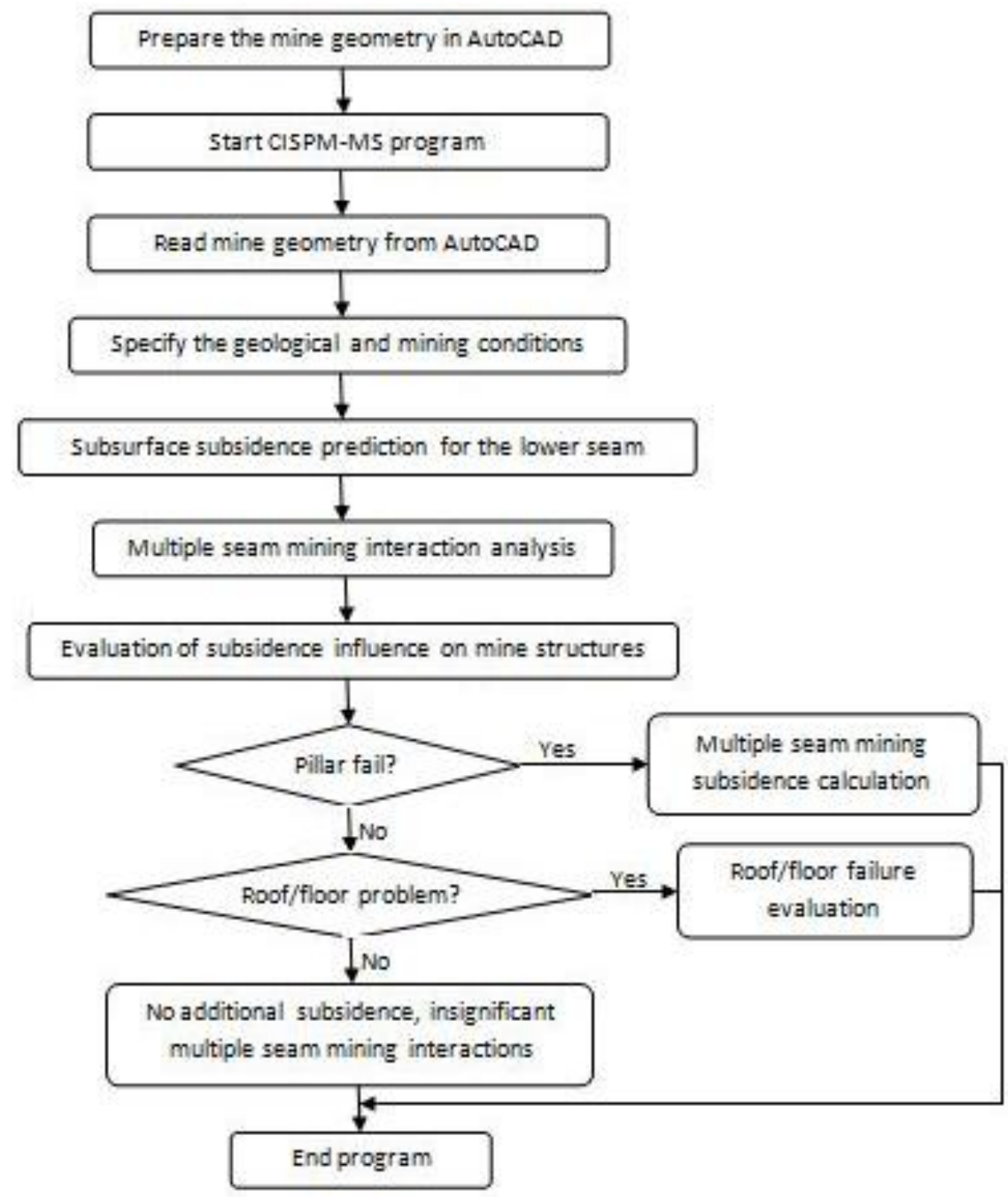

Figure 7.4 Flow chart of the CISPM-MS program 


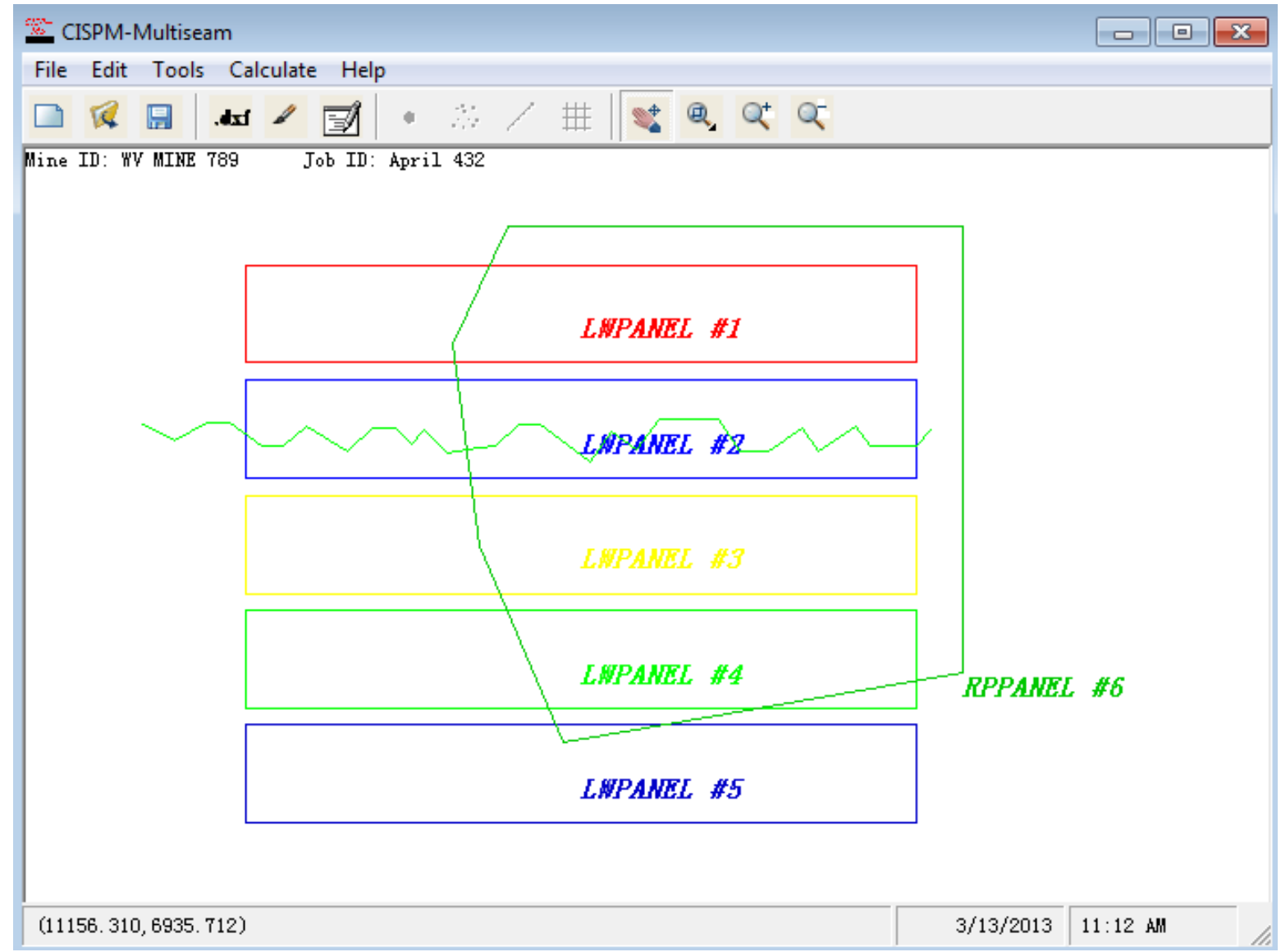

Figure 7.5 Interface of the CISPM-MS program

The output of this program includes two main parts, the multi-seam mining interaction results and the multi-seam mining surface subsidence. The assessments of multi-seam mining influence on pillar, roof, floor and interburden stability are based on the calculations of pillar safety factors, roof and floor strains and interburden permeability changes. Detailed informations are generated in a report through the program. For the multi-seam mining subsidence prediction, the output will be shown in tabular format for further analysis. The post-processing of the program results are demonstrated in the case studies in Chapter 5.

\subsection{Longwall Mining Impacts on Hydrological System}

The subsurface subsidence prediction model is applied in the studies of the effects of longwall mining on the hydrological system. Three potential effects on the hydraulic system include: (1) water pooling on the surface area, (2) temporary redistribution of hydrological system, and (3) dewatering of surface streams and subsurface aquifers. Each potential influence is assessed with a program section as shown in Fig. 7.6. For assessing the first potential influence, 
the program will predict the surface subsidence data and impose these data to the initial surface topography. The possible water pooling area can be determined by analyzing the post-mining surface topography information. The assessment of the second potential influence is based on the subsurface subsided area predictions. The user needs to specify the location and thickness of the target aquifer. The program will determine the temporary redistribution of the groundwater. The assessment of the dewatering of surface and subsurface water bodies should based on the premining and post-mining groundwater flow modeling results. The program will calculate the overburden strata permeability change due to longwall mining. This program will provide the longwall mining induced overburden permeability change data for the external ground water modeling program.

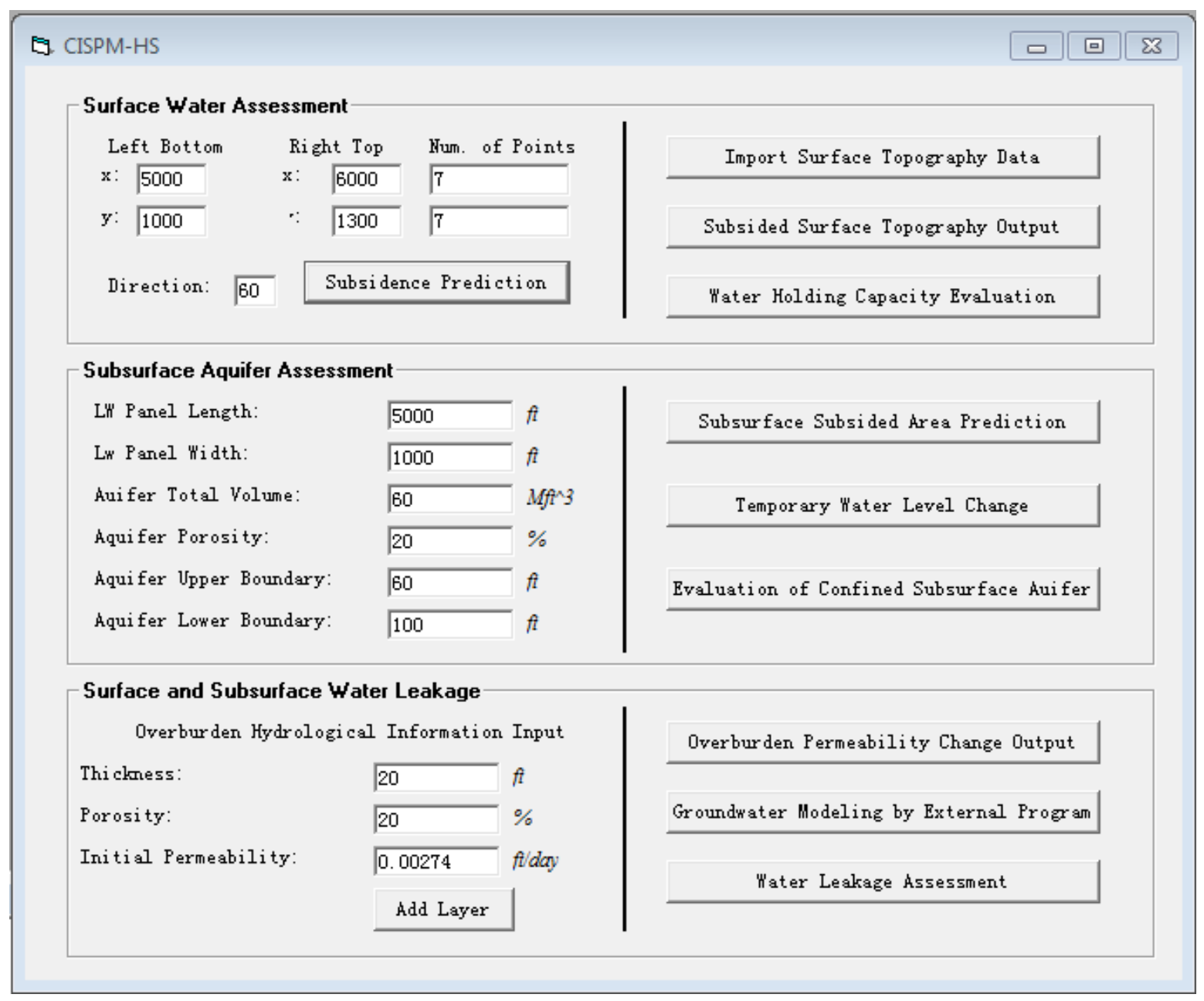

Figure 7.6 Interface of the computer program for evaluating longwall mining impacts on hydrological system 
The output of the program will include the assessment of the three types of subsidence impacts on hydrological system. These assessments will be shown in program generated reports, and post-processing of the program results can be conducted based on these data as demonstrated in the case study in Chapter 6.

\subsection{Summaries}

A computer software suite is developed to predict the subsurface movements and deformations over the longwall mining panel. The applications of the subsurface subsidence prediction on, pre-driven longwall recovery room support design, multi-seam mining interactions and subsidence prediction and longwall mining impacts on overburden hydrological systems, are also incorporated in this software. This software suite provides a tool for analyzing almost all the subsidence related problems of coal mining operations. 


\section{CHAPTER 8 SUMMARIES AND CONCLUSIONS}

\subsection{Conclusions}

The research objective of this dissertation is to develop an enhanced subsurface subsidence prediction model and to explore the potential applications of this model in the studies of ground control problems related to mining subsidence. The advantage of using the subsurface subsidence model in the studies is its capability to consider large movements and deformations in the overburden strata.

An enhanced subsurface subsidence prediction model considering overburden stratifications is developed in this research. The model employs the influence function method for subsurface subsidence prediction layer by layer from the immediate roof to the ground surface. The final subsurface subsidence parameters (i.e., subsidence factor, offset distance of inflection point, radius of major influence) are determined by empirical formulae based on collected subsurface subsidence measurements. A case study is conducted for the verification of the model. The predicted subsurface movements and deformations agree well with the general observations over longwall mining operations. The influence of the thick hard rock layers on the subsurface subsidence can be easily identified from the prediction results. This model can help us to gain a better understanding about the distributions of subsurface movements and deformation in the overburden strata above a longwall panel. Such an understanding will help guide the designs of gob well methane recovery, studies of mining effects on surface and subsurface hydrologic systems, and assessment of mine structural stability in the overburden strata.

The fracture mechanics approach have been applied to analyze the dynamic loading of pre-driven recovery room system (including the longwall powered supports, the fender pillar, the standing supports and barrier pillars) in longwall mining operations. This approach provides a much simpler alternative to the numerical methods, especially for those with limited resources. The dynamic subsidence development curve is adopted here to describe the immediate roof line deflection. This curve is very useful in determine the support load and evaluate the support and roof conditions. The load-displacement characteristic curves of the longwall supports and 
standing supports are also considered in the design process. This analytical model is able to consider the dynamic loading process and the roof-support interactions as longwall face is approaching the pre-driven longwall recovery room. It can be used to facilitate the pre-driven longwall recovery room design and to assess the performance of the system. A case similar to a published one is simulated with the model showing a good agreement between the simulation and field measurements.

The enhanced subsurface subsidence prediction model was used to analyze the interactions in multi-seam mining operations. A number of important parameters to quantify the subsurface subsidence influences to subsurface mine structures have been proposed. They include: (1) the critical strain for causing tensile cracks in the mine roof and floor, (2) the method to determine subsidence induced pillar load, and (3) the failure criteria based method to determine pillar strength under the influence of subsurface subsidence. The methodology to assess the multi-seam mining interactions has been incorporated in the subsidence prediction model CISPM-MS for multi-seam mining operation.

Two case studies, a case of remnant structure and a case of mining inside the subsidence influence zone, were conducted to illustrate CISPM-MS's capability to assess the multi-seam mining interactions, which showed a good agreement with the field observations. Multi-seam mining interactions may affect the stability of the roof, floor, rib and pillars, and induce high cost of supplemental supports or even more severe ground control problems. Understanding of the mechanism of these multi-seam mining interactions will greatly help mitigate the negative effects of these interactions. Assessing the multi-seam mining interactions with reliable tools before and during the mining operation is essential for the planning and designing of multi-seam mining operations. A profitable and safe multi-seam operation can be achieved through this process.

The enhanced subsurface subsidence prediction model provides a good tool for analyzing the longwall mining influence on surface and subsurface hydrological systems. The total strain calculated in the subsurface subsidence prediction represents the shrinkage or expansion of the rock volume in the overburden strata. Such change would affect the permeability of the overburden strata. The relationship between the total strain and the permeability change is established. A case study is presented to demonstrate the capability of the subsurface subsidence prediction model and its application in studying the subsidence effects on surface and subsurface 
hydrological systems. Due to relatively large overburden depth and overburden composition in the case, the longwall mining operation will have very insignificant influence to the surface reservoir and the underground mining operation.

A computer software suite is developed to predict the subsurface movements and deformations over the longwall mining panel. The applications of the subsurface subsidence prediction on, pre-driven longwall recovery room support design, multi-seam mining interactions and subsidence prediction and longwall mining impacts on overburden hydrological systems, are also incorporated in this software. This software suite provides a tool for analyzing almost all the subsidence related problems of coal mining operations.

\subsection{Research Significance and Outcomes}

The outcomes of this research are:

(1) An enhanced subsurface subsidence prediction tool for longwall mining panels with consideration of overburden stratifications,

(2) A greater understanding of the mechanism of the subsidence-related ground control problems,

(3) Innovative method of using subsidence results to derive stress, strain and permeability change, and quantify the subsidence effects on mine structure stability and the hydrological system sustainability.

\subsection{Recommendations for the Future Research}

Based on the conclusions carried out in this research, the following work is recommended for any future studies:

(1) Calibration of the subsurface subsidence prediction model. The accuracy of the subsurface subsidence prediction model is essential for its applications in ground control problems. In the current stage, subsurface subsidence measurements in four sites are collected to calibrate the model. However, more subsurface subsidence measurements from the mines with different mining methods, various layouts and different overburden stratifications should be collected to calibrate the model.

(2) Refinement of the methodologies to apply strata deformations in assessing ground control failure. The predicted subsurface subsidence-induced deformations (i.e., 
horizontal, vertical, shear and total strains, curvature, etc) are used directly to assess the failure condition of the inter-burden strata, the roof and floor and are also be indirectly used to estimate the stress and strength of the pillars in the mines. The mathematical models developed for relating the predicted subsurface deformations to the water permeability and stabilities of mine roof, floor and pillars should be refined with more field cases. More efforts are needed to improve the methodologies to associate the predicted strata deformations to the ground control hazards.

(3) Field validation of the program. The developed program incorporated the subsurface subsidence prediction and its applications in solving ground control problems, which is able to solve almost all the issues that related to subsidence in coal mine operations. However, the newly developed program needs to be validated with more field cases to improve its accuracy and applicability. 


\section{REFERENCES}

Anderson, M. P., 1992, "Applied Groundwater Modeling," Department of Geology and Geophysics. University of Wisconsin, Madison, Wisconsin, 341 pp.

Agioutantis, Z. and M.K. Karmis, 2008, "SDPS Surface Deformation Prediction System for Windows Version 6.0, Quick Reference Guide and Working Examples," Department of Mining and Minerals Engineering, Virginia Polytechnic Institute and State University, VA, 248 pp.

Akinkugbe, O. O., 2004, "A Simple Two-Dimensional Boundary Element Program for Estimating Multiple Seam Interaction," M.S. Dissertation, 2004, West Virginia University, Morgantown, WV, $174 \mathrm{pp}$.

Akinkugbe, O. O. and K. Heasley, 2004, "The New Two-Dimensional Lamodel Program," Proc. 24th Int'l Conference on Ground Control in Mining, Ed. S.S. Peng, West Virginia University, WV, pp. 146-153.

Bai, M. and D. Elsworth, 1994, "Modeling of Subsidence and Stress-dependent Hydraulic Conductivity of Intact and Fractured Porous Media," Rock Mechanics and Rock Engineering, Vol. 27, No. 4, pp. 209-234.

Barczak, T. M., 2001, "Updating the NIOSH Support Technology Optimization Program (STOP) With New Support Technologies and Additional Design Features," Proceedings of the 20th International Conference on Ground Control in Mining, S.S. Peng, ed., West Virginia University, pp. 337-346.

Barczak, T.M., S. C. Tadolini, and P. Zhang, 2007, "Evaluation of Support and Ground Response as Longwall Face Advances into and Widens Pre-Driven Recovery Room," Proceedings of the 26th International Conference on Ground Control in Mining, S.S. Peng, ed., West Virginia University, pp. 160-172.

Barkley, D., 2007, "Longwall Mining in Illinois: A Controversy Over Planned Subsidence of Flat Farmland," Proceedings of the 26th International Conference on Ground Control in Mining, S.S. Peng, ed., West Virginia University, pp. 67-71.

Bauer, E., J. Listak, M. Berdine, W. Bookshar, D. Raab, and T. Mucho, 1988, "Longwall Recovery Utilizing the Open Entry Method and Various Cement-Concrete Supports," Proceedings of the 7th International Conference on Ground Control in Mining, S.S. Peng, ed., West Virginia University, pp 30-42. 
Bauer, E., J. Listak, and M. Berdine, 1989, "Assessment of Experimental Longwall Recovery Rooms for Increasing Productivity and Expediting Equipment Removal Operations," US Bureau of Mines, Report of Investigation RI9248, 26 pp.

Booth, C.J., 2002, "The Effects of longwall coal mining on overlying aquifers. In: Younger P.L. and Robins N.S. (eds.)," Mine Water Hydrogeology and Geochemistry, Geological Society, London, Special Publication, pp. 17-45.

Booth, C.J., 2006, "Groundwater as an environmental constraint of longwall coal mining," Environmental Geology, Vol. 49, No. 6, pp. 796-803.

Booth, C. J., 2007, "Confined-Unconfined Changes Above Longwall Coal Mining Due to Increases in Fracture Porosity," Environment \& Engineering Geosciences, Vol 8, No. 4, pp. 355367.

Booth, C.J. and C. B. Greer, 2011, "Application of MODFLOW using TMR and discrete-step modification of hydraulic properties to simulate the hydrogeological impact of longwall mining subsidence on overlying shallow aquifers," Mine Water - Managing the Challenges: Proc. 11th IMWA Congress, Aachen, Germany, pp. 211-216.

Chandrashehar, K., R. Nath, and S. Tandon, 1987, "Design of Coal Pillars under Weak Floor Conditions," Proc. 28th US Symposium on Rock Mechanics, Tucson, pp. 1073-1081.

Chase, F. E., P. Worley, and C. Mark, 2007, "Multiple-seam Mining Interactions: Case Histories from the Harris No. 1 Mine," Proc. of New Technology for Ground Control in Multiple-Seam Mining, Ed. C. Mark, R. J. Tuchman, National Institute for Occupational Safety and Health, Pittsburgh, PA, pp. 63-72.

Chen, S. G. and W. Hu, 2009, "A Comprehensive Study on Subsidence Control Using COSFLOW," Geotechnical and Geological Engineering, Vol. 27, No. 3, pp. 305-314.

Chekan, G. and J. Listak, 1993, "Design Practices for Multiple-Seam Longwall Mines," Information Circular 9360, U. S. Bureau of Mines, Pittsburgh, PA, 35 pp.

Conte, D. and L. Moses, 2005, "The Effects of Subsidence Resulting from Underground Bituminous Coal Mining on Surface Structures and Features and on Water Resources: Second ACT 54 Five-Year Report," California University of Pennsylvania, Califorlia, PA, 11 pp.

Cui, X, X. Miao, J. Wang, H. Liu, Y. Song, H. Liu, and X. Hu, 2000, "Improved prediction of differential subsidence caused by underground mining," International Journal of Rock Mechanics \& Mining Science, Vol. 37, No. 12, pp. 615-27. 
Du, X., 2010, “The Impacts of Longwall Mining on Groundwater systems," Ph.D. Dissertation, 2010, West Virginia University, Morgantown, WV, 310 pp.

Dyni, R.C., 1991, "Subsidence Resulting from Multiple-Seam Longwall Mining in the Western United States: A Characterization Study," US Bureau of Mines, Report of Investigation RI9297, $20 \mathrm{pp}$.

Esterhuizen, G.S. and C. O. Karacan, 2005, "Development of Numerical Models to Investigate Permeability Changes and Gas Emission around Longwall Mining Panel," The 38th U.S. Symposium on Rock Mechanics (USRMS), Anchorage, Alaska, pp. 1-13.

Forster, I. R., 1995, "Impact of Underground Mining on the Hydrologeologi-cal Regime, Gentral Coast NSW," Conference on Engineering Geology of the Newcastle-Gosford Region, The university of Newcastle, Newcastle ,NSW, Australia., pp. 156-168.

Gale, W., 2006, "Water Inflow Issues above Longwall Panels," Proceedings, 2006 Coal Operators' Conference, Ed. N. Aziz, University of Wollongong \& the Australasian Institute of Mining and Metallurgy, Australia, pp. 175-179.

Gale, W., 2010, "Review and Estimation of the Hydraulic Conductivity of the Overburden above Longwall Panels, Experience from Australia," Proc. 29th Int'l Conference on Ground Control in Mining, Ed. T. Barczak et al., West Virginia University, WV, pp. 340-347.

Gale, W., 2011, "Investigation into Abnormal Surface Subsidence Above a Longwall Panel in the Southern Coalfield, Australia," Proc. 30th Int'l Conference on Ground Control in Mining, Ed. T. Barczak et al., West Virginia University, WV, pp. 12-20.

Gauna, M. and S. Phillipson, 2008, "Evaluation of a Multiple Seam Interaction Coal Pillar Bump," Proceedings of $27^{\text {th }}$ International Conference on Ground Control in Mining, Ed. S.S. Peng et al., Morgantown, WV, pp. 51-59.

Griffith, A, 1921, "The Phenomena of Rupture and Flow in Solids," Philosophical Transactions of the Royal Society of London, Series A, mathematical and Physical Sciences, pp. 163-198.

Gutierrez, J.J., L. E. Vallejo, and J. S. Lin, 2010, "Impact of Longwall Mining on Highways," 44th US Rock Mechanics Symposium and 5th US-Canada Rock Mechanics Symposium, Salt Lake City, UT, pp. 1-12.

Gurtunca, G., 1984, "Studies of Subsurface Subsidence in the Southern Coalfield of New South Wales," Ph. D. Dissertation, 1984, Univeristy of New South Wales, New South Wales, Austrilia, $331 \mathrm{pp}$. 
Guo, H., D. P. Adhikary, and M. S. Craig, 2009, "Simulation of mine water inflow and gas emission during longwall mining," Rock Mechanics and Rock Engineering, Vol. 42, No. 1, pp. 25-51.

Guo, H., L. Yuan, B. Shen, Q. Qu, and J. Xue, 2012, "Mining-induced Strata Stress Changes, Fractures and Gas Flow Dynamics in Multi-seam Longwall Mining," International Journal of Rock Mechanics \& Mining Sciences, Vol. 54, No. 9, pp. 129-139.

Han, J.S., Y. Luo, and S.S. Peng, 2005, "Analysis of Entry Stability Associated with Multi-seam Mining-A Case Study," Proceedings of $24^{\text {th }}$ International Conference on Ground Control in Mining, Ed. S. S. Peng et al., Morgantown, WV, pp. 87-92.

Hanna, K. and K. Heasley, 2011, "Engineering Geophysics - Mine Subsidence Risk Assessment Study," Proc. 30th Int'l Conference on Ground Control in Mining, Ed. T. Barczak et al., West Virginia University, WV, pp. 296-307.

Hasenfus, G. J., K. L. Johnson, and D. W. Su, 1988, "Hydrogeomechanics Study of Overburden Aquifer Response to Longwall Mining," Proceedings 7th International Conference on Ground Control in Mining, Ed. S. S. Peng, West Virginia University, Morgantown, WV, pp. 149-162.

Haycocks, C., M. Karmis, and E. Topuz, 1981, "Optimizing Productive Potential in Multi-Seam Underground Coal Mining," Paper in Symposium on Underground Mining (Proc. Coal Conf. and Expo VI, Louisville, pp. 151-163.

Haycocks, C., M. Karmis, and B. Ehgartner, 1982, "Multiple Seam Mine Design," Paper in State-of-the-Art of Ground Control in Longwall Mining and Mine Subsidence, SME, AIME, pp. 59-65.

Haycocks, C., M. Karmis, E. Barko, J. Carman, B. Ehgartner, S. Hudock, and S. Webster, 1983, "Ground Control Mechanisms in Multi-Seam Mining," U.S. Bureau of Mines, 328 pp.

Heasley, K.A. and L.W. Saperstein, 1987, "Recent insight into longwall strata movements deduced from subsidence analysis," Mining Engineering, Vol. 282, No. 9, pp. 872-876.

Heasley, K.A. and Z.G. Agioutantis, 2007, "LaModel: a Boundary-Element Program for Coal Mine Design," Proceedings: New Technology for Ground Control in Multiple-seam Mining, Ed. C. Mark and R.J. Tuchman, NIOSH, pp. 29-33.

Hoek, E., C. Carranza-Torres, and B. Corkum, 2002, "Hoek-Brown Failure Criterion-2002 Edition," Proc. 5th North American Symposium-NARMS-TAC, Toronto.

Hoek, E., 1994, "Strength of Rock and Rock Masses," ISRM New Journal, Vol. 2, No. 2, pp. 416. 
Hoek, E., P. K. Kaiser, and W.F. Bawden, 1995, Support of Underground Excavations in Hard Rock, Balkema, Rotterdam. 215 pp.

Hoek, E. and E.T. Brown, 1997, "Practical Estimates of Rock Mass Strength," Int'l. J. Rock Mech. \& Mining Sci. \& Geomechanics Abstracts, Vol. 34, No. 8, pp. 1165-1186.

Hoek, E., 2004, Practical Rock Engineering - an Ongoing Set of Notes, Rocscience website; http://www.rocscience.comi.

Holla, L. and M. Armstrong, 1986, "Measurement of subsurface strata movement by multiborehole instrumentation," Bull. Proc. Australas. Inst. Min. Metall., Vol. 291, No. 3, pp. 65-72.

Holla, L. and B. Hughson, 1987, "Strata movement associated with longwall mining," Proc. Aust. Tunnelling Conf., 6th, Ed. V. Parkville, Melbourne, Austrilia, pp. 211-216.

Holland, C., 1951, "What Happens and Why in Multiple-Seam Mining," Coal Age, Vol.56, No.8, pp. 89-93.

Hsiung, S. and S.S. Peng, 1987, "Design Guidelines for Multiple-Seam Mining, Part 1," Coal Mining, Vol. 24, No. 9, pp. 42-46.

Iannacchione, A., S.J. Tonsor, M. Witkowski, J. Benner, A. Hale, and M. Shendge, 2008, "The Effects of Subsidence Resulting from Underground Bituminous Coal Mining on Surface Structures and Features and on Water Resources, 2003 to 2008," Pennsylvania Department of Environmental Protection Report, 513 pp.

Iannacchione, A., M. Witkowski, J. Benner, A. Patil, and N. Iannacchione, 2011, "Surface Structures Impacted by Subsidence from Pennsylvania Coal Mines, 2003 to 2008," Proc. 30th Int'l Conference on Ground Control in Mining, Ed. T. Barczak et al., West Virginia University, WV, pp. 286-295.

Itasca Consulting Group, Inc., 2006, Flac 3D Version 3.1 Example Applications, Minneapolis, MN, pp.2-1 to 2-17.

Jaiswal, A. and B. K. Shrivastva, 2009, "Numerical Simulations of Coal Pillar Strength," International Journal of Rock Mechanics \& Mining Science, Vol. 46, pp. 779-788.

Kanniganti, R., 1996, "Interactive Prediction Software for Underlying Multi-Seam Design," M. S. Thesis, Virginia Polytechnic Institute and State University, Blacksburg, VA, 171 pp.

Kramer, J., Y. Luo, and S. S. Peng, 1998, "An Analytical Approach to Determine Stress Distribution in Longwall Chain Pillars," Proceedings 17th International Conference on Ground Control in Mining, Ed. S. S. Peng, West Virginia University, Morgantown, WV, pp. 162-168. 
Karmis, M., Z. Agioutantis, and A. Jarosz, 1990, "Subsidence Prediction Techniques in the United States: A State-of-the-Art Review," Mineral Resources Engineering, Vol. 3, No. 3, pp.197-210.

Karmis, M., C. Haycocks, and Z. Agioutantis, 1992, "The Prediction of Ground Movements caused by Mining," Proceedings, 3rd Workshop on Surface Subsidence due to Underground Mining, Ed. S. S. Peng, West Virginia University, Morgantown, WV, pp. 1-9.

Karmis, M., Z. Agioutantis, and K. Andrews, 2008, "Enhancing Mine Subsidence Prediction and Control Methodologies," Proc. 27th Int'l Conference on Ground Control in Mining, Ed. S.S. Peng et al., West Virginia University, WV, pp. 131-136.

Karabin, G.J. and M. Evanto, 1994, "Experiences with the Boundary Element Method of Numerical Modeling as a Tool for Resolve Complex Ground Control Problems," Proceedings of the 13th International Conference on Ground Control in Mining, S.S. Peng, ed., West Virginia University, pp. 201-213.

Karacan, C.O. and G. Goodman, 2009, "Hydraulic conductivity changes and influence factors in longwall overburden determined by slug tests in gob ventholes," International Journal of Rock Mechanics \& Mining Sciences, Vol. 46, No. 7, pp. 1162-1174.

Kendorski, F. S., 1993, "Effect of Full-Extraction Mining on Ground and Sur-face Waters," Proc. 12th Int'l Conference on Ground Control in Mining, Ed. S.S. Peng, West Virginia University, WV, pp. 412-425.

Kendorski, F. S., 2006, "Effect of Full-Extraction Underground Mining on Ground and Surface Waters: A 25-Year Retrospective," Proc. 25th Int'l Conference on Ground Control in Mining, Ed. S.S. Peng et al., West Virginia University, WV, pp. 425-430.

King, H. J., B. N. Whittaker, and A. S. Batchelor, 1972, "The Effects of Interactions in Mine Layouts," Paper in Proceedings of the Fifth International Strata Control Conference. Nat. Coal Board, Vol. 17, pp. 1-11.

Knothe, S., 1953 "Effect of time on formation of basin subsidence," Archives of Mining and Steel Industry, Vol. 1, No. 1, pp. 1-7.

Knothe, S., 1957, "Observation of Surface Movements Under Influence of Mining and Their Theoretical Interpretation," Proc. European Congress on Ground Movement, Ed. J. T. Whetton, Leeds, UK, pp. 210-218.

Kook, J., C. Scior, P. Fischer, and M. Hegemann, 2008, "Subsidence Prediction for Multiple Seam Extraction under Consideration of Time Effects by the use of Geomechanical Numerical 
Models," Proc. 27th Int'l Conference on Ground Control in Mining, Ed. S.S. Peng et al., West Virginia University, WV, pp. 143-147.

Kratzsch, H., 1983, “Mining Subsidence Engineering,” Springer, Berlin, 543 pp.

Kwinta, A., 2012, "Prediction of strain in a shaft caused by underground mining," International Journal of Rock Mechanics \& Mining Sciences, Vol. 55, No. 3, pp. 28-32.

Lawrence W., 2009, "A Method for the Design of Longwall Gateroad Roof Support," International Journal of Rock Mechanics \& Mining Sciences, Vol. 46, No. 4, pp. 789-795.

Lee, J W, 2005, "Development of a numerical model representative of rock failure mechanisms associated with the impact of lateral displacement," ME Thesis, University of Wollongong, Wollongong, Austrilia, 137 pp.

Li, G, I. Forster, M. Fellowes, and A. Myers, 2006, "A Case Study on Longwall Mining under the Tidal Waters of Lake Macquarie," Coal 2006: Coal Operators' Conference, Ed. N. Aziz, University of Wollongong \& the Australasian Institute of Mining and Metallurgy, pp. 293-304.

Li, G., P. Steuart, R. Paquet, and R. Ramage, 2011, "A Case Study on Mine Subsidence Due to Multi-Seam Longwall Extraction," Proceedings of the Second Australasian Ground Control in Mining Conference, Sydney, NSW, Austrilia, pp. 191-200.

Li, Y. and B. Qiu, 2012, "Investigation into Key Strata Movement Impact to Overburden Movement in Cemented Backfill Mining Method," Procedia Engineering, Vol. 31, pp. 727-733.

Lu, J., K. Morsy, A. Ray, and S.S. Peng, 2008, "Effects of Rock/Coal Interface Properties on Coal Pillar Strength," Proc. 27th International Conference on Ground Control in Mining, Ed. S. S. Peng \& C. Mark, Morgantown, WV, pp. 262-267.

Luo, J., 1997, “Gateroad Design in Overlying Multi-seam Mines,” M.S. Thesis, 1997, Virginia Polytechnic Institute and State University, Blacksburg, Virginia, 117 pp.

Luo, Y., 1989, "Integrated Computer Model for Predicting Surface Subsidence Due to Underground Coal Mining -- CISPM,” Ph.D. Dissertation, 1989, West Virginia University, Morgantown, WV, UMI order No. 9020385, 168 pp.

Luo, Y. and S. S. Peng, 1991, "A Comprehensive Computer Model For Predicting Dynamic Subsidence For Longwall Operations," Proceedings of the 11th International Conference on Ground Control in Mining, Ed. N.I. Aziz and S.S. Peng, West Virginia University, Morgantown, WV, pp. 511-516.

Luo, Y. and S.S. Peng, 1993, "Using influence function method to predict surface subsidence 
caused by high extraction room and pillar method," Proceedings, 17th Int. FIG Symposium on Deformation Measurements and 6th Canadian Symposium on Mining Surveying (Canadian Institute of Geomatics), Banff, Alberta, pp. 341-353.

Luo, Y. and S.S. Peng, 2000, "Prediction of Subsurface Subsidence for Longwall Mining Operations," Proc. 19th Int'l Conference on Ground Control in Mining, Ed. S.S. Peng, West Virginia University, Morgantown, WV, pp. 163-170. 72.

Luo, Y., S. S. Peng, C. T. Holland, and Y. Q. Zhang, 2001, "Simulation of water seepage through, and stability of, coal mine barrier pillars, "SME Annual Meeting Pre-print 01-131, pp. $1-7$.

Luo, Y., S. Peng, and Z. Zhu, 2008, "Upgraded Comprehensive and Integrated Subsidence Prediction Model CISPM - W," Proc. 27th Int'l Conference on Ground Control in Mining, Ed. S.S. Peng et al., West Virginia University, Morgantown, WV, pp. 123-130.

Luo, Y. and J.W. Cheng, 2009, "An Influence Function Method Based Subsidence Prediction Program for Longwall Mining Operations in Inclined Coal Seams," Journal of Mining Science and Technology, Vol. 19, No. 9, pp. 592-598.

Luo, Y. and S.S. Peng, 2010, "Subsurface Subsidence Prediction Model and Its Potential Applications in the Study of Longwall Subsidence Effects on Hydrologic System," SME Transactions, Vol. 328, pp.458-465.

Luo, Y. and B. Qiu, 2012a, "Enhanced Subsurface Subsidence Prediction Model Considering Overburden Stratifications," Mining Engineering, Vol. 64, No. 10, pp. 78-84.

Luo, Y. and B. Qiu, 2012b, "CISPM-MS: A Tool to Predict Surface Subsidence and to Study Interactions Associated with Multi-Seam Mining Operations," Proc. 31th Int'l Conference on Ground Control in Mining, Ed. T. Barczak et al., West Virginia University, WV, pp. 56-62.

Luo, Y., 2013, Surface Subsidence Engineering, SME, Littleton, CO, (Publication in process).

Luxbacher, K. D., S. S. Erdogan, and C. Ö. Karacan, 2009, "Modeling Methane Emissions and Ventilation Needs by Examination of Mining Induced Permeability Changes and Related Damage to Ventilation Controls," 43rd U.S. Rock Mechanics / Geomechanics Symposium, Asheville, NC, pp. 1-8.

Mandle, R.J., 2002, "Groundwater modeling guidance," Groundwater Modeling Program, Michigan Department of Environmental Quality, 55 pp. 
Mark, C. and A.T. Iannacchione, 1992, "Coal pillar mechanics: theoretical models and field measurements compared," Proceedings of the Workshop on Coal Pillar Mechanics and Design, Pittsburgh, PA: US Department of the Interior, Bureau of Mines, IC. Vol. 9315, pp. 78-93.

Mark, C., 2007a, "Multiple-seam Mining in the United States: Background," Proc. of New Technology for Ground Control in Multiple-Seam Mining, Ed. C. Mark, R. J. Tuchman, National Institute for Occupational Safety and Health, Pittsburgh, PA, pp. 3-14.

Mark, C., 2007b, "Multiple-seam Mining in the United States: Lessons for Ground Control," Proc. of New Technology for Ground Control in Multiple-Seam Mining, Ed. C. Mark, R. J. Tuchman, National Institute for Occupational Safety and Health, Pittsburgh, PA, pp. 45-54.

Mark, C., 2007c, "Extreme Multiple-seam Mining in the Central Appalachian Coalfields," Proc. of New Technology for Ground Control in Multiple-Seam Mining, Ed. C. Mark, R. J. Tuchman, National Institute for Occupational Safety and Health, Pittsburgh, PA, pp. 55-62.

Mark, C., F. E. Chase, and D. M. Pappas, 2007a, "Analysis of Multiple Seam Stability," Proc. 26th Int'l Conference on Ground Control in Mining, Ed. S.S. Peng, West Virginia University, WV, pp. 5-18.

Mark, C., F. E. Chase, and D. M. Pappas, 2007b, "Multiple-seam Mining in the United States: Design Based on Case Histories," Proc. of New Technology for Ground Control in MultipleSeam Mining, Ed. C. Mark, R. J. Tuchman, National Institute for Occupational Safety and Health, Pittsburgh, PA, pp. 15-27.

Mark, C. and L. Barker, 2012, "Large Scale Ground Instability Caused By Failure of Underlying Pillars: a Case Study of Dynamic Multiple Seam Interaction," Proc. 31th Int'l Conference on Ground Control in Mining, Ed. T. Barczak et al., West Virginia University, WV, pp. 1-4.

Matetic, R. J., G. J. Chekan, and J. A. Galek, 1987, "Design considerations for multiple-seam mining with case studies of subsidence and pillar load transfer," The 28th US Symposium on Rock Mechanics (USRMS), Ed. J. Dacmen, Tucsan, AZ, pp.1095-1106.

Matetic, R. J., J. Liu, and D. Elsworth, 1995, "Modeling the Effects of Longwall Mining on the Ground Water System,” US Bureau of Mines, Report of Investigation RI9561, 20 pp.

Michalek, S.J. and K.K. Wu, 2000, "Potential Problems Related To Mining Under Or Adjacent To Flooded Workings," Proc. 19th Int'l Conference on Ground Control in Mining, Ed. S.S. Peng, West Virginia University, WV, pp. 199-203.

Moebs, N.N. and R.M. Stateham, 1986, Coal Mine Roof Instability: Categories and Causes. U.S. Bureau of Mines, IC9076, 15 pp. 
Morsy, K., A. Yassien, and S. S. Peng, 2006, "Multiple Seam Mining Interactions - A Case Study," Proc. 25th Int'l Conference on Ground Control in Mining, Ed. S.S. Peng et al., West Virginia University, WV, pp. 308-314.

Munsamy, L., I. Canbulat, and D.P. Roberts, 2004, "Risk Assessment: Single Seam Mining," Proceedings of the $23^{\text {rd }}$ International Conference on Ground Control in Mining, Ed. S.S. Peng et al., Morgantown, WV, pp. 154-163.

National Coal Board (NCB), 1975, “Subsidence Engineers' Handbook," National Coal Board, London.

NIOSH, 2010, “STOP - Support Technology Optimization Program,” Version: 3.4 (04-15-2010).

Oyler, D.C., R. C. Frith, D. R. Dolinar, and C. Mark, 1998, "International Experience with Longwall mining into Pre-Driven Rooms," Proceedings of the 17th International Conference on Ground Control in Mining, Ed. S.S. Peng, West Virginia University, WV, pp. 44-53.

Oyler, D.C., C. Mark, D. R. Dolinar, and R. C. Frith, 2001, "A Study of Ground Control Effects of Mining Longwall Faces into Pre-Driven Longwall Recovery Room," Geotechnical and Geological Engineering, Vol.19, No. 2, pp. 137-168.

Peng, S. S. and U. Chandra, 1980, "Getting the most from multiple seam reserves," Coal Mining Processing, Vol. 17, No. 11, pp. 78-84.

Peng, S.S. and Y. Luo, 1988, "Monitoring and Prediction of Surface Dynamic Subsidence Due to Longwall Coal Mining," Proc. 5th International Symposium on Deformation Measurement, Ed. C. Chrzanowski and W. Wells, University of New Brunswick, Fredericton, NB, Canada, pp. 320-429.

Peng, S.S., 1992, Surface Subsidence Engineering, SME, Littleton, CO. 161 pp.

Peng, S.S. and Y. Luo, 1992, "Comprehensive and Integrated Subsidence Prediction Model CISPM (V2.0)," Proc. 3rd Workshop on Surface Subsidence Due to Underground Mining, Ed. S.S. Peng, West Virginia University, Morgantown, WV, pp. 22-31.

Peng, S.S., Y. Luo, and Z.M. Zhang, 1995, "Subsidence Parameters -- Their Definitions and Determination," AIME-SME Transactions, Vol. 300, Littleton, CO, pp. 60-65.

Peng, S.S., 2006, “Longwall Mining, Second Edition,” West Virginia University, Morgantown, WV. $621 \mathrm{pp}$.

Peng, S.S., 2007, "Ground Control Failures - A Pictorial View of Case Studies," West Virginia University, Morgantown, WV. 333 pp. 
Peng, S.S., 2008, "Coal Mine Ground Control, Third Edition," West Virginia University, Morgantown, WV. 764 pp.

Phillips, C.A., 2012, "Report of Investigation into the Mine Explosion at the Upper Big Branch Mine April 5, 2010 Boone / Raleigh Co., West Virginia," West Virginia Office of Miners' Health, Safety \& Training, 230 pp.

Preusse, A., H. Kateloe, and A. Sroka, 2012, "Subsidence and Uplift Prediction in German and Polish Hard Coal Mining," Proc. 31th Int'l Conference on Ground Control in Mining, Ed. T. Barczak et al., West Virginia University, WV, pp. 1-10.

Pulse, R., 1990, “Ground Stability Evaluation Around Collapsed Longwall Face," Memorandum to B. D. Owens, MSHA File \#6017, 2 pp.

Qiu, B. and Y. Luo, 2011, "Subsurface Subsidence Prediction Model and Its Potential Applications for Longwall Mining Operations," Journal of Xi'an University of Science and Technology, Vol. 31, No. 6, pp. 823-829.

Qiu, B. and Y. Luo, 2012, "Longwall Pre-driven Recovery Room Support Design Using Analytical Solutions for an Elliptical Crack in an Infinite Plate," 2012 Transactions of the Society for Mining, Metallurgy and Exploration, Vol. 332, pp. 450-457.

Qiu, B. and Y. Luo, 2013, "Applications of Subsurface Subsidence Model to Study Longwall Subsidence Influences on Overburden Hydraulic System," paper accepted by 2013 SymposiumEnvironmental Considerations in Energy Production.

Reiss, L, 1980, “The Reservoir Engineering Aspects of Fractured Formations," Houston, TX: Gulf Publishing Co., 108 pp.

Rutqvist, J. and O. Stephansson, 2003, "The Role of Hydro-mechanical Coupling in Fractured Rock Engineering," Hydrogeology Journal, Vol. 11, No. 1, pp.7-40.

Shen, B., B.A. Poulsen, and Q. Qu, 2011, "Overburden Strata Movement And Stress Change Induced By Longwall Mining," 45th U.S. Rock Mechanics / Geomechanics Symposium, San Francisco, California, pp. 1-8.

Shu, D. and A. Bhattacharyya, 1990, "Relationship between Subsurface and Surface Subsidence - A Theoretical Model,” Mining Science and Technology, Vol. 11, No. 3, pp. 307-319.

Shu, D. and A. Bhattacharyya, 1993, "Prediction of Subsurface Subsidence Movements due to Underground Coal Mining," Geotechnical and Geological Engineering, Vol. 11, No. 4, pp. 221234. 
Singh, G.S.P. and U.K. Singh, 2009, "A numerical modeling approach for assessment of progressive caving of strata and performance of hydraulic powered support in longwall workings," Computers and Geotechnics, Vol. 36, No. 7, pp. 1142-1156.

Singhal, B.B.S. and R.P. Gupta, 2010, "Applied hydrogeology of fractured rocks, second edition," Springer Dordrecht Heidelberg London New York, 408 pp.

Somerton, W.H., I.M. Soylemezoglu, and R.C. Dudley, 1974, Effect of Stress on Permeability of Coal, Petroleum Engineering Laboratory, Department of Mechanical Engineering, University of California, Berkeley, USBM OFR \#45-74, 56 pp.

Stemple, D., 1956, "A Study of Problems Encountered in Multiple Seam Coal Mining in the Eastern U. S.," Bulletin of the Virginia Polytechnic Institute, Engineering Experiment Station Series No. 107, Blacksburg, VA, 64 pp.

Styler, N., 1984, "Prediction of inter-strata movements above longwall faces," The 25th U.S. Symposium on Rock Mechanics (USRMS), Ed. Evanston, IL, pp. 651-658.

Stone, R., 2012, "The Extraction of Main Heading Pillars with a Longwall at Nre Wongawilli Colliery," Proceedings of the 31st International Conference on Ground Control in Mining, Ed. S.S. Peng, West Virginia University, WV, pp 1-10.

Su, D., L. Stull, M. Jaime, and J. Lu, 2012, "Ultra-Close Multiple-Seam Mining - Analysis and Verification," Proc. 31th Int'l Conference on Ground Control in Mining, Ed. T. Barczak et al., West Virginia University, WV, pp. 1-7.

Tadolini, S.C., Y. Zhang, and S. S. Peng, 2002, "Pre-driven Experimental Longwall Recovery Room under Weak Roof Conditions-Design, Implementation, and Evaluation," Proceedings of the 21st International Conference on Ground Control in Mining, Ed. S.S. Peng et al., West Virginia University, WV, pp 1-10.

Tadolini, S.C., T.M. Barczak, and Y.Q. Zhang, 2003, "The Effect of Standing Support Stiffness on Primary and Secondary Bolting Systems," Proceedings, 22nd international conference on ground control in mining, Ed. S.S. Peng et al., West Virginia University, WV, pp 1-10.

Tadolini, S., 2003, "Ground Control Support Considerations for Pre-Driven Longwall Recovery Rooms,” Ph.D. Dissertation, 2003, West Virginia University, Morgantown, WV, 181 pp.

Thomas, R., 2008, "Recent Developments in Pre-driven Recovery Road Design," Proceedings of the 27th International Conference on Ground Control in Mining, Ed. S.S. Peng et al., West Virginia University, WV, pp. 197-205. 
Trckova, J., 2009, "Experimental 3-D Modeling of Surface Subsidence Affected by Underground Mining Activities," The Journal of The Southern African Institute of Mining and Metallurgy, Vol. 109, No. 12, pp. 739-744.

Tsang, P. and S.S. Peng, 1992, "A Model for Floor Stability Analysis," New Technology in Mine Health and Safety: proceedings of the symposium held at the SME Annual Meeting, Phoenix, Arizona, pp. 225-233.

Vutukuri, V. S. and R. N. Singh, 1995, "Mine inundation-case histories," Mine Water and the Environment, Vol. 14, No.1, pp. 107-130.

Wade, S.A., 2008, "Stream Flow Characterization over Longwall Coal Mines in Pennsylvania, Ohio, and West Virginia," M.S. Thesis, West Virginia University, 333 pp.

Wynne, T., J. C. Stankus, S. S. Peng, and C. T. Holland, 1993, "Design and Implementation of Roof Control Systems for a Longwall Full Face Recovery Room and Chutes at Mettiki Mine," Proceedings, Longwall USA, Maclean Hunter Presentations Inc., Aurora, CO, June 8-10, 1993, pp.148-158.

Whittaker, B., P. Gaskell, and D. Reddish, 1990, "Subsurface Ground Strain and Fracture Development Associated with Longwall Mining," Mining Science and Technology, Vol. 10, No. 1, pp. 71-80.

Witkowski, M., 2011, "The Effects of Longwall Coal Mining on the Hydrogeology of Southwestern Pennsylvania," Proc. 30th Int'l Conference on Ground Control in Mining, Ed. T. Barczak et al., West Virginia University, WV, pp. 314-319.

Xie, H, H. Zhou, J. Wang, L. Li, and M.A. Kwasniewski, 1999, "Application of Flac to Predict Ground Surface Displacement Due to Coal Extraction and Its Comparative Analysis," Chinese Journal of Rock Mechanics and Engineering, Vol. 18, No. 4, pp. 397-401.

Yao, X., B. Whittaker, and D. Reddish, 1991, "Influence of Overburden Mass Behavioral Properties on Subsidence Limit Characteristics," Mining Science and Technology, Vol. 13, No. 2, pp. 167-173.

Zhang, J., J. C. Roegiers, M. Bai, and Y. Zhang, 2001, "Stress-dependent Permeability Variation and Mine Subsidence," The 38th U.S. Symposium on Rock Mechanics (USRMS), Ed. D. Elsworth et al., Washington D.C., pp. 685-690.

Zhang, Y.Q., Y. Luo, J.S. Han, and S.S. Peng, 2005, "Impact of Lower Seam Caving on Upper Seam Mining - A Case Study," Paper presented at the SME Annual Meeting, Salt Lake City, UT, Preprint No. 05-125, 6pp. 
Zhang, P., M. Mishra, J. Trackemas, E. Zeglen, C. Huff, S. S. Peng, and J. Chen, 2006, "PreDriven Longwall Recovery Room Under Weak Roof Conditions-Design, Evaluation, and Monitoring," Proceedings of the 25th International Conference on Ground Control in Mining, Ed. S.S. Peng et al., West Virginia University, WV, pp. 221-228.

Zhang, Y.Q., M. Milam, M. Mishra, W.J. Hudak, and R. Kimutis, 2012, "Requirements and Performance of Pumpable Cribs in Longwall Tailgate Entries and Bleeders," Proc. 31st Int'l Conference on Ground Control in Mining, Ed. S.S. Peng et al., West Virginia University, WV, pp. 1-11.

Zhou, Y., 1988, “Designing for Upper Seam Stability in Multi-Seam Mining,” Ph.D.Dissertation, Virginia Polytechnic Institute and State University, Blacksburg, VA, 202 pp.

Zimmermann, K. and R. Fritschen, 2007, "Study about the Dynamic Influence of Longwall Mining in the US on Surface Structures," Proc. 26th Int'l Conference on Ground Control in Mining, Ed. S.S. Peng et al., West Virginia University, WV, pp. 79-84.

Zipf, R. K., 2007, "Failure Mechanics of Multiple-seam Mining Interactions," Proc. of New Technology for Ground Control in Multiple-Seam Mining, Ed. C. Mark, R. J. Tuchman, National Institute for Occupational Safety and Health, Pittsburgh, PA, pp. 73-88. 


\section{APPENDIX}

Vita:

Mr. Biao Qiu was born on June 22, 1985 in Hubei, People's Republic of China. He earned his B.S. degree in 2006, and M.S. degree in 2009, both from Xi'an University of Science and Technology in China. In August, 2009, he enrolled in the Ph.D. program in Mining Engineering at West Virginia University. Thereafter, he has been working as a graduate research assistant in the Department of Mining Engineering, West Virginia University.

His research focused on rock mechanics, ground control and mine subsidence. In 2010, he received the Robert E. Stitzel Graduate Student Travel Award of West Virginia University. He was also the recipient of 2012-2013 Syd S. Peng Ground Control in Mining Scholarship and the 2013 Mining Engineering Faculty Award for Graduate Students.

\section{Author's Publication List during Ph.D. Study:}

Luo, Y., and B. Qiu, 2013, "Identifying Root Causes for Subsidence over Abandoned Coal Mine - A Case Study," paper accepted by $47^{\text {th }}$ US Rock Mechanics/Geomechanics Symposium.

Qiu, B., and Y. Luo, 2013, “Applications of Subsurface Subsidence Theories to Ground Control in Coal Mines," paper accepted by $47^{\text {th }}$ US Rock Mechanics/Geomechanics Symposium.

Qiu, B., and Y. Luo, 2013, "Applications of Subsurface Subsidence Model to Study Longwall Subsidence Influences on Overburden Hydraulic System," Proceedings of 2013 SymposiumEnvironmental Considerations in Energy Production, Ed. J.R. Craynon, Charleston, WV, pp. 297-307.

Qiu, B., and Y. Luo, 2013, "Improved Model to Assess Stress Condition on Buried Pipelines Affected By Mine Subsidence," paper accepted by WMC2013.

Luo, Y., B. Qiu, and M. M. Li, 2013, "Reducing Drilling Noise in Roof Bolting Operation through Rationalized Drilling," paper accepted by WMC2013.

Qiu, B., and Y. Luo, 2013, "Development of CISPM-MS and Its Applications in Assessing Multi-Seam Mining Interactions," Paper presented to 2013 SME Annual Meeting, Denver, CO, Feb. 24-27, 2013, Pre-print No. 13-PP204, 16 pp (in peer review).

Luo, Y., C. Collins, B. Qiu, and M. M. Li, 2013, "Rationalize Drilling Control for Noise Reduction during Roof Bolting Operation," Paper presented to 2013 SME Annual Meeting, Denver, CO, Feb. 24-27, 2013, Pre-print No. 13-PP201, 13 pp (in peer review).

Luo, Y., and B. Qiu, 2012, "CISPM-MS, a Tool to Predict Surface Subsidence and to Study Interactions Associated with Multi-Seam Mining Operations," Proceedings of the 31st International Conference on Ground Control in Mining, T. Barczak et al., ed., West Virginia University, pp. 56-62. 
Qiu, B., and Y. Luo, 2012, "Longwall Pre-driven Recovery Room Support Design Using Analytical Solutions for an Elliptical Crack in an Infinite Plate," 2012 Transactions of the Society for Mining, Metallurgy and Exploration, Vol. 332, pp. 450-457.

Luo, Y., and B. Qiu, 2012, "Enhanced Subsurface Subsidence Prediction Model Considering Overburden Stratifications," Mining Engineering, Vol. 64, No. 10, pp. 78-84.

Li, Y., and B. Qiu, 2012, "Investigation into Key Strata Movement Impact to Overburden Movement in Cemented Backfill Mining Method”, Procedia Engineering, Vol. 31, pp. 727-733.

Qiu, B., and Y. Luo, 2011, "Subsurface Subsidence Prediction Model and Its Potential Applications for Longwall Mining Operations", Journal of Xi'an University of Science and Technology, Vol. 31, No. 6, pp. 823-829.

\section{Author's Technical Report List during Ph.D. Study:}

Luo, Y., M.M. Li and B. Qiu, 2013, Subsidence Prediction, Influence Assessment and Recommended Mitigation Measures for Waynesburg Allegheny Wesleyan Methodist Church, a report submitted to Alpha Natural Resources, 24 pp.

Luo, Y. and B. Qiu, 2013, Recommended Location for Setup Entry of Longwall Panel $12 B$ to Avoid Subsidence Damages to Houses on North Avenue of Cameron, WV, a report submitted to Consol Energy, Inc., 15 pp.

Luo, Y. and B. Qiu, 2013, Assessment of Longwall Subsidence Influences to CityWater Tank Cameron, $W V$, a report submitted to Consol Energy, Inc., 14 pp.

Luo, Y. and B. Qiu, 2012, Subsidence Prediction and Influence Assessment and Recommended Mitigation Measures for Michael's Structures, a report submitted to Consol Energy, Inc., 60 pp.

Luo, Y. and B. Qiu, 2012, Development of Drilling Control Technology to Reduce Roof Bolter Noise, Interim report submitted to WV Coal and Energy Research Bureau, $46 \mathrm{pp}$.

Luo, Y. and B. Qiu, 2012, Feasibility Study of Longwall Mining under Cameron Reservoir, a report submitted to Consol Energy, Inc., $28 \mathrm{pp}$.

Luo, Y. and B. Qiu, 2012, Subsidence Prediction and Influence Assessment for Longwall Mining near a Water Tank belong to City of Mannington, $W V$, a report submitted to Consol Energy, Inc., $16 \mathrm{pp}$.

Luo, Y., B. Qiu and M.M. Li, 2012, Investigation and Causational Analysis for Structural Damages on Two Structures on Polpar Avenue,Moundsville, WV, a report submitted to Consol Energy, Inc., 29 pp.

Luo, Y. and B. Qiu, 2012, Subsidence Prediction and Influence Assessment, Surface Topography Effect Analysis for Structures in Kiger's Property, a report submitted to Alpha Natural Resources, $17 \mathrm{pp}$.

Luo, Y. and B. Qiu, 2012, Subsidence Prediction, Influence Assessment and Recommended Mit- 
igation Measures for Structures in Wells Property, a report submitted to Alpha Natural Resources, $25 \mathrm{pp}$.

Luo, Y. and B. Qiu, 2012, Subsidence Prediction, Influence Assessment and Recommended Mitigation Measures for Kerr House, a report submitted to Alpha Natural Resources, 22 pp.

Luo, Y. and B. Qiu, 2011, Characterization Studies of Surface Subsidence over Foundation Mine - Development of a Multi-Seam Mining Subsidence Prediction Program (CISPM-MS), Program and User Manual submitted to Alpha Natural Resources.

Qiu, B. and Y. Luo, 2011, Investigation Study of the Stress Field Surrounding a Well Bore and a Rectangular Tunnel, a report submitted to Stolar Research Corp, 13 pp.

Luo, Y. and B. Qiu, 2011, Subsidence Predictions, Influence Assessment and Recommended Mitigation Measures for Two Reservoirs of the Wheeling Creek Watershed Project, Final report submitted to Consol Energy, Inc., 35 pp.

Luo, Y. and B. Qiu, 2011, Subsidence Prediction, Pipeline Stress Estimation and Recommended Mitigation Measures for REX Gas Pipeline over Two Longwall Panels, a report submitted to Porter Wright \& Arthur LLP, 36 pp.

Luo, Y. and B. Qiu, 2011, Subsidence Prediction, Influence Assessment and Recommended Mitigation Measures for Newton's Three Main Structures, a report submitted to Consol Energy, Inc., $50 \mathrm{pp}$.

Luo, Y. and B. Qiu, 2011, Recommendation on Recovery Line Location for Longwall Panel 4B to Avoid Subsidence Influences on Structures in Walt/McCardle Adverse Property (Revised Edition), a report submitted to Consol Energy, Inc., 13 pp.

Luo, Y., J.W. Cheng and B. Qiu, 2011, Causational Analyses of an Elevated CO Event, Determination of the Status of Coal Oxidation and Mine Atmosphere in Longwall Panel 9F, Pinnacle Mine, Report to Cliffs Natural Resources, $35 \mathrm{pp}$.

Luo, Y. and B. Qiu, 2011, Assessment of Subsidence Influences on Belmond Water Tower and Recommended Mitigation Measures, a report submitted to Ohio Valley Coal Co., 46 pp.

Luo, Y. and B. Qiu, 2011, Development of Drilling Control Technology to Reduce Roof Bolter Noise, Interim report submitted to WV Coal and Energy Research Bureau, 23 pp.

Luo, Y. and B. Qiu, 2011, Assessment of Probability and Potential Influences of Past Highwall Mining Operation on Planned I-69 Extension (Indiana), Final report submitted to LA Gates Company, 36 pp.

Luo, Y. and B. Qiu, 2010, Assessment of Subsidence Influences on Belmond Water Tower for Three Mining Plans and Recommended Mitigation Measures, a report submitted to Ohio Valley Coal Company, 43 pp. 
Luo, Y. and B. Qiu, 2010, Assessment of Subsidence Influences and Recommendations for Longwall Mining Operation near Glen Easton Bridge, a report submitted to Consolidation Coal Moundsville Office, $27 \mathrm{pp}$. 